UNIVERSIDADE DE BRASÍLIA - UNB

FACULDADE DE CIÊNCIAS DA SAÚDE

DEPARTAMENTO DE ENFERMAGEM

PROGRAMA DE PÓS-GRADUAÇÃO EM ENFERMAGEM

MAYARA ÁGUIDA PORFÍRIO MOURA

CONSULTA DE ENFERMAGEM À CRIANÇA NA ATENÇÃO BÁSICA

BRASÍLIA 


\author{
UNIVERSIDADE DE BRASÍLIA - UNB \\ FACULDADE DE CIÊNCIAS DA SAÚDE \\ DEPARTAMENTO DE ENFERMAGEM \\ PROGRAMA DE PÓS-GRADUAÇÃO EM ENFERMAGEM
}

MAYARA ÁGUIDA PORFÍRIO MOURA

CONSULTA DE ENFERMAGEM À CRIANÇA NA ATENÇÃO BÁSICA

Tese apresentada como requisito parcial para obtenção do título de Doutor em Enfermagem pelo Programa de PósGraduação em Enfermagem da Universidade de Brasília.

Área de concentração: Políticas, Práticas e Cuidado em Saúde e Enfermagem. Linha de pesquisa: Processo de Cuidar em Saúde e Enfermagem.

Orientadora: Dr. ${ }^{a}$ Diana Lúcia Moura Pinho

BRASÍLIA 


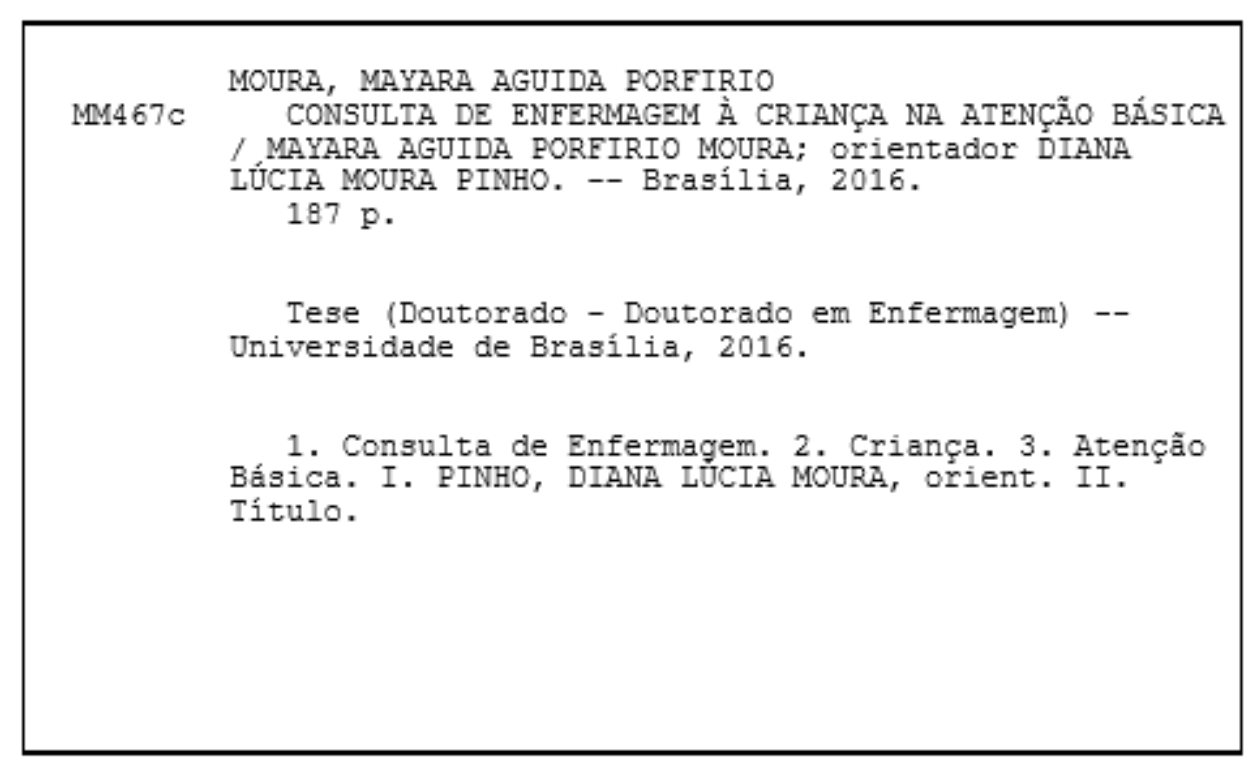




\title{
CONSULTA DE ENFERMAGEM À CRIANÇA NA ATENÇÃO BÁSICA
}

Tese apresentada como requisito parcial para a obtenção do título de Doutor em Enfermagem pelo Programa de Pós-Graduação em Enfermagem da Universidade de Brasília.

\author{
BANCA EXAMINADORA
}

Profa. Dra. Diana Lúcia Moura Pinho PPGENF/Universidade de Brasília Presidente

\section{Profa. Dra. Cristine Alves Costa de Jesus PPGENF/Universidade de Brasília Membro Interno}

Profa. Dra. Moema da Silva Borges PPGENF/Universidade de Brasília Membro Interno

Prof. Dr. Rinaldo de Souza Neves Membro Externo - FEPECS

Profa. Dra. Marina Morato Stival Membro Externo - FCE/UNB

Profa. Dra. Ivone Kamada PPGENF/Universidade de Brasília Suplente 
Dedico esta obra a Deus, à Nossa Senhora, à minha família e, em especial, ao meu filho Matheus. 


\section{AGRADECIMENTOS}

A nobreza do agradecimento está em reconhecer que jamais haveria vitória em uma luta solitária. Por isso, agradeço imensamente a Deus por todo cuidado e sabedoria ao longo de minha caminhada. Não foi fácil, mas houve fé em vencer. Fé que haveria, para cada dificuldade, uma prece e uma luz divina a me iluminar. Nossa Senhora, obrigada por ter me dado forças. Pois quando as lágrimas e o suor foram presentes, logo entendi seriam para mim sábios ensinamentos.

Agradeço à Universidade de Brasília - UNB, que me acolheu como filha e que, mesmo distante de casa, permitiu que eu me sentisse ainda mais forte, pela grandeza dos conhecimentos adquiridos. Ao Programa de Pós-graduação em Enfermagem, por todo apoio e êxito na conquista desse sonho, que carrega também as valiosas contribuições dos docentes queridos e competentes. Em especial, à minha orientadora, Dra. Diana Lúcia Moura Pinho, por todo incentivo e ensinamento compartilhados em muitas tardes de estudo. Obrigada por acreditar no meu trabalho, pelo incentivo à pesquisa e pela dedicação em transmitir tantos conhecimentos que contribuíram para minha formação profissional.

Aos membros da banca examinadora, Dra. Cristine Alves Costa de Jesus, Dra. Moema da Silva Borges, Dr. Rinaldo de Souza Neves, Dra. Marina Morato Stival e Dra. Ivone Kamada, por suas valorosas contribuições e reflexões para o aprimoramento desta tese.

Ao meu eterno porto seguro, minha base e força, que foi essencial para essa conquista: minha família. Ao meu pai Paulo, obrigada pela condição, esforço e confiança nos meus estudos. Sua torcida e vibração me acompanham desde sempre, e foram fundamentais na minha formação. À minha mãe Mara, exemplo de amor e paciência incondicionais, que sempre soube me escutar e me ensinar o dom da resiliência. Ao meu irmão Lucas, obrigada pelas conversas e a companhia que somente a fraternidade proporciona.

Agradeço ao meu filho, Matheus Henrique, por toda força que você me transmite. Que os frutos do meu estudo possam contribuir para lhe proporcionar um futuro promissor.

Aos tios Manoel Neto e Marly, que junto com Arthur e Matheus, puderam me garantir um maior conforto e viabilidade na conquista dessa vitória. A todos os meus parentes, amigos e colegas, pelas experiências compartilhadas e pelo convívio caloroso nessa caminhada, pelo conforto e pela palavra amiga, muito obrigada.

A todos que contribuíram de alguma forma para a construção deste estudo, o meu muito obrigada. 
"A persistência é o menor caminho do êxito".

(Charles Chaplin) 
MOURA, M.Á.P. Consulta de Enfermagem à criança na atenção básica. 2016. 180p. Tese (Doutorado) - Departamento de Enfermagem, Faculdade de Ciências da Saúde, Universidade de Brasília, Brasília, 2016.

INTRODUÇÃO: A Consulta de Enfermagem à criança na atenção básica é uma atividade privativa do enfermeiro, pautada na Política Nacional da Atenção Básica, por meio de ações de vigilância à saúde e abrangendo como foco a prevenção de doenças e promoção da saúde. OBJETIVO: Analisar a prática da Consulta de Enfermagem às crianças menores de cinco anos na rede de Atenção Básica, em Teresina-PI, no ano de 2012. MÉTODO: Trata-se de um estudo exploratório e descritivo, com uso de método misto, por meio da estratégia explanatória sequencial. O estudo foi realizado em duas das 87 Unidades Básicas de Saúde da Família, da Rede de Atenção à Saúde de Teresina-PI, uma com a maior produção e a outra com menor produção de consultas de enfermagem no ano de 2012. Os participantes foram sete enfermeiras que atuavam nas unidades. A coleta de dados foi realizada no primeiro semestre de 2013, em duas fases, por meio de levantamento de dados no Sistema de Informação da Atenção Básica/SIAB e no Sistema de Informação Ambulatorial do Sistema Único de Saúde - SIA/SUS, seguida de observação, questionário e entrevista. Os dados quantitativos foram analisados em frequências estatísticas simples e os dados qualitativos foram analisados com o auxilio do software IRAMUTEQ. RESULTADO: No ano de 2012, foram produzidas, nas 87 unidades das três regionais de saúde do município de Teresina/PI, $63.416(16,9 \%)$ consultas com crianças menores de cinco anos, de um universo de 374.080 consultas envolvendo todos os ciclos de vida. Constatou-se que as práticas utilizadas são sistematizadas, a partir de um protocolo institucionalizado. Observou-se ainda que o objetivo central da consulta nas Unidades A e B está relacionado, primeiramente, à atualização e ao cadastro para auxilio financeiro governamental, Bolsa Família 23\% e 20\% respectivamente, seguido de ações de promoção da saúde, com $23 \%$ na UBS A e $20 \%$ na UBS B e, finalmente, às doenças e agravos em curso, representando $12 \%$ e $10 \%$, respectivamente. As temáticas abordadas se articulam diretamente aos objetivos das consultas e têm o mesmo comportamento nas duas Unidades, representadas por temas relacionados: à Alimentação, ao Crescimento e Desenvolvimento, ao programa Bolsa Família e à Vacinação e à Higiene. Quanto às representações sociais dos enfermeiros sobre a prática de consulta de enfermagem, foi possível desvelar seus sentidos, organizando-os em cinco classes: 1) A base Legal da consulta - O protocolo, 18,8\%; 2) O espaço social da consulta - o acolhimento, 18,8\%; 3) As dimensões socioafetivas da consulta - o vínculo, 15,9\%; 4) A dimensão técnica da consulta - 
tecnologia para o cuidado, 23,2\%; 5) A consulta como espaço de poder - a autonomia profissional, 23,2\%. CONCLUSÃO: A prática da consulta de enfermagem na atenção básica da Rede de Saúde do município de Teresina/PI está regularmente institucionalizada. Essa prática é percebida pelos enfermeiros, por um lado, como uma tecnologia do cuidado que possibilita a construção de vínculo, o acolhimento e a autonomia profissional. Por outro lado, ela é percebida, nesse contexto, como uma forma de atualizar dados para o auxílio financeiro governamental.

Palavras-chaves: Enfermagem; Criança; Atenção Primária à Saúde; Consulta de Enfermagem. 
MOURA, M.A.P. Nursing consultation to children in primary care. 2016. 180p. Thesis (PhD) - Department of Nursing, Faculty of Health Sciences, University of Brasília, Brasília, 2016.

INTRODUCTION: Nursing consultation to children in primary care is a private activity of nurses, based on the National Primary Care Policy, through health surveillance and encompassing as a focus disease prevention and health promotion. GOAL: To analyze the practice of nursing consultation to children under five years old in the network of Primary Care, in Teresina - PI, Brazil, in 2012. METHODS: This is an exploratory and descriptive study, using a mixed methodology, through sequential explanatory strategy. The study was conducted in two of the 87 Basic Units of Family Health, from the Health Care Network of Teresina-PI, one of which with the largest production and the other with the lowest production of nursing consultations in 2012. The participants were ten nurses who work in these units. Data collection was performed in the first half of 2013, in two stages, through the Information System of Primary Care/ SIAB and Outpatient Information System of the Unified Health System - SIA / SUS, followed by observation, questionnaire and interview. Quantitative data were analyzed in simple statistical frequencies and qualitative data were analyzed with the help of IRAMUTEQ software. RESULTS: In the year of 2012 there were produced, in 87 units of the three health city centers of Teresina / PI, 63,416 (16.9\%), consultations with children under five years old, of a universe of 374080 consultations involving all lifecycles. It was found that the applied practices are systematized from an institutionalized protocol. It was also observed that the main objective of the consultation in Units A and B are related primarily to updates and registrations for government financial aids, Bolsa Família $23 \%$ and $20 \%$ respectively, followed by health promotion, with $23 \%$ in UBS A and $20 \%$ in UBS B. Finally, ongoing health issues and diseases accounted for $12 \%$ and $10 \%$, respectively. The themes are linked directly to the objectives of consultations and have the same behavior in both units, represented by issues related to: Food, Growth and Development, Family Grant, Vaccination and Hygiene. In respect of the social representations of nurses on the nursing practice consultation, it was possible to unveil the meanings these consultations into five classes: 1) The legal basis of consultation - The protocol, 18.8\%; 2) The social space of the consulted hosts, $18.8 \%$; 3) The affectionate dimensions - the bond, $15.9 \%$; 4) The technical dimension of consultation - care technology, 23.2\%; 5) The consultation as a power space - professional autonomy, 23.2\%. CONCLUSION: The practice of nursing consultation in the basic attention of the Health Network of the city of Teresina/PI is regularly 
institutionalized. This practice is perceived by nurses, on one hand, as a care technology that enables the construction of bond, welcoming experiences and professional autonomy. On the other hand, this technology is perceived, in this context, as a way to update data for the government financial aids.

Keywords: Nursing; Child; Primary Health Care; Nursing consultation. 
MOURA, M.A.P. Consulta de enfermería a los niños en la atención primaria. 2016. 180 p. Tesis (Doctorado) - Departamento de Enfermería de la Facultad de Ciencias de la Salud, Universidad de

Brasilia,

Brasilia, 2016.

INTRODUCCIÓN: Consulte la enfermería al niño en atención primaria es una actividad privada de enfermeras, que se guía en la política nacional de atención primaria de salud a través de actividades de vigilancia que cubren un enfoque en la prevención de enfermedades y promoción de la salud. Para el análisis de la práctica de la consulta de enfermería a niños menores de cinco años en la red de Atención Primaria, Teresina-PI en 2012. MÉTODOS: Se trata de un estudio exploratorio y descriptivo, con el uso del método mixto por la estrategia explicativa secuencia. El estudio se realizó en dos de las 87 Unidades Básicas de Salud de la Familia, Red de Servicios Médicos de Teresina-PI, uno con la producción más grande y el otro con una menor producción de la consulta de enfermería en 2012. Los participantes fueron diez enfermeras que trabajan en las unidades. La recolección de datos se llevó a cabo en la primera mitad de 2013, en dos etapas, a través de la recolección de datos en el Sistema de Información de Primaria / SIAB y Sistema de Información para pacientes externos del Sistema Único de Salud - SIA / SUS, la observación, cuestionario y entrevista. Los datos cuantitativos se analizaron en frecuencias simples estadísticas y datos cualitativos fueron analizados con la ayuda de software IRAMUTEQ. RESULTADO: En el año 2012 se produjeron en 87 unidades de los tres regional de salud de la ciudad de Teresina / PI, 63.416 (16,9\%), con niños menores de cinco años de un universo de 374080 ciclos de vida de todas las consultas que se refieran. Se encontró que las prácticas utilizadas son sistematizadas de un protocolo institucional. También se observó que el principal objetivo de la consulta en las unidades A y B están relacionadas básicamente para actualizar y solicitar asistencia financiera del gobierno, Bolsa Familia 23\% y 20\%, respectivamente, seguido de promoción de la salud, con un $23 \%$ en UBS El y $20 \%$ en las enfermedades y las enfermedades en curso B y UBS representó el $12 \%$ y $10 \%$, respectivamente. Los temas están vinculados directamente a los objetivos de las consultas y tiene el mismo comportamiento en ambas unidades, representadas por las cuestiones relacionadas con: Alimento, Crecimiento y Desarrollo y Familiar siguieron los sujetos, la vacunación y la higiene. Las representaciones sociales de los enfermeros sobre la consulta práctica de enfermería, fue posible dar a conocer los significados de las consultas de enfermería que se organizan en cinco clases: 1) La base de una consulta legal - El protocolo, el 18,8\%; 2) El espacio social de la acogida consultados, el 18,8\%; 3) Las dimensiones afectivas socio de consultoría - el vínculo, el 15,9\%; 4) La dimensión técnica de 
la consulta - la tecnología para el cuidado, el 23,2\%; 5) La consulta como espacio de poder la autonomía profesional, el 23,2\%. CONCLUSIÓN: La práctica de la consulta de enfermería en la atención básica de la Red de Salud de la ciudad de Teresina / PI, se institucionaliza con regularidad. Esta práctica es percibido por las enfermeras, por un lado como una tecnología asistencial que posibilita la construcción de vínculo, la bienvenida y la autonomía profesional y por el otro, esta tecnología se percibe en este contexto como una forma de actualizar los datos de la ayuda financiera del gobierno.

Palabras clave: Enfermería; infantil; Atención primaria de salud; Consulta de enfermería. 


\section{LISTA DE FIGURAS}

Figura 1 - Gráfico linear das publicações analisadas

Figura 2 - Tendências dos modelos assistenciais nos trabalhos selecionados de 2005-2015. Brasília, 2016...... .46

Figura 3 - Dificuldades no cuidado de enfermagem à criança na atenção básica evidenciado pela revisão. Brasília, 2016. .53

Figura 4 - Estratégia explanatória sequencial do método misto. .62

Figura 5 - Síntese das fases da estratégia explanatória sequencial segundo coleta e análise dos dados. Brasília, 2016.

Figura 6 - Mapa Político geográfico da cidade de Teresina-PI, segmentado por regionais de saúde, 2016. .64

Figura 7 - Plano de análise dos dados. Brasília, 2016.

Figura 8 - Crianças menores de cinco anos cadastradas em relação à regional de saúde e zona a que pertence em Teresina-PI no ano de 2012

Figura 9 - Consultas de Enfermagem realizadas na atenção básica por mês no ano de 2012

Figura 10 - Turno de trabalho das enfermeiras por unidades básicas pesquisadas. Teresina-PI, 2016. .87

Figura 11 - Idade das enfermeiras por unidades básicas de saúde pesquisadas (UBS A, B). Teresina-PI, 2016

Figura 12 - Estado civil das enfermeiras que trabalham nas unidades básicas de saúde pesquisadas. Teresina-PI. 2016. .88

Figura 13 - Duração da Consulta de Enfermagem por equipe Saúde da Família nas unidades em estudo. Brasília, 2016.

Figura 14 - Objetivos das Consultas de Enfermagem segundo as enfermeiras das unidades pesquisadas de Teresina-PI, 2016. .96

Figura 15 - Procedimentos realizados pela enfermeira na Consulta de Enfermagem nas unidades em estudo. Brasília, 2016.

Figura 16 - Comparativo entre as temáticas abordadas durante a Consulta de Enfermagem nas duas unidades básicas de saúde estudadas. Brasília, 2016. .98

Figura 17 - Dendograma das classes. 102 
Figura 18 - Análise de similitude de palavras sobre a Consulta de enfermagem à criança na atenção básica de Teresina-PI, 2016 143

Figura 19 - Nuvens de palavras Brasília sobre a Consulta de enfermagem à criança na atenção básica de Teresina-PI, 2016. 


\section{LISTA DE QUADROS}

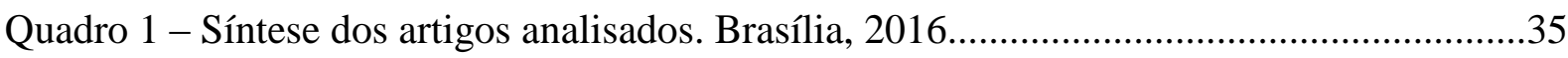

Quadro 2 - Necessidades existentes no contexto do cuidado de enfermagem à criança na rede de atenção básica, segundo política, estrutura e organização do trabalho. Brasília, 2016........46 Quadro 3 - Necessidades existentes no contexto do cuidado de enfermagem à criança na rede de atenção básica, segundo formação e prática profissional. Brasília, 2016...........................49 Quadro 4 - Estratificação das fases da pesquisa segundo os objetivos propostos. Brasília, 2016

Quadro 5 - Síntese comparativa da descrição da Consulta de Enfermagem à criança em duas unidades básicas de saúde. Brasília, 2016. 


\section{LISTA DE TABELAS}

Tabela 1 - Crianças atendidas por Regional de saúde e Zona segundo gênero e faixa etária, no município de Teresina-PI, em 2012. .73

Tabela 2 - Consultas de enfermagem a crianças menores de cinco anos segundo mês do ano de 2012 na regional centro/norte de Teresina-PI .78

Tabela 3 - Consultas de enfermagem a crianças menores de cinco anos, segundo mês do ano de 2012 na regional leste/sudeste de Teresina-PI .79

Tabela 4 - Consultas de enfermagem as crianças menores de cinco anos segundo mês do ano de 2012 na regional sul de Teresina-PI .81

Tabela 5 - Consulta de Puericultura segundo Regional e mês do ano de 2012 em Teresina-PI. .83

Tabela 6 - Atendimento individual do enfermeiro na atenção básica por regional e zona segundo mês do ano de 2012 em Teresina-PI. Brasília, 2016. .84

Tabela 7 - Visitas domiciliares realizadas por enfermeiros no ano de 2012 em Teresina-PI. Brasília, 2016 


\section{LISTA DE SIGLAS}

\begin{tabular}{|c|c|}
\hline AIDPI & Atenção Integrada às Doenças Prevalentes da Infância \\
\hline BDENF & Base de dados em Enfermagem \\
\hline CAPES & Coordenação de Aperfeiçoamento de Pessoal de nível Superior \\
\hline $\mathbf{C E}$ & Consulta de Enfermagem \\
\hline COFEN & Conselho Federal de Enfermagem \\
\hline ECA & Estatuto da Criança e do Adolescente \\
\hline ESF & Estratégia Saúde da Família \\
\hline EqSF & Equipe Saúde da Família \\
\hline FIA & Ficha de Atendimento Ambulatorial \\
\hline FMS & Fundação Municipal de Saúde \\
\hline IBGE & Instituto Brasileiro de Geografia e Estatística \\
\hline LILACS & Literatura Latino-Americana e do Caribe em Ciências da Saúde \\
\hline NOB & Norma Operacional Básica \\
\hline ONU & Organização das Nações Unidas \\
\hline PI & Piauí \\
\hline SAE & Sistematização da Assistência de Enfermagem \\
\hline PAISC & Programa de Assistência Integral à Saúde da Criança \\
\hline PNAB & Política Nacional da Atenção Básica \\
\hline PSF & Programa Saúde da Família \\
\hline SAME & Serviço de Arquivo Médico e Estatístico \\
\hline SIAB & Sistema de Informação da Atenção Básica \\
\hline SIA & Sistema de Informação Ambulatorial \\
\hline SIM & Sistema de Informação de Mortalidade \\
\hline SUS & Sistema Único de Saúde \\
\hline TCLE & Termo de Consentimento Livre e Esclarecido \\
\hline
\end{tabular}




\section{SUMÁRIO}

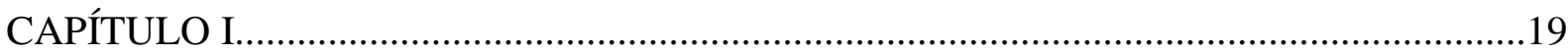

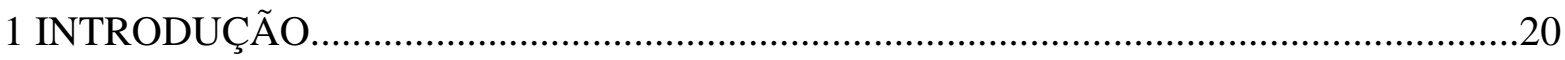

1.1 Contextualização do Problema e Delimitação do Objeto de Estudo...................................20

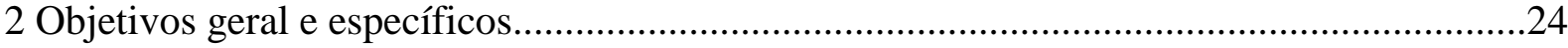

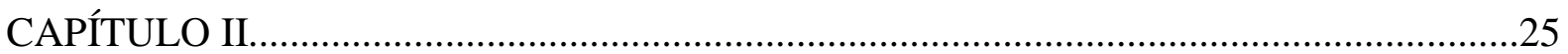

3. REFERENCIAL TEÓRICO/ CONTEXTUALIZAÇÃO TEMÁTICA.................................26

3.1 A construção histórica da consulta de enfermagem à criança na rede de atenção básica

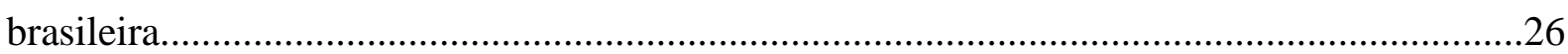

3.2 PRÁTICAS DE ENFERMAGEM À CRIANÇA NA ATENÇÃO BÁSICA: caracterização e contribuições das produções científicas............................................................................32

3.3 A Teoria das Representações Sociais e a Consulta de enfermagem.....................................54

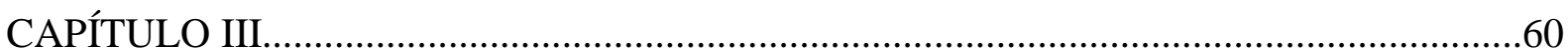

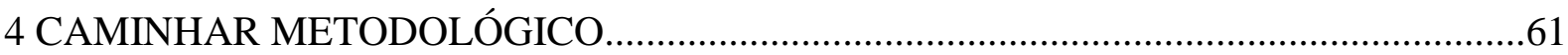

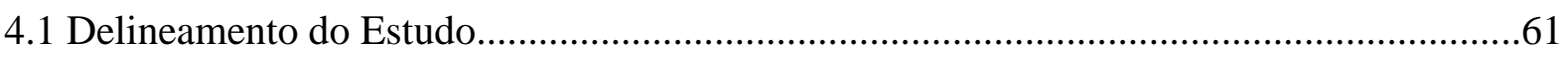

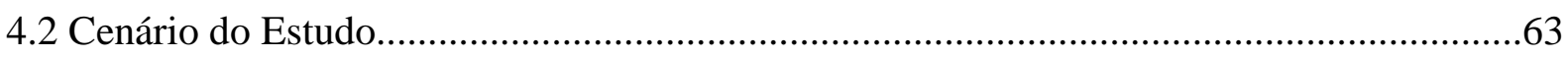

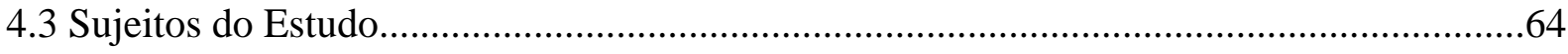

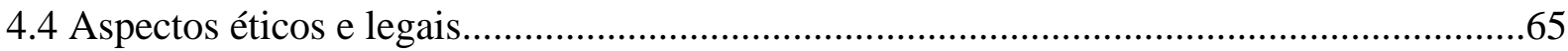

4.5 Procedimentos e instrumentos para coleta dos dados.........................................................65

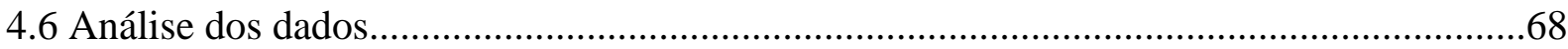

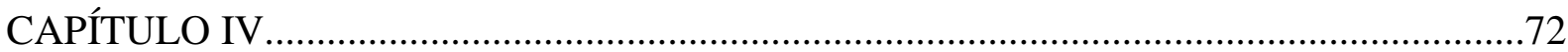

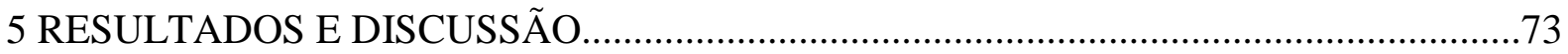

5.1 Quantidade de crianças menores de cinco anos, Consultas de Enfermagem, puericulturas, atendimentos individuais e visitas domiciliares realizadas pelos enfermeiros da rede de

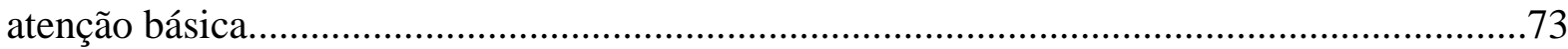

5.2 Perfil sociodemográfico dos enfermeiros da rede de atenção básica.....................................87

5.3 Descrição da Consulta de Enfermagem e o registro em duas realidades distintas da atenção básica Teresinense.

5.4 Representações sociais das enfermeiras sobre a Consulta de Enfermagem à criança na atenção básica de Teresina- PI..........................................................................................100

5.4.1 Organização do campo representacional........................................................................100

5.4.2 Descriçãa do conteúdo das classes..............................................................................102 
5.4.2.1 CLASSE 1: Base legal da consulta - protocolo. 102

5.4.2.2 CLASSE 4: Dimensão técnica da consulta - tecnologia do cuidado 111

5.4.2.3 CLASSE 3: Dimensão socioafetiva da consulta - o vínculo. 122

5.4.2.4 CLASSE 2: Espaço social da consulta - acolhimento. 128

5.4.2.5 CLASSE 5: A consulta como espaço de poder - a autonomia profissional. .136

5.5.3 Análise de similitude e nuvem de palavras. 141

5.6 Integração dos resultados .145

6 CONSIDERAÇÕES FINAIS .148

REFERÊNCIAS 149

APÊNDICE

ANEXOS 


\section{INTRODUÇÃO}

\subsection{Contextualização do Problema e Delimitação do Objeto de Estudo}

Em função dos avanços científicos e tecnológicos, bem como da preocupação com a qualidade de vida e direitos da criança, ao longo das últimas décadas têm sido implementadas transformações na assistência de saúde infantil, no contexto das Políticas Públicas de Saúde brasileiras, posicionando a figura do enfermeiro como elemento fundamental (PEREIRA; FERREIRA, 2014; MELLO et al., 2012). Em convergência com essas tendências que emergiram e na perspectiva de melhorar a compreensão sobre a assistência à saúde da criança, considerando a importância da consulta de enfermagem na resolutividade das ações de vigilância à saúde, com foco na prevenção de doenças e na promoção da saúde, buscou-se realizar uma investigação científica sobre a Consulta de Enfermagem à criança, no contexto da rede de atenção básica de Teresina-PI.

Nesse contexto, a Política Nacional da Atenção Básica (PNAB) integra as experiências implantadas no campo da saúde brasileira e da consolidação do Sistema Único de Saúde (SUS). Tal política atualmente é considerada prioridade, pois é a principal porta de entrada da rede de atenção à saúde. Desenvolvida de maneira descentralizada, com capilaridade e proximidade da população a ser assistida, essa política constitui uma rede de atenção básica que considera o usuário como sujeito em sua singularidade, dentro de seu contexto sociocultural, na perspectiva de uma atenção integral e pautada pelos princípios do SUS, a saber: a universalidade, a acessibilidade, o vínculo, a continuidade do cuidado, a responsabilização, a humanização, a equidade e a participação social (BRASIL, 2016; 2012).

Instituída em 2006, por meio da Portaria No 648 e revisada em 2011, a Portaria No 2.488, PNAB conceitua a atenção básica como um conjunto de práticas voltadas para o indivíduo e para a coletividade, e que abrangem a promoção da saúde, proteção, prevenção de agravos e manutenção da saúde, incluindo a atenção integral à saúde da criança (BRASIL, 2012; MELO; TONETE; SILVA, 2009; BRASIL, 2006).

A atenção integral à saúde da criança engloba a redução da mortalidade infantil, tendo como estratégias: a vigilância à saúde pela equipe da atenção básica; vigilância da mortalidade infantil e educação continuada das equipes de atenção à criança (BRASIL, 2005). Cabe destacar que a atenção à saúde da criança é uma prioridade e se encontra na agenda política do Governo Brasileiro há décadas, a exemplo do Estatuto da Criança e do Adolescente (ECA), do Programa de Assistência Integral à Saúde da Criança (PAISC) e da Atenção Integrada às Doenças Prevalentes da Infância 
(AIDPI) (XIMENES NETO, 2011; FELICIANO et al., 2008, FIGUEREDO; MELLO, 2007; ALVES, 2003).

A Política Nacional da Atenção Básica expressa e regulamenta a realização da Consulta de Enfermagem na atenção básica como atribuições específicas do enfermeiro, operacionalizada com base nas normativas ou protocolos preconizados pelo Ministério da Saúde e demais esferas responsáveis (BRASIL, 2012; ALMEIDA Et al., 2012; MELO; TONETE; SILVA, 2009; BRASIL, 2006).

A Consulta de Enfermagem é uma atividade exercida privativamente pelo enfermeiro, representando um modo de processo de trabalho que incorpora técnicas científicas na identificação de situações de saúde e doença, na promoção da saúde, prevenção de doença, no tratamento e na recuperação do usuário, caracterizada pelas etapas do Processo de Enfermagem (PE): Coleta de dados de enfermagem ou histórico de enfermagem; Diagnóstico de enfermagem; Planejamento de enfermagem; Implementação; e Avaliação de enfermagem (COFEN 2009; 1993).

A Sistematização da Assistência de Enfermagem (SAE) é entendida como uma metodologia científica implementada e ampliada na prática assistencial do Enfermeiro, conferindo ao paciente, família ou comunidade uma maior segurança, melhoria na qualidade da assistência prestada e implicando para o profissional a validação de sua autonomia. Nessa perspectiva, ressalta-se que o enfoque de tal metodologia não engloba somente a doença, mas concretiza a proposta de promover, manter ou restaurar os níveis de saúde (MENEZES; PRIEL; PEREIRA, 2011; TANNURE; PINHEIRO, 2010; NOBREGA; SILVA, 2009).

Desta forma, o Conselho Federal de Enfermagem (COFEN, 2009) acrescenta ainda, pela Resolução No 358 de 15 de outubro de 2009, que dentro do contexto descrito, o processo de Enfermagem deve ser realizado, deliberada e sistematicamente, independente do ambiente (público ou privado) em que acontece o cuidado profissional de Enfermagem. Ressalta-se que, na atenção básica, a referida resolução considera que o Processo de Saúde de Enfermagem corresponde ao termo Consulta de Enfermagem.

A Consulta de Enfermagem foi regulamentada pelo Conselho Federal de Enfermagem, por meio da Resolução $N^{\circ}$ 159, de 19 de abril de 1993, e define no seu artigo $1^{\text {o }}$ a obrigatoriedade da Consulta de Enfermagem no desenvolvimento da assistência de enfermagem. A Consulta de Enfermagem segue em expansão, em virtude de uma maior incorporação e regulamentação pelas instituições de saúde brasileiras (COFEN, 2009; SANTANA; MARTINS; GUIMARÃES, 2008; COFEN, 1993).

Embora haja regulamentação da Consulta de Enfermagem e a sua normatização na PNAB, as orientações específicas quanto às características a serem abordadas no cotidiano da atenção básica, tais como metodologia, plano assistencial ou a própria Sistematização da Assistência de 
Enfermagem, são abordados instrumentos e conteúdos com mínima padronização de orientações. Entretanto, a Fundação Municipal de Saúde de Teresina, em uma tentativa de suprir essa lacuna e fundamentar as ações de enfermagem, instituiu o protocolo de "Sistematização da Assistência de Enfermagem para a Consulta de Enfermagem à criança na atenção básica" (ALMEIDA et al., 2012).

O Protocolo de Enfermagem, publicado para uso na atenção básica de saúde e em ambulatórios, tem como objetivo guiar o profissional no intuito de contribuir para a redução dos índices de morbidade e mortalidade das crianças, propondo uma assistência de enfermagem qualificada e planejada. Esse protocolo define a Consulta de Enfermagem como uma avaliação sistemática que, no contexto das crianças de 0 a 10 anos, deve abarcar os temas como: crescimento e desenvolvimento, nutrição, imunização, cuidados e higiene, entre outras temáticas que envolvem a criança, pautando-se nas publicações do Ministério da Saúde (ALMEIDA et al., 2012).

Com isso, a enfermagem assume importante protagonismo na implantação e consolidação da política de atenção básica. Segundo dados do Ministério da Saúde (BRASIL, 2014), no Piauí existem 213 municípios com a Estratégia Saúde da Família (ESF), contando com 1.573 equipes credenciadas e 1.231 implantadas, repercutindo uma estimativa de cobertura populacional de $96,3 \%$, o que representa cerca de 3.045.837 pessoas assistidas. No município de Teresina, são 415 equipes credenciadas pelo MS, porém apenas 236 estão cadastradas no sistema e, dessas, 224 implantadas, tendo uma estimativa de população coberta de 772.800 , representando 93,08\% da população.

Barreto, Nery e Costa (2012) apontam, nessa mesma direção, que o Piauí é o estado brasileiro que possui a maior cobertura populacional da ESF, mesmo tendo sido iniciada em 1994, pois obteve uma ampliação significativa a partir de 2000, e em 2010 representava cerca de 1.100 equipes Saúde da Família, atendendo três milhões de usuários nos serviços de atenção básica fornecidos pelo estado. É importante ressaltar a existência de ampla cobertura da atenção básica para todas as idades, em especial para a faixa etária de menores de cinco anos, por se tratar de uma etapa oportuna para a realização de ações de promoção da saúde e prevenção de doenças infantis. Nessa perspectiva, questiona-se: Como se dá a prática da Consulta de Enfermagem a crianças menores de cinco anos na rede de atenção básica no Município de Teresina-PI? E quais as representações sociais dos enfermeiros sobre esta prática?

Ribeiro, Ohara e Saparolli (2009) abordam a Consulta de Enfermagem à criança como "uma prática de larga escala na atenção básica, realizada contínua e sistematicamente”. Segundo os autores, a Consulta de Enfermagem é indispensável à vigilância, visando à promoção e manutenção da saúde da criança, à redução da incidência de doenças e o aumento da chance de um acompanhamento de um crescimento e desenvolvimento saudáveis. Os autores ressaltam que essa 
prática é a base do cuidado de Enfermagem, e que além de representar o processo de trabalho da enfermagem, oportuniza um grande avanço para a autonomia profissional, enfatizando as ações de promoção da saúde e prevenção de doenças por meio de ações sistematizadas.

No presente estudo, optou-se por analisar a prática da Consulta de Enfermagem em menores de cinco anos de idade, por entender que tal estratificação constitui um intervalo de idade utilizado por pesquisas científicas nas principais bases de dados da Enfermagem, a exemplo das plataformas SciELO, BIREME e LILACS. Além disso, ela se caracteriza como uma faixa etária utilizada em estatísticas pelo Poder Público federal, pois nela ocorrem importantes mudanças fisiológicas que exigem do enfermeiro maior atenção durante a Consulta de Enfermagem.

Nesse escopo, justifica-se o presente estudo pela importância de compreender aspectos gerais pouco explorados na prática da Consulta de Enfermagem, no contexto da saúde da criança na rede de atenção básica de Teresina-PI, realidade bastante difundida. Dessa forma, o presente estudo poderá contribuir para o melhoramento dessa prática, além de suprir as carências na literatura científica. 


\section{Objetivos geral e específicos}

Objetivo geral:

- Analisar a prática da Consulta de Enfermagem às crianças menores de cinco anos na rede de Atenção Básica, Teresina-PI, no ano de 2012.

Objetivos específicos:

- Caracterizar na rede e nas unidades de saúde da atenção básica de Teresina-PI, no ano de 2012, as crianças menores de cinco anos cadastradas pelas equipes da ESF, segundo regional, zona, gênero e faixa etária;

- Identificar o quantitativo de Consultas de enfermagem às crianças, puericulturas, atendimento individual e visitas domiciliares realizadas pelos enfermeiros, segundo demanda;

- Identificar o perfil sociodemográfico dos enfermeiros;

- Descrever a Consulta de Enfermagem quanto às características: estrutura física e equipamentos, a partir de relatos dos enfermeiros;

- Verificar a percepção dos enfermeiros, segundo relatos, quanto ao processo de trabalho, duração da consulta, participantes, objetivos da consulta, procedimentos e temas abordados.

- Apreender as Representações Sociais dos enfermeiros sobre a Consulta de Enfermagem à criança na rede de atenção básica de Teresina. 


\section{REFERENCIAL TEÓRICO/ CONTEXTUALIZAÇÃO TEMÁTICA}

Este capítulo apresenta o referencial teórico e a contextualização temática da pesquisa aqui desenvolvida, em quatro partes. Os tópicos: 3.1( A construção histórica da consulta de enfermagem à criança na rede de atenção básica brasileira) e 3.2 (Práticas de enfermagem à criança na atenção básica: caracterização e contribuições das produções científicas) foram apresentados no formato de artigos a serem publicados em periódicos qualificados. O tópico 3.3 (Consulta de Enfermagem à criança na atenção básica como objeto das representações sociais), por sua vez, refere-se a uma construção teórica fundamental para uma melhor compreensão desta tese.

\subsection{A construção histórica da consulta de enfermagem à criança na rede de atenção básica brasileira}

O Brasil detém uma ampla história de políticas públicas de saúde à criança, repleta de detalhes deontológicos que culminam com a Consulta de Enfermagem, na proposta de promover a saúde e prevenir doenças. Orientada pela necessidade e o contexto político-social brasileiro vivenciado ao longo dos anos, a enfermagem se sobressaiu, nesse arcabouço evolutivo, agregando práticas à criança coerentes com tais políticas implementadas.

Esse recorte trata de uma reflexão que objetiva discutir a trajetória evolutiva da consulta de enfermagem à criança na atenção básica, que compôs a história das políticas públicas de saúde brasileira nos séculos XX e XXI. Para tanto, foram considerados: literatura temática atualizada, legislações brasileiras e artigos publicados na base de dados dos Periódicos da Coordenação de Aperfeiçoamento de Pessoal de Nível Superior - CAPES nos últimos 30 anos.

Os registros mais antigos sobre o cuidado à criança remetem a um tipo de cuidado muito diferente do vivenciado pela atualidade; tratava-se de fardo estressante e insuportável para a família, que o delegava a outras pessoas, privando a criança dos serviços de saúde, até o século XIX. Depois de muitos anos, em 1924, a Organização das Nações Unidas (ONU) lançou a Declaração dos Direitos da Criança, assegurando direitos, benefícios de assistência à saúde, tratamento e cuidados especiais (ALVES, 2003).

As práticas que tinham o caráter do modelo alternativo foram inicialmente desenvolvidas nas décadas de quarenta e sessenta, estagnando-se até meados da década de noventa, para enfim estabelecer os fundamentos das atuais políticas de saúde no Brasil. Uma importante contribuição foi 
realizada em 1940, com a criação dos Serviços Nacionais de Saúde e do Serviço Especial de Saúde Pública, que realizavam ações centralizadas e verticais de saúde pública, havendo uma associação entre medicina preventiva e curativa, influenciado pela medicina preventiva norte-americana. Esses serviços compunham as bases para a atenção primária no Brasil (RIBEIRO; OHARA; SAPAROLLI, 2009).

Em 1960, a Consulta de Enfermagem foi instituída em todo território brasileiro, e visava exclusivamente ao cuidado do binômio mãe e filho, na perspectiva de um controle sobre a gestante e as crianças sadias (PAIM, 2003). Contudo, constata-se que a enfermagem emerge em território brasileiro num momento em que o modelo de atenção à saúde não era muito oportuno, pois o modelo médico assistencialista privatista limitava a sua autonomia. Ainda nessa época, o Brasil contava com uma política de saúde centrada no modelo de atenção médico-assistencial privatista e sanitarista. Porém, decorrente das deficiências existentes, surge o modelo de vigilância da saúde, composto por iniciativas que propunham ações de promoção da saúde e prevenção de doenças (CASTRO; FAUSTO, 2012; TEIXEIRA; PAIM; VILASBÔAS, 2002).

Existia, ainda, nessa época, uma enfermagem mais passiva, que auxiliava o médico na "assistencialização" de suas atribuições nos hospitais. Ela contribuía com o enfoque hospitalocêntrico, privando-se de seu caráter autônomo proposto e necessário na concretização da Consulta de Enfermagem, repercutindo em privação da sua independência durante muitas décadas.

Outras consequências advindas desse modelo de atenção à saúde evidenciam programas de assistência à saúde infantil focados no tratamento da doença com ênfase em atividades e ações hospitalocêntricas. Esse modelo se detém a solucionar especificamente as queixas patológicas da criança, tendo como porta de entrada, as unidades de pronto atendimento (TRAPÉ; FUJIMORE; BERTOLOZZI, 2009).

Percebe-se, então, que a assistência de enfermagem à criança estava focada no atendimento hospitalar com enfoque em uma patologia em curso, e suas atribuições eram bastante limitadas pelo contexto daquela época.

Na década de setenta, ocorreu a criação do Sistema Nacional de Saúde, por meio da Lei No 6.229, que visava ao desenvolvimento de diversos programas que atendiam aos grupos especiais ou prioritários, como era o caso da saúde materno-infantil, possuindo caráter essencialmente verticalista (PAIM, 2009).

Com isso, percebe-se que o modelo médico assistencialista privatista gerou, consigo, a perda da noção de integralidade do cuidado à saúde, causando prejuízos também às crianças, conduzindo a limitações e fragmentações no seu cuidado. Para minimizar esses aspectos, foi necessário que, em 1978, a declaração de Alma-Ata resgatasse a discussão sobre a inter-relação entre doença, pobreza e o desenvolvimento, focando a reorientação do modelo de atenção à saúde, promovendo, assim, 
ações que priorizam a promoção da saúde e prevenção de doenças, marcas características da atenção básica (TRAPE; FUJIMORE; BERTOLOZZI, 2009).

A década de setenta foi marcada pela ascensão e queda do modelo médico-assistencialista privatista, evidenciado pela expansão e esgotamento dele e dando visibilidade aos seus efeitos negativos resultantes da medicalização, das disparidades existentes na saúde da população e da elitização das práticas médicas. Com as reflexões e questionamentos emergidos, o movimento sanitário indicou a necessidade de reforma setorial a nível nacional (CASTRO; FAUSTO, 2012).

Registra-se que, para ter tido a necessidade de tamanha evolução, foi necessário conviver em um momento histórico não muito oportuno para a saúde das crianças. Os índices de morbidade e mortalidade infantil datados da década de 80 eram altíssimos, e os registros conferem uma forte ligação desses índices com doenças infecciosas e parasitárias, bem como a assombrosa desnutrição. Na tentativa de reverter essa situação, o Ministério da Saúde, junto com o Ministério da Previdência e Assistência Social em 1982 traçaram as Ações Básicas da Assistência Integral à Saúde da Criança, que visavam substituir ações baseadas em patologias por uma assistência que contemplasse o processo de crescimento e desenvolvimento, envolvendo ações básicas nas seguintes áreas: aleitamento materno, controle de doenças diarreicas, respiratórias e imunização (ALVES, 2003).

Em 1984, o Governo Federal oficializa o Programa Assistência Integral à Saúde da Criança (PAISC), fundamentado na avaliação das condições sanitárias e epidemiológicas da população infantil brasileira, que associa as altas taxas de mortalidade infantil aos problemas de desnutrição e infecção com elevadas taxas de mortalidade. O programa objetivava assegurar às crianças ações básicas que pudessem contribuir para a minimização dos agravos e diminuição da morbimortalidade infantil, principalmente entre crianças menores de cinco anos. O PAISC constitui-se de cinco ações básicas: promoção do aleitamento materno, bem como demais orientações alimentares; controle da diarreia; controle de doenças respiratórias agudas; acompanhamento do esquema vacinal; e monitoramento do crescimento e desenvolvimento infantil (FIGUEREDO; MELO, 2007; BRASIL, 1984).

Um importante marco para a Consulta de Enfermagem no Brasil ocorre no auge dos anos 80, com a legitimação da Consulta por meio da lei do exercício profissional da Enfermagem, Lei $\mathrm{N}^{\circ}$ 7.498 de 25 de junho de 1986, promulgada pelo Decreto $N^{\circ} 94.406$ de 08 de junho de 1987. Tais normativas supracitadas regulamentam, entre outras atividades privativas do enfermeiro, a Consulta de Enfermagem e a prescrição da assistência de Enfermagem (BRASIL, 1987; 1986).

Após quase quatro décadas de existência da Consulta de Enfermagem nas instituições de saúde no Brasil, ela acabou por se transformar em uma ação voltada para o atendimento, visando à melhoria da qualidade da assistência prestada nos serviços de saúde, garantindo avanços para o 
campo da enfermagem, por meio da sua legitimação (RIBEIRO; SAPAROLLI; SILVA, 2002; SANTOS, et al., 2008).

A partir dessa nova perspectiva para a enfermagem na década de oitenta, o diretor geral das Organizações das Nações Unidas (ONU) incrementa a ênfase da importância da enfermagem, com um conclame no qual convida os enfermeiros a assumir o novo papel na assistência primária de saúde à população, destacando o quanto é importante essa categoria profissional para o êxito de ações de promoção da saúde. Além disso, em 1988 emerge a Reforma Sanitária, que considera a recomendação da ONU em trabalhar com uma equipe multiprofissional, a fim de potencializar a garantia da melhoria da qualidade da assistência prestada (RIBEIRO; SAPAROLLI; SILVA, 2002; MAHLER, 1986).

No mesmo ano em discussão (década de 80), concretiza-se outro importante marco: a nova Constituição Federal brasileira (BRASIL, 1988). Ela considera o conceito de saúde como direito social, devendo essa ser cooperada técnica e financeiramente, entre esferas Federal e Estadual, prestando assistência à população. A saúde é garantida por meio de uma rede organizada e hierarquizada pautada na descentralização, integralidade e participação da população.

Ineditamente, no Brasil, a saúde é vista como um direito da sociedade, um direito garantido a todo cidadão por meio da Constituição Federal, uma conquista atribuída também ao movimento da Reforma Sanitária, direito de caráter democrático e participativo (PAIM, 2009).

Em 1990, ocorre a implantação do Sistema Único de Saúde (SUS), representando um progresso incomum na consolidação e na organização dos serviços de saúde brasileiro, em especial destaca-se a incorporação de medidas que beneficiaram e fortaleceram a rede de atenção básica. A chamada Lei Orgânica da Saúde, N 8.080 dispõe sobre as condições para promoção, proteção e recuperação da saúde, bem como sobre o funcionamento e organização dos serviços correspondentes (ESCOREL, et al., 2007; BRASIL, 1990a).

No mesmo ano, o Estatuto da Criança e do Adolescente (ECA) foi regulamentado pela Lei № 8.069 de 13 de julho de 1990 que, entre outros direitos, assegura a saúde da criança através de um atendimento integral nos serviços de saúde por intermédio do Sistema único de Saúde (BRASIL, 1990b).

Em 1993, o Conselho Federal de Enfermagem publicou a Resolução No 159, que dispõe sobre a Consulta de Enfermagem como um modo de trabalho que incorpora técnicas científicas na identificação de situações de saúde e doença para elaborar ações de planejamento, prescrição e implementação. Essas ações da consulta visam: à promoção da saúde, à prevenção de doença, ao tratamento e à recuperação (COFEN, 1993).

Dentre as vantagens apontadas na Consulta de Enfermagem, destaca-se a maior aproximação dessa com o modelo que explora a compreensão, respeito e sensibilidade do que com o modelo 
tecnicista e mecanicista. Nessa ocasião, o enfermeiro deve priorizar e valorizar a participação do paciente, para que o mesmo possa se sentir à vontade para informá-lo sobre seus problemas e preocupações envolvendo o processo saúde/doença (SANTANA; MARTINS, 2008).

Já no ano de 1994, ocorre a implantação do Programa Saúde da Família, incorporado à Política Nacional da Saúde, que preconizava a participação de uma equipe multiprofissional que se responsabilizaria e vincularia as famílias numa população adstrita, atuando na detecção de problemas de saúde e situações de risco à comunidade, elaboração de atividades em prol do enfrentamento dos determinantes saúde/doença e o desenvolvimento de educação em saúde e na assistência integral (BRASIL, 2006).

No início, havia o "Programa Saúde da Família"; porém, a partir de 1996, o próprio Ministério da Saúde passa a denominá-lo de "Estratégia Saúde da Família", por se tratar de uma estratégia de reorientação do modelo assistencial vivenciado naquele momento. Ressalta-se que essa mudança traz consigo uma divisão na história, pois se antes de 1996 a cobertura era direcionada a grupos vulneráveis, considerados de maneira precárias, após a referida data passa a ser considerada estratégia de reorientação no modelo de atenção à saúde (RODRIGUES, 2011).

A Estratégia Saúde da Família tem apresentado, nos últimos vinte anos, um crescimento expressivo com resultados positivos nos indicadores de saúde e qualidade de vida da população assistida. É importante ressaltar que a Saúde da Família é entendida como uma estratégia de reorientação do modelo assistencial, com ações de promoção da saúde, prevenção, recuperação, reabilitação de doenças e agravos mais frequentes, como também de manutenção da saúde da comunidade (BRASIL, 2011).

Em 2005, é publicada a agenda de compromissos para a saúde integral da criança e a redução da mortalidade infantil, apresentando como estratégias: a vigilância à saúde pela equipe da atenção básica (ações objetivando minimizar os riscos de pessoas com maior vulnerabilidade, destacando a busca ativa daqueles não acompanhados pela ESF e visitas domiciliares para a captação dos usuários); vigilância da mortalidade infantil (de responsabilidade do gestor municipal, porém realizada pela equipe da ESF no intuito de desvelar e analisar a viabilidade) e educação continuada das equipes de atenção à criança (capacitação teórico-prática) (BRASIL, 2005).

Em duas décadas de implantação e evolução, o Sistema único de Saúde representa um progresso singular no campo na saúde pública brasileira. Por essa razão, os serviços de saúde passaram por uma regionalização, com os processos simultâneos de descentralização e municipalização. Entretanto, surgiram consigo novos desafios pautados na fragmentação de suas ações e programas. Para isso, foi necessário pactuar, entre as três esferas gestoras (município, estados federativos e União), o campo dos sistemas de saúde. 
O Governo Federal, em 22 de fevereiro de 2006, publica a portaria $\mathrm{N}^{\mathrm{o}} 399$, que dispõe sobre o Pacto pela Saúde, que prioriza: redução da mortalidade infantil e o fortalecimento da atenção básica (BRASIL, 2011; RODRIGUES 2011; BRASIL, 2006a; 2005a).

Com o enfoque na atenção básica, o Ministério da Saúde lança, em 2006, a Política Nacional da Atenção Básica, por meio da portaria nº 648, definindo a atenção básica como um integrado de ações, de âmbito individual ou conjunto, que desenvolve promoção, proteção e recuperação da saúde de maneira integrada. Devendo ser considerada a porta de entrada dos usuários nos serviços de saúde, é orientada pelos princípios e diretrizes do SUS (BRASIL, 2012; 2011; RODRIGUES, 2011; LOBO; LIMA; ACIOLI, 2011; BRASIL, 2006a; 2005a).

A Consulta de Enfermagem se reforça, assim, em 15 de outubro de 2009, quando o Conselho Federal de Enfermagem publicou a Resolução $\mathrm{N}^{\circ} 358$, que revoga a Resolução $\mathrm{N}^{\circ}$ 272/2002 e legitima a Sistematização da Assistência de Enfermagem como instrumento que organiza o processo de trabalho e orienta o enfermeiro na prestação do cuidado, devendo possuir fundamentação teórica que o direcione (COFEN, 2009).

Em 2011, o Ministério da Saúde publicou a Portaria No 2.488, que aprova a Política Nacional da Atenção Básica (PNAB), com a revisão de diretrizes e normas organizacionais para a atenção básica, em especial para a Estratégia Saúde da Família. A nova portaria sobre a PNAB não revoga a anterior ( $N^{\circ}$ 648/2006), estabelecendo apenas que o Ministério da Saúde, por meio das secretarias, fica encarregado de publicar guias e manuais que orientem tal política, definindo também os recursos orçamentários do Ministério destinados a onerar com os gastos dessa política (BRASIL, 2012; LOBO, LIMA, ACIOLI, 2011; BRASIL, 2011; BRASIL, 2005).

No mesmo ano, o MS, por meio da Portaria No 1.654 de 19 de julho de 2011, institui, dentro da atual política de saúde pública, o Programa de Melhoria do Acesso e da Qualidade da Atenção Básica (PMAQ-AB) e do seu respectivo incentivo financeiro, denominado de componente de qualidade do piso de atenção básica variável - PAB variável. O referido programa objetiva conduzir a ampliação e o acesso à atenção básica, estabelecendo um padrão de qualidade comparável em diversos âmbitos (nacionais, municipais e locais) (BRASIL, 2012b).

Nesse momento histórico, percebe-se que a Consulta de Enfermagem à criança na atenção básica se encontra em um momento de avaliação, aperfeiçoamento e reformulação das práticas. Isso representa certa fase de maturidade, seguramente evidenciada por instrumentos que podem conferir qualidade de vida para as crianças e o atendimento dos pré-requisitos básicos da saúde por meio da Política de Atenção Básica, em convergência com a nova proposta de saúde conceituada pela OMS.

A consulta de enfermagem à criança na atenção básica não emergiu como uma prática perfeitamente finalizada. Muito pelo contrário, percebe-se que, ao longo dos anos, essa prática que 
garante qualidade de vida às crianças teve influências sociais, políticas e econômicas, e está em construção, ainda que em meio aos desafios e dificuldades.

A história da Consulta de Enfermagem à criança na atenção básica foi construída de forma fragmentada e se aperfeiçoa em virtude das políticas e necessidades advindas com o decorrer dos anos. A problemática, a partir de temas como "Consulta de Enfermagem", "Saúde da Criança" e "Atenção básica", integra o arcabouço teórico, que inicialmente era abordado separadamente, e somente no final do século XX e início do século XXI foi articulado junto aos demais construtos, fortalecendo a visão do cuidado integral da saúde da criança no contexto da atenção básica.

\subsection{Práticas de enfermagem à criança na atenção básica: caracterização e contribuições das produções científicas}

Em 2011, o Ministério da Saúde (MS) publica a Portaria № 2.488, que aprovou a Política Nacional da Atenção Básica (PNAB) com a revisão de diretrizes e normas organizacionais para a atenção básica, em especial para a Estratégia Saúde da Família. A Portaria No 648 de 2006, do MS, que institui a PNAB, define a "atenção básica" como um conjunto de atividades práticas voltadas para o indivíduo e/ou coletividade, durante seu ciclo de vida, que abrangem a promoção da saúde, proteção, prevenção de agravos e manutenção da saúde (BRASIL, 2012; BRASIL, 2006).

Melo, Tonete e Silva, (2009) acrescentam que a prática de enfermagem à criança na atenção básica está centrada no cuidado integral, na vigilância à saúde e na promoção da saúde. Com base nesses princípios, a enfermagem comunitária brasileira tem como objetivo cuidar da saúde, além do monitoramento do crescimento e desenvolvimento infantil e dos agravos mais prevalentes. A enfermagem desempenha papeis, funções e responsabilidades importantes para o cuidado à criança, buscando construir espaços de cuidado em saúde junto às famílias, na perspectiva da integralidade, humanização, equidade, cidadania e intersetorialidade, garantindo direito à saúde e uma vida saudável.

Moura e Rocha (2012) relatam uma realidade da assistência de Enfermagem no cuidado à criança na atenção básica, descrevendo-a com o foco na Consulta de Enfermagem, seguindo a proposta da Política Nacional da Atenção Básica. Destacam, ainda, a atuação do enfermeiro nesse contexto, que contribui para a qualidade de vida das crianças, articulando saberes e práticas no cotidiano da atenção básica, garantindo assim condições mais saudáveis para essas crianças. Na atenção básica, a enfermagem é considerada uma profissão de referência em relação ao cuidado à criança, como também pela promoção da saúde e prevenção de doenças. 


\section{MÉTODO}

Trata-se de uma revisão integrativa que utiliza trabalhos publicados de julho de 2005 a julho de 2015, ou seja, um recorte temporal dos últimos dez anos, tendo como fonte de consulta a base de dados da Literatura Latino-Americana e do Caribe em Ciências da Saúde - LILACS, disponibilizada nos Periódicos da Coordenação de Aperfeiçoamento de Pessoal de Nível Superior CAPES. Foram utilizados os seguintes descritores em português: “enfermagem”, "atenção primária à saúde" e "criança", cruzadas somente com o boleano "and".

Definiu-se como pergunta: Qual a caracterização dos estudos sobre a prática de Enfermagem à criança na atenção básica, e quais as contribuições dessas práticas para a criança no contexto da atenção básica?

Inicialmente foram localizados sessenta e dois estudos disponibilizados diretamente na base de dados da Literatura Latino-Americana e do Caribe em Ciências da Saúde - LILACS e doze nos Periódicos da CAPES. Nesse primeiro recorte, houve a necessidade de se optar somente por artigos completos, que se referiam às temáticas: enfermagem, criança e/ou atenção primária à saúde no título ou resumo. A partir de uma segunda divisão, houve a exclusão de trabalhos repetidos entre as fontes pesquisadas e trabalhos que apresentavam uma abordagem não focalizada em nosso objeto de estudo, bem como os que se tratavam de revisões (bibliográficas ou sistemáticas). Dessa maneira, restaram dezenove publicações a serem exploradas, como mostra a Figura 01.

Procedeu-se à leitura e releitura exaustiva das publicações, para então seguir com a elaboração da caracterização dos artigos publicados, na construção do estado da arte, reportando aspectos relevantes, a saber: abordagem e metodologia; modelo de atenção à saúde; estratégias de ação do enfermeiro; natureza das práticas e abrangência da prática. 


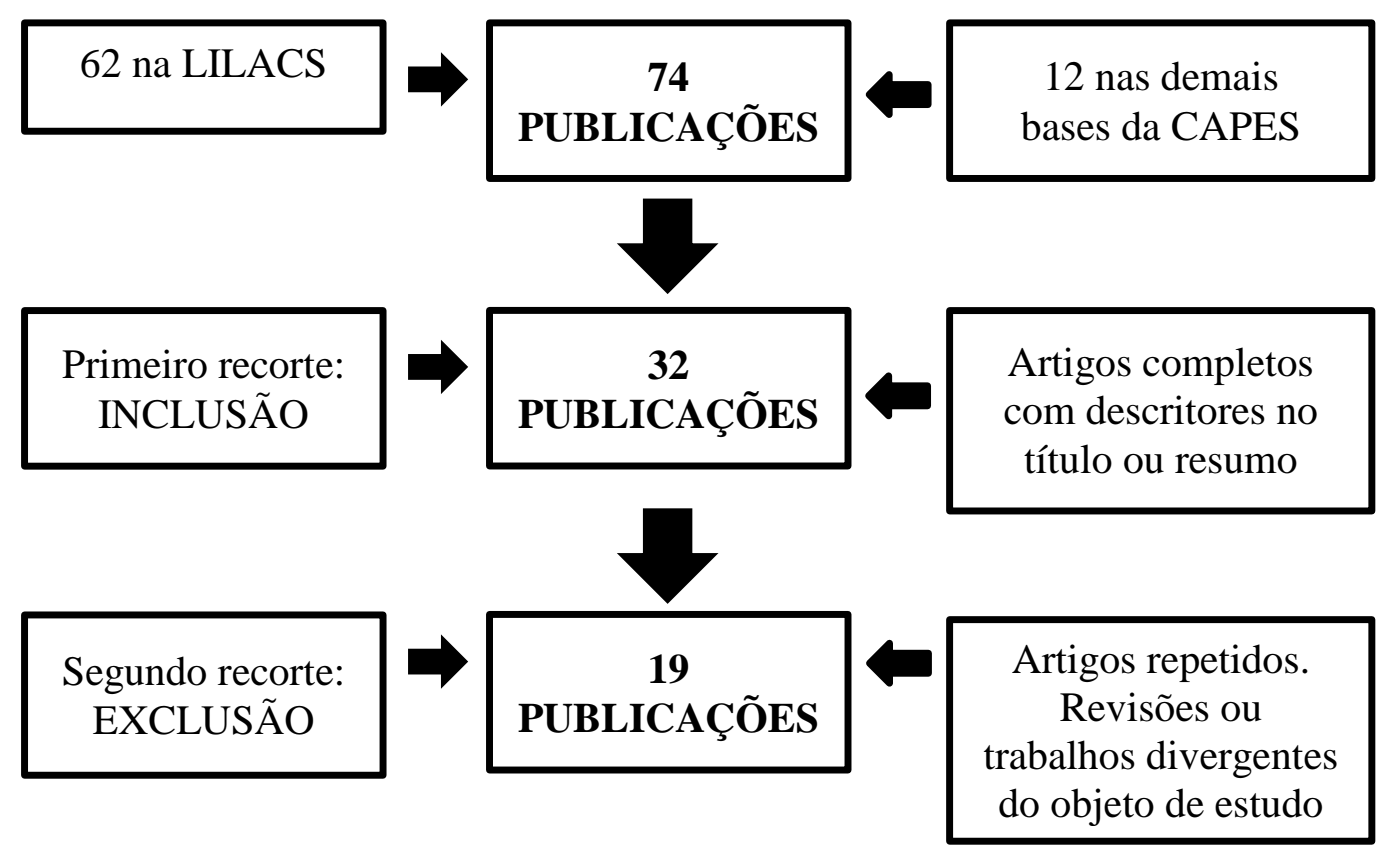

Figura 1. Gráfico linear das publicações analisadas. 


\section{PRÁTICAS DE ENFERMAGEM À CRIANÇA NA ATENÇÃO BÁSICA: caracterização dos artigos}

Em síntese, o quadro 1 descreve a caracterização dos artigos revisados sob os aspectos: abordagem e metodologia; modelo de atenção à saúde; estratégias de ação do enfermeiro; natureza das práticas e abrangência da prática.

Quadro 1. Síntese dos artigos analisados. Brasília, 2016.

\begin{tabular}{|c|c|c|c|c|c|}
\hline Referência & $\begin{array}{l}\text { Abordagem/ } \\
\text { Metodologia }\end{array}$ & $\begin{array}{l}\text { Modelo de } \\
\text { atenção à saúde }\end{array}$ & $\begin{array}{l}\text { Estratégias de ação do } \\
\text { enfermeiro }\end{array}$ & $\begin{array}{l}\text { Natureza das } \\
\text { práticas }\end{array}$ & $\begin{array}{l}\text { Abrangência } \\
\text { da prática }\end{array}$ \\
\hline $\begin{array}{l}\text { ANDRADE, G.N.; REZENDE, T.M.R.L.; MADEIRA, } \\
\text { A.M.F. Child Health Booklet: experiences of } \\
\text { professionals in primary health care. Rev. esc. enferm. } \\
\text { USP, São Paulo, v. } 48, \text { n.5, p. } 857-864 \text {, out., } 2014 \text {. }\end{array}$ & $\begin{array}{l}\text { Qualitativa } \\
\text { Fenomenológico }\end{array}$ & Vigilância à saúde & $\begin{array}{l}\text { Caderneta de saúde da } \\
\text { criança como instrumento } \\
\text { que amplia o campo de } \\
\text { prática. }\end{array}$ & $\begin{array}{l}\text { Vigilância } r \text { em } \\
\text { saúde }- \text { práticas } \\
\text { assistenciais }\end{array}$ & Individual \\
\hline $\begin{array}{l}\text { SILVA, R.M.M.; VIERA, C.S.. Acesso ao cuidado à } \\
\text { saúde da criança em serviços de atenção primária. Rev. } \\
\text { bras. enferm., Brasília, v.67, n.5, p.794-802, } \\
\text { out., 2014. }\end{array}$ & $\begin{array}{l}\text { Qualitativa. } \\
\text { Dialética } \\
\text { hermenêutica }\end{array}$ & $\begin{array}{l}\text { Modelo médico- } \\
\text { assistencial privatista }\end{array}$ & $\begin{array}{l}\text { Práticas sem resolutividade, } \\
\text { continuidade e não } \\
\text { responsabilização }\end{array}$ & $\begin{array}{l}\text { Processos } \text { de } \\
\text { trabalho práticas } \\
\text { fragmentadas }\end{array}$ & Individual \\
\hline $\begin{array}{l}\text { SOUZA, R.S.; Et al. Atenção à saúde da criança: prática } \\
\text { de enfermeiros da saúde da família. REME Rev. Min. } \\
\text { enferm., Belo Horizonte, v.17, n.2, p.95-103, abr./jun., } \\
2013 \text {. }\end{array}$ & $\begin{array}{l}\text { Qualitativa } \\
\text { Não descreve }\end{array}$ & $\begin{array}{l}\text { Modelo médico- } \\
\text { assistencial privatista }\end{array}$ & $\begin{array}{l}\text { Ações de promoção e } \\
\text { prevenção de doença que } \\
\text { apresentam fragilidade no } \\
\text { cumprimento. }\end{array}$ & $\begin{array}{l}\text { Processos } \quad \text { de } \\
\text { trabalho práticas } \\
\text { fragmentadas }\end{array}$ & $\begin{array}{l}\text { Individual } \\
\text { coletivo }\end{array}$ \\
\hline $\begin{array}{l}\text { MODES, P.S.S.A.; GAIVA, M.A.M. Structure of } \\
\text { children's basic health units: descritive study. Online } \\
\text { Braz. J. Nurs.(online), Rio de Janeiro, v.12, n. 3, p.471- } \\
11 \text {, set., } 2013 \text {. }\end{array}$ & $\begin{array}{l}\text { Quantitativa } \\
\text { Estudo descritivo } \\
\text { e avaliativo }\end{array}$ & Vigilância à saúde & $\begin{array}{l}\text { É tido como fundamental } \\
\text { para a implementação da } \\
\text { rotina de cuidados a criança. }\end{array}$ & $\begin{array}{l}\text { Vigilância } \quad \text { em } \\
\text { saúde }- \text { práticas } \\
\text { assistenciais }\end{array}$ & $\begin{array}{l}\text { Individual } \\
\text { coletivo }\end{array}$ \\
\hline $\begin{array}{l}\text { OLIVEIRA, F.F.S.; et al. Consulta de puericultura } \\
\text { realizada pelo enfermeiro na estratégia saúde da família. } \\
\text { Rev. RENE, Fortaleza, 14, 4, p. 694-703, out.-dez., } \\
\text { 2013. }\end{array}$ & $\begin{array}{l}\text { Quantitativa } \\
\text { Observacional } \\
\text { descritiva }\end{array}$ & Vigilância à saúde & $\begin{array}{l}\text { Realiza Consulta de } \\
\text { enfermagem desenvolvendo } \\
\text { com frequência o histórico e } \\
\text { exame físico }\end{array}$ & $\begin{array}{l}\text { Vigilância } \quad \text { em } \\
\text { saúde }- \text { práticas } \\
\text { assistenciais }\end{array}$ & $\begin{array}{l}\text { Individual } \\
\text { coletivo }\end{array}$ \\
\hline $\begin{array}{l}\text { REICHERT, A.P.S.; Et al. Vigilância do crescimento } \\
\text { infantil: conhecimentos e práticas de enfermeiros da } \\
\text { atenção primária à saúde. Rev. RENE, Fortaleza, v.13, } \\
\text { n.1, p.114-26, jan./fev., 2012. }\end{array}$ & $\begin{array}{l}\text { Quantitativa } \\
\text { Transversal }\end{array}$ & Vigilância à saúde & $\begin{array}{l}\text { Pautada na vigilância da } \\
\text { saúde à criança com } \\
\text { utilização de tecnologias } \\
\text { educativas }\end{array}$ & $\begin{array}{l}\text { Processos } r \text { de } \\
\text { trabalho práticas } \\
\text { fragmentadas e } \\
\text { tecnicistas }\end{array}$ & $\begin{array}{l}\text { Individual } \\
\text { coletivo }\end{array}$ \\
\hline
\end{tabular}


Cont. Quadro 1. Síntese dos artigos analisados. Brasília, 2016.

\begin{tabular}{|c|c|c|c|c|c|}
\hline $\begin{array}{l}\text { GAUTERIO,D.P.;IRALA, D.A.; CEZAR-VAZ, } \\
\text { M.R. Puericultura em enfermagem: perfil e } \\
\text { principais problemas encontrados em crianças } \\
\text { menores de um ano. Rev. Bras. Enferm., Brasília, } \\
\text { v.65, n.3, p. 508-513, mai./jun., 2012. }\end{array}$ & $\begin{array}{l}\text { Qualitativa } \\
\text { Descritivo } \\
\text { exploratório }\end{array}$ & Vigilância à saúde & \begin{tabular}{l}
\multicolumn{3}{l}{ Consulta de Enfermagem em } \\
puericulturas: avaliar e \\
intervir no processo \\
saúde/doença
\end{tabular} & $\begin{array}{l}\text { Vigilância em saúde } \\
-\quad \text { práticas } \\
\text { assistenciais }\end{array}$ & Individual \\
\hline $\begin{array}{l}\text { SOUSA, F.G.M.; ERDMANN, A.L. Qualificando o } \\
\text { cuidado à criança na atenção primária de saúde. } \\
\text { Rev. Bras. Enferm., Brasília, v.65, n.5, p. 795-802, } \\
\text { set./out., } 2012 \text {. }\end{array}$ & $\begin{array}{l}\text { Qualitativa } \\
\text { Grounded theory }\end{array}$ & Vigilância à saúde & $\begin{array}{lr}\text { Agir } & \text { compartilhado, } \\
\text { enriquecido } & \text { por } \\
\text { subjetividades. O cuidado é } \\
\text { singular. }\end{array}$ & $\begin{array}{lr}\text { Vigilância em } & \text { saúde } \\
-\quad \text { práticas } & \text { de } \\
\text { aprimoramento } & \text { do } \\
\text { cuidado } & \end{array}$ & Individual e coletivo \\
\hline $\begin{array}{l}\text { BARBOZA, C.L.; BARRETO, M.S.; MARCON, } \\
\text { S.S. Registros de puericultura na atenção básica: } \\
\text { estudo descritivo. Online Braz. J. Nurs.(online), } \\
\text { Rio de Janeiro, v.11, n. 2, p.359-71, ago., 2012. }\end{array}$ & $\begin{array}{l}\text { Quantitativa } \\
\text { Descritiva }\end{array}$ & Vigilância à saúde & $\begin{array}{l}\text { Puericultura: promover } \\
\text { saúde e prevenir riscos }\end{array}$ & $\begin{array}{l}\text { Vigilância em saúde } \\
-\quad \text { práticas } \\
\text { assistenciais }\end{array}$ & Individual e coletivo \\
\hline $\begin{array}{l}\text { MOURA, M.A.P.; ROCHA, S.S. Dinâmica da } \\
\text { Assistência de Enfermagem no cuidado à criança na } \\
\text { atenção básica. Nursing, Barueri, v.167, n. 14, p. } \\
221-6 \text {, abr., 2012. }\end{array}$ & $\begin{array}{l}\text { Qualitativa } \\
\text { História } \quad \text { Oral } \\
\text { Temática }\end{array}$ & Vigilância à saúde & $\begin{array}{l}\text { Consulta de Enfermagem, } \\
\text { ações de promoção da saúde } \\
\text { e prevenção de doenças }\end{array}$ & $\begin{array}{l}\text { Vigilância em saúde } \\
-\quad \text { práticas } \\
\text { assistenciais }\end{array}$ & Individual \\
\hline $\begin{array}{l}\text { MONTEIRO, A.I.; Et al. A expressão da autonomia } \\
\text { do enfermeiro no acompanhamento do crescimento } \\
\text { e desenvolvimento da criança. Rev. Enferm. } \\
\text { UERJ, Rio de Janeiro, v.19, n.3, p. 426-31, } \\
\text { jul./set., 2011. }\end{array}$ & $\begin{array}{l}\text { Qualitativa } \\
\text { Descritivo }\end{array}$ & Vigilância à saúde & $\begin{array}{l}\text { Promoção da saúde e } \\
\text { prevenção de doenças. } \\
\text { Práticas emancipatórias }\end{array}$ & $\begin{array}{l}\text { Processos de trabalho } \\
\text { práticas assistenciais } \\
\text { e de aprimoramento } \\
\text { do cuidado }\end{array}$ & Coletivo \\
\hline $\begin{array}{l}\text { SOUSA, F.G.M.; ERDMANN, A.L.; MOCHEL, } \\
\text { E.G.. Condições limitadoras para a integralidade do } \\
\text { cuidado à criança na atenção básica de } \\
\text { saúde. Texto contexto - enferm., Florianópolis, v. } \\
\text { 20, n. spe, p. 263-271, } 2011\end{array}$ & $\begin{array}{l}\text { Qualitativa } \\
\text { Grounded theory }\end{array}$ & $\begin{array}{l}\text { Modelo médico- } \\
\text { assistencial } \\
\text { privatista }\end{array}$ & $\begin{array}{l}\text { Ações fragmentadas. } \\
\text { Falta planejamento, } \\
\text { interdisciplinaridade, } \\
\text { continuidade do cuidado. }\end{array}$ & $\begin{array}{l}\text { Processos de trabalho } \\
\text { práticas fragmentadas } \\
\text { e tecnicistas }\end{array}$ & Individual e coletivo \\
\hline $\begin{array}{l}\text { TOMASI, E. et al. Características da utilização de } \\
\text { serviços de atenção básica à saúde nas regiões Sul e } \\
\text { Nordeste do Brasil: diferenças por modelo de } \\
\text { atenção. Ciênc. saúde coletiva, RJ, v. 16, n. 11, p. } \\
\text { 4395-404, Nov., 2011. }\end{array}$ & $\begin{array}{l}\text { Quantitativa } \\
\text { Transversal }\end{array}$ & Vigilância à saúde & $\begin{array}{lll}\begin{array}{l}\text { Atendimentos } \\
\text { enfermagem }\end{array} & \text { básicos } & \text { de } \\
\end{array}$ & $\begin{array}{l}\text { Processos de trabalho } \\
\text { Práticas fragmentadas } \\
\text { e tecnicistas }\end{array}$ & Individual \\
\hline $\begin{array}{l}\text { SOUSA, F.G.M.; ERDMANN, A.L.; MOCHEL, } \\
\text { E.G. Modelando a integralidade do cuidado à } \\
\text { criança na atenção básica de saúde. Rev. Gaúcha } \\
\text { Enferm. (Online), Porto Alegre, v. } 31 \text {, n.4, p. 701- } \\
\text { 7, dez., } 2010 .\end{array}$ & $\begin{array}{l}\text { Qualitativa } \\
\text { Grounded theory }\end{array}$ & Vigilância à saúde & $\begin{array}{l}\text { Manutenção e promoção da } \\
\text { saúde com integralidade do } \\
\text { cuidado }\end{array}$ & $\begin{array}{l}\text { Fortalecimento de } \\
\text { práticas familiares } \\
\text { para a promoção da } \\
\text { saúde r infantil- } \\
\text { praticas assistenciais }\end{array}$ & Individual e coletivo \\
\hline
\end{tabular}


Cont. Quadro 1. Síntese dos artigos analisados. Brasília, 2016.

\begin{tabular}{|c|c|c|c|c|c|}
\hline $\begin{array}{l}\text { BICUDO, D.M. Et al. Organization of primary care child } \\
\text { health professional's seconds: qualitative research. Online } \\
\text { Brazilian Jounaul of Nursing, Rio de Janeiro, v. 9, n. 1, p. } \\
\text { 1-14, abr., } 2010 \text {. }\end{array}$ & $\begin{array}{l}\text { Qualitativa } \\
\text { Descritiva }\end{array}$ & $\begin{array}{l}\text { Modelo médico- } \\
\text { assistencial privatista } \\
\text { e vigilância à saúde }\end{array}$ & $\begin{array}{l}\text { Práticas do modelo } \\
\text { hegemônico e de } \\
\text { promoção da saúde }\end{array}$ & $\begin{array}{l}\text { Processos de trabalho - } \\
\text { práticas gerenciais }\end{array}$ & $\begin{array}{l}\text { Individual } \\
\text { coletivo }\end{array}$ \\
\hline $\begin{array}{l}\text { SAPAROLLI, Eliana Campos Leite; ADAMI, Nilce Piva. } \\
\text { Avaliação da estrutura destinada à consulta de enfermagem à } \\
\text { criança na atenção básica. Rev. esc. enferm. USP, São } \\
\text { Paulo, v. } 44 \text {, n. 1, p. 92-98, Mar., 2010. }\end{array}$ & $\begin{array}{l}\text { Quanti-quali } \\
\text { Descritiva e } \\
\text { avaliativa }\end{array}$ & Vigilância à saúde & $\begin{array}{l}\text { Promoção, proteção e } \\
\text { recuperação da saúde }\end{array}$ & $\begin{array}{l}\text { Processo de trabalho - } \\
\text { - práticas gerenciais }\end{array}$ & Estrutural \\
\hline $\begin{array}{l}\text { MELO, D.F.; LIMA, R.A.G.; SCOCHI, C.G.S. A saúde de } \\
\text { crianças em situação de pobreza: entre a rotina e a } \\
\text { eventualidade de cuidados cotidianos. Rev.Latino-am } \\
\text { enferm., São Paulo, } 15 \text {, n.e., p., 1-8, set./out., } 2007 \text {. }\end{array}$ & $\begin{array}{l}\text { Qualitativa } \\
\text { Hermenêutica. }\end{array}$ & Vigilância à saúde & $\begin{array}{l}\text { Ações básicas rue } \\
\text { envolvem } \quad \text { valores, } \\
\text { vínculos } \\
\text { responsabilização }\end{array}$ & $\begin{array}{l}\text { Vigilância em saúde - } \\
\text { práticas assistenciais }\end{array}$ & $\begin{array}{l}\text { Individual } \\
\text { coletivo }\end{array}$ \\
\hline $\begin{array}{l}\text { PRADO, S.R.L.A.; FUJIMORI, E. Registro em prontuário } \\
\text { de crianças e a prática da integralidade. Rev. bras. } \\
\text { enferm., Brasília, v. } 59 \text {, n. } 1 \text {, p. } 67-71 \text {, Fev., } 2006 \text {. }\end{array}$ & $\begin{array}{l}\text { Quantitativo } \\
\text { Transversal }\end{array}$ & Vigilância à saúde & $\begin{array}{l}\text { Pelos registros, percebe- } \\
\text { se práticas integrativas, } \\
\text { sistemáticas e contínuas }\end{array}$ & $\begin{array}{l}\text { Vigilância em saúde - } \\
\text { práticas assistenciais }\end{array}$ & Individual \\
\hline
\end{tabular}


$\mathrm{Na}$ distribuição quantitativa dos artigos por ano de publicação, percebe-se um crescimento acentuado de publicações referentes à temática de enfermagem na saúde da criança, no contexto da atenção básica a partir de 2010, destacando-se o ano de 2012 com o maior número de publicações.

A Consulta de Enfermagem foi regulamentada pela Resolução № 159 de 19 de abril de 1993 e o estabelecimento em 1994 do então chamado, "Programa Saúde da Família", as dezenove publicações evidenciam dois importantes marcos deontológicos para justificar o destaque quantitativo demostrando no quadro 1: Em 2006 e 2012, a publicação e revisão da Política Nacional da Atenção Básica (Portaria Nº 648 e N².488) e em 2009, a publicação da Resolução No 358 pelo Conselho Federal de Enfermagem, que dispõe sobre a implementação do Processo de Enfermagem nos ambientes de serviços de saúde, e em especial destaca-se a implantação na rede de atenção primária (BRASIL, 2012; RODRIGUES, 2011; COFEN, 2009; BRASIL, 2006; COFEN, 1993).

Percebe-se que as publicações deontológicas sobre a temática da atenção básica e do processo de enfermagem que envolve a atenção básica, de certa forma, inspiram e influenciam pesquisas a serem publicadas nos anos subsequentes. Os marcos apresentados estabelecem novas diretrizes e conhecimentos que carecem de estudos práticos, corroborando, assim, com a evolução das práticas de enfermagem no cuidado à criança na $\mathrm{AB}$.

A abordagem metodológica dos artigos revisados apresentou uma maior predominância de estudos qualitativos, representando mais da metade das publicações encontradas (onze), seguida pela abordagem quantitativa, que registra seis pesquisas e a abordagem mista, com uma publicação.

Flick (2009) defende a pesquisa qualitativa como sendo aquela com o intuito de entender, descrever e explicar fenômenos sociais a partir de experiências individuais ou em grupo, considerando interações e comunicações entre os mesmos, podendo ser acrescidos documentos que fomentem a pesquisa. Essa abordagem detalha a maneira pelo qual está sendo construída uma realidade vivida, considerando o seu contexto histórico e suas particularidades.

A pesquisa mista, ou também denominada pesquisa de métodos mistos, segundo Johnson, Onwuegbuzie e Turner (2007) configura-se como aquela em que os pesquisadores combinam elementos qualitativos com quantitativos, objetivando um maior aprofundamento do conhecimento.

No uso de pesquisas com abordagem qualitativas e quantitativas, Pope e Mays (2009) confirmam que essas podem ser independentes e complementares, podendo também utilizar a 
pesquisa qualitativa como preliminar da pesquisa quantitativa, estabelecendo abordagens mais completas e complexas para o alcance do objetivo proposto, contemplando o objeto do estudo.

Ao se relacionar o ano de publicação com a abordagem empregada nas pesquisas, observa-se características próprias de cada uma. Em relação à abordagem qualitativa, percebese que há trabalhos distribuídos ao longo da temporalidade estudada, buscando descrever seus fenômenos em um cotidiano repleto de subjetividade e especificidades, capazes de construir documentos que revelem tal realidade. A pesquisa quantitativa encontrada mais nos últimos anos do período de tempo estudado, reflete o caráter avaliativo, numa perspectiva de mensurar o que foi implementado, e as pesquisas mistas, dispostas nos últimos anos da temporalidade pesquisada, demonstram as possibilidades mais completas e complexas que envolvem o objeto de estudo.

No quadro 1 são apresentados os delineamentos metodológicos empregados nos estudos que compõem esta revisão. Nota-se a diversidade existente nos trabalhos, destacando estudos: fenomenológicos; dialéticos e hermenêuticos; descritivo; avaliativos; observacionais exploratórios; Grounded theory e transversais.

Percebe-se, então, que as metodologias mais empregadas nos artigos analisados demostram claramente suas potencialidades e incorporam também peculiaridades da temática proposta, tendo em vista o objetivo em descrever, analisar, construir modelos teóricos e mensurar dados relativos à enfermagem na saúde da criança no contexto da atenção básica.

Em relação aos participantes, a maior predominância ocorreu com os sujeitos: enfermeiros, seguidos dos profissionais da saúde. Em relação à participação dos sujeitos em pesquisas sobre a temática em discussão, mostrou-se semelhante à encontrada em uma revisão realizada por Lentsck, Kluthcovsky, Kluthcovsky (2010). Tais informações refletem a riqueza obtida por diferentes percepções.

Dentre os artigos selecionados e apresentados no quadro 1, percebe-se uma tendência a trabalhos sobre a assistência à criança ou ao processo de trabalho que envolve a enfermagem no contexto da atenção básica. Para isso, justifica-se, então, a predominância de tais sujeitos.

O quadro 1 ilustra também os espaços geográficos que foram cenários de estudo nos artigos. Destacam-se trabalhos desenvolvidos em São Paulo, Paraná, Piauí e Maranhão.

Trabalho desenvolvido por Lima (2011) e Canella, Silva e Jaime (2013) encontraram resultados semelhantes no que se refere ao estado federativo e região com maior produção. Entretanto, Lentsck, Kluthcovsky e Kluthcovsky (2010) descrevem, além de São Paulo, os estados de Bahia e Ceará como grandes produtores científicos nessa área temática, dados que divergem dos encontrados na presente pesquisa. 


\section{Relatos das práticas de enfermagem no cuidado à criança na atenção básica}

O cotidiano da enfermagem no cuidado à criança na atenção básica oportuniza o conhecimento de particularidades típicas da realidade vivenciada no Brasil. Neste tópico, pretende-se identificar estas práticas descritas em pesquisas anteriormente realizadas, revelando como ocorreram e destacando características importantes do processo de implementação, que possam contribuir para a produção de conhecimento, bem como para a problematização de novos estudos nessa área. Em síntese, buscar-se-á relacionar nos artigos objeto desta revisão, as práticas com o modelo de atenção à saúde, a atuação da enfermagem, a natureza ou foco das ações, e o perfil ou âmbito discutido pelos artigos.

As práticas de enfermagem no cuidado à criança na atenção básica brasileira serão abordadas a partir de: 1) Práticas assistenciais; 2) Práticas tecnicistas e fragmentadas; 3) Práticas de gerenciamento; e 4) Práticas de aprimoramento do cuidado.

Quanto às práticas assistenciais, Andrade, Rezende e Madeira (2014) descrevem-nas como aquelas vivenciadas por enfermeiros e médicos em Belo Horizonte, onde a caderneta de saúde da criança é tida como um instrumento que amplia a prática profissional por meio de informações obtidas em seu conteúdo, possibilitando o diálogo com a família da criança assistida.

Em Picos-PI, Oliveira et al., (2013) revelam uma outra realidade, na qual a prática assistencial à criança na atenção básica ocorre com mais frequência a partir das etapas: histórico de enfermagem e exame físico. E os aspectos contemplados segundo os autores, são: verificação da antropometria; investigação dos reflexos em função da idade e atividades de educação em saúde com as temáticas: aleitamento materno exclusivo e orientação acerca da higiene das crianças.

Modes e Gaiva (2013) relatam as práticas assistenciais focando o papel do enfermeiro como fundamental para a implementação dos cuidados à criança na rede de atenção básica, mesmo considerando suas limitações estruturais. Tais práticas, segundo os autores, consideram os princípios do Sistema Único de Saúde (SUS) e as políticas para assistência das crianças.

A prática de enfermagem à criança na atenção básica de Teresina-PI, relatada por Rocha e Moura (2012), é descrita em torno de uma dinâmica regida por Consultas de Enfermagem eletivas ou de urgência, conforme as necessidades da criança. Essa realidade vivencia a Política Nacional da Atenção Básica, tendo como base ações de baixa complexidade que desenvolvam a promoção da saúde e a prevenção de doenças. São relatadas 
modificações nessa política, que beneficiam o cuidado à criança, a saber: aumento da quantidade de consultas até um ano de vida da criança e visita domiciliar que oportuniza a aproximação da equipe de saúde da família. As autoras destacam que, nesse estudo, foram constatadas ações com faixa etária mais ampliada, em virtude da incorporação do programa bolsa família nas atribuições do enfermeiro que atuam na atenção básica.

Sousa, Erdmann e Mochel (2010) afirmam que as práticas relacionadas à criança na atenção básica, em São Luís-MA, compõem-se de ações, intervenções e interações capazes de gerar a promoção e manutenção da saúde no desenrolar longitudinal do crescimento e desenvolvimento da criança. Segundo os autores, as práticas de cuidado à criança na atenção básica devem ser integrais, articulando o saber e o fazer. Além disso, descrevem que esse momento é caracterizado pelo modo de encontro dos profissionais da saúde com a criança e sua família, sob uma perspectiva de trabalho em equipe e através de práticas intersetoriais, tendo em vista o saber técnico no uso de tecnologias.

Barboza, Barreto e Marcon (2012) revelam que, em Maringá-PR, as práticas de cuidado à criança da unidade básica de saúde ocorrem, principalmente, no primeiro ano de vida, envolvendo a equipe Saúde da Família, no intuito de diagnosticar patologias, promover saúde e prevenir agravos. Em contrapartida, os autores afirmam que os registros nos prontuários das práticas exercidas pelos enfermeiros são escassos, representando apenas 17,4\% de uma análise de cento e oitenta e um prontuários. Além desta problemática, existem ainda outras inadequações como registros desconexos e segmentados, dificultando, assim, uma assistência planejada e contínua.

As práticas evidenciadas pelos registros nos prontuários encontrados por Prado e Fujimore (2006), em São Paulo-SP, diferem das anteriormente descritas. As práticas são sistemáticas, com a participação de vários profissionais, que descrevem as ações desenvolvidas numa perspectiva de integralidade e continuidade da assistência prestada. As práticas registradas evidenciam ações referentes ao peso e altura adequados, em divergência dos poucos registros da avaliação nutricional pelos profissionais, além de adequação nos seguintes itens: acompanhamento do crescimento e desenvolvimento, desenvolvimento neuropsicomotor, alimentação (incluindo aleitamento materno), estado mórbido e o processo de enfermagem dentro da Consulta de Enfermagem, que é ofertada na mesma proporção da Consulta Médica, ou seja, quatro consultas até onze ou doze meses.

Mello, Lima e Scochi (2007) acrescentam que as práticas de cuidado à criança na atenção básica, em Ribeirão Preto-SP, têm o caráter contingencial, devendo lidar com situações que remetam à eventualidade, incerteza e acontecimentos associados às experiências 
singulares de cada um, integrando as práticas e as técnicas vivenciadas nesse contexto. Para isso, necessita-se de uma reorganização dos serviços, pautada na percepção materna, criatividade e singularidade de cada indivíduo, no intuito de desvelar a promoção da saúde e vigilância à saúde que contemplam os projetos, atitudes, crenças e valores das mães e famílias, entendendo que as ações curativas também remetem às problemáticas sociais vivenciados pelos mesmos.

Em Rio Grande-RS, as práticas de enfermagem à criança ocorrem por meio de Consultas de Enfermagem em puericultura, agendadas uma vez ao mês ou por quinzena em caso de riscos de agravos. Constatou-se que a maioria das crianças estava eutrófica, revelando boas práticas de alimentação e nutrição, com encaminhamento ao pediatra em casos de doenças, ou necessidade de prescrição de ferro e vitamina A (GAUTERIO; IRALA; CEZARVAZ, 2012).

Monteiro et al. (2011) realizaram um estudo do tipo pesquisa-ação em Natal-RN, considerando o acompanhamento do crescimento e desenvolvimento como eixo central do cuidado à criança na rede de atenção básica. $\mathrm{O}$ autor supramencionado e seus colaboradores propuseram um trabalho de acompanhamento do crescimento e desenvolvimento com enfermeiros e cuidadores de crianças, numa perspectiva de construção de uma prática emancipatória, a qual explora a autonomia, diálogo e participação de todos no cuidado à criança. Como resultados, os cuidadores das crianças tiveram acesso a mais informações que contribuíram na tomada de decisão que envolvia o processo saúde/doença, e os enfermeiros obtiveram mais autonomia e aproximação com a realidade na qual estas crianças vivem, gerando, consequentemente, maior qualidade de vida.

As práticas fragmentadas e tecnicistas são aquelas que relatam a assistência voltada para doença ou queixa relatada na perspectiva normativa ou técnica de procedimento, sem haver percepção da integralidade no cuidado.

Silva e Vieira (2014) constataram, em Cascavel-PR, as inúmeras dificuldades existentes na prática dos profissionais da saúde que lidam em seu cotidiano na atenção básica com criança. A falta de acolhimento, resolutividade e acessibilidade foram importantes achados dessa pesquisa, que revelam a existência de prática fragmentada em relação ao proposto pela Política Nacional da Atenção Básica (PNAB).

Souza et al. (2013) revelam que, embora os enfermeiros busquem práticas de promoção de saúde e prevenção de doenças, tais iniciativas vão de encontro às dificuldades vivenciadas no próprio sistema de saúde, em valores culturais e aspectos socioeconômicos da 
mãe e situação familiar, comprometendo assim a proposta das práticas inicialmente citadas. Tal situação retrata o modelo de saúde e o modelo socioeconomicocultural.

Nessa mesma perspectiva, Reichert et al. (2012) descrevem que, embora as enfermeiras realizem a Consulta de Enfermagem, existem fragilidades que comprometem a vigilância à saúde, a saber: acompanhamento rotineiro do desenvolvimento neuropsicomotor, orientações quanto ao peso da criança e o registro na caderneta de saúde da criança.

As práticas de enfermagem no cuidado à criança na atenção básica relatadas por Tomasi et al., (2011) enfocam os procedimentos, tendo como característica marcante os serviços de atendimento básico realizados pela enfermagem (que compreendem $33 \%$ dos serviços) nas unidades básicas de saúde nas regiões Sul (Rio Grande do Sul e Santa Catarina) e Nordeste (Alagoas, Paraíba, Pernambuco, Piauí e Rio Grande do Norte) brasileiro. Outras atividades, como visita domiciliar e imunização, também são relatadas, bem como o perfil de atendimento, o qual registra que $24 \%$ destes atendimentos são direcionados à criança. Os autores discutem as diferenças existentes nas práticas desenvolvidas em unidades básicas tradicionais e com a estratégia Saúde da Família.

De acordo com Souza, Erdmann e Mochel (2011), esse tipo de prática tida como fragmentada também é encontrada na realidade do cuidado à criança na atenção básica de São Luís-MA, representando a ausência de planejamento, interdisciplinaridade e continuidade do cuidado.

Em relação às práticas gerenciais, referem-se ao modelo de atenção, à territorialização, à força de trabalho e às necessidades a serem supridas no cuidado integral às crianças na atenção básica. Em Curitiba-PR, destaca-se a problemática relativa ao entendimento das ações da atenção básica, principalmente à diversidade de modelos que permeiam as práticas em saúde e que resistem, independentemente do âmbito em que ocorram, interferindo na organização dos serviços de saúde. Além disso, observa-se uma verdadeira dicotomia entre: a estrutura física, recursos destinados à atenção básica e o modelo de atenção à saúde que se pretende seguir (BICUDO et al., 2010).

Contudo, Saparolli e Adami (2010) revelam que existe uma realidade que difere da relatada anteriormente. No município de São Paulo, a avaliação das estruturas referentes à prática de enfermagem à criança na atenção básica apresenta-se satisfatória em relação aos critérios normativos preconizados, revelando uma realidade coerente com a Política, imprimindo indiretamente qualidade do cuidado de enfermagem por meio de condições favoráveis às mesmas. 
As práticas de aprimoramento do cuidado relatadas nos artigos são aquelas que visam ao melhoramento de práticas em si. Estudos realizados por Monteiro et al. (2011) apontam como aprimoramento de práticas uma formação com educação crítica e problematizadora, que instrumentalize o futuro profissional e potencialize sua percepção em relação à promoção do cuidado, tendo em vista o fortalecimento científico da enfermagem, contribuindo com ações inovadoras no acompanhamento das crianças na atenção básica, gerando maior fortalecimento profissional com a sua valorização.

Sousa e Erdmann (2012) acrescentam que o cuidado à criança na atenção básica possui sentidos diferentes, mas que se originam no valor da vida e da dignidade humana, e que se constroem mediante esforços, colaboração, comunicação e no fazer/agir.

Os artigos revisados descrevem a prática vivenciada em distintos períodos temporais, colocando em evidência aspectos singulares que compõem a realidade vivenciada na saúde brasileira. Observou-se, nos estudos analisados e respeitando as suas singularidades, que esses guardam semelhanças no que tange aos modelos de atenção à saúde.

A Figura 2 apresenta a tendência dos modelos de atenção à saúde no período de 2005 a 2015, constatando-se que há maior predominância dos modelos de atenção à vigilância da saúde.

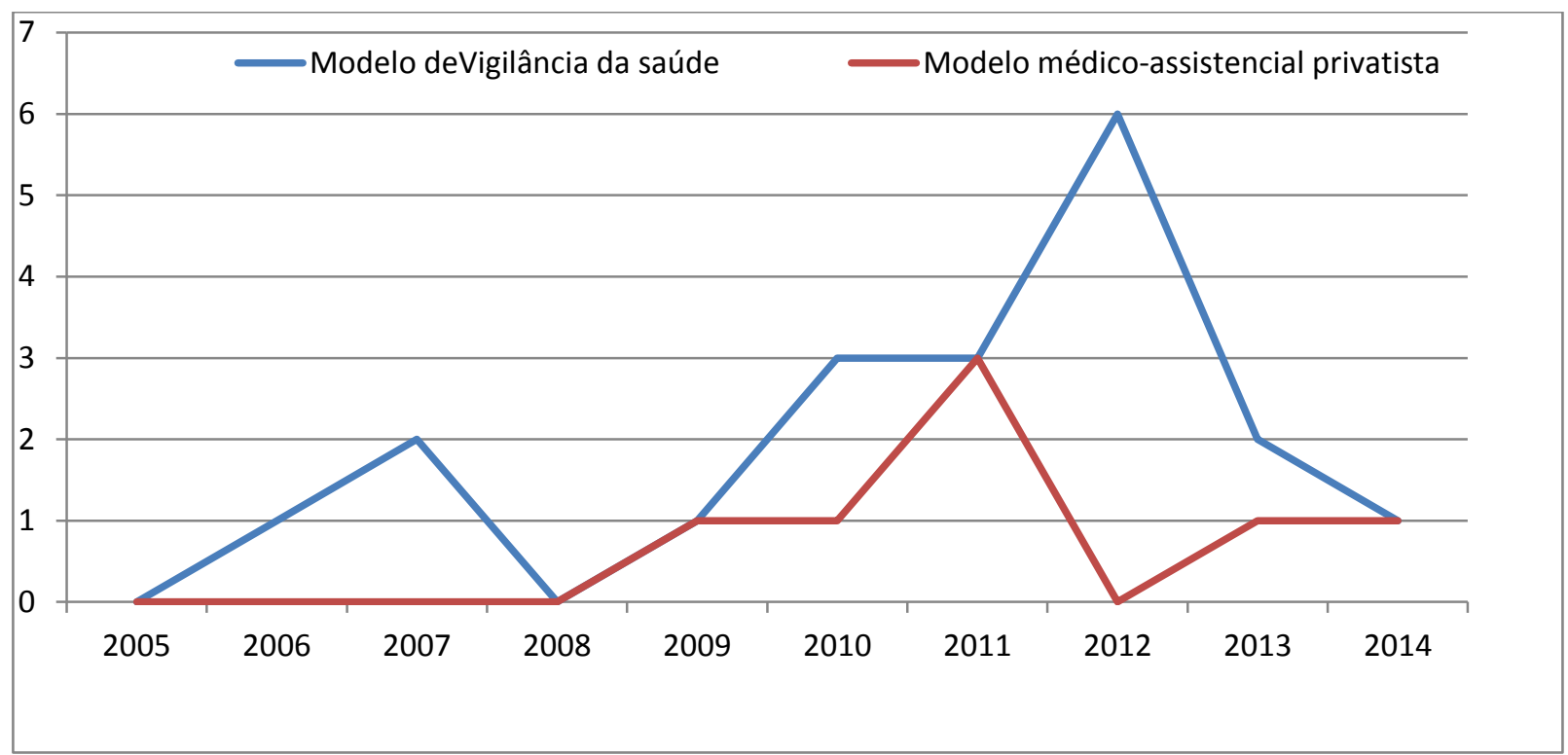

Figura 2. Tendências dos modelos assistenciais nos trabalhos selecionados de 2005-2015. Brasília, 2016. 
Ao longo da última década, é perceptível a predominância de modelos de vigilância da saúde relatados nos artigos sobre as práticas de Enfermagem no cuidado à criança na atenção básica. Quando comparado ao modelo médico-assistencial privatista, observa-se que, nos últimos anos, vem apresentando diminuição quantitativa acentuada, refletindo-se na progressiva expansão e concretização do SUS e nas atuais Políticas de Atenção Básica.

\section{Necessidades do cuidado de enfermagem à criança na rede de atenção básica}

As necessidades no contexto do cuidado de enfermagem à criança na rede de atenção básica foram analisadas quanto: 1) Política, estrutura e organização do trabalho; 2) Formação e prática profissional.

Quanto à política, estrutura e organização do trabalho, desvelam-se as necessidades existentes na prática de cuidado à criança em relação à Política Nacional da Atenção Básica; organização do trabalho; estrutura física e registro de prontuários, como apresenta o Quadro 2.

É importante o conhecimento das práticas que compõem as ações de promoção da saúde e prevenção de doenças e as barreiras que impedem a concretização da mesma, seja ela, institucional, cultural, socioeconômica e familiar (SOUZA et al., 2013). Silva e Vieira (2014) revelam mais necessidades oriundas da ausência de acolhimento, resolutividade e acessibilidade à criança na atenção básica.

Modes e Gaiva (2013) destacam a necessidade de uma estrutura com instalações físicas mínimas e investimento em muitos aspectos, dentre eles: espaços físicos para atividades educacionais e para acolher usuários, tendo em vista um bom atendimento para o usuário e familiares.

No respaldo do cuidado à criança, faz-se necessário que o enfermeiro registre suas observações e ações, entendendo a importância do referido registro. Situação que se difere dos achados encontrados por Barboza, Barreto e Marconi (2012), onde se verificou um baixo número de registro em prontuários, além das fragmentações ou até mesmo a ausência de informações, sugerindo, portanto, a inclusão de uma ficha padrão de atendimento à criança bem como a sensibilização da equipe Saúde da Família para com os registros, a fim de superar as dificuldades encontradas.

A prática de cuidado à criança na atenção básica requer a conscientização da população dos aspectos relativos a essa temática, tendo em vista a importância da sensibilização e compreensão pela população das ações de promoção da saúde e prevenção de 
doenças, no intuito de favorecer a acessibilidade a populações carentes (GAUTERIO; IRALA; CEZAR-VAZ, 2012).

Quadro 2. Necessidades existentes no contexto do cuidado de enfermagem à criança na rede de atenção básica, segundo política, estrutura e organização do trabalho. Brasília, 2016.

\begin{tabular}{|c|c|}
\hline AUTOR/ANO & $\begin{array}{l}\text { NECESSIDADES DO CUIDADO DE ENFERMAGEM À CRIANÇA } \\
\text { NA ATENÇÃO BÁSICA }\end{array}$ \\
\hline $\begin{array}{l}\text { Silva e Vieira } \\
(2014)\end{array}$ & Rever os princípios da Politica Nacional da Atenção Básica (PNAB) na prática. \\
\hline Souza et al. (2013) & $\begin{array}{l}\text { Compreender como as práticas de promoção da saúde e prevenção de doenças } \\
\text { ocorrem e quais os empecilhos para uma assistência integral. }\end{array}$ \\
\hline $\begin{array}{l}\text { Modes e Gaiva } \\
(2013)\end{array}$ & $\begin{array}{l}\text { Contemplar a estrutura física mínima desejável para a atuação das unidades } \\
\text { básica de saúde. }\end{array}$ \\
\hline $\begin{array}{l}\text { Barboza, Barretos } \\
\text { e Marcon (2012) }\end{array}$ & $\begin{array}{l}\text { Implementar uma ficha padrão para o registro das consultas de puericultura. } \\
\text { Sensibilizar a equipe a registrar nos prontuários as atividades realizadas. }\end{array}$ \\
\hline $\begin{array}{l}\text { Gauterio, Irala e } \\
\text { Cezar-Vaz (2012) }\end{array}$ & $\begin{array}{l}\text { Sensibilizar a população sobre as ações relativas à atenção básica: promoção da } \\
\text { saúde e prevenção de doenças. } \\
\text { Repensar a acessibilidade em populações economicamente desfavorecidas. }\end{array}$ \\
\hline $\begin{array}{l}\text { Costa } \quad \text { Et al., } \\
(2012)\end{array}$ & Planejamento de ações de cuidado à criança. \\
\hline Assis Et al., (2011) & Rever o processo de trabalho das equipes. \\
\hline $\begin{array}{l}\text { Bicudo Et al., } \\
(2010)\end{array}$ & $\begin{array}{l}\text { Necessidade de investimentos em recursos humanos, infraestrutura conforme a } \\
\text { Política da Atenção Básica }\end{array}$ \\
\hline $\begin{array}{l}\text { Saparolli e Adami } \\
\text { (2010) }\end{array}$ & Estrutura física e recursos materiais \\
\hline $\begin{array}{l}\text { Vasconcelos Et al., } \\
\text { (2009) }\end{array}$ & Acessibilidade e qualidade dos serviços prestados no cuidado à criança \\
\hline $\begin{array}{l}\text { Giovanella } E t \text { al., } \\
(2009)\end{array}$ & Reconhecer os limites da estratégia Saúde da Família \\
\hline
\end{tabular}

Moura e Rocha (2012) acrescentam que tais ações de promoção da saúde e prevenção de doenças estão em consonância com o proposto pela Política da Atenção Básica Brasileira e contribuem diretamente para a qualidade de vida das crianças, garantindo práticas mais saudáveis no cotidiano delas. 
Segundo Costa et al., (2012) faz-se necessário um planejamento para oferta do cuidado à criança, tendo em vista a superação de ações de cunho curativo e emergencial, promovendo, assim, melhorias das práticas implementadas a esse grupo.

As necessidades relacionadas à organização do trabalho, segundo Assis et al. (2011) decorrem da distância existente entre nossas políticas públicas de saúde brasileiras e a realidade, por não apresentarem nenhum tipo de vínculo ou acolhimento direcionado à criança, não atendendo, assim, às estratégias para a promoção da saúde e prevenção de doenças consonantes com o Pacto em Defesa da Vida e as demais políticas públicas e diretrizes do SUS.

Bicudo et al., (2010) asseveram que as necessidades práticas de cuidado à criança pela enfermagem na atenção básica estão relacionadas com a infraestrutura e capacitação dos profissionais que trabalham na estratégia Saúde da Família, no intuído de uma maior aproximação com as práticas preconizadas pela Política e que garantam a integralidade das ações.

Existe a necessidade de se garantir condições mínimas para que o cuidado de enfermagem à criança na atenção básica possa ser efetivado. Tendo em vista tais necessidades, Saparolli e Adami (2010) referem que a estrutura de área física, instalações e materiais disponíveis são imprescindíveis para a assistência que se pretende realizar, dentro da consulta de enfermagem.

Segundo a Política, cabe aos gestores e demais órgãos responsáveis promover melhores condições de trabalho, equiparando a realidade com a proposta política, além de reconhecer os limites existentes pela estratégia Saúde Família. Aos profissionais cabe um melhor planejamento de ações voltadas à criança, como o registro em prontuário, além de reflexões sobre as possibilidades de acessibilidade e qualidade dos serviços prestados por meio do processo de trabalho. A população carece de instruções sobre funções e significados da atenção básica para a nova perspectiva que se pretende atingir: o conceito de saúde.

$\mathrm{Na}$ Formação e prática profissional, discute-se a prática de cuidado à criança pela enfermagem na atenção básica, pontuadas pela criatividade, formação profissional, reformulação das práticas, acolhimento e práticas de cuidado à criança pela enfermagem. 
Quadro 3. Necessidades existentes segundo formação e prática profissional. Brasília, 2016.

\begin{tabular}{|c|c|}
\hline AUTOR/ANO & \begin{tabular}{lllll} 
NECESSIDADES & DO & \multicolumn{2}{c}{ CUIDADO } & DE \\
ENFERMAGEM & À & CRIANÇA & NA & ATENÇÃO \\
BÁSICA & & & &
\end{tabular} \\
\hline Andrade, Rezende e Madeira (2014) & Investir em formação e capacitação dos profissionais \\
\hline Oliveira et al. (2013) & Capacitação dos enfermeiros \\
\hline Reichert et al. (2012) & Capacitação dos enfermeiros \\
\hline Assis et al., (2011) & Investir em educação permanente \\
\hline Santos et al. (2012) & Criatividade dos profissionais \\
\hline Monteiro et al. (2011) & Educação crítica e problematizadora \\
\hline Tomasi et al. 2011 & Criatividade dos profissionais \\
\hline Monteiro et al. (2011) & Capacitação dos profissionais \\
\hline Souza, Erdmann e Mochel (2010) & $\begin{array}{l}\text { Repensar o cuidado com integralidade, intersetorialidade e } \\
\text { interdisciplinaridade }\end{array}$ \\
\hline Escorel et al. (2007) & Criatividade dos profissionais \\
\hline Mello, Lima e Scochi, (2007) & Repensar ações, relações e compromissos da EqSF \\
\hline
\end{tabular}

Andrade, Rezende e Madeira (2014) revelam a necessidade de investimentos na capacitação dos profissionais, médicos e enfermeiros, que trabalham nas ações básicas de vigilância à saúde da criança sobre as potencialidades e possibilidades da caderneta de saúde da criança para a promoção de saúde dela.

Nessa mesma perspectiva Oliveira et al. (2013) também consideram a necessidade de capacitar os enfermeiros por meio da educação permanente, objetivando contribuir para a melhoria da qualidade da assistência de enfermagem prestada focada na promoção da saúde. Reichert et al. (2012) também descrevem tais necessidades de atualização dos enfermeiros, para manter seguros em seus conhecimentos e habilidades na prática à criança.

A criatividade também é apontada como um instrumento necessário, capaz de superar as limitações existentes no cotidiano da atenção básica, na busca por modelos mais efetivos e eficazes, devendo-se adequar a realidades e aos contextos nos quais estão inseridos (TOMASI et al. 2011).

Corroborando esses pensamentos, Monteiro et al. (2011) enfatizam a necessidade de uma educação crítica e problematizadora, que instrumente o futuro profissional e potencialize sua percepção em relação à promoção do cuidado, tendo em vista o fortalecimento científico 
da enfermagem, contribuindo com ações inovadoras no acompanhamento das crianças na atenção básica, gerando, assim, um maior fortalecimento profissional com a sua valorização. Essas ações contribuem para uma formação mais prática e também para o fortalecimento científico da enfermagem, tendo como frutos uma maior produtividade e visibilidade profissional.

Souza, Erdmann e Mochel (2010) aprofundam tais constatações e acrescentam aos desafios e inquietações que decorrem da necessidade de se repensar as práticas de saúde e o cuidado à criança, na perspectiva da integralidade por meio de ações interdisciplinares e intersetoriais.

Repensar as relações entre comunidade e equipe Saúde da Família, as ações e os compromissos, remete a uma construção de um cotidiano repleto de saberes e práticas de cuidados que contemplam as necessidades da realidade local (MELLO; LIMA; SCOCHI, 2007).

Nesse sentido, surgem evidências que apontam para a reformulação das práticas por meio da capacitação dos profissionais com ações de educação em saúde, crescimento e desenvolvimento e organização da assistência. Acrescenta-se, a essas medidas, a utilização da criatividade, a educação crítica e problematizadora no melhor preparo desses profissionais.

Com isso, percebem-se as necessidades existentes na produção científica selecionada, sobre o cuidado de enfermagem à criança na rede de atenção básica, mostrando, assim, as fragilidades e desafios a serem minimizados por novas ações, políticas e atitudes no que se refere a esta temática. Vale ressaltar a importância dos pontos apresentados e discutidos anteriormente para a concretização/realização do cuidado de enfermagem à criança na rede de atenção básica.

\section{Desafios no contexto de cuidado à criança pela enfermagem na atenção básica}

Nos artigos revisados, percebe-se uma diversidade de desafios no cotidiano do cuidado de enfermagem à criança na rede de atenção básica. Essas dificuldades, evocadas pela busca de uma assistência com integralidade (em um modelo assistencial e de organização do trabalho que se aproxime da Política Nacional da Atenção Básica), devem levar à construção de vínculo e acolhimento garantidos, contribuindo, dessa forma, com a resolutividade da assistência, adequando a demanda existente à capacidade de atendimento às unidades da ESF. 
A integralidade no cuidado à saúde da criança na atenção básica implica em desafios e inquietações referentes ao pensar em saúde e no cuidado à criança, entendendo-a como um sistema complexo composto de ações de integralidade, interdisciplinaridade e intersetorialidade, visando à promoção da saúde e, em especial, ao crescimento e desenvolvimento da criança. Diante dessa situação, é necessário modelar a integralidade, recriando novos modos de cuidados e de cuidar, associando saberes e tecnologias relacionais e subjetivas (SOUSA; ERDMANN; MOCHEL, 2011).

Na busca da integralidade das ações da atenção à saúde da criança, Souza et al. (2013) acrescentam que as dificuldades encontradas na efetividade desse principio nas ações se referem às barreiras dispostas pelo próprio sistema de saúde, valores culturais e aspectos socioeconômicos da mãe e do contexto familiar, variáveis que podem se refletir na inefetividade da qualidade da assistência.

Na busca pela promoção da saúde em ações básica, Andrade, Rezende e Madeira (2014) acrescentam com o uso da caderneta de saúde da criança é preciso diminuir as limitações de conhecimento sobre a caderneta, evitando a fragmentação das informações resultantes da falta de cuidado, de interesse e da dificuldade de seu uso no cotidiano da atenção básica.

Para Melo, Lima e Scochi (2007), a assistência à saúde da criança pauta-se não somente na criança sadia, mas contempla também crianças com enfermidades envolvidas em valores e experiências diferentes em seu cuidado. Para isso, deve existir integração de saberes e práticas.

Contribuindo para um melhor entendimento das dificuldades relacionadas à integralidade, Sousa, Erdmann e Mochel (2010) asseguram que essas limitações constituemse de três pilares: política e gerencial, institucional e estrutural das unidades básicas de saúde. Nesse contexto, destaca-se a ausência de insumos, medicamentos e inadequação de estrutura física, além de problemas relacionados à falta de comunicação ou um encontro com a própria equipe, no intuito de socializar o tratamento ou cuidado. Os autores apresentam a procura por serviços de média e alta complexidade em virtude da baixa resolutividade na rede de atenção básica. Essa problemática acarretando também em falta de confiança e descrédito nos serviços da atenção básica, na percepção da população e dos profissionais. Essas dificuldades tornamse um ciclo vicioso, que produz e reproduz outras dificuldades.

A falta de integralidade é oriunda das práticas do modelo assistencial hegemônico que, entre outras consequências, destaca uma assistência fragmentada e tradicionalista realizada 
pelos profissionais em saúde, dentre eles o enfermeiro. Consequentemente, essa prática ocorre desprovida de contextualização e interdisciplinaridade (MONTEIRO et al., 2011).

Para Prado e Fujimore (2006), o maior desafio na construção de um Sistema Único de Saúde - SUS é contemplar a mudança do modelo de atenção à saúde como um todo, incluindo a sua acessibilidade aos serviços de saúde. É necessário rever a organização e estrutura do trabalho realizado na atenção básica, garantindo, assim, mais inclusão social e menos seletividade.

Outro aspecto importante é a estrutura mínima para a efetividade das ações de promoção da saúde e prevenção de doenças na efetividade do cumprimento da qualidade da assistência prestada. Modes e Gaiva (2013) retratam as dificuldades oriundas da falta desta estrutura mínima.

A organização do trabalho da enfermagem na atenção básica, segundo Assis et al. (2011), desconhece vínculo e acolhimento que proporcione a promoção da saúde da criança e atenda à Política Nacional da Atenção Básica. Essa organização centra-se isoladamente nas queixas e condutas a serem tomadas diante das situações nas quais existe a presença de doença. Isso dificulta o cuidado à criança na consulta de enfermagem, obedecendo à lógica hospitalocêntrica e privando a criança de melhores condições de crescimento e desenvolvimento com qualidade. As enfermeiras relatam que suas dificuldades pautam-se na ausência de planejamento da assistência, além da alta rotatividade dos médicos que compõem a equipe e que geram também uma sobrecarga do trabalho de enfermagem, repercutindo em ações predominantemente curativas e não preventivas, desvinculando-se da proposta preconizada pela Política Nacional da Atenção Básica e as diretrizes do Sistema Único de Saúde (SUS).

Fortalecendo as discussões supracitadas, Bicudo et al. (2010) descrevem as dificuldades e limitações da equipe de enfermagem, em virtude da grande demanda que ocorre na atenção básica, gerando consequentemente trabalho excessivo para os profissionais que compõem a Equipe Saúde da Família, em relação à capacidade de atendimento.

Dentre as dificuldades mais relatadas na literatura, e que demanda maior atenção por parte dos profissionais, pesquisadores e gestores da Política Nacional da Atenção Básica, segundo Vasconcelos et al., (2009), está a baixa eficácia e efetividade dos serviços de saúde relacionados à assistência à criança em ações de promoção da saúde e prevenção de doenças e estão relacionados com os altos índices de morbidade e mortalidade infantil. Contudo, os autores supracitados referem contraditoriamente a esta afirmação que a estratégia Saúde da 
Família também alcançou sucesso, justificado por ações genuínas dos profissionais que compõem a equipe Saúde da Família.

No que se refere à força de trabalho, Escorel et al. (2007) contribuem afirmando que os contratos temporários ou vínculos trabalhistas precários empobrecem a sustentabilidade do programa, pois, segundo os autores, vínculos empregatícios formais, estáveis e protegidos legalmente fazem com que o profissional se sinta mais apto e envolvido naquele contexto social que abrange sua área delimitada. Devendo, ainda, ser continuamente estimulado e capacitado pelos órgãos gestores a treinamentos, a fim de que superem os problemas que emergem em seu cotidiano.

Peculiarmente, Ribeiro, Siqueira e Pinto (2010) definem como ponto crítico na avaliação da atenção à criança a questão relacionada aos exames solicitados e dos medicamentos prescritos. No primeiro caso, a acessibilidade tornou este recurso inviável, e no caso dos medicamentos, observa-se que mais da metade dos usuários dos serviços de saúde não recebem o medicamento gratuitamente de forma regular e constante. Outro ponto observado pelos mesmos autores é a baixa cobertura das visitas domiciliares.

Em síntese, apontam-se nesta revisão teórica, os desafios existentes na realidade brasileira referente ao cuidado à criança pela enfermagem na rede de atenção básica. Essas dificuldades elucidam e fazem emergir propostas para possíveis avanços e progressos na Política Nacional da Atenção Básica, como também na transgressão do cuidado de enfermagem à criança, pautado na assistência integral, organização do trabalho tendo como base a política, vínculo, acolhimento, resolutividade e a capacidade de atendimento compatível com a demanda da população.

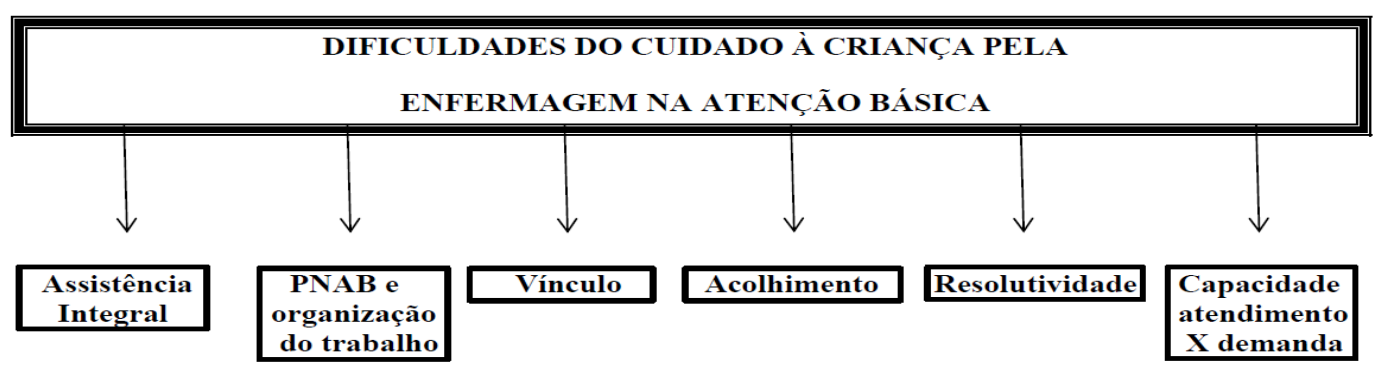

Figura 3. Dificuldades no cuidado de enfermagem à criança na atenção básica evidenciadas pela revisão da literatura. Brasília, 2016. 


\subsection{A Teoria das Representações Sociais e a Consulta de enfermagem}

\section{A Teoria das Representações Sociais (TRS)}

A Teoria das Representações Sociais (TRS) se origina na Europa em 1961, por meio das importantes contribuições de Moscovici em seu estudo "La psychanalyse: son image et son public", na área da psicologia social (MOSCOVICI, 1978).

Moscovici (1995) resgata a definição de representações sociais como aquela oriunda da sociologia e antropologia, por meio das representações coletivas de Durkheim e LéviBruhl. Para Durkheim (1978), as representações coletivas significam uma forma existente de como um grupo pensa nas suas relações com os objetos que o afetam, em outras palavras, a sociedade rege o pensamento na vida social, e desta forma organiza esse pensamento, utilizando para isso a sociedade homogênea na sua totalidade.

Moscovici, ao contrário de Durkheim, prefere o adjetivo "social" em relação ao termo "coletivo", por se tratar de um social móvel do mundo moderno, transformado pela divisão social do trabalho e a emersão da ciência como novo saber. Contudo, Moscovici defende a permanência da relação entre individual e social, ao mesmo tempo em que entende que o social transforma o indivíduo (CASTRO, 2004).

A definição de representações sociais começou a partir das importantes contribuições de Durkheim sobre representações coletivas na escola positivista de tradição sociológica. Nesse momento, o pressuposto teórico básico que regia a linha de pensamento considerava a sociedade como um conjunto de fatos sociais, entendida da forma em que as representações jamais poderiam se reduzir a representações individuais (ARRUDA, 2002).

Entretanto, Nóbrega (2003) afirma que a inserção da Teoria das Representações Sociais (TRS) provoca significativas mudanças ao estabelecer a ruptura com a visão dicotômica do positivismo e dos modelos funcionalistas vigentes. Essa ruptura se justifica por mais dois motivos: pela diversidade existente entre indivíduos e grupos e pelo reconhecimento da importância da comunicação enquanto fenômeno que possibilita uma conversão entre indivíduos em uma rede de interações de indivíduos e grupos.

Jodelet (2001) acrescenta que essas representações podem ser também compreendidas como uma forma de conhecimento, socialmente elaborado e compartilhado, tendo uma intenção prática e concorrendo à construção de uma realidade comum a um conjunto social. 
Entende-se, dessa forma, que a Teoria das Representações sociais considera tanto os comportamentos individuais quanto os fatos sociais.

Em uma definição mais aprofundada, Moscovi (1978) refere as Representações Sociais como produção e não reprodução ou reação a estímulos exteriores, mas a utilização e seleção de informações a partir de repertório circulante na sociedade, vivenciado pelos seus indivíduos. Não são tidos como simples opiniões sobre, ou imagens de, mas verdadeiras teorias coletivas sui generis, destinadas à interpretação e à elaboração do real. Assim, representar um objeto, pessoa ou coisa não consiste apenas em desdobrá-lo, repeti-lo ou reproduzi-lo, mas em reconstruí-lo, retocá-lo e modificá-lo.

Jovchelovitch (1995) considera as representações sociais como fenômeno mediador entre indivíduo e sociedade, intermediado pelo diálogo, discurso, rituais padrões de trabalho, produção, arte e cultura. Nessa perspectiva, Jodelet (2007) acrescenta que o pensamento na teoria das representações sociais integra sentimentos, afetividade, emoções, desejos, imaginário e as identidades. Esse complexo forma a subjetividade, individual e social ou coletiva na construção das representações sociais.

Em outra definição, Minayo (1995, p. 89) aborda da seguinte forma:

\footnotetext{
"Representações sociais é um termo filosófico que significa a reprodução de uma percepção retida na lembrança ou do conteúdo do pensamento. Nas ciências sociais são definidas como categorias de pensamento que expressam a realidade, explicam-na justificando-a ou questionando-a".
}

As representações sociais podem englobar sistematicamente ilusões, contradições e verdades; além disso, significam um substrato para análise do social, pois retratam e refratam a realidade vivida por algum segmento da sociedade (MINAYO, 1995).

Reconhece-se que a ideia central da teoria das representações sociais é estudar o processo cognitivo dentro de sua estrutura social, de forma contextualizada (MOSCOVICI, 2007). Não existem representações isoladas de objetos ou sujeitos (JODELET, 2001).

Nóbrega (2003) afirma que as representações sociais são elaboradas por meio da comunicação que repercute em interações e mudanças, podendo constituir três modos de elaboração com níveis diferentes: 1) Cognitivo (composto por símbolos e imagens); 2) Formação das Representações sociais (objetivação e ancoragem); e 3) Edificação das condutas (opiniões, atitudes e estereótipos). 
$\mathrm{Na}$ formação das representações sociais, a objetivação ocorre pela concretização dos abstratos, corporificando os pensamentos, tornando-os físicos e visíveis, com o intuito de transformar em objeto o que é representado. A objetivação pode ocorrer de três formas: construção seletiva, esquematização estruturante e naturalização. A ancoragem está dialeticamente articulada à objetivação, e permite a incorporação do que é desconhecido ou novo. Está estruturada por meio de três condições: atribuição de sentido; instrumentalização do saber e o enraizamento no sistema de pensamento (NOBREGA, 2003).

Moscovici (2001) retrata que esses dois processos, objetivação e ancoragem, não são dissociáveis, e constituem uma relação dinâmica e simultânea. Ambos possuem a função de transformar o não familiar em familiar.

No estudo das representações sociais existem três tipos de esferas: do subjetivo; do inter-subjetivo e do trans-subjetivo. Na esfera subjetiva, a representação social é expressiva e significativa, e carrega valores que os sujeitos concedem a um objeto localizado no seu entorno social e físico a partir de suas sensibilidades e desejos; na esfera inter-subjetiva, a representação é meio de compreensão e serve como ferramenta de interpretação e da construção dos significados compartilhados acerca de objetos de negociação; e na esfera trans-subjetiva, a representação é aparelho cultural, normas sociais, valores, pressões ligadas às relações sociais e permite construir as ferramentas e as interpretações (JODELET, 2007).

No Brasil, a Teoria das Representações Sociais se disseminou a partir da década de 90, nas áreas aplicadas e não nas áreas de conhecimento, em virtude de três circunstâncias: 1) Avanço da "cultura anticientífica brasileira"; 2) Aumento no panorama das ciências sociais e 3) Concepção das universidades sobre a sociedade (CAMARGO, 2007).

As funções das representações sociais, segundo Nóbrega, 2003, são: formação de condutas; orientação das comunicações sociais; identitária (imagem positiva do grupo e sua especificidade) e justificadora (que permitem aos atores manterem ou reforçarem os comportamentos de diferenciação social).

\section{Consulta de enfermagem à criança na atenção básica como objeto das representações sociais}

Por se tratar de uma temática pouco explorada por pesquisadores, a discussão será conduzida primeiramente pelas contribuições advindas das revisões publicadas sobre as 
representações sociais na área da enfermagem, considerando as limitações, seguida pelos estudos que envolvem representações sociais no cuidado e na consulta de enfermagem. Acrescenta-se também, que os estudos datam de um recorte dos últimos quinze anos, em virtude da escassez de publicações sobre as Representações Sociais no contexto da Consulta de Enfermagem à criança na rede de atenção básica.

As contribuições das representações sociais para a enfermagem, segundo Martinez, Souza e Tocantins (2012) reportam a necessidade de entender a opinião de grupos sociais sobre determinados fenômenos que vivenciam e como estes caracterizam os aspectos relacionados ao processo saúde doença. Dessa forma, possibilita que os pesquisadores possam estabelecer uma representação social específica sobre um dado objeto de estudo, permitindo compreender, organizar e adequar sua prática profissional e assistencial, além de compreender a ocorrência de um determinado fenômeno a partir de outra perspectiva, mais aprofundada, segundo ideia, compreensão e interpretação dos grupos sociais que vivenciam as atividades do cotidiano. Esse saber prático, socialmente elaborado e compartilhado pelos sujeitos tido como Representações Sociais, são capazes de reger as interações entre as pessoas e os fenômenos e condutas em relação às práticas sociais e assistenciais.

Silva, Martini e Becker (2011) acrescentam que as contribuições das representações sociais em dissertações e teses de enfermagem, resgatam temáticas que envolvem: o processo de cuidar do ser humano; processo de trabalho; a dimensão educativa em enfermagem e saúde, dentre de outros. Para as autoras desse estudo, é possível identificar o crescente interesse dos pesquisadores pela teoria das representações sociais, demonstrado pelo reconhecimento da contribuição dessa teoria no desenvolvimento de pesquisas, considerando os aspectos psicossociais do processo saúde e doença na vida dos diversos grupos sociais.

As pesquisas sobre representações sociais na área da enfermagem possibilitam o entendimento do comportamento humano, em suas dimensões cognitivas, afetivas e sociais, servindo de substrato para a interpretação das práticas que cercam o ser humano. As representações sociais são reconhecidas por meio do estudo minucioso do pesquisador, com sua análise e interpretação, a partir da opinião, imagem e comportamento dos grupos sociais. Enfim, é importante destacar que os estudos realizados especificamente pela enfermagem, dão sentido tanto às práticas assistenciais, aos aspectos da profissão, como também às características do processo saúde-doença. Dessa maneira, permitem compreender as relações estabelecidas entre os sujeitos e o fenômeno, os pacientes e equipes multiprofissionais. Nessa perspectiva, apresenta-se o profissional, seus conhecimentos, tipo de cuidado e a elaboração do seu significado (MARTINEZ; SOUZA; TOCANTINS, 2012). 
A Teoria das Representações Sociais (TRS) tem sido empregada amplamente para investigar objetos psicossociais relacionados ao cotidiano da enfermagem, principalmente ao cuidado a grupos específicos e prioritários nas políticas publicas de saúde. O intuito de considerar os conhecimentos não especializados, tido como as representações sociais, na compreensão do que seja saúde e cuidados com a saúde apresenta um interesse pragmático: fornecer elementos para a implantação ou aprimoramento de serviços de enfermagem (SILVA; CAMARGO; PADILHA, 2011).

As limitações das representações sociais nas dissertações e teses da enfermagem, segundo Silva, Camargo e Padilha (2011) decorrem do fato que os estudos se auto classificam como pesquisas de "representações sociais"; contudo, não consideram propriamente a teoria como marco teórico. Há ainda no campo da saúde, e especificamente na enfermagem, certa confusão, por parte dos pesquisadores, do que seja o fenômeno (teorias do senso comum) e a teoria propriamente dita (teorias científicas que têm como objeto de conhecimento as teorias do senso comum). Por outro lado, há a valorização em considerar o conhecimento leigo para se compreender os cuidados em relação à saúde, o que amplia e contextualiza os estudos sobre a atenção em relação à saúde.

Borges, Queiroz e Silva (2011) relatam que as representações sociais entre usuários e profissionais da saúde detêm um mesmo sentido e significado, pautado na ética, sensibilidade, solidariedade, afetividade e compromisso com a prática humanizadora. Contudo, as percepções e expectativas entre usuários e profissionais demonstram manifestações particulares e específicas. Se por um lado o usuário anseia por um cuidado integral que atenda suas necessidades, por outro os profissionais preferem técnicas e um tratamento mais impessoal. Essa discrepância ocasiona insatisfação de ambos.

Sobre as representações sociais da Consulta de enfermagem, Gomes e Oliveira (2005) afirmam que os enfermeiros detêm um conhecimento construído de maneira compartilhada e em comum no seu cotidiano profissional. Percebe-se também que esse conhecimento possui um objetivo prático, contribuindo para a construção de uma realidade específica de um determinado conjunto social. Nesse contexto, as práticas exercidas pelos enfermeiros, como prescrição de medicação, educação em saúde, solicitação de exames laboratoriais, atendimento direto à clientela, entre outros, influenciam na representação que possuem da consulta, ao mesmo tempo em que a forma como a consulta impregna o imaginário desses profissionais (tecnologia/espaço médicos, momento dialógico com a clientela, poder institucional e relacional, além de outros aspectos) delimita e conforma ações e práticas específicas. Para os enfermeiros, a consulta de enfermagem é permeada e perpassada pelo 
processo educativo, sendo esse o elemento aglutinador e comum na fala de todos os profissionais. Os autores ainda destacam que, na atualidade, a consulta de enfermagem se apresenta e representa um espaço e uma tecnologia constituída de desafios enfrentados pela profissão, que sofre influência das relações de poder que permeiam a equipe de saúde e das políticas e programas governamentais da área, bem como das exigências atuais com relação ao aumento de qualidade na prestação dos serviços de saúde à população.

Essa reflexão permite colocar em evidência as contribuições das representações sociais no campo da enfermagem e desvelam que o processo de cuidar envolve os aspectos biopsicossociais da saúde e da doença. Embora os estudos demonstrem tamanha potencialidade, há ainda pouca aplicabilidade no cotidiano da enfermagem.

Contudo, ainda é vasto o campo a ser explorado pela Teoria das Representações Sociais envolvendo temáticas e situações emergentes da atualidade, que envolvam novas políticas públicas com práticas específicas e enraizadas. A Consulta de Enfermagem à Criança na rede de atenção básica remete à inovação da Política Nacional da Atenção Básica com a tradicional prática assistencial do enfermeiro.

Os estudos revisados sobre a temática das representações sociais na Consulta de Enfermagem à criança na atenção básica pautam-se em aspectos generalistas e não específicos, o que fomenta ainda mais a necessidade de novos estudos sobre aspectos específicos de práticas tão comuns no cotidiano da atenção básica, como é a Consulta de Enfermagem à criança. 


\section{CAMINHAR METODOLÓGICO}

\subsection{Delineamento do Estudo}

No intuito de aprofundar a compreensão de como se dá a prática da Consulta de Enfermagem às crianças menores de cinco anos no contexto da rede de atenção básica de Teresina-PI e quais as representações dos enfermeiros sobre esta prática, optou-se por um estudo de natureza exploratória e descritiva, com a utilização do método misto, por meio da estratégia explanatória sequencial à luz da Teoria das Representações Sociais. Essa pesquisa foi desenvolvida no primeiro semestre de 2013.

Creswell e Clark (2013) propõem uma definição para métodos mistos que engloba uma coleta e análise rigorosa de dados quantitativos e qualitativos, considerando a questão norteadora da pesquisa. Nela existe uma combinação, que vincula ou integra os dados qualitativos e quantitativos concomitantemente estruturados e planejados de maneira sequencial, podendo construir um com o outro, em um único estudo com múltiplas fases.

O’Cathain e Thomas (2009) definem o método misto como aquele que combina estudos qualitativos e quantitativos, entendendo que seu uso simultâneo remete a potencialidades e fragilidades diferentes, abrangendo melhor o objeto de estudo. O método misto oferece uma compreensão ampliada da dinâmica, mesclando aspectos importantes sobre uma mesma temática. Remete a estudos mais completos com informações de natureza distintas.

Nesse método, optou-se pela estratégia explanatória sequencial (CRESWELL; CLARK, 2013; CRESWELL, 2007), que é considerada a mais direta de todas as estratégias, caracterizada pelas fases de coleta e análise de dados quantitativos, seguidos pela coleta e análise de dados qualitativos, integrando-se na fase de interpretação de resultados. Nesse tipo de estudo, utilizam-se os resultados da fase qualitativa para explicar achados da pesquisa quantitativa. Em outras palavras, trata-se de um projeto de duas fases diferentes e interativas entre si.

Optou-se pelo uso desse método e estratégia, pois oportunizam a compreensão do objeto de estudo e contemplam as possibilidades existentes nos objetivos. Para entendimento, a Figura 4 apresenta as fases da estratégia explanatória sequencial e os objetivos propostos em cada uma delas. 


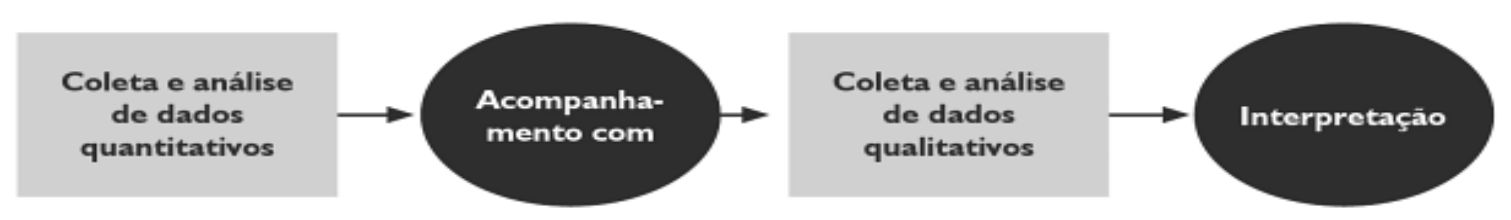

Figura 4. Estratégia explanatória sequencial do método misto.

Fonte: Creswell e Clark (2013).

Quadro 4. Fases da pesquisa segundo os objetivos propostos. Brasília, 2016.

\begin{tabular}{|c|c|c|}
\hline \multicolumn{3}{|c|}{ MÉTODO MISTO - ESTRATÉGIA EXPLANÁTORIA SEQUENCIAL } \\
\hline \multirow{2}{*}{$\begin{array}{c}\mathbf{1}^{\mathbf{a}} \mathbf{F A S E} \\
\text { QUANTITATIVA }\end{array}$} & \multicolumn{2}{|c|}{$2^{\text {a }}$ FASE } \\
\hline & QUALITATIVA & INTERPRETACÃO \\
\hline - Caracterizar na rede e nas & - Descrever a Consulta de & - Analisar a prática da \\
\hline unidades de saúde da atenção & Enfermagem à criança quanto & Consulta de Enfermagem \\
\hline básica de Teresina-PI no ano de & ao processo de trabalho, & às crianças menores de \\
\hline 2012, as crianças menores de & duração da consulta, & cinco anos na rede de \\
\hline cinco anos cadastradas pelas & participantes, objetivos da & atenção básica, Teresina- \\
\hline equipes Saúde da Família, & consulta, procedimentos $\mathrm{e}$ & PI no ano de 2012. \\
\hline segundo regional, zona, gênero e & temas abordados. & \\
\hline faixa etária; & - $\quad$ Identificar o perfil & \\
\hline - Identificar o quantitativo de & sociodemográfico & \\
\hline Consultas de enfermagem às & enfermeiros participantes desta & \\
\hline crianças, puericulturas, & pesquisa; & \\
\hline atendimento individual e visitas & - Apreender as Representações & \\
\hline domiciliares realizados pelos & Sociais dos enfermeiros sobre & \\
\hline enfermeiros segundo demanda; & a Consulta de Enfermagem à & \\
\hline - Relatar a Consulta de & criança na rede de atenção & \\
\hline Enfermagem, quanto às & básica de Teresina. & \\
\hline $\begin{array}{l}\text { características: estrutura física e } \\
\text { equipamentos observados; }\end{array}$ & & \\
\hline & & \\
\hline
\end{tabular}

Na figura 5, apresenta-se o resumo das fases desta pesquisa, segundo coleta e análise dos dados. 


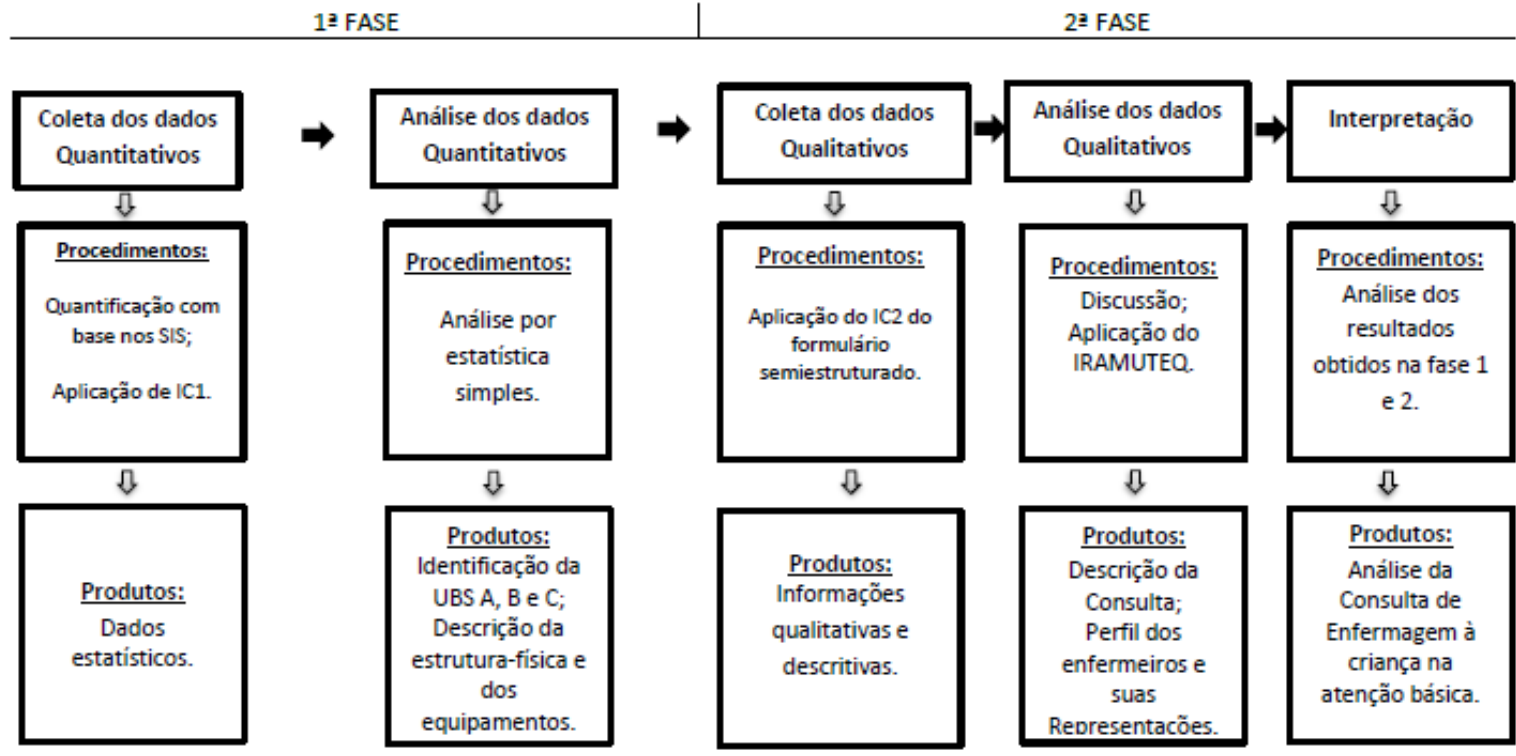

Figura 5. Síntese das fases da estratégia explanatória sequencial segundo coleta e análise dos dados. Brasília, 2016.

\subsection{Cenário do Estudo}

O cenário de estudo desta pesquisa caracterizou-se pelas unidades básicas de saúde da ESF, pertencentes à Fundação Municipal de Saúde de Teresina, estado do Piauí. Segundo informações da Fundação Municipal de Saúde da Prefeitura de Teresina, esse modelo de assistência à saúde atende zonas urbanas e rurais, divididas estrategicamente nas seguintes regionais: 1) Centro/norte; 2) Leste/sudeste; e 3) Sul.

A figura 4 representa o mapa do município de Teresina segmentado por regionais. Em destaque, de amarelo, seguem as regionais: Centro/norte; Leste/sudeste; e Sul, cenário de estudo.

O universo desta pesquisa constituiu-se de oitenta e sete unidades básicas de saúde distribuídas nas três regionais (vinte e quatro na regional centro norte; trinta e três na leste sudeste; e trinta na sul). As unidades básicas de saúde selecionadas para compor a amostra da segunda fase desta pesquisa seguiram os seguintes critérios de inclusão: unidade básica de saúde vinculada à ESF de Teresina-PI, que em 2012 apresentava menor e maior quantidade de Consultas de Enfermagem registrada pelos Sistemas de Informação em Saúde, independente 
da região. Como critério de exclusão, foram utilizadas as unidades básicas de saúde sem registro de consultas no sistema e unidades básicas criadas antes de 2012.
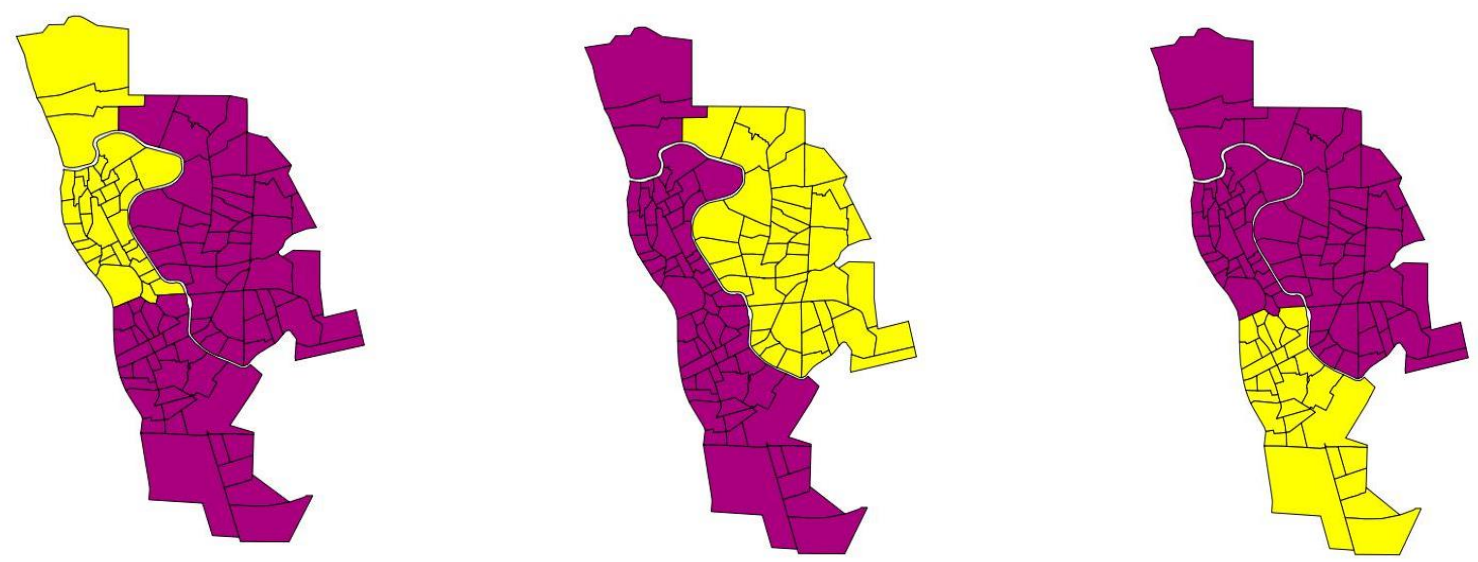

Figura 6. Mapa Político geográfico da cidade de Teresina-PI, segmentado por regionais de saúde, 2016.

Fonte: Fundação Municipal de Teresina-PI.

Para efeito do presente estudo adotou-se a denominação "UBS A" para designar a unidade básica de saúde com maior quantidade de Consultas de Enfermagem e "UBS B" para a unidade com menor quantidade.

O estudo piloto foi realizado em uma unidade básica de saúde, que possuía um quantitativo médio de produção de consultas de enfermagem, equivalente a media de produção das unidades "A" e "B" incluídas no estudo. A unidade básica selecionada para o teste piloto está localizada na zona urbana da regional leste/sudeste de Teresina e dispõe de três equipes, sendo denominada neste estudo de UBS C.

\subsection{Sujeitos do Estudo}

A Fundação Municipal de Saúde, em 2012, possuía duzentos e oitenta e seis enfermeiros lotados nas três regionais, sendo: setenta e nove nas unidades básicas de saúde da regional centro-norte; cento e oito na regional leste-sudeste; e noventa e nove na regional sul (PIAUÍ, 2013).

O universo desta pesquisa se compõe dos duzentos e oitenta e seis enfermeiros que integram a Fundação Municipal de Saúde, de modo que a amostra foi constituída de oito enfermeiros, dos quais sete participaram desta pesquisa, a partir da aplicação dos critérios de 
inclusão: enfermeiros efetivos pertencentes às equipes Saúde da Família que trabalhavam nas duas unidades básicas de saúde que constituem o cenário de estudo da pesquisa (UBS A e UBS B), que se encontravam em atividade no momento da coleta. E os critérios de exclusão eliminaram uma participante, que por questões profissionais, optou por não participar.

Os enfermeiros que participaram desta pesquisa tiveram direito de privacidade e de confidencialidade dos dados preservados. Para isso, os nomes dos sujeitos da pesquisa foram substituídos por "Enfermeiro" seguido da letra da qual representa a unidade básica de saúde (A - pertencentes à unidade básica com maior quantidade de consulta de enfermagem à criança no ano de 2012; B - com menor quantidade; C - com a média da produção das unidades A e B) sendo precedido por uma numeração sucessiva e aleatória, não levando em consideração a ordem de realização da coleta de dados.

\subsection{Aspectos éticos}

Esta pesquisa foi aprovada pelo Comitê de Ética na Pesquisa (CEP) da Universidade Federal do Piauí - UFPI, obedecendo aos preceitos éticos e legais acordados na Resolução No 466/2012 com o C.A.A.E. $N^{\circ}$ 29002714.0.0000.5214. Em seguida, procedeu-se a coleta de dados com os sujeitos, informando esclarecimentos importantes sobre a pesquisa; com a aceitação verbal prévia dos depoentes, prosseguiu-se com a assinatura do Termo de Consentimento Livre e Esclarecido T.C.L.E. (ANEXO A) respeitando os aspectos éticos existentes.

\subsection{Procedimentos e instrumentos para coleta dos dados}

A descrição da coleta de dados seguiu o projeto explanatório das pesquisas mistas, que segundo Creswell e Clark (2013) são procedimentos que primeiro coletam os dados quantitativos, seguidos de análise dos mesmos, para então utilizar os dados obtidos para coletar e analisar os dados qualitativos.

Retomando a questão norteadora: como se dá a prática da Consulta de Enfermagem à criança na atenção básica? Quais as representações dos enfermeiros sobre essa prática? 
Na primeira fase constitui-se a quantificação na atenção básica de Teresina-PI, em 2012, do número de crianças menores de cinco anos cadastradas pelas ESF, a quantidade de Consultas de enfermagem, a população e as crianças menores de cinco anos, de puericulturas, $\mathrm{o}$ atendimento individual e visitas domiciliares realizadas exclusivamente pelos enfermeiros. Para isso, utilizaram-se fontes secundárias obtidas nos SIAB e SIA/SUS disponíveis na homepage: www.datasus.gov.br. Por conta da desatualização dos Sistemas de Informação na época da coleta (segundo semestre de 2013), foi necessário consultar as informações nos bancos dados disponíveis nos setores responsáveis da Fundação Municipal de Saúde.

Ainda na primeira fase, para relatar a Consulta de Enfermagem, quanto às características "estrutura física" e "equipamentos observados", foi elaborado o Instrumento de Coleta 1 (IC1), para registro dos dados de observação, a saber: estrutura física e equipamentos, por meio da observação sistemática e direta do pesquisador (APÊNDICE A).

Para a construção deste instrumento, tomou-se como referência publicações recentes e normativas preconizadas pelo Ministério da Saúde, além dos dados preliminares da presente pesquisa. A definição das categorias observadas antes e durante a Consulta de Enfermagem a crianças na atenção básica são apresentadas a seguir:

\section{Instrumento de Coleta 1 (IC1):}

1) Estrutura física mínima da ESF, composta por: consultório médico; consultório de enfermagem; ambiente para armazenamento e dispensação de medicamentos; laboratório; sala de vacina; banheiro público; banheiro exclusivo para os funcionários; expurgo; cabines com leitos em número suficiente para toda a equipe; cozinha; sala de procedimentos; e, se forem compostas por profissionais de saúde bucal, a existência de consultório odontológico com equipamento odontológico completo;

2) Equipamentos mínimos: presença de balança e antropômetro infantil; a quantidade de Consultórios de enfermagem para cada equipe da UBS; a identificação com logomarcas do SUS e da ESF; se o consultório de Enfermagem possui luz branca (ou natural) e ventilação adequada; piso e paredes laváveis; pia com água e dispensador de sabão; mesa e cadeiras adequadas para a consulta; maca e instrumentos para o exame físico adaptado para atendimento infantil (estetoscópio, esfigmomanômetro, otoscópio, lanterna, fita métrica, termômetro); e desenhos, brinquedos ou decoração para crianças. 
A aplicação do IC1 possibilitou uma análise por meio de dez questões fechadas e estruturadas aplicado pela pesquisadora no ambiente de trabalho das enfermeiras a partir do procedimento de observações gerais. $\mathrm{O}$ desenvolvimento desse instrumento possibilitou o registro das observações acerca do cotidiano da Consulta de Enfermagem, vivenciada na atenção básica, permitindo estabelecer uma comparação com o estabelecido nas normativas oficiais da consulta de enfermagem.

Foram registrados os dados de observação geral e sistemática nos sete consultórios de enfermagem das unidades básicas de saúde UBS (A e B), no período da coleta de dados.

A proposta inicial previa a aplicação de um instrumento (IC1 e IC2) no decorrer da Consulta de Enfermagem à criança, pela enfermeira de cada equipe que compunha a unidade básica, por meio da observação direta pelo pesquisador. Entretanto, houve rejeição por parte das enfermeiras em serem observadas e analisadas, justificada pelas mesmas como sentimentos como vergonha, medo, constrangimento, excesso de trabalho e pelo desafio de serem analisadas em uma pesquisa que certamente iria comparar as práticas com os pressupostos teóricos que, muitas vezes, se distanciam da realidade na qual estas enfermeiras trabalham ou vivenciam.

Assim, modificou-se o instrumento de coleta de dados, passando a ser aplicado pela pesquisadora na fase 1 a partir da observação direta, geral e sistemática da estrutura física da unidade básica de saúde (IC1).

Na segunda fase, ocorreram entrevistas semiestruturadas, agendadas e registradas em equipamento de gravação de áudio tecnologicamente adequado, com aplicação do instrumento de coleta 2 (IC2) que versa sobre os seis itens descritos abaixo, além de um roteiro semiestruturado com questões abertas (IC3), que é dividido em duas partes, o perfil do enfermeiro participante e as questões sobre as representações sociais elaboradas pelas enfermeiras sobre a prática da Consulta de Enfermagem, essas últimas aplicadas com técnica de entrevista com profundidade.

A aplicação dos instrumentos de coleta teve a duração em média de 40 minutos. Após o término da coleta de dados, as gravações foram transcritas do oral para o escrito, pela pesquisadora.

Apresentam-se, a seguir, os itens que compõem o IC2: 


\section{Instrumento de Coleta 2 (IC2):}

1) Processo de trabalho, aborda-se cadastro atualizado das crianças de sua área; agenda de trabalho semanal com base no perfil populacional; quantidade de dias do mês destinado ao atendimento de criança; tipo de atendimento; priorização de grupos de risco ou crianças com fatores de risco; acolhimento; Consulta de enfermagem sistemática ou não; aplicação da Sistematização da Assistência de Enfermagem (SAE); Solicitação de exames complementares; prescrição de medicamentos; e registro em prontuários.

2) Duração da realização da consulta: avaliando a média de uma consulta em minutos, relatadas pelas enfermeiras.

3) Participantes da Consulta de Enfermagem: quem participa acompanhando a criança e quem acompanha o enfermeiro (restante da equipe ou estagiário).

4) Objetivos da consulta de enfermagem, tais como: Promoção da saúde e prevenção de doenças; Doença ou agravo em curso; Educação em saúde; Retorno; Bolsa Família e Cadastro /primeira consulta.

5) Procedimentos realizados ou relatados pelo enfermeiro, como: lavagem das mãos; administração de medicamentos; medidas antropométricas; toque terapêutico; uso de brinquedos; orientações alimentares; e curativos.

6) Temáticas abordadas pelo enfermeiro durante a Consulta de Enfermagem, como: Alimentação infantil; Crescimento e Desenvolvimento; Vacinações; Bolsa Família; Mudanças biopsicossociais da infância e Desenvolvimento neuropsicomotor.

\subsection{Análise dos dados}

Na primeira fase, os dados coletados nos Sistemas de Informação em Saúde (SIAB e SIA/SUS) e os coletados com o IC1 foram quantificados por meio de frequência estatística simples e são apresentados na forma de figuras, quadros e tabelas.

$\mathrm{Na}$ segunda fase, foram analisados os dados referentes à descrição da Consulta de Enfermagem às crianças menores de cinco anos nas UBS A e B relatadas pelos enfermeiros, discutidos com base na literatura científica e as normativas do Ministério da Saúde. No final da construção dessa etapa, tece-se uma síntese das principais diferenças das UBS A e B. 
Discute-se o perfil sociodemográfico dos enfermeiros participantes desta pesquisa, tendo como base os dados obtidos por meio dos critérios mensurados, evidenciando aproximações e distanciamentos entre os sujeitos pesquisados.

Para análise das representações sociais dos enfermeiros sobre a Consulta de Enfermagem à criança na atenção básica foi adotada a análise de conteúdo de Representações Sociais. Baseado nisso, foram preparadas as transcrições das entrevistas, tendo como formatação as normativas e instruções do software utilizado por esta pesquisa: IRAMUTEQ (Interface de R pour les Analyses Multidimensionnelles de Textes et de Questionnaires) na versão 0.6 alpha, construindo, assim, o corpus. A preparação contou com a correção, codificação e organização em arquivos, para então processar o tratamento analítico, como mostra a figura 6.

O software IRAMUTEQ (Interface de $R$ pour les Analyses Multidimensionnelles de Textes et de Questionnaires), foi desenvolvido pelo francês Pierre Ratinaud em 2009 e incorporado no Brasil a partir de 2013. Trata-se de um programa informático, que por meio do software R, permite diferentes formas de análises estatísticas sobre corpus textuais e sobre tabelas por palavras. Esse software possibilita as análises: estatísticas textuais clássicas; pesquisa de especificidades de grupos; classificação hierárquica descendente; análises de similitude e nuvem de palavras, que podem contribuir para estudos que têm o conteúdo simbólico proveniente dos materiais textuais como uma fonte importante de dados de pesquisa que repercutem em diferentes possibilidades de análise advindas de seu rigor estatístico (CAMARGO; JUSTO, 2013).

As representações sociais da Consulta de Enfermagem à criança na atenção básica elaboradas pelas enfermeiras evidenciaram cinco classes semânticas relacionadas entre si por meio da Classificação Hierárquica Descendente. A produção destas classes ocorreu por meio do processamento do corpus pelo software IRAMUTeq, o qual forneceu uma análise completa e profunda, permitindo uma leitura e consequente análise, e com base nos discursos dos depoentes possibilitou, ainda, a nomeação e interpretação das classes semânticas, tendo como base as representações sociais das enfermeiras.

No relatório (rapport complét) gerado pelo referido software, o corpus está apresentado da seguinte forma: dividido em 10 textos, com 109 segmentos de textos, em 1.042 formas, total de 3.978 ocorrências, apresentando média de ocorrência por forma de 3.8, gerando cinco classes com 69 Unidades de Contexto Elementares (UCEs), com um aproveitamento textual de $63,30 \%$. Para análise dos dados, foram apreciadas somente as palavras com frequência igual ou superior a seis e um $\mathrm{x}^{2}$ igual ou superior a quatro. 
Para a análise e interpretação de um corpus, as operações mais importantes são: C1(dendograma de Classificação Hierárquica Descendente - CHD), C2 (descrição das classes), D1 (seleção das UCEs mais características de cada classe) e D3 (Classificação Hierárquica Ascendente - CHA), que foram empregadas neste estudo para a construção das classes da pesquisa (CAMARGO, 2005).

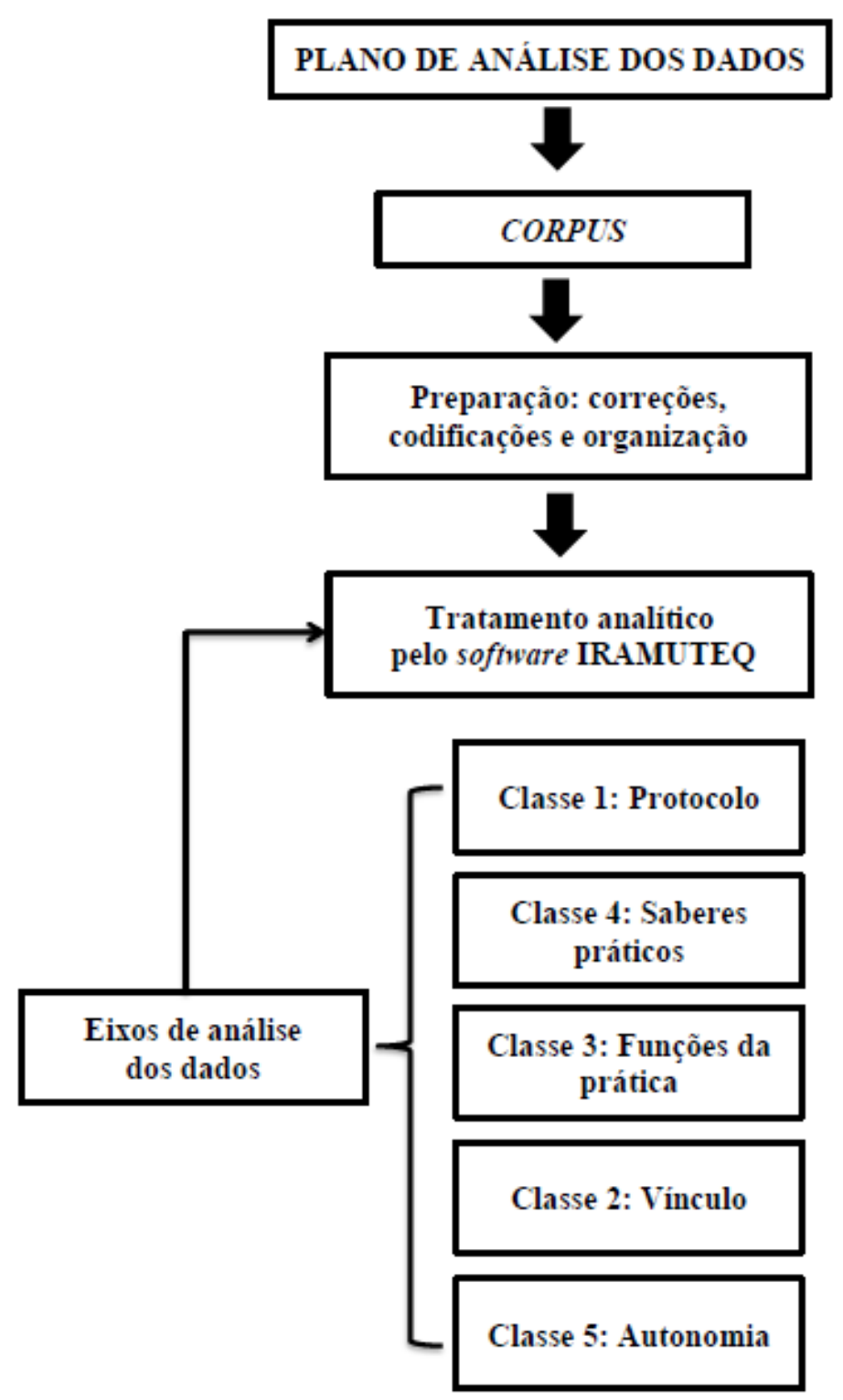

Figura 7. Plano de análise dos dados. Brasília, 2016.

Para análise das representações sociais, Spink (1995) aponta a teoria implícita como técnica qualitativa de análise de discurso, na qual o trabalho de interpretação segue as seguintes etapas: 1) transcrição das entrevistas; 2) leitura flutuante; 3) retomar os objetivos da 
pesquisa para ter clareza no objeto de estudo e mapear o discurso a partir dos temas emergentes; 4) construir mapas que transcrevem toda a entrevista, possibilitando ver a associação de ideias entre as dimensões; 5) transportar essas imagens para gráficos, pontuando as relações entre elementos cognitivos, práticas e afetividade. 


\section{RESULTADOS E DISCUSSÃO}

5.1 Quantidade de crianças menores de cinco anos, Consultas de Enfermagem, puericulturas, atendimentos individuais e visitas domiciliares realizadas pelos enfermeiros da rede de atenção básica

$\mathrm{Na}$ busca de informações capazes de subsidiar o planejamento, monitoramento e avaliação da rede de atenção básica, existem os SIS, que dispõem de registros pertinentes à saúde da criança, bem como a realização da Consulta de Enfermagem, que ocorre nas unidades Básicas de Saúde vinculadas à estratégia Saúde da Família.

Tendo como referencial os SIS, apresentam-se as informações referentes às crianças menores de cinco anos cadastradas na atenção básica de Teresina-PI, estratificadas por regional, zona, gênero e faixa etária em 2012, disposto na tabela 1.

Tabela 1. Crianças atendidas por Regional de saúde e Zona segundo gênero e faixa etária, no município de Teresina-PI, em 2012.

\begin{tabular}{l|l|c|c|c|c|c}
\hline Regional & Zona & \multicolumn{2}{|c|}{ Gênero } & \multicolumn{2}{c|}{ Faixa etária } & \multicolumn{2}{l}{\begin{tabular}{l} 
Total \\
crianças \\
menores de 5 \\
\cline { 3 - 7 }
\end{tabular}} & & Feminino & Masculino & $<1$ ano & $1-4$ anos & & \\
anos \\
\hline Centro/norte & Urbana & 2.455 & 2.471 & 290 & 4.636 & 4.926 \\
\hline Centro/norte & Rural & 46 & 57 & 0 & 103 & 103 \\
\hline Leste/sudeste & Urbana & 3.376 & 3.467 & 389 & 6.454 & 6.843 \\
\hline Leste/sudeste & Rural & 627 & 691 & 88 & 1.230 & 1.318 \\
\hline Sul & Urbana & 2.813 & 2.899 & 230 & 5.482 & 5.712 \\
\hline Sul & Rural & 57 & 60 & 09 & 108 & 117 \\
\hline
\end{tabular}

Fonte: SIAB. 
A Tabela 1 apresenta o quantitativo de crianças atendidas, respeitando a distribuição por regional. No ano de 2012 foram atendidas 19.019 crianças menores de cinco anos, sendo que a regional com maior e menor número de crianças menores de cinco anos respectivamente são: leste/sudeste (urbana) e norte (rural). A distribuição por gênero não apresentou diferenças significativas, porém a faixa etária de um a quatro anos representa a maioria (18.013 crianças, 94,7\%) das crianças menores de cinco anos, que mesmo sem uma distribuição equitativa por faixa etária disponibilizada nos SIS por meio do SIAB, apresenta um quantitativo superior quando comparado aos menores de um ano (1.006 crianças, 5,3\%).

Para uma melhor visualização das aproximações e diferenças existentes na distribuição quantitativa por regional e as zonas urbana e rural das crianças menores de cinco anos cadastradas na rede de atenção básica em 2012, são apresentadas na Figura 8.

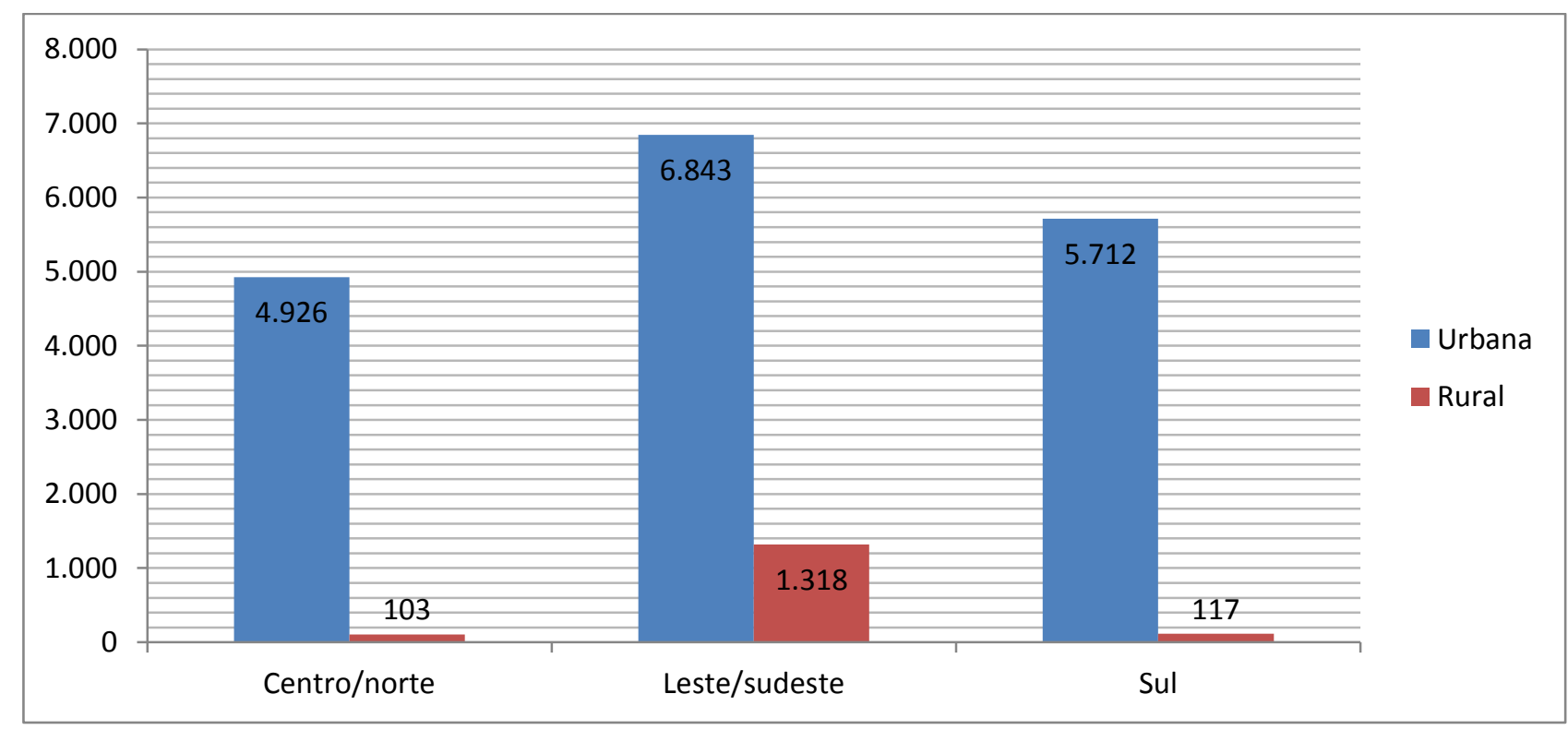

Figura 8. Crianças menores de cinco anos cadastradas/atendidas segundo a regional de saúde e zona, em Teresina-PI no ano de 2012.

Fonte: SIAB.

A Figura 8 apresenta o quantitativo de crianças menores de cinco anos distribuídas por regional e zona. A regional leste/sudeste em ambas as zonas (urbana e rural) registram o maior número de crianças na cidade de Teresina-PI, ao contrário da regional centro/norte, apontando a região com menor quantitativo de crianças cadastradas. As zonas urbanas das três regionais estudadas representam $91,9 \%$ de todas as crianças cadastradas/atendidas na atenção 
básica, o que representa um quantitativo de 17.481 menores de cinco anos. Já na zona rural, este percentual é de $8,1 \%$, com apenas 1.538 crianças.

Os resultados dispostos na Tabela 1 e Figura 8 revelam diferença quantitativa quando comparados aos números apresentados no último censo realizado pelo Instituto Brasileiro de Geografia e Estatística (IBGE, 2011) no município de Teresina-PI. Segundo o IBGE, a população total teresinense de crianças menores de cinco anos em 2010 foi de 59.337, sendo 29.409 do sexo feminino e 29.928 do masculino; entretanto, observa-se que não há diferenças expressivas entre os sexos com um ligeiro predomínio de crianças do sexo masculino. No que se refere ao local de residência, o IBGE afirma que 55.226 das crianças menores de cinco anos atendidas/cadastradas estão na zona urbana, representando 93\%, enquanto 4.111 residem na zona rural, o que representa 7\%. Por conseguinte, os percentuais dos resultados encontrados convergem com os dados apresentados pelo IBGE.

Para o ano de 2012, pontuando na região mais populosa como a regional leste/sudeste, destaca-se que isso ocorre possivelmente pelo fato dessas compreenderem a região de bairros mais populosos, quando comparados às demais regionais, segundo o IBGE (2011) no ano de 2010.

Os quantitativos descritos acima revelam que, embora o censo seja de 2010 e as Consultas de Enfermagem realizadas de 2012, o percentual de crianças menores de cinco anos cadastradas/atendidas na rede de atenção básica de Teresina-PI, comparada com o censo 2010, representam somente $32 \%$ da população nesta faixa etária. Esses dados se contrapõem aos 93,5\% de cobertura populacional estimada pela estratégia Saúde da Família, divulgado pelo Ministério da Saúde (BRASIL, 2013). A diferença pode ser explicada em função dos cálculos, considerando que a cobertura populacional dimensiona a quantidade de Equipes Saúde da Família para a população total do município e não considera o quantitativo de atendimentos realizados por cada equipe.

A Tabela 1 e o Figura 8 possibilitaram a visualização do quantitativo das crianças menores de cinco anos cadastrados/atendidos na atenção básica de Teresina-PI; entretanto, faz-se necessário o uso de outras estratégias que coloquem em evidência os princípios de integralidade, universalidade e acessibilidade dos serviços de saúde da atenção básica à saúde da criança.

Quanto ao atendimento geral em todas as faixas do ciclo vital, observa-se que as Consultas de Enfermagem realizadas na rede de atenção básica de Teresina tiveram um comportamento variável, registrando ao menos quatro involuções no ano de 2012 (Figura 9). 


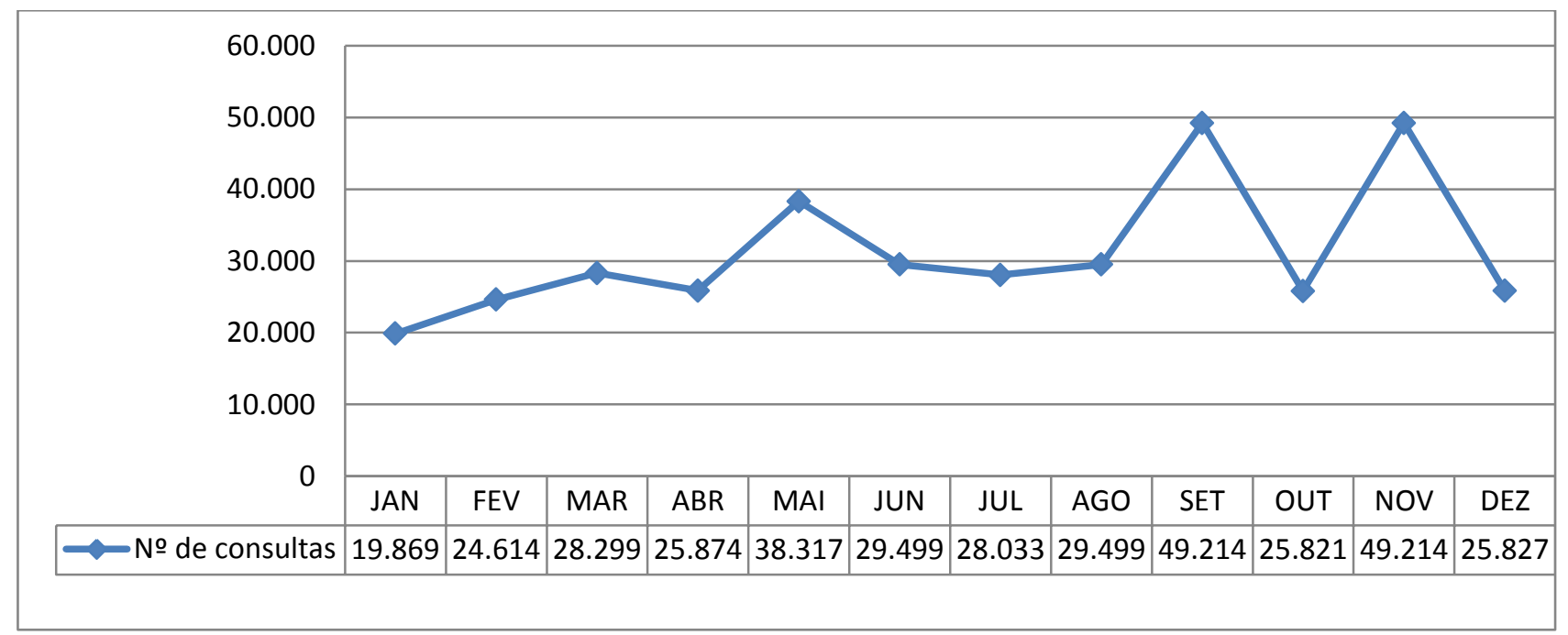

Figura 9. Consultas de Enfermagem realizadas na atenção básica de Teresina, segundo mês no ano de 2012.

Fonte: SIA/SUS.

Legenda: JAN - janeiro; FEV = fevereiro; MAR - março; ABR - abril; MAI - maio; JUN - junho; JUL - julho; AGO - agosto; SET - setembro; OUT - outubro; NOV - novembro; DEZ - dezembro.

Em uma totalidade de 374.080 consultas realizadas pelos enfermeiros aos indivíduos em todos os ciclos da vida, destacam-se os meses de setembro e novembro como os mais produtivos e os de janeiro e fevereiro como os menos produtivos, perfazendo uma média mensal de aproximadamente 31.173 consultas distribuídas entre os duzentos e oitenta e seis enfermeiros que compõem as Equipes Saúde da Família. Em média, são realizadas pelos Enfermeiros cerca de cinco Consultas de Enfermagem por dia (segunda à sexta-feira), com duração média de uma hora para cada Consulta em um turno de trabalho. Isto representa uma produção diária de 1.430 Consultas para uma média populacional em 2012 de 818.297 pessoas, ou seja, a representatividade da produção da Consulta de Enfermagem por todas as equipes na população teresinense corresponde a um percentual aproximadamente $0,17 \%$ dia e $3,8 \% / \mathrm{mês}$.

Com os dados apresentados na Figura 9, observa-se que os meses mais produtivos remetem aos finais de semestre, momento que geralmente ocorre a atualização do programa Bolsa Família, bem como época que antecede as eleições (primeiro e segundo turno), considerando que 2012 foi ano de eleição no Brasil.

A Consulta de Enfermagem constitui uma das atribuições específicas do enfermeiro na PNAB, que visa ações direcionadas a indivíduos ou famílias cadastradas na estratégia Saúde da Família, em todas as fases de vida, independentemente do cenário (unidade básica de 
saúde, domicílio, escola, associações, entre outros), devendo prestar assistência planejada pela equipe ou à demanda espontânea, respeitando o protocolo existente (BRASIL, 2012).

A Consulta de Enfermagem é uma atividade privativa do enfermeiro, que com base em métodos científicos, identifica situações de saúde e doença, objetivando promover saúde, fundamentada em princípios de universalidade, equidade, resolutividade e integralidade de suas ações, adequando às necessidades da população. A Consulta de Enfermagem deve ser instituída em todos os níveis assistenciais em instituições públicas ou privadas, tendo como base legal a Resolução № 159 de 19 de abril de 1993 do Conselho Federal de Enfermagem (COFEN, 1993).

Ribeiro, Ohara e Saparoli (2009) ressaltam a importância da Consulta de Enfermagem no âmbito da atenção básica no resgate do cuidado e da educação por meio de uma assistência sistematizada de enfermagem visando à promoção, proteção e recuperação da saúde desses indivíduos.

Embora a representatividade das Consultas de Enfermagem produzidas na rede de atenção básica de Teresina-PI seja limitada, a mesma apresenta potencialidades por se tratar de uma atribuição do enfermeiro descrita na Política Nacional da Atenção Básica-PNAB, além de possuir base deontológica e se configurar em um instrumento para a ação profissional para o indivíduo/família atendida.

A Tabela 2 apresenta o quantitativo de consultas de enfermagem produzidas no ano de 2012, na regional centro/norte, por unidade básica de saúde.

São vinte e quatro unidades básicas de saúde vinculadas à estratégia Saúde da Família da regional centro/norte, sendo vinte e uma urbanas, apresentadas como CNU (centro/norte urbana) e três rurais CNR (centro/norte rural), estas totalizaram 15.216 consultas no ano de 2012 na regional centro/norte, sendo a CNU12 a unidade com maior número de consultas, representando 1.472 e as unidades com o menor quantitativo registrado foram as CNU09 e CNR03, com 175 consultas em cada uma. 
Tabela 2. Consultas de enfermagem a crianças menores de cinco anos segundo mês do ano de 2012 na regional centro/norte de Teresina-PI.

\begin{tabular}{|c|c|c|c|c|c|c|c|c|c|c|c|c|c|}
\hline MÊS & 01 & 02 & 03 & 04 & 05 & 06 & 07 & 08 & 09 & 10 & 11 & 12 & Total \\
\hline CNU01 & 0 & 82 & 18 & 168 & 196 & 31 & 75 & 0 & 0 & 66 & 80 & 42 & 758 \\
\hline CNU02 & 152 & 0 & 206 & 0 & 139 & 260 & 260 & 0 & 164 & 146 & 0 & 0 & 1.327 \\
\hline CNU03 & 44 & 52 & 42 & 0 & 44 & 90 & 90 & 52 & 68 & 115 & 0 & 0 & 597 \\
\hline CNU04 & 32 & 84 & 49 & 71 & 42 & 54 & 44 & 28 & 58 & 43 & 77 & 38 & 620 \\
\hline CNU05 & 39 & 64 & 69 & 45 & 57 & 62 & 0 & 0 & 50 & 79 & 63 & 54 & 582 \\
\hline CNU06 & 76 & 64 & 78 & 89 & 77 & 228 & 15 & 77 & 0 & 103 & 80 & 123 & 1.010 \\
\hline CNU07 & 09 & 08 & 0 & 13 & 09 & 15 & 15 & 08 & 60 & 22 & 13 & 13 & 185 \\
\hline CNU08 & 40 & 76 & 110 & 148 & 43 & 123 & 63 & 76 & 34 & 83 & 148 & 166 & 1.110 \\
\hline CNU09 & 07 & 28 & 0 & 12 & 05 & 33 & 13 & 23 & 0 & 42 & 0 & 12 & 175 \\
\hline CNU10 & 68 & 67 & 78 & 58 & 110 & 87 & 74 & 45 & 37 & 78 & 79 & 36 & 817 \\
\hline CNU11 & 18 & 15 & 46 & 25 & 49 & 40 & 68 & 20 & 74 & 90 & 25 & 36 & 506 \\
\hline CNU12 & 87 & 126 & 71 & 68 & 128 & 235 & 235 & 126 & 102 & 157 & 109 & 28 & 1.472 \\
\hline CNU13 & 16 & 33 & 22 & 23 & 21 & 18 & 0 & 45 & 46 & 0 & 0 & 23 & 247 \\
\hline CNU14 & 24 & 0 & 01 & 0 & 103 & 07 & 25 & 56 & 56 & 0 & 31 & 0 & 303 \\
\hline CNU15 & 0 & 45 & 49 & 0 & 0 & 07 & 56 & 04 & 67 & 71 & 73 & 73 & 445 \\
\hline CNU16 & 100 & 184 & 208 & 04 & 289 & 07 & 06 & 02 & 06 & 06 & 04 & 0 & 816 \\
\hline CNU17 & 37 & 78 & 76 & 29 & 149 & 67 & 43 & 99 & 28 & 108 & 72 & 57 & 843 \\
\hline CNU18 & 15 & 17 & 16 & 49 & 94 & 14 & 16 & 12 & 18 & 36 & 08 & 06 & 301 \\
\hline CNU19 & 26 & 36 & 14 & 21 & 32 & 25 & 06 & 19 & 31 & 28 & 49 & 44 & 331 \\
\hline CNU20 & 0 & 85 & 73 & 49 & 100 & 136 & 34 & 22 & 35 & 94 & 49 & 49 & 726 \\
\hline CNU21 & 02 & 78 & 49 & 25 & 17 & 44 & 195 & 14 & 79 & 128 & 77 & 55 & 763 \\
\hline CNR01 & 55 & 52 & 0 & 63 & 60 & 130 & 193 & 44 & 106 & 35 & 63 & 63 & 864 \\
\hline CNR02 & 12 & 25 & 22 & 19 & 26 & 28 & 0 & 0 & 30 & 81 & 0 & 0 & 243 \\
\hline CNR03 & 7 & 28 & 0 & 12 & 05 & 33 & 13 & 23 & 0 & 42 & 0 & 12 & 175 \\
\hline Total & 866 & 1327 & 1297 & 991 & 1795 & 1774 & 1539 & 795 & 1149 & 1653 & 1100 & 930 & 15216 \\
\hline
\end{tabular}

Fonte: SIA/SUS.

Legenda: CNU = unidade básica de saúde situada na regional centro norte, zona urbana; e CNR = unidade básica de saúde situada na regional centro norte, zona rural.

A Tabela 3 distribui o quantitativo de Consultas de Enfermagem a crianças menores de cinco anos, realizadas na rede de atenção básica da regional leste/sudeste (urbana e rural) nos meses pertencentes ao ano de 2012 em Teresina-PI. 
Tabela 3. Consultas de enfermagem a crianças menores de cinco anos, segundo mês do ano de 2012 na regional leste/sudeste de Teresina-PI.

\begin{tabular}{|c|c|c|c|c|c|c|c|c|c|c|c|c|c|}
\hline $\mathrm{ME} S$ & 01 & 02 & 03 & 04 & 05 & 06 & 07 & 08 & 09 & 10 & 11 & 12 & Total \\
\hline LSU01 & 33 & 32 & 16 & 23 & 41 & 52 & 0 & 24 & 42 & 0 & 68 & 33 & 364 \\
\hline LSU02 & 16 & 31 & 18 & 27 & 52 & 0 & 0 & 17 & 124 & 14 & 350 & 148 & 797 \\
\hline LSU03 & 33 & 65 & 101 & 71 & 0 & 227 & 162 & 24 & 80 & 0 & 0 & 0 & 763 \\
\hline LSU04 & 0 & 0 & 121 & 24 & 32 & 21 & 19 & 27 & 34 & 35 & 45 & 97 & 455 \\
\hline LSU05 & 28 & 06 & 14 & 28 & 11 & 31 & 30 & 12 & 28 & 04 & 09 & 03 & 204 \\
\hline LSU06 & 0 & 0 & 04 & 0 & 102 & 0 & 0 & 0 & 108 & 150 & 0 & 0 & 364 \\
\hline LSU07 & 48 & 62 & 108 & 204 & 333 & 124 & 127 & 96 & 99 & 184 & 0 & 0 & 1.385 \\
\hline LSU08 & 0 & 0 & 0 & 0 & 431 & 0 & 2.716 & 0 & 0 & 0 & 0 & 0 & 3.147 \\
\hline LSU09 & 59 & 124 & 0 & 57 & 0 & 21 & 72 & 0 & 40 & 193 & 50 & 0 & 616 \\
\hline LSU10 & 30 & 02 & 10 & 0 & 0 & 25 & 35 & 82 & 58 & 30 & 78 & 55 & 405 \\
\hline LSU11 & 0 & 24 & 29 & 28 & 48 & 0 & 28 & 17 & 28 & 54 & 51 & 24 & 331 \\
\hline LSU12 & 240 & 0 & 186 & 322 & 326 & 25 & 64 & 182 & 0 & 424 & 105 & 40 & 1.914 \\
\hline LSU13 & 15 & 31 & 35 & 32 & 28 & 12 & 47 & 17 & 17 & 10 & 21 & 438 & 703 \\
\hline LSU14 & 0 & 0 & 575 & 0 & 0 & 0 & 0 & 0 & 0 & 0 & 0 & 0 & 575 \\
\hline LSU15 & 0 & 0 & 0 & 152 & 0 & 161 & 0 & 60 & 0 & 392 & 0 & 0 & 765 \\
\hline LSU16 & 31 & 89 & 152 & 144 & 359 & 218 & 0 & 69 & 145 & 332 & 368 & 222 & 2.129 \\
\hline LSU17 & 01 & 15 & 06 & 113 & 18 & 04 & 04 & 13 & 44 & 28 & 42 & 18 & 306 \\
\hline LSU18 & 0 & 17 & 37 & 62 & 64 & 92 & 49 & 01 & 03 & 20 & 92 & 0 & 437 \\
\hline LSU19 & 0 & 0 & 0 & 0 & 209 & 0 & 0 & 0 & 0 & 0 & 0 & 0 & 209 \\
\hline LSU20 & 0 & 235 & 0 & 0 & 0 & 0 & 0 & 0 & 0 & 0 & 429 & 239 & 903 \\
\hline LSU21 & 98 & 111 & 210 & 106 & 126 & 129 & 82 & 83 & 82 & 112 & 116 & 40 & 1.295 \\
\hline LSU22 & 167 & 236 & 170 & 230 & 422 & 420 & 260 & 102 & 201 & 0 & 41 & 47 & 2.296 \\
\hline LSU23 & 60 & 0 & 49 & 38 & 70 & 53 & 47 & 27 & 35 & 0 & 304 & 0 & 683 \\
\hline LSU24 & 0 & 692 & 482 & 605 & 0 & 469 & 418 & 188 & 473 & 570 & 730 & 596 & 5.223 \\
\hline LSU25 & 89 & 153 & 76 & 260 & 485 & 0 & 98 & 67 & 130 & 91 & 232 & 78 & 1.759 \\
\hline LSU26 & 12 & 10 & 18 & 18 & 22 & 0 & 11 & 18 & 0 & 19 & 55 & 117 & 300 \\
\hline LSU27 & 17 & 0 & 50 & 0 & 48 & 35 & 14 & 31 & 0 & 0 & 261 & 153 & 609 \\
\hline LSU28 & 0 & 0 & 0 & 0 & 0 & 0 & 0 & 0 & 0 & 0 & 0 & 119 & 119 \\
\hline LSR01 & 17 & 0 & 0 & 0 & 0 & 0 & 0 & 0 & 97 & 87 & 183 & 0 & 384 \\
\hline LSR02 & 0 & 24 & 19 & 03 & 0 & 0 & 0 & 0 & 97 & 87 & 183 & 0 & 384 \\
\hline LSR03 & 0 & 0 & 0 & 0 & 0 & 0 & 24 & 25 & 0 & 0 & 169 & 0 & 218 \\
\hline LSR04 & 0 & 0 & 366 & 0 & 0 & 324 & 0 & 0 & 0 & 369 & 0 & 0 & 1.059 \\
\hline LSR05 & 150 & 90 & 240 & 117 & 0 & 89 & 0 & 0 & 112 & 0 & 78 & 95 & 971 \\
\hline Total & 1144 & 2049 & 3092 & 2664 & 3227 & 2532 & 4307 & 1182 & 2077 & 3205 & $\begin{array}{l}406 \\
0\end{array}$ & $\begin{array}{l}256 \\
2\end{array}$ & 32072 \\
\hline
\end{tabular}

Fonte: SIA/SUS.

Legenda: LSU = unidade básica de saúde situada na regional leste sudeste, zona urbana; e LSR = unidade básica de saúde situada na regional leste sudeste, zona rural. 
A regional leste/sudeste (LS) possui vinte e oito unidades básicas de saúde na zona urbana (LSU) e cinco unidades básicas rurais (LSR), que totalizaram 32.191 Consultas de Enfermagem no ano de 2012. A unidade básica de saúde com maior número de consultas foi a LSU24, com 5.223 e o menor quantitativo foi registrada na unidade LSU28, com 119 consultas Tabela 3 .

A Tabela 4 apresenta as de Consultas de Enfermagem a crianças menores de cinco anos durante o ano de 2012 nas unidades básicas da regional sul (urbana e rural), na atenção básica de Teresina-PI.

São vinte e seis unidades básicas de saúde urbanas na regional sul (SLU) e quatro rurais (SLR) totalizando trinta unidades que registraram no ano de 2012 um total de 16.009 consultas, observa-se na Tabela 4, que a unidade SLU08 representou o maior quantitativo de consultas, totalizando 2.026 e a SLU25 com a menor quantidade, representando, 79 consultas.

Consolidando as três regionais e suas respectivas zonas urbanas e rural, que compõem a rede de atenção básica de Teresina-PI, constata-se a produção de 63.416 consultas durante o ano de 2012, representando uma média mensal de 5.284 consultas de crianças com menos de cinco anos de idade, em toda a rede de atenção básica. Comparando a população menores de cinco anos segundo o censo do IBGE em 2010 (2011) que foi de 59.337 crianças, a produção de consultas por dia representa $2,2 \%$ da população infantil e por mês $8,8 \%$.

Nessa perspectiva, é possível inferir que a atenção à saúde de crianças menores de cinco anos em termos da produção de Consultas de Enfermagem representa apenas 8,8\% da população geral, de crianças nesta faixa etária, na rede de atenção básica de Teresina. Entretanto, faz-se necessário quantificar o mínimo de consultas estipuladas pelo Ministério da Saúde aos menores de cinco anos.

De acordo com o MS (BRASIL, 2005), independente da motivação na procura do atendimento, a consulta deve ser um momento que oportunize uma análise integrativa e preditiva sobre a saúde da criança. Como eixo central desse atendimento, tem-se o acompanhamento sistemático do crescimento e desenvolvimento infantil, o qual dispõe da quantidade mínima de consulta. Para o primeiro ano de vida, devem ser realizadas, pelo menos, sete consultas (antes de 15 dias, primeiro mês, segundo, quarto, sexto, nono e décimo segundo), no segundo ano de vida, deverão ser realizadas, pelo menos, duas consultas (décimo oitavo mês e vigésimo quarto), sendo que dos três aos 10 anos, a recomendação é de no mínimo uma consulta para cada ano de vida da criança. 
Tabela 4. Consultas de enfermagem as crianças menores de cinco anos segundo mês do ano de 2012 na regional sul de Teresina-PI.

\begin{tabular}{|c|c|c|c|c|c|c|c|c|c|c|c|c|c|}
\hline$M \hat{E} S$ & 01 & 02 & 03 & 04 & 05 & 06 & 07 & 08 & 09 & 10 & 11 & 12 & Total \\
\hline SLU01 & 36 & 99 & 79 & 108 & 0 & 139 & 100 & 0 & 187 & 143 & 113 & 33 & 1.037 \\
\hline SLU02 & 05 & 35 & 04 & 08 & 20 & 04 & 0 & 01 & 0 & 16 & 03 & 02 & 98 \\
\hline SLU03 & 17 & 21 & 36 & 27 & 71 & 32 & 23 & 18 & 42 & 51 & 0 & 31 & 369 \\
\hline SLU04 & 30 & 45 & 44 & 37 & 71 & 43 & 34 & 50 & 39 & 28 & 41 & 50 & 512 \\
\hline SLU05 & 13 & 15 & 18 & 18 & 56 & 219 & 0 & 42 & 26 & 35 & 23 & 88 & 553 \\
\hline SLU06 & 17 & 20 & 13 & 13 & 0 & 0 & 0 & 20 & 50 & 24 & 0 & 29 & 186 \\
\hline SLU07 & 0 & 28 & 49 & 0 & 79 & 37 & 55 & 47 & 60 & 38 & 50 & 50 & 493 \\
\hline SLU08 & 170 & 168 & 143 & 113 & 295 & 190 & 262 & 149 & 108 & 170 & 0 & 258 & 2.026 \\
\hline SLU09 & 26 & 59 & 90 & 39 & 61 & 0 & 94 & 34 & 46 & 87 & 94 & 119 & 749 \\
\hline SLU10 & 25 & 19 & 64 & 54 & 49 & 100 & 64 & 43 & 54 & 44 & 88 & 41 & 645 \\
\hline SLU11 & 70 & 84 & 105 & 209 & 82 & 85 & 48 & 85 & 150 & 121 & 123 & 96 & 1.258 \\
\hline SLU12 & 27 & 0 & 24 & 154 & 35 & 0 & 78 & 0 & 70 & 70 & 75 & 52 & 585 \\
\hline SLU13 & 22 & 35 & 21 & 17 & 33 & 22 & 24 & 31 & 60 & 52 & 32 & 0 & 349 \\
\hline SLU14 & 05 & 04 & 06 & 06 & 06 & 11 & 10 & 01 & 06 & 14 & 0 & 12 & 81 \\
\hline SLU15 & 28 & 67 & 40 & 77 & 75 & 78 & 88 & 10 & 50 & 36 & 108 & 33 & 690 \\
\hline SLU16 & 38 & 55 & 145 & 64 & 66 & 95 & 29 & 45 & 37 & 0 & 83 & 90 & 747 \\
\hline SLU17 & 09 & 11 & 13 & 16 & 38 & 02 & 21 & 10 & 12 & 18 & 0 & 15 & 165 \\
\hline SLU18 & 03 & 11 & 03 & 0 & 10 & 14 & 06 & 05 & 10 & 12 & 13 & 05 & 92 \\
\hline SLU19 & 30 & 01 & 94 & 03 & 73 & 04 & 0 & 21 & 43 & 01 & 57 & 20 & 347 \\
\hline SLU20 & 62 & 35 & 23 & 55 & 44 & 08 & 97 & 18 & 46 & 84 & 95 & 110 & 677 \\
\hline SLU21 & 0 & 79 & 125 & 0 & 56 & 111 & 63 & 68 & 60 & 95 & 70 & 88 & 815 \\
\hline SLU22 & 119 & 0 & 202 & 93 & 112 & 98 & 52 & 61 & 83 & 43 & 91 & 0 & 954 \\
\hline SLU23 & 19 & 31 & 30 & 42 & 63 & 66 & 31 & 30 & 35 & 30 & 149 & 124 & 650 \\
\hline SLU24 & 0 & 28 & 49 & 0 & 79 & 37 & 55 & 47 & 60 & 38 & 50 & 50 & 493 \\
\hline SLU25 & 01 & 05 & 05 & 0 & 12 & 03 & 03 & 17 & 0 & 05 & 18 & 10 & 79 \\
\hline SLU26 & 18 & 40 & 33 & 53 & 41 & 41 & 34 & 44 & 23 & 37 & 44 & 29 & 437 \\
\hline SLR01 & 14 & 27 & 07 & 20 & 11 & 30 & 11 & 09 & 23 & 12 & 0 & 22 & 186 \\
\hline SLR02 & 13 & 10 & 19 & 16 & 0 & 16 & 10 & 12 & 07 & 06 & 11 & 0 & 120 \\
\hline SLR03 & 0 & 0 & 0 & 0 & 0 & 100 & 56 & 68 & 82 & 77 & 115 & 89 & 587 \\
\hline SLR04 & 1 & 03 & 03 & 02 & 24 & 22 & 33 & 08 & 13 & 08 & 0 & 02 & 119 \\
\hline Total & 818 & 1035 & 1487 & 1244 & 1562 & 1607 & 1381 & 994 & 1482 & 1395 & 1546 & 1548 & 16099 \\
\hline
\end{tabular}

Fonte: SIA/SUS.

Legenda: SLU = unidade básica de saúde situada na regional sul, zona urbana; e CLR = unidade básica de saúde situada na regional sul, zona rural. 
Portanto, enumera-se como doze o padrão mínimo de consultas às crianças menores de cinco anos. Considerando somente as crianças cadastradas nas estratégias Saúde da Família (19.019 menores de cinco anos) e o total de Consultas de Enfermagem produzidas no ano de 2012 (63.419), é possível afirmar que cada criança menor de cinco anos foi consultada pelo enfermeiro ao menos três vezes no ano de 2012, quantidade esta maior que a média de consultas de crianças de 0 a 5 anos.

A rede de atenção básica de Teresina-PI organizou o atendimento às crianças por meio da institucionalização do "Protocolo de Enfermagem na atenção à saúde da criança", conferindo maior respaldo para as atribuições do enfermeiro inserido na PNAB, pautando em metas, diretrizes e princípios norteadores do cuidado para população alvo e de risco. Além de descrever a operacionalização da Consulta de Enfermagem a crianças de zero a dez anos e dos cuidados de Enfermagem direcionados a este grupo, respeitando o número de consultas preconizadas pelo Ministério da Saúde, o referido protocolo orienta as atribuições do enfermeiro na identificação de riscos e nas condutas a serem tomadas em situações especiais, caso necessário (BRASIL, 2012).

Nessa perspectiva, considera-se pertinente discutir mais três temáticas relacionadas com a saúde da criança e a atenção básica, por meio de dados disponíveis nos SIS (SIAB e o SIA/SUS) no ano de 2012, como: as puericulturas realizadas; atendimentos individuais do enfermeiro e as visitas domiciliares realizadas exclusivamente pelo enfermeiro.

A Tabela 5 descreve o quantitativo de consultas de puericultura realizadas na atenção básica no ano de 2012, distribuídos por mês e regional/zona.

Pela tabela 5, constata-se que foram realizados 88.635 atendimentos de puericultura na rede de atenção básica de Teresina-PI, no ano de 2012, sendo a regional leste/sudeste, zona urbana, representado o maior número e o menor quantitativo registrado foi na regional sul zona rural.

Em um estudo realizado por Campos et al. (2011) a respeito da vivência do enfermeiro sobre a Consulta de Enfermagem em puericultura, discute-se a importância da Consulta de Enfermagem em ampliar a puericultura, havendo interação entre o enfermeiro e o paciente no intuito de instrumentar a assistência para ações de promoção da saúde e prevenção de doenças. 
Tabela 5. Consulta de Puericultura segundo Regional e mês do ano de 2012 em Teresina-PI.

\begin{tabular}{l|l|l|l|l|l|l}
\hline \multicolumn{1}{c|}{ Regional } & $\begin{array}{l}\text { Centro/norte } \\
\text { Urbana }\end{array}$ & $\begin{array}{l}\text { Centro/norte } \\
\text { Rural }\end{array}$ & $\begin{array}{l}\text { Leste/sudeste } \\
\text { Urbana }\end{array}$ & $\begin{array}{l}\text { Leste/ } \\
\text { sudeste } \\
\text { Rural }\end{array}$ & $\begin{array}{l}\text { Sul } \\
\text { Urbana }\end{array}$ & $\begin{array}{l}\text { Rural } \\
\text { Janeiro }\end{array}$ \\
\hline Fevereiro & 1.797 & 2.287 & 1.914 & 162 & 1.919 & 220 \\
\hline Março & 1.862 & 278 & 1.896 & 138 & 1.633 & 176 \\
\hline Abril & 2.462 & 281 & 2.244 & 373 & 2.109 & 181 \\
\hline Maio & 2.390 & 321 & 2.717 & 306 & 2.396 & 228 \\
\hline Junho & 1.975 & 335 & 3.007 & 345 & 2.353 & 302 \\
\hline Julho & 1.695 & 223 & 2.363 & 356 & 2.160 & 193 \\
\hline Agosto & 2.057 & 275 & 2.187 & 410 & 1.915 & 239 \\
\hline Setembro & 2.337 & 217 & 2.746 & 391 & 2.228 & 197 \\
\hline Outubro & 2.707 & 164 & 3.318 & 392 & 2.839 & 237 \\
\hline Novembro & 1.924 & 193 & 2.541 & 367 & 2.270 & 195 \\
\hline Dezembro & 1.483 & 154 & 1.605 & 163 & 1.566 & 147 \\
\hline Total & 24.976 & 2.966 & 29.097 & 3.562 & 25.469 & 2.565 \\
\hline Fong & & & & & 2.081 \\
\hline
\end{tabular}

Fonte: SIAB.

Embora os números apresentados não façam a distinção do profissional que a realizou, observa-se uma diferença quantitativa destas consultas quando comparada com as consultas de enfermagem destinada aos menores de cinco anos na atenção básica no ano de 2012.

A Tabela 6 apresenta o quantitativo de atendimentos individuais realizados pelo enfermeiro na atenção básica no ano de 2012, segundo o mês e regional/zona. 
Tabela 6. Atendimento individual do enfermeiro na atenção básica por regional e zona segundo mês do ano de 2012 em Teresina-PI.

\begin{tabular}{l|l|l|l|l|l|l}
\hline \multicolumn{1}{c|}{ Regional } & $\begin{array}{l}\text { Centro } \\
\text { norte } \\
\text { Mês }\end{array}$ & $\begin{array}{l}\text { Centro } \\
\text { norte } \\
\text { Urbana }\end{array}$ & $\begin{array}{l}\text { Leste } \\
\text { sudeste } \\
\text { Urbana }\end{array}$ & $\begin{array}{l}\text { Leste } \\
\text { sudeste } \\
\text { Rural }\end{array}$ & $\begin{array}{l}\text { Sul } \\
\text { Urbana }\end{array}$ & Rural \\
\hline Janeiro & 8.157 & 852 & 9.241 & 1.450 & 8.097 & 378 \\
\hline Fevereiro & 9.325 & 657 & 9.539 & 1.112 & 8.092 & 790 \\
\hline Março & 9.166 & 744 & 10.521 & 2.045 & 8.858 & 610 \\
\hline Abril & 10.394 & 911 & 215.429 & 1.915 & 10.754 & 656 \\
\hline Maio & 9.615 & 952 & 9.406 & 1.629 & 8.820 & 787 \\
\hline Junho & 8.068 & 915 & 8.861 & 1.479 & 8.315 & 608 \\
\hline Julho & 7.475 & 518 & 8.568 & 1.501 & 257.652 & 559 \\
\hline Agosto & 8.254 & 867 & 9.556 & 1.434 & 8.188 & 522 \\
\hline Setembro & 7.739 & 1.073 & 10.170 & 1.827 & 7.739 & 684 \\
\hline Outubro & 9.307 & 754 & 12.292 & 1.704 & 9.604 & 659 \\
\hline Novembro & 8.636 & 690 & 9.304 & 1.999 & 8.646 & 585 \\
\hline Dezembro & 6.008 & 590 & 6.804 & 1.091 & 6.064 & 282 \\
\hline Total & 102.144 & 9.523 & 319.691 & 19.186 & 350.829 & 7.120 \\
\hline Fonte: SIAB & & & & & & \\
\hline
\end{tabular}

Fonte: SIAB.

Os resultados dispostos na tabela 6 revelam uma produção anual de 808.493 atendimentos de enfermagem registrados, destacando as regiões sul zona urbana com maior quantitativo, sendo que a mesma região na zona rural representa o menor quantitativo de atendimento realizado pelo enfermeiro.

Trabalhos como o de Matumoto et al. (2012) revelam a produção do atendimento de enfermeiros em algumas unidades da atenção básica em Ribeirão Preto-SP, nos anos de 2006 a 2009, com resultados bem menores (128.274) do que os dados encontrados pela presente pesquisa. Os referidos autores indicam o crescimento e a transformação que ocorre com a contribuição dos enfermeiros para atendimentos voltados para condições agudas.

$\mathrm{O}$ atendimento individualizado realizado pelo enfermeiro revela o potencial produzido pelo profissional na rede de atenção básica, contudo os dados não referem à faixa etária atendida. 
A tabela 7 apresenta o quantitativo de visitas domiciliares realizadas pelos enfermeiros vinculados à estratégia Saúde da Família, distribuídas por mês, regional e zona.

Tabela 7. Visitas domiciliares realizadas por enfermeiros no ano de 2012 em Teresina-PI.

\begin{tabular}{l|l|l|l|l|l|l}
\hline Regional & $\begin{array}{l}\text { Centro } \\
\text { norte } \\
\text { Mrbana }\end{array}$ & $\begin{array}{l}\text { Centro } \\
\text { norte } \\
\text { Rural }\end{array}$ & $\begin{array}{l}\text { Leste } \\
\text { sudeste } \\
\text { Urbana }\end{array}$ & $\begin{array}{l}\text { Leste } \\
\text { sudeste } \\
\text { Rural }\end{array}$ & $\begin{array}{l}\text { Sul } \\
\text { Urbana }\end{array}$ & $\begin{array}{l}\text { Sul } \\
\text { Rural }\end{array}$ \\
\hline Janeiro & 954 & 86 & 778 & 101 & 844 & 60 \\
\hline Fevereiro & 717 & 89 & 647 & 99 & 821 & 73 \\
\hline Março & 708 & 76 & 1.923 & 117 & 902 & 77 \\
\hline Abril & 924 & 92 & 1.302 & 100 & 2.002 & 84 \\
\hline Maio & 993 & 73 & 1.108 & 92 & 1.078 & 105 \\
\hline Junho & 956 & 68 & 795 & 73 & 997 & 62 \\
\hline Julho & 1.068 & 91 & 732 & 118 & 901 & 92 \\
\hline Agosto & 923 & 62 & 893 & 91 & 961 & 70 \\
\hline Setembro & 888 & 78 & 891 & 105 & 795 & 98 \\
\hline Outubro & 912 & 64 & 769 & 91 & 945 & 100 \\
\hline Novembro & 891 & 85 & 738 & 94 & 849 & 81 \\
\hline Dezembro & 656 & 43 & 529 & 66 & 685 & 42 \\
\hline Total & 10.590 & 907 & 11.105 & 1.147 & 11.780 & 944 \\
\hline Fonte: SIAB & & & & & & \\
\hline
\end{tabular}

Fonte: SIAB.

As visitas domiciliares realizadas exclusivamente pelo enfermeiro representaram um quantitativo de 36.473 , podendo indicar que este é um procedimento ainda pouco explorado pelo enfermeiro em 2012. As visitas são desenvolvidas na zona urbana da regional sul contrapondo-se à regional norte zona rural, tida como região de menor realização das visitas domiciliares.

A Visita domiciliar é preconizada pela Fundação Municipal de Saúde como procedimento operacional padrão, entendida como o ato de visitar o paciente em seu domicílio, com a finalidade de intervir no processo saúde/doença, conhecendo a realidade vivenciada pelo paciente, realizar procedimentos ou busca ativa de patologias. Possui como técnica as etapas de planejamento, execução, registro e avaliação do procedimento realizado (BRASIL, 2012). 
Assim como o atendimento individual do enfermeiro, a visita domiciliar apresenta potencialidades que estão condicionadas e limitadas à falta de registro da faixa etária atendida pelos SIS.

Em termos gerais, esta análise possibilitou uma discussão importante sobre dados quantitativos referentes à produção da enfermagem e à saúde da criança na atenção básica, por meio dos Sistemas de Informação em Saúde (Sistema de Informação da Atenção Básica SIAB e o Sistema de Informação Ambulatorial do SUS - SIA/SUS).

Esses resultados possibilitaram realizar o mapeamento do município de Teresina-PI, apresentando a quantidade de crianças cadastradas por região e zona, facilitando a identificação das áreas com maior e menor quantitativo de consultas, considerando a faixa etária de zero a cincos anos. Estabeleceu-se ainda a produção da Consulta de Enfermagem às crianças menores de cinco anos na rede de atenção básica para o ano de 2012, por meio de frequência simples da produção mensal das equipes. Esses dados possibilitaram a análise crítica da cobertura populacional da estratégia Saúde da Família, cotejando os dados do quantitativo populacional do censo 2010 realizado pelo IBGE. Permite-se inferir que, embora haja adequação do número de Equipes da estratégia Saúde da Família em relação à estimativa populacional, as Equipes não possuem o cadastro de indivíduos equivalente ao valor disponibilizado pelo IBGE.

Tal fato é evidenciado pela análise das Consultas de Enfermagem em menores de cinco anos, em que o cadastro de crianças remete ao quantitativo de 19.019, enquanto o IBGE descreve que o município de Teresina-PI detém de 59.337 crianças, no ano de 2012. Com base nestes dados, foi possível avaliar a abrangência da atenção básica por meio do número de Consultas de Enfermagem em relação às crianças menores de cinco anos cadastradas e a população referenciada pelo IBGE.

Por fim, pode-se compreender, a partir dos dados dos SIS, que o atendimento individual realizado pelo enfermeiro é seguido pela puericultura realizada pela Equipe da estratégia Saúde da Família, e a Visita domiciliar é realizada exclusivamente pelo enfermeiro à população adscrita a sua área. 


\subsection{Perfil sociodemográfico dos enfermeiros da rede de atenção básica}

O perfil sociodemográfico das sete enfermeiras que participaram do estudo e que trabalham nas UBS A e UBS B possibilita um aprofundamento acerca da natureza do cuidado à criança, evidenciando elementos que contribuam para este processo.

Investigando o perfil sociodemográfico dos enfermeiros que participaram do estudo, verificou-se que todos eram do sexo feminino e trabalham nos turnos manhã e tarde, dispostos na Figura 10, e segmentados por unidade básica de saúde pesquisada.

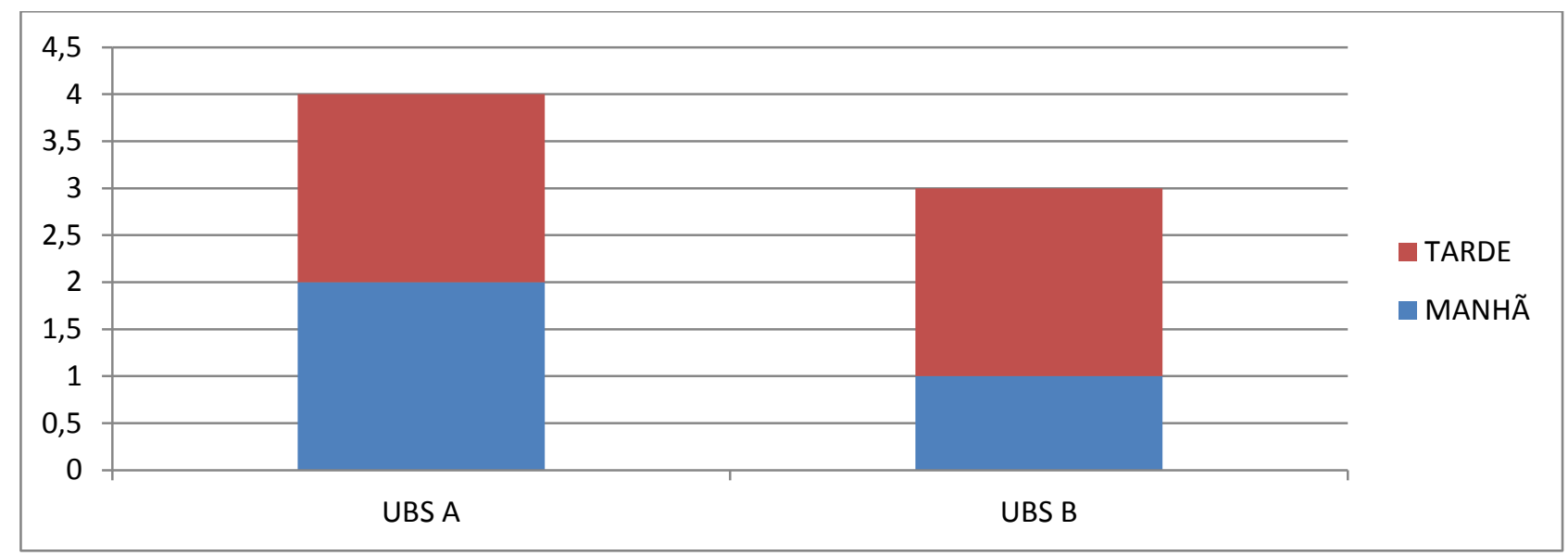

Figura 10. Turno de trabalho das enfermeiras por unidades básicas pesquisadas. Teresina-PI, 2016.

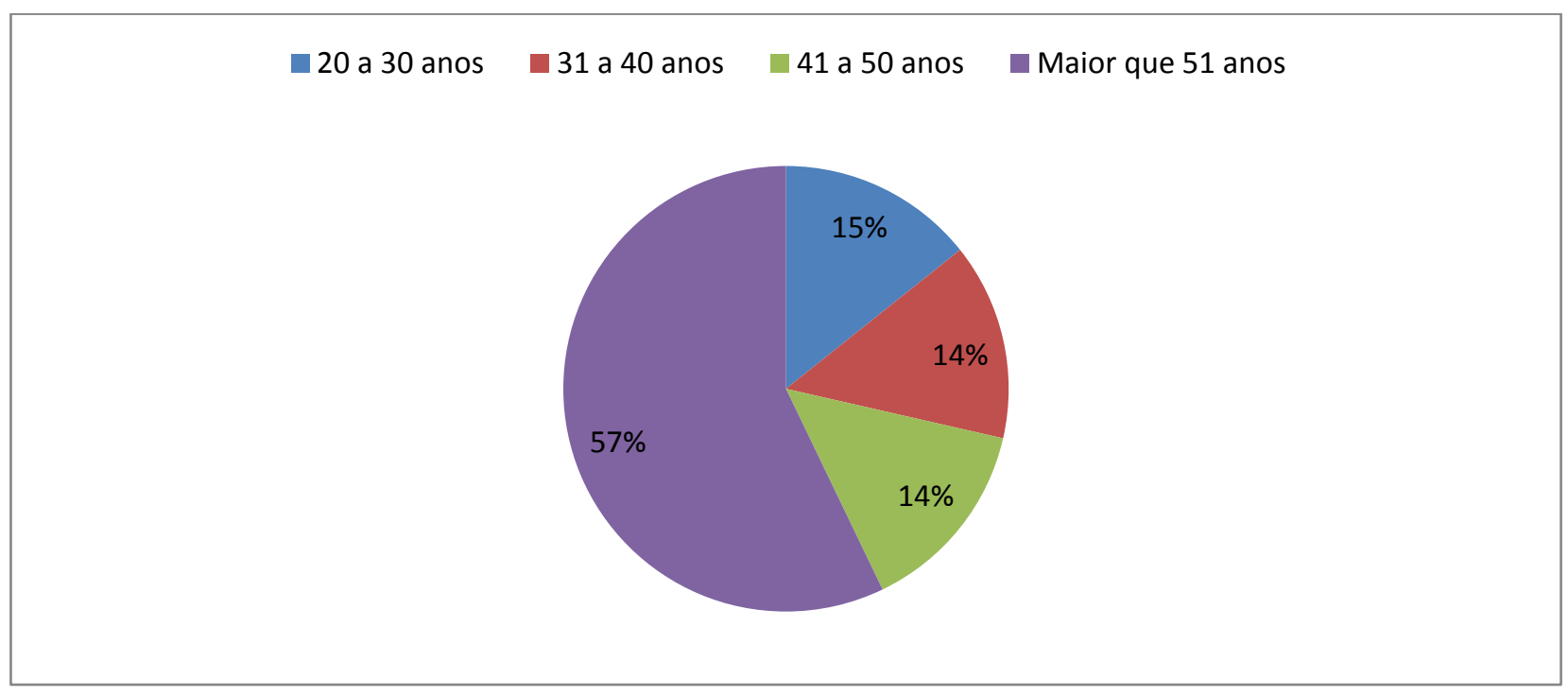

Figura 11. Idade das enfermeiras por unidades básicas de saúde pesquisadas (UBS A, B). Teresina-PI. 2016. 
A faixa etária predominante foi a superior de cinquenta e um anos, representando $57 \%$, resultado semelhante foi encontrado em relação ao Estado civil de casado.

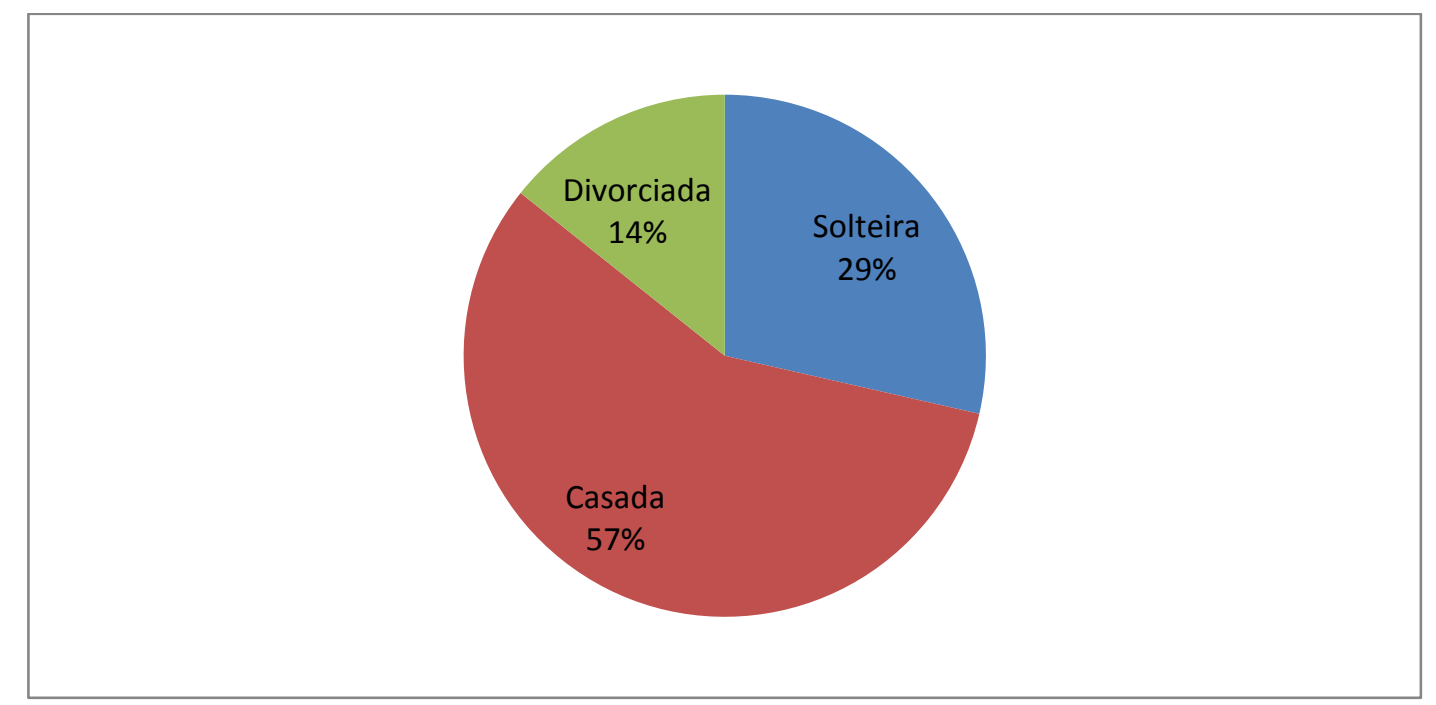

Figura 12 Estado civil das enfermeiras que trabalham nas unidades básicas de saúde pesquisadas. Teresina-PI. 2016.

O tempo de formação profissional na área variando entre 2 a 35 anos. Enquanto que houve maior predominância no tempo de serviço na estratégia Saúde da Família, superior a 10 anos. seis tinham naturalidade piauiense, sendo quatro naturais da capital e as demais do interior, as demais eram carioca e maranhense.

Todas eram especialistas, nas mais diversas áreas do conhecimento. A saber: saúde pública, saúde da família, educação profissional, terapia intensiva, terapias complementares, sistemas e serviços em saúde, médico cirúrgico, terapeuta naturalista e epidemiologia. Neste amostral, não havia mestre ou doutores. Em relação à atualização profissional, somente uma pessoa não possuía curso de quarenta horas nos últimos cinco anos.

Em um estudo desenvolvido por Corrêa Et al. (2012) sobre o perfil sociodemográfico dos enfermeiros de Cuiabá-MT, encontram-se resultados divergentes dos encontrados pela presente pesquisa. Reportam-se a enfermeiros do gênero masculino, com idade mais jovem. Em relação ao estado civil, observa-se a predominância de casados e a naturalidade do próprio estado cenário do estudo, houve semelhanças e aproximações com os resultados este estudo. 
Também na perspectiva do perfil sociodemográfico dos enfermeiros, Faria, David e Acioli (2012) revelam em um estudo realizado no Rio de Janeiro-RJ, que corroboram o estudo anterior, o qual descreve a participação do gênero masculino em grupo consideravelmente jovem.

Espindôla, Lemos e Reis (2011) convergem quanto à constatação das diferenças entre os resultados em discussão e os resultados dispostos em sua pesquisa, realizada no município de Anápolis-GO, onde o perfil dos enfermeiros apresentou ambos os gêneros e a faixa etária predominante foi dos 20-30 anos.

Dentre as pautas supracitadas, a feminilidade da enfermagem se destaca pela forte influência da figura da mulher como agente do cuidado, estando intimamente entrançada desde seus primórdios. Dessa forma, os autores Splendor e Roman (2003) explicam a grande quantidade de mulheres como força de trabalho da enfermagem. Por esta justificativa e pela absoluta presença de mulheres como sujeitos desta pesquisa, optou-se por caracterizá-las pelo gênero das discussões a seguir.

Corrêa et al. (2012) e Espindôla, Lemos e Reis (2011) divergem, apresentando um perfil de enfermeiras que, em sua maioria, formaram-se há menos de 5 anos, mas corroboram o presente estudo no que se refere à grande quantidade de profissionais com especialização e que participaram de cursos de capacitação nos últimos 4 anos.

Em relação à especialização, Faria, David e Acioli (2012) apresentam resultados semelhantes, contudo, registram que a contratação é do tipo temporária, o que diverge do estudo em questão, vez que optou-se por pesquisar somente enfermeiras efetivas, considerando ser esta uma força de trabalho genuína e duradoura.

Conhecer o perfil de quem cuida proporciona reflexões sobre suas práticas. As enfermeiras possuem um considerável tempo de trabalho e formação, e destacam-se por possuírem especialização e cursos capazes de contribuir em seu cotidiano. 


\subsection{Descrição da Consulta de Enfermagem e o registro em duas realidades distintas da atenção básica Teresinense}

Ao se optar por estudar duas realidades distintas (UBS A e B), faz-se necessário descrever como ocorre a Consulta, entendendo que suas divergências podem explicar suas características marcantes. Nesse intuito, instiga-se uma análise comparativa das duas unidades, pautando-se nas categorias e variáveis observadas e relatadas pelos participantes, a saber: processo de trabalho; tempo de duração da Consulta de Enfermagem; estrutura (física e equipamentos), instrumentos e recursos utilizados; participantes envolvidos na consulta; objetivos; procedimentos realizados; e temáticas abordadas durante a Consulta de Enfermagem.

Foram entrevistadas quatro enfermeiras na UBS A e três enfermeiras entrevistadas na UBS B. A UBS A é localizada no bairro Vale quem tem, e segundo Silva Junior (2014) possui uma população que representa cerca de $2,62 \%$ da cidade de Teresina, sendo que $72 \%$ das pessoas vivem com renda mensal de até um salário mínimo. A taxa de alfabetização da população com dez ou mais anos de idade é igual a 92,7\% em 2010, e tem o comércio como importante atividade econômica, $52 \%$, seguida pela prestação de serviços, $27 \%$. A UBS B está localizada no bairro vermelha, e em 2010, tinha uma população que representava $0,74 \%$ de Teresina, sendo que 59\% possuíam renda mensal de até um salário mínimo. Possui taxa de alfabetização de $96,6 \%, 62 \%$ trabalham no comercio, seguido de $26 \%$ com serviços prestados.

Sobre a estrutura física e equipamentos, a UBS A apresenta uma estrutura física que atende parcialmente à estrutura física mínima, sendo composta por: consultório médico; consultório de enfermagem; ambiente de armazenamento e dispensação de medicamentos; sala de coleta de exames para laboratório; sala de vacina; banheiro público e banheiro exclusivo para funcionário; expurgo; cozinha; sala de procedimentos e consultório odontológico. Esta unidade básica de saúde dispõe de balança e antropômetro infantil. Os Consultórios de Enfermagem são individualizados por equipe Saúde da Família, dispõem de piso e paredes laváveis, possui pia com água e dispensador de sabão, luz branca e ventilação adequada com ruídos controlados, com mesas e cadeiras adequadas para a Consulta de Enfermagem à criança. Dentro do consultório, é possível encontrar maca e instrumentos básicos para o exame físico da criança. Entretanto, não dispõe de desenhos, brinquedos ou decoração educativa voltada para o público infantil. Não possui também placas nas portas 
identificando o Consultório com informações que contemplem a equipe com logomarcas do Sistema Único de Saúde (SUS) e a Estratégia Saúde da Família (ESF).

A estrutura física da UBS B é semelhante à UBS A. Possui balança e antropômetro infantil além de consultórios individualizados por equipe com identificação do número da equipe, nome da enfermeira, turno de trabalho e as logomarcas do Sistema Único de Saúde (SUS) e a Estratégia Saúde da Família (ESF). Nestes consultórios, as paredes e pisos são laváveis, havendo luz branca e ventilação adequada, possuem pia com água e dispensador de sabão, mesas, cadeiras, maca e instrumentos básicos para o exame físico infantil. Os Consultórios possuem desenhos, brinquedos e decoração voltados para o público infantil com teor informativo e educacional.

As duas unidades básicas estudadas apresentam parcialmente a estrutura mínima, atendendo parcialmente ao proposto pelo MS, e necessária para o desenvolvimento da Política Nacional da Atenção Básica-PNAB, incluindo recursos materiais (SAPAROLLI; ADAMI, 2010; BRASIL, 2000). Estando de acordo também com Ribeiro, Ohara e Saparolli (2009).

Os processos de trabalhos das duas unidades básicas de saúde possuem características distintas: enquanto as enfermeiras da 'UBS A' apresentam cadastro atualizado com o número de crianças assistidas pela equipe, a organização do atendimento segue tanto um agendamento semanal como base o perfil populacional, quanto à demanda espontânea. Em contrapartida, as enfermeiras da 'UBS B' apresentam cadastro desatualizado e o atendimento ocorre a partir da demanda espontânea, ou seja ocorre o atendimento à livre demanda durante todos os dias da semana, sem agendamento prévio visando priorizar grandes áreas ou programas como saúde da criança, saúde da mulher, HIPERDIA por dias da semana.

Na discussão sobre a demanda espontânea na estratégia da atenção básica, autores como Farias e Campos (2012) contribuem apresentando resultados que conferem o excesso que ocorre com a demanda espontânea como algo motivado não somente pela procura da população pelos serviços de saúde, mas também pela desestruturação do planejamento que ocorre entre as equipes que trabalham na unidade básica de saúde. Nessa realidade, a porta de entrada possui consideráveis entraves burocráticos, dinamizando a atenção básica centrada do médico, com um acolhimento que realiza triagem de doenças e não como organizador do processo de trabalho das equipes.

Metade das enfermeiras que trabalham na 'UBS A' revelam não priorizar nenhum grupo de risco no atendimento à criança, e na 'UBS B' somente uma não realiza atendimento com prioridade. Nos relatos das enfermeiras da 'UBS B' foi possível perceber um acolhimento mais sistematizado, por meio de ações como escuta qualificada, avaliação das 
necessidades de saúde, classificação de risco e análise de vulnerabilidade, enquanto que na 'Unidade A' somente uma enfermeira relatou realizar no acolhimento a avaliação das necessidades de saúde. Isto demostra que embora seja uma unidade com o perfil de demanda espontânea, a equipe encontra-se mais receptiva e preparada para o acolhimento dos pacientes que a procuram.

Para Rebello, Koopmans e Romano (2012), o acolhimento constitui um grande desafio, em virtude da necessidade de transgredir ao local da recepção da demanda espontânea, devendo compreender ainda uma relação afetuosa, incorporando sentido como uma passagem para o acolhimento nos processos de saúde e produção de cuidado.

O MS discute o acolhimento à demanda espontânea no volume I e II dos cadernos de atenção básica de $n^{\circ} 28$. Neles, são destacados que o cuidado à demanda espontânea é fundamentado nos princípios e diretrizes do acolhimento e da escuta qualificada, a fim de potencializar sua resolutividade por meio de uma gestão reflexiva e de boas práticas, respeitando a humanização dos serviços de saúde, propiciando a construção de vínculos entre a população e a equipe Saúde da Família. Dessa forma, a atenção primária contribui sendo entendida como a porta de entrada dos serviços de saúde do Sistema Único de Saúde (BRASIL, 2012).

Houve maior predominância de Consultas de Enfermagem assistemáticas nos dois casos em estudo. Quanto aos casos referidos como sistemáticos (utilizando como padrão a Sistematização da Assistência de Enfermagem), a UBS A apresentou um caso, descrevendo as etapas, a saber: histórico, diagnóstico de enfermagem e implementação. Caso idêntico quando comparado com uma enfermeira pertencente à UBS B, nesta mesma unidade encontrou-se uma segunda enfermeira que afirma praticar todas as etapas da Sistematização da Assistência de Enfermagem durante a Consulta de Enfermagem à criança em seu cotidiano na atenção básica.

Este último decorre preconizado pela Fundação Municipal de Saúde de Teresina-PI, onde se estima que a Consulta de Enfermagem englobe a particularidade da sistematização, envolvendo uma avaliação mais completa (BRASIL, 2012). A situação que compreende a “consulta sistemática parcial” descrita anteriormente não contempla a Resolução No358 do Conselho Federal de Enfermagem, que prevê as cinco etapas: Histórico ou coleta de dados; diagnóstico de enfermagem; planejamento de enfermagem; implementação e avaliação, a serem implementadas no âmbito da atenção básica com a criança.

Em termos de semelhança, ao comparar as duas unidades básicas de saúde em estudo, destaca-se a participação do enfermeiro em seu processo de trabalho, no que se refere à 
solicitação de exames complementares e prescrição de medicamentos conforme protocolo da Fundação Municipal de Saúde. Em relação ao registro em prontuário, a maioria refere realizar registros caracterizados como "básico", entretanto, na UBS A, uma enfermeira afirma ser detalhada neste momento. Ao contrário disso, na outra unidade de saúde em estudo, duas enfermeiras afirmam ser simplificado e a terceira relaciona a necessidade da informação como fator decisivo no momento do registro do prontuário.

Com base no Protocolo da Fundação Municipal de Saúde de Teresina-PI, o enfermeiro no âmbito da Consulta à Criança na atenção básica pode solicitar os exames de: hemograma, parasitológico de fezes e exame de urina rotina 1 ou EAS. Os medicamentos que podem ser prescritos, incluem: paracetamol de $200 \mathrm{mg} / \mathrm{ml}$; dipirona gota $500 \mathrm{mg} / \mathrm{ml}$; benzoato de benzila a 25\%-loção; permetrina a 1\%- loção; permanganato de potássio- tópico; nistatina oral; nistatina creme/ cetoconazol creme; sais de reidratação oral; solução fisiológica nasal; sulfato ferroso gotas ou suspensão; vitamina A; mebendazol; metronizadol e albendazol (BRASIL, 2012).

As enfermeiras relataram o tempo de duração da Consulta de Enfermagem, nas duas unidades analisadas, conforme apresentado na Figura 13

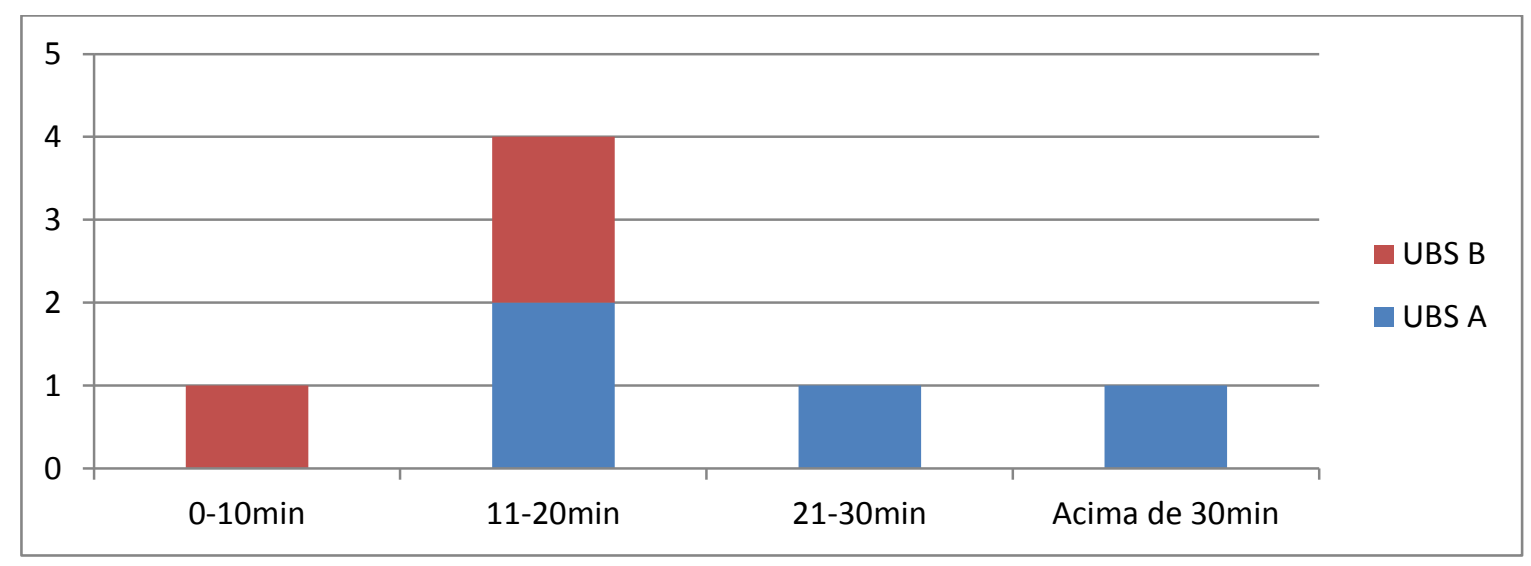

Figura 13. Duração da Consulta de Enfermagem relatada pela enfermeira das unidades básicas em estudo. Teresina, 2016.

Na figura 13 é possível perceber a distinção que ocorre entre as Consultas das UBS A e B. Enquanto na UBS B prevalece o tempo médio de Consulta de Enfermagem menor que vinte minutos, na unidade oposta, esta duração ocorre em tempo superior aos vinte minutos, caracterizando, assim, perfis distintos. 
Em sua maioria, os enfermeiros relataram que a duração de Consulta com uma criança é feita após elas terem sido pesadas e medidas. Dois enfermeiros relatam realizar o procedimento de mensuração das medidas antropométricas das crianças na Consulta, os demais delegam este procedimento ao técnico de enfermagem ou agente comunitário de saúde.

O MS, em que a Consulta de Enfermagem na atenção básica deve ter em média a duração de vinte minutos, perfazendo cerca de três consultas por hora (OLIVEIRA Et al., 2012; BRASIL, 2006); autores como Ribeiro, Ohara e Saparolli (2009) apontam temporalidade prevista em virtude do tipo de Consulta de Enfermagem a ser prestada. Neste ponto de vista, a primeira consulta deve ocorrer em cerca de sessenta minutos; o retorno em trinta minutos; consultas de emergência de quinze a trinta minutos; consulta de avaliação específica aproximadamente quinze minutos.

Em relação à equipe, existe uma diferença significativa: na UBS A houve maior predomínio do técnico de enfermagem como acompanhante do enfermeiro na consulta, havendo somente uma enfermeira com estagiário de enfermagem. Diferentemente, na UBS B, a predominância foi do estagiário de enfermagem, realizando a coparticipação na Consulta, em relação aos técnicos de enfermagem que compõem a equipe Saúde da Família. Em ambos os casos, os estagiários referidos são do curso de bacharelado em Enfermagem.

Em relação ao acompanhamento das mães, o papel materno é correlacionado com a alimentação, em outras palavras: o aleitamento, os laços alimentares e de cuidados nos primeiros anos de vida se estreitam, fazendo com que a mãe seja considerada como principal ser cuidadora. Em convergência, a condição materna é tida como essencial, genuína, importante e indispensável para o cuidado de crianças (CORRÊA, et al., 2009; SOARES; COELHO, 2008).

Para Boehs et al. (2011) a percepção dos profissionais que compõem a equipe Saúde da Família sobre o cuidado materno com seus filhos menores de seis anos, decorre do fato de recorrerem ao setor popular, entretanto, a equipe ressalta uma maior dependência das mesmas com o serviço de saúde, disponibilizado na atenção básica, que oportuniza o aprendizado de cuidados básicos voltados para a criança, bem como a medicalização de seus problemas de saúde.

A presença de estudantes de enfermagem na atenção básica é reportado por estudiosos como Araújo et al. (2013) que referenciam a percepção dos demais trabalhadores sobre a parceria em construção do ensino-serviço. Além do sentimento de desvalorização destes trabalhadores, ocorrem modificações na dinâmica de trabalho tornando-a mais onerosa em sua 
temporalidade, requerendo, portanto, mais tempo para realizar atividades habituais. $\mathrm{O}$ questionamento é marco significativo do discente, que indaga acerca da rapidez das práticas realizadas no cotidiano da atenção básica.

Contudo, quanto se trata de atribuições dos membros da equipe Saúde da Família segundo a Política Nacional da Atenção Básica (BRASIL, 2012) existem funções comuns e pertinentes a todos os membros, que englobam uma dimensão de trabalho em equipe em prol do cuidado a uma população adscrita, cabendo ao profissional, o técnico de enfermagem, que compõem a equipe, o desenvolvimento das demais implicações específicas a sua área, produzindo, assim, sua singularidade.

O processo de trabalho dos técnicos de enfermagem na atenção básica objetiva, ainda, atender usuários deste serviço, no intuito do enfrentamento às doenças ou problemas de saúde, havendo necessidade de maximizar algumas potencialidades (CARDOSO Et al., 2011).

No tocante aos objetivos da Consulta de Enfermagem relatados pelas enfermeiras na UBS A, a figura 11 apresenta os resultados que pautam os objetivos, considerando o propósito profissional individual e singular de cada profissional. Ocorreu predominância dos seguintes objetivos: promoção da saúde e prevenção de doenças (Política Nacional da Atenção Básica) e o cadastro ou atualização dos dados da criança frente ao programa de auxílio financeiro governamental: Bolsa família, na garantia da continuidade do recebimento deste benefício. Em contrapartida, na unidade com menor produção de Consultas de Enfermagem não houve diferenças entre os objetivos, mas destaca-se que não houve relato das enfermeiras sobre o objetivo da Consulta de Enfermagem em relação ao retorno/continuidade. 


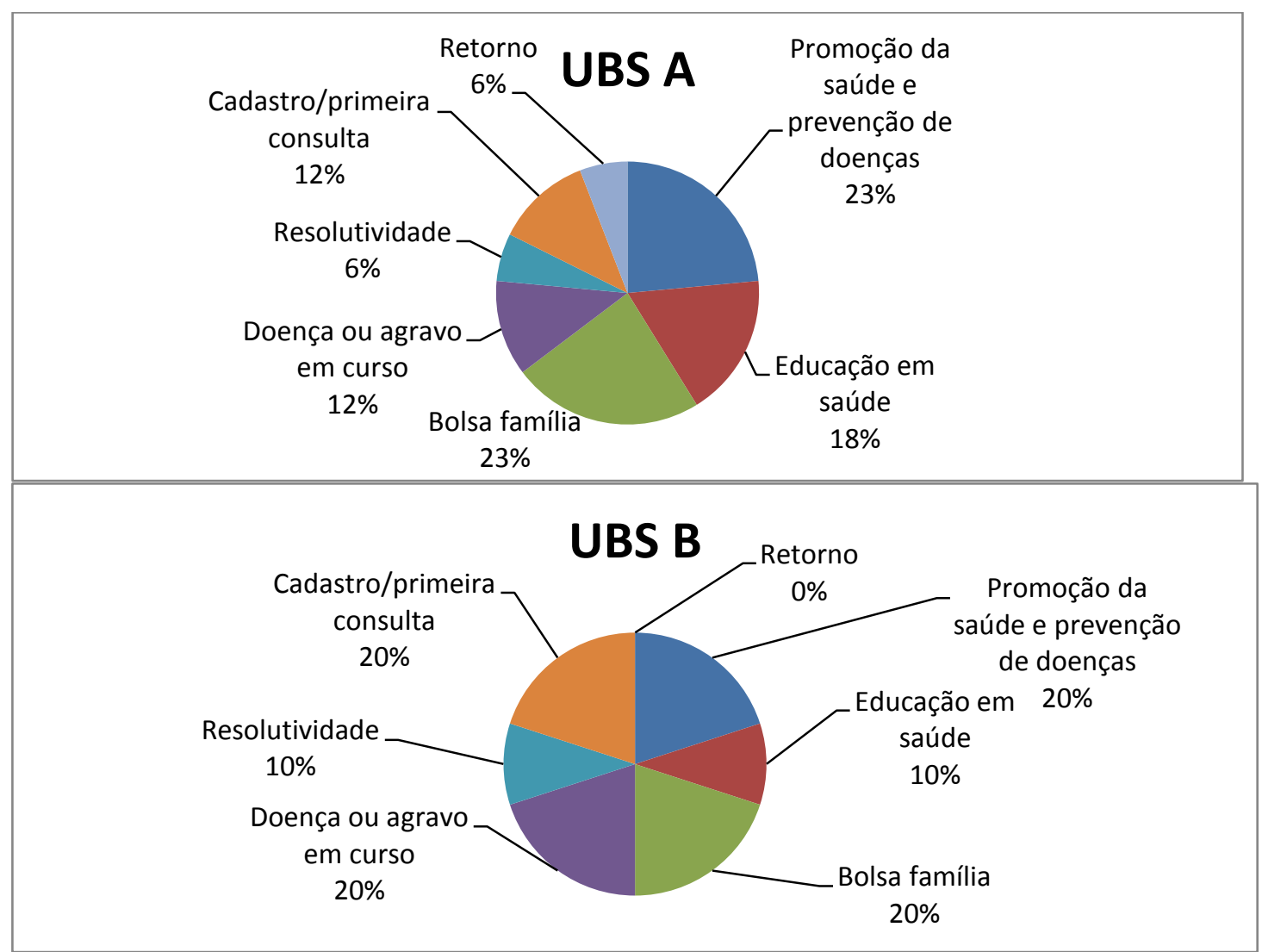

Figura 14. Objetivos das Consultas de Enfermagem segundo as enfermeiras das unidades pesquisadas de Teresina-PI, 2016.

O destaque para os objetivos: "Promoção da saúde e prevenção de doença" advém do contexto da atenção básica dentro da Política Nacional da Saúde em um sentido mais amplo de saúde que engloba práticas de cuidado e gestão no âmbito individual e coletivo, com garantia de resolutividade e organização dos serviços de saúde (BRASIL, 2012).

Autores como Moura e Rocha (2012) articulam as dimensões do cuidado à criança com os saberes e práticas das ações que envolvem a promoção da saúde e a prevenção de doença na atenção básica, entendendo-as como parte do referencial concedido ao enfermeiro em seu cotidiano do cuidado prestado à criança.

O programa de auxílio de renda denominado "Bolsa família" está envolvido com a Política Nacional da Atenção Básica por meio das atribuições dos agentes comunitários da saúde. Estes devem desenvolver ações que estabeleçam vínculos e contato permanentes com as famílias de sua área, considerando a proposta da Política supracitada. O agente comunitário de saúde deve considerar não somente o referido programa, mas qualquer outro programa similar de transferência de renda ou enfrentamento de vulnerabilidades proposta pelo governo federal, estadual ou municipal. O retorno ou continuidade do cuidado é oportunizado por meio de um processo de trabalho que estabeleça vínculo entre usuários e profissionais. Considerado 
de extrema importância enquanto princípio orientador, o retorno ou continuidade do cuidado deve ocorrer com integralidade dentro da proposta Nacional da Atenção Básica (BRASIL, 2012).

Em outro aspecto pesquisado, a figura 12 descreve os procedimentos realizados ou relatados pelos enfermeiros na Consulta de Enfermagem e as respectivas ocorrências nas duas unidades em estudo.

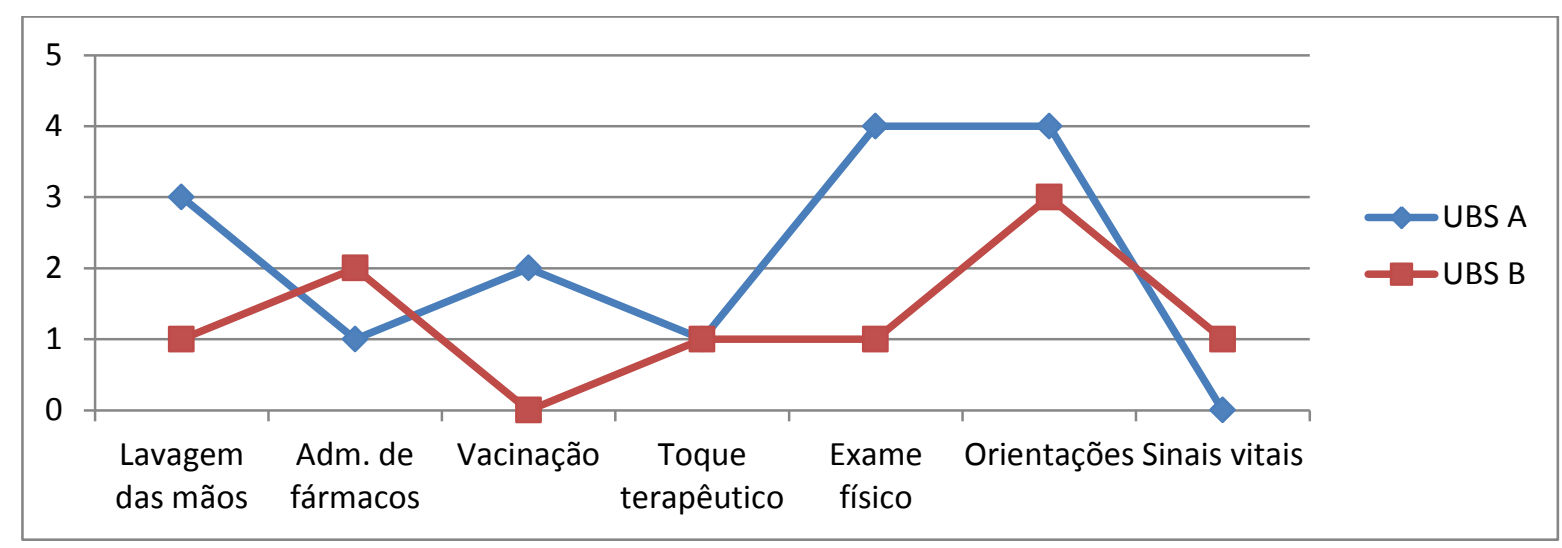

Figura 15. Procedimentos relatados pelos enfermeiros na prática Consulta de Enfermagem, 2016.

Neste item, destacam-se na UBS A: o exame físico e as orientações repassadas à mãe/criança seguindo o protocolo proposto pela Fundação Municipal de Saúde, não havendo relatos de verificação dos sinais vitais das crianças. Por outro lado, na UBS B, as orientações também prevaleceram em detrimento do quesito vacinação à criança.

O comportamento expresso na Figura 12 apresenta as especificidades de cada unidade pesquisada, entretanto, somente as orientações às mães estão presentes nas duas unidades. Os demais procedimentos fazem parte do cuidado de enfermagem à criança, mais apresentam-se próximos ou distintos nos casos apresentados.

As temáticas abordadas durante a Consulta de Enfermagem estão dispostas na figura 13, que apresenta o comparativo entre as unidades estudadas. 


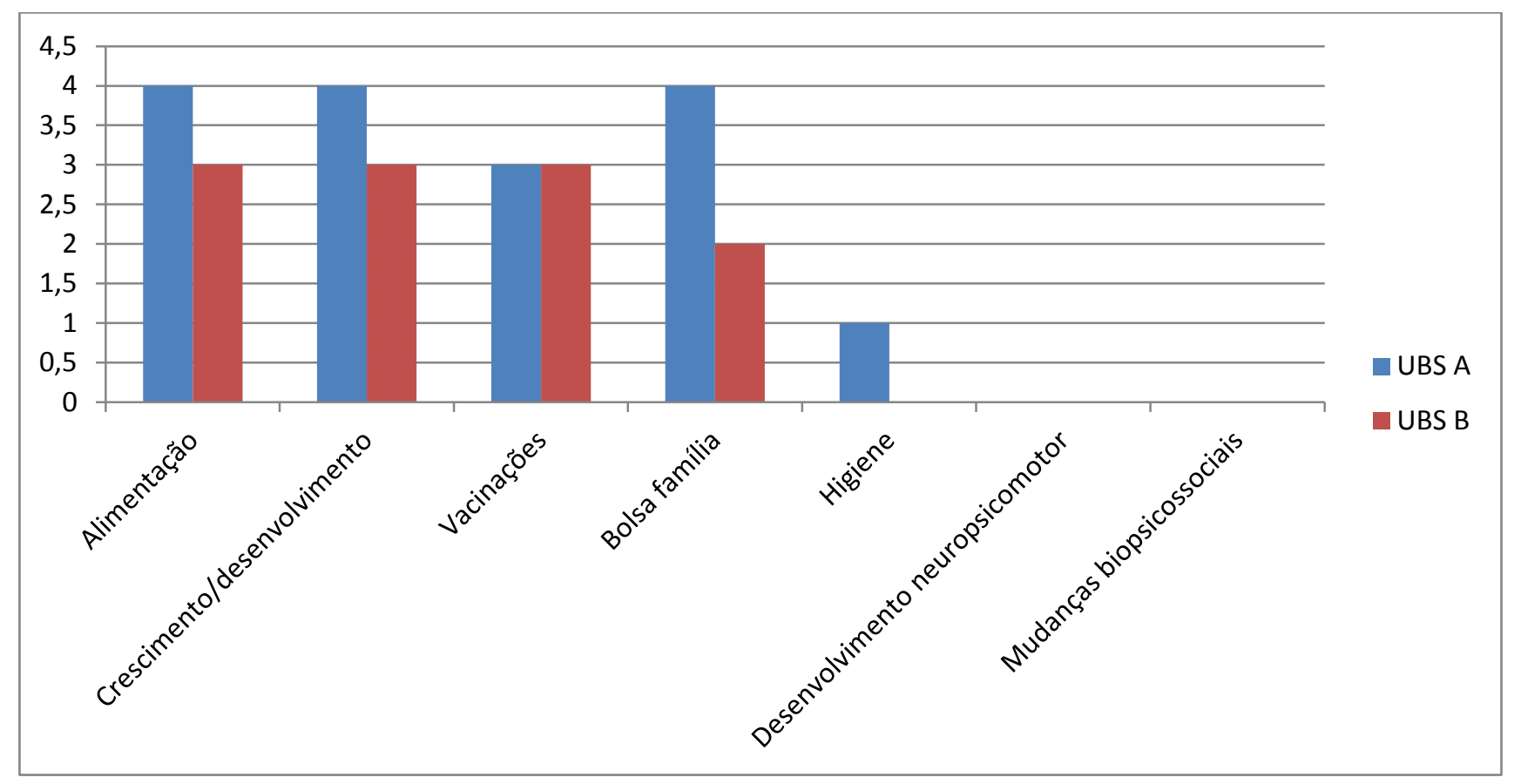

Figura 16. Comparativo entre as temáticas abordadas durante a Consulta de Enfermagem nas duas unidades básicas de saúde estudadas. Teresina, 2016.

Entre as temáticas conversadas durante a Consulta de Enfermagem, ressalta-se que não houve nenhum registro sobre mudanças biopsicossociais da infância e desenvolvimento neuropsicomotor da criança. Isto representa um importante vazio de conhecimento sobre esta área inexplorada pela enfermagem.

Em um estudo desenvolvido por Martins et al. (2013b), constatou-se a deficiência que existe no acompanhamento do desenvolvimento neuropsicomotor da criança na atenção básica. Isto decorre da ausência da padronização do registro no cartão da criança, que se apresenta incompleto, ausente, repercutindo na não integralidade do cuidado à criança em sua avaliação e na continuidade.

O Quadro 5 apresenta uma síntese das principais diferenças encontradas na descrição da Consulta de Enfermagem nas duas unidades de referência deste estudo. 
Quadro 5. Síntese comparativa da descrição da Consulta de Enfermagem nas unidades pesquisadas em Teresina-PI, 2016.

\begin{tabular}{|c|c|c|}
\hline $\begin{array}{l}\text { Unidades } \\
\text { Categorias } \\
\text { analisadas }\end{array}$ & UBS A & UBS B \\
\hline $\begin{array}{ll}\text { Estrutura (física } & \mathrm{e} \\
\text { equipamentos), } & \\
\text { instrumentos } & \mathrm{e} \\
\text { recursos observados } & \end{array}$ & $\begin{array}{l}\text { Estrutura física parcialmente } \\
\text { atendida conforme preconizado. } \\
\text { Possui limitações quanto à: } \\
\text { adequação das paredes, instrumentos } \\
\text { e desenhos, brinquedos e decoração } \\
\text { infantil. }\end{array}$ & $\begin{array}{l}\text { Estrutura física parcialmente } \\
\text { atendida conforme preconizado. } \\
\text { Possui identificação nas portas e } \\
\text { desenhos, brinquedos e decoração } \\
\text { infantil. }\end{array}$ \\
\hline $\begin{array}{l}\text { Processo de trabalho } \\
\text { relatado }\end{array}$ & $\begin{array}{l}\text { Atendimento agendado e demanda } \\
\text { espontânea. Acolhimento restrito. }\end{array}$ & $\begin{array}{l}\text { Somente demanda espontânea. } \\
\text { Acolhimento mais amplo. }\end{array}$ \\
\hline $\begin{array}{l}\text { Relato da duração da } \\
\text { Consulta }\end{array}$ & $\begin{array}{l}\text { Tendência para temporalidade } \\
\text { superior a } 20 \text { minutos. }\end{array}$ & $\begin{array}{l}\text { Tendência para temporalidade } \\
\text { inferior a } 20 \text { minutos. }\end{array}$ \\
\hline $\begin{array}{l}\text { Participantes da } \\
\text { Consulta relatados }\end{array}$ & $\begin{array}{l}\text { Exclusivamente a mãe. } \\
\text { Predominância da participação do } \\
\text { técnico de enfermagem. }\end{array}$ & $\begin{array}{l}\text { Exclusivamente a mãe. } \\
\text { Predominância da participação do } \\
\text { estagiário de enfermagem. }\end{array}$ \\
\hline $\begin{array}{l}\text { Objetivos da Consulta } \\
\text { relatados }\end{array}$ & $\begin{array}{l}\text { Compreende todos os preconizados } \\
\text { pela Política Nacional da Atenção } \\
\text { Básica. }\end{array}$ & Não inclui o retorno do paciente. \\
\hline $\begin{array}{l}\text { Procedimentos } \\
\text { relatados }\end{array}$ & $\begin{array}{l}\text { Destaque para exame físico e } \\
\text { orientações. } \\
\text { Não houve relatos de mensuração } \\
\text { dos sinais vitais. }\end{array}$ & $\begin{array}{l}\text { Destaque para orientações e } \\
\text { administração de medicamentos. } \\
\text { Não houve relatos de vacinação. }\end{array}$ \\
\hline Temática relatada & Menor variedade de temas. & Maior variedade de temas. \\
\hline
\end{tabular}

O Quadro 5 expõe as principais aproximações e distanciamentos que existem nas unidades básicas de saúde com maior e menor produção de Consulta de Enfermagem a criança menor de cinco anos.

Das sete categorias analisadas, duas apresentam aproximações: a estrutura física parcialmente atendida conforme o preconizado pelo Ministério da Saúde e a presença da mãe como principal acompanhante da Consulta de Enfermagem à criança. Estas aproximações representam fatores limitantes tanto dos órgãos públicos que provem a estrutura mínima como da participação de outros integrantes da família no cuidado à criança. Contudo ressalta-se que estas duas peculiaridades não repercutem diretamente no quantitativo da produção de Consulta de Enfermagem a criança menor de cinco anos. 
Em relação aos demais aspectos avaliados que se apresentam de forma antagônica nas duas unidades, infere-se destacando que essas características distintas formam um arcabouço que justificam a qualidade das unidades básicas em serem maior e menor produtoras de Consulta de Enfermagem à criança. 


\subsection{Representações sociais das enfermeiras sobre a Consulta de Enfermagem à criança na atenção básica de Teresina- PI}

Para desvelar as representações sociais elaboradas por enfermeiras sobre a Consulta de Enfermagem à criança na rede de atenção básica de Teresina-PI, os dados foram transcritos e organizados em um corpus de texto. Esse corpus foi processado no software e apresentado segundo a Classificação Hierárquica Descendente, que representa uma organização que considera a relação das classes semânticas, as quais se atribuem seus respectivos sentidos, originado de seus saberes e práticas vivenciadas no cotidiano da Consulta de Enfermagem à criança na atenção básica, pelos grupos de enfermeiros participantes.

\subsubsection{Organização do campo representacional}

O software IRAMUTEQ gerou o dendograma de Classificação Hierárquica Descendente das classes do corpus que ilustra a relação entre as classes existentes. O corpus foi dividido em duas partições (subcorpus) e sequencialmente por mais duas na primeira partição, portanto, essas partições originaram cinco classes. Na primeira partição, assim como na segunda, foram formadas as cinco classes, de modo que as classes 5, 2, 3 e 4 tiveram maior proximidade de conteúdo. No entanto, as classes 4 e 5 tiveram maiores valores de $x^{2}$ (quiquadrado), o que representa uso de palavras de maior significância no corpus do texto, registra-se que as classes 2 e 5 tiveram maior quantidade de segmentos de textos, o que significa maior abrangência.

As classes foram nomeadas de acordo com a semelhança das ideias em relação às palavras analisáveis que dão sentido, nas UCEs: Classe 1 - A base legal da consulta - O protocolo; Classe 4 A dimensão técnica da consulta - tecnologia para o cuidado; Classe 3 As dimensões sócio-afetivas da consulta - o vinculo; Classe 2 - O espaços social da consulta - o acolhimento; e Classe 5 - A consulta como espaço de poder - a autonomia profissional.

Nesse sentido, as palavras analisáveis foram distribuídas nas cinco classes, da seguinte forma: Classe 1, com 13 UCEs e 22 palavras analisáveis, correspondente a 18,8\%; Classe 4, com 16 UCEs e 29 palavras analisáveis, correspondente a 23,2\%; Classe 3, com 11 UCEs e 18 palavras analisáveis, que corresponde a 15,9\%; Classe 2, com 13 UCEs e 26 palavras analisáveis, correspondente a 18,8\% das UCEs; e a classe 5 com 16 UCEs e 24 palavras analisáveis, equivalente a 23,2\% do total das UCEs. (Figura 17). 


\section{Representações sociais das enfermeiras sobre a Consulta de Enfermagem à criança na} atenção básica de Teresina- PI

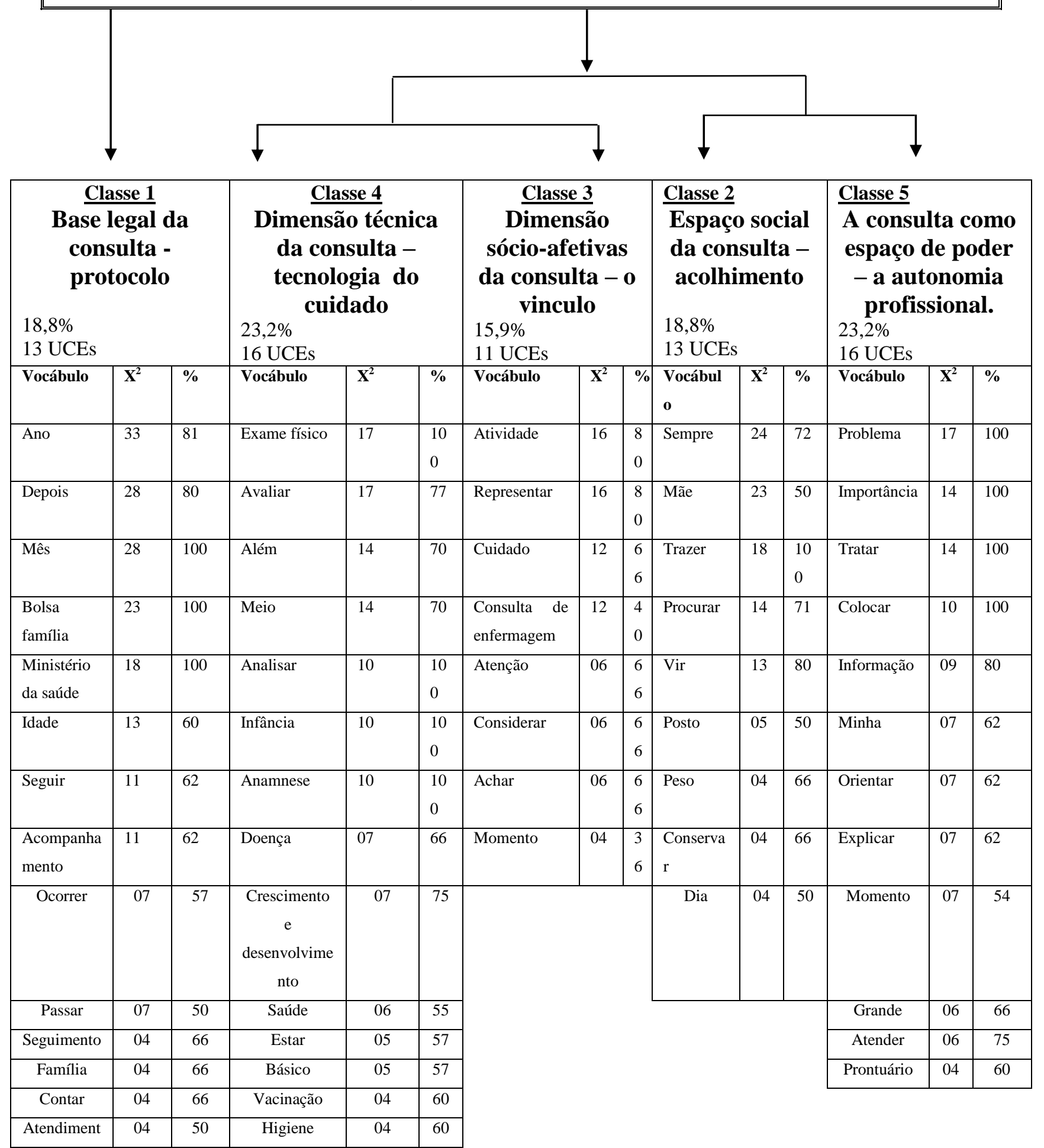

Figura 17. Dendograma das classes.

Fonte: Relatório Iramuteq, 2016. 


\subsubsection{Descrição do conteúdo das classes}

\subsubsection{CLASSE 1: Base legal da consulta - protocolo}

A Classe 1 é constituída de 13 segmentos de textos (UCEs), com 22 palavras analisáveis, correspondente a $18,8 \%$ (Figura 17). Trata-se de classe importante e independente, não se articulando com as demais diretamente. Observa-se que nesta classe, o depoimento que apresentou maior quantidade de segmentos foi o depoimento da enfermeira 01 (suj_1). Os vocábulos mais significativos são: ano, depois, mês, bolsa família e Ministério da Saúde, com o $x^{2}$ respectivamente de: 33, 28, 28, 23 e 18 (figura 18).

Este conjunto de vocábulos formam as representações sociais dos enfermeiros sobre o cotidiano da Consulta de Enfermagem à criança na atenção básica, tendo como característica principal o PROTOCOLO. Para Moscovici (2011), as representações sociais evidenciam as interações interpessoais, construídas no decurso da comunicação e da cooperação entre indivíduos, o que constitui uma realidade social. Em um maior aprofundamento, o referido autor destaca que, quando se estudam as representações sociais, estuda-se o ser humano enquanto ser questionador, que pensa, compreende, e não quando ele processa a informação ou se comporta. Em síntese, as representações sociais devem ser estudadas como um meio de compreender e comunicar o que anteriormente se forma ao longo de uma construção.

Na Classe 1, retrata-se o respaldo legal para o exercício da Consulta de Enfermagem à criança na atenção básica. Pauta-se nos protocolos, que se inicia na primeira semana de vida do recém-nascido com a visita domiciliar puerperal, seguida pelos retornos e novas consultas na unidade básica de saúde, com frequência periódica dependente da faixa etária a ser atendida, contemplando, também, as atualizações semestrais do Programa Bolsa Família, e, por último, finalizado pela continuidade no seguimento da adolescência. Em outras palavras, são utilizados os protocolos: 1) Visita puerperal e Primeira Semana de Vida; 2); Consultas à criança e retornos; 3) Programa Bolsa Família; e 4) Consulta ao adolescente.

Inicialmente, o retorno aos binômios mãe e filho à comunidade em que vivem marca o início da Consulta de Enfermagem à criança na atenção básica, partindo dos princípios que cercam a primeira semana de vida da criança e a visita domiciliar puerperal. Entrançada com os cuidados maternos, a visita domiciliar puerperal proporciona um cuidado especial para as crianças, pois se trata de um momento de muitas expectativas e mudanças. Esta visita marca 
também o início de um calendário o ser seguido pela criança, que contará com o retorno da mesma na unidade básica de saúde, proporcionando uma familiarização entre a criança e a estratégia Saúde da Família.

A consulta de enfermagem à criança começa na visita domiciliar de puerpério que ocorre nos sete primeiros dias depois do parto, nela ocorrem orientações fundamentais, além de explicações sobre higiene da criança e o uso somente de álcool a 70 no coto umbilical (Enfermeira B2).

Nesta ocasião marcamos o retorno da criança e da mãe no consultório de enfermagem com um mês e damos continuidade seguindo o calendário básico do Ministério da Saúde de acordo com a idade da criança (Enfermeira A1).

As depoentes B2 e A1 retratam um cotidiano em comum, repleto de cuidados à criança desenvolvidos na rotina de acompanhamento pela enfermagem, que mesmo em diferentes contextos, em domicílio ou na unidade básica de saúde, contempla o proposto pelo Ministério da Saúde.

No que se refere à atenção ao recém-nascido, o Ministério da Saúde (BRASIL, 2012e) destaca os seguintes princípios assistenciais do cuidado: qualidade, integralidade, resolutividade, continuidade com responsabilização; formação de vínculos entre profissional de saúde e usuário; promoção da saúde e prevenção de doenças; integração; acolhimento; abordagem de risco e vigilância à saúde. Na vigilância à saúde do recém-nascido, destacam-se as seguintes ações, tendo em vista o objeto deste estudo: continuidade do cuidado nos serviços de saúde, ou seja, captação do recém-nascido pela atenção básica de saúde após alta hospitalar, por meio de visita domiciliar; visita domiciliar na primeira semana após o parto, com avaliação global e de risco da criança, apoio ao aleitamento materno e encaminhamento para à Primeira Semana Saúde Integral na atenção básica de saúde (abordagem global da criança e da mãe na atenção básica); e manutenção do calendário de consultas à criança conforme o preconizado pelo Ministério da Saúde ou de acordo com as necessidades.

A Primeira Semana Saúde Integral, segundo o MS (BRASIL, 2005a; 2005b) afirma que os profissionais da saúde devem dedicar um interesse especial na avaliação das condições de saúde da mãe e da criança, aproveitando a oportunidade para promover o incentivo ao aleitamento materno e apoio às dificuldades encontradas. Além de realizar cuidados como 
aplicação de vacinas na mãe e na criança, agendamento das consultas no pós-parto e acompanhamento do bebê. Todos os recém-nascidos deverão ser acolhidos pelas unidades básicas de saúde na primeira semana de vida, para a checagem dos cuidados essenciais.

A primeira semana de vida e atuação no pré-natal representam situações especiais que podem facilitar a adesão das orientações e cuidados prestados ao binômio mãe e filho. É na primeira semana que surgem dúvidas, inseguranças e questionamentos das famílias, sendo esse período precioso para a atuação da equipe, de modo que seus profissionais possam ser reconhecidos como um ponto de apoio para a superação dessa etapa. No entanto, ressalta-se que o foco da atenção de todos os profissionais é o binômio mãe-bebê, dessa forma, ambos se beneficiarão do cuidado integral e multiprofissional na Primeira Semana Saúde Integral (BRASIL, 2005a).

Em Teresina, o protocolo de enfermagem na atenção à saúde da criança tem como meta garantir a assistência a todos os recém-nascidos na primeira semana de vida, por meio da visita domiciliar, identificando os fatores de risco para morbimortalidade infantil com o seu respectivo acompanhamento, além de monitorar o cumprimento do calendário mínimo de consultas destinadas à criança (ALMEIDA, et al., 2012).

Nessa perspectiva, as ações desenvolvidas na primeira semana de vida são fundamentais para o desenvolvimento do cuidado de enfermagem dentro do contexto da consulta, gerando inúmeros benefícios no que concerne à promoção da saúde e prevenção de doenças. Essas ações são potencializadas por serem realizadas em ambiente domiciliar.

A visita domiciliar potencializa o desenvolvimento do cuidado à criança (ser humano) por entender o contexto de sua morada, fazendo isto parte da assistência à saúde. No ambiente da criança, o laço afetivo-social é mantido, o que influencia no processo saúde-doença dos indivíduos. Na visita domiciliar, ocorre um momento único, o qual a enfermagem, por meio da observação, pode mensurar estilo de vida, condições socioeconômicas, preferências pessoais e culturais, bem como problemas intrafamiliares (SANTANA; MARTINS; GUIMARÃES, 2008).

Esta é concebida como uma atividade para subsidiar as intervenções no planejamento de ações para a promoção da saúde do indivíduo e família. Considerada um instrumento essencial, é empregada pelos profissionais para a construção do cuidado, com o objetivo de atender a necessidade precisa e imediata do usuário (RODRIGUES, 2009).

A PNAB preconiza como atribuição específica do enfermeiro a assistência da saúde aos indivíduos ou famílias cadastrados, podendo ser realizada em domicílio, nas diversas fases do 
desenvolvimento humano. Em síntese, a Consulta de Enfermagem à criança em domicílio é prevista e fundamentada deontologicamente pela referida política (BRASIL, 2012a).

A Primeira Semana Saúde Integral está envolvida no âmbito da visita domiciliar, compreendendo uma responsabilidade específica do enfermeiro que trabalha na estratégia Saúde da Família, desempenhando, com isso, a Consulta de Enfermagem à criança.

Diferentemente deste enfoque, um depoimento atípico, relata o pré-natal como um momento que engloba o cuidado de enfermagem à criança.

Interessante que eu faço o acompanhamento durante o pré-natal e depois com crianças de seis a vinte e quatro meses, depois disso é com a médica. Gosto muito do vínculo que ocorre na atenção básica com a família, é algo gratificante. (Enfermeira B1).

O depoimento revela pontos importantes para discussão. O primeiro deles, por considerar pré-natal como um momento de cuidado à criança, muito embora seja mais considerado o enfoque materno. Em segundo, a quebra de vínculos com a criança entre o parto e os seis meses de vida da criança, seguido novamente por uma ruptura prematura. E a contradição da própria enfermeira, em afirmar existir vínculos neste sistema, tido para ela como gratificante.

Este depoimento revela discrepâncias quando comparado aos princípios assistenciais do cuidado perinatal. A ausência de promoção de vínculo entre o profissional e o usuário dos serviços de saúde repercute na falta de confiança e de corresponsabilidade, proporcionando grandes problemas ao usuário. $\mathrm{O}$ acompanhamento do pré-natal é bastante significativo para o recém-nascido, pois é por meio de uma assistência qualificada e humanizada com integração das ações, que será possível atender às reais necessidades da criança na vigilância de sua saúde (BRASIL, 2012e).

O reconhecimento do pré-natal como um momento de cuidado à criança reflete sobre os muitos significados existentes na Consulta de Enfermagem durante a gestação, em especial para à criança, no acompanhando do ciclo de vida humano.

A Consulta de Enfermagem à criança compreende uma dimensão muito ampla que segue tendo como base os preceitos do Ministério da Saúde. O acompanhamento da promoção da saúde e prevenção de doenças acontece com a frequência mínima estabelecida no calendário da criança, ou com base em suas queixas ou necessidades. 
A Consulta de Enfermagem à criança nesta unidade básica de saúde segue os padrões preconizados pelo Ministério da Saúde, onde se faz o acompanhamento da puericultura principalmente em menores de dois anos seguindo o calendário mensal e depois disso ocorre bimestralmente até os sete anos de idade. (Enfermeira A2).

A Consulta de Enfermagem à criança na atenção básica ocorre com maior frequência nos dois primeiros anos de vida seguindo o que o Ministério da Saúde define, depois segue pelo menos duas vezes ao ano por conta da idade ou conforme o aparecimento de queixas. (Enfermeira A4).

As representações sociais das enfermeiras sobre a Consulta de Enfermagem à criança se envolvem em duas dimensões construídas: 1) A de seguir o Ministério da Saúde como referência neste cuidado, por meio de manuais, impressos, entre outros; e 2) Atentar para a faixa etária como indicador da quantidade de consultas necessárias, considerando que os dois primeiros anos de vida demandam mais atenção dos profissionais. É valido ressaltar que não somente a idade influencia na quantidade de consultas, mas também as queixas e as necessidades advindas do usuário.

O calendário de Consultas de Enfermagem à criança segundo o Ministério da Saúde (BRASIL, 2005b) é no seguinte esquema: para o primeiro ano de vida, devem ser realizadas, pelo menos, sete consultas (antes de 15 dias, primeiro mês, segundo, quarto, sexto, nono e décimo segundo), no segundo ano de vida, deverão ser realizadas, pelo menos, duas consultas (décimo oitavo mês e vigésimo quarto), sendo que dos três aos 10 anos, a recomendação é de, no mínimo, uma consulta para cada ano de vida da criança. Destaca-se que independente da motivação pela procura do atendimento, a consulta deve ser um momento que oportuniza uma análise integrativa e preditiva sobre a saúde da criança.

Por meio destes depoimentos, pode-se perceber que na prática na Consulta de Enfermagem à criança na atenção básica de Teresina, realmente é adotado o que o Ministério da Saúde propõe como mínimo de consultas para a criança nos dois primeiros anos de vida e também nas crianças de até dez anos. Na primeira fase (crianças menores de dois anos) recebem um acompanhamento mais rigoroso, tendo em vista a necessidade de cuidados essenciais.

O calendário preconizado pelo Ministério da Saúde, não é o único existente. Autores como Ribeiro, Ohara e Saparolli (2009) defendem a ideia de que a criança deve realizar 
consultas de 0 a 6 meses, mensalmente, de 7 a 12 meses, bimensais e acrescenta que de 13 a 36 meses estas consultas devem ser trimestrais, de 37 a 48 meses, semestrais e após 48 meses devem ser anuais. Este cronograma considera principalmente a vulnerabilidade típica de cada faixa etária, devendo ser flexível mediante a presença de agravos de saúde ou necessidades da criança.

Segundo o protocolo da Fundação Municipal de Teresina, a Consulta de Enfermagem à criança de zero a dez anos deve ser operacionalizada da seguinte maneira: Calendário mínimo (primeira semana, primeiro mês, segundo, quarto, sexto, nono, décimo segundo, décimo oitavo e vigésimo quarto), depois segue semestralmente até o sexto ano e anualmente dos sete aos 10 anos. Esta deve ser composta de avaliação sistemática do crescimento e desenvolvimento, estado vacinal, acuidade auditiva e visual, medidas antropométricas e estado nutricional, higiene oral e corporal, desenvolvimento neuropsicomotor, social e psíquico, tendo em vista a prescrição de cuidados de enfermagem e terapêutica a ser adotada.

Existem diferenças entre calendários de consultas mínimas à criança, verificou-se que a realidade estudada aborda o calendário mais compatível com o estabelecido pelo Ministério da Saúde e pelas instâncias locais, assegurando uma frequência de consultas tendo com base as necessidades fisiológicas humanas para esta idade.

A Consulta de enfermagem à criança, nas representações sociais das enfermeiras está bem delineada, a ponto de não causar maiores problemas com as atribuições de outros profissionais que também compõem a equipe Saúde da Família.

Depois disso, ela (mãe ou responsável) segue com a criança para o consultório médico se tiver com alguma doença séria ou se precisar de um encaminhamento especializado. Caso não haja, eles vão para o consultório de enfermagem para serem consultados por mim seguindo o protocolo da consulta conforme é para ser (Enfermeira A1).

O depoimento da enfermeira A1 revela, nas entrelinhas, a diretriz da promoção da saúde e da prevenção de doenças existentes na Política Nacional da Atenção Básica e dinâmica assistencial do enfermeiro, que realiza a Consulta à criança ou puericultura (BRASIL, 2012a; MOURA; ROCHA, 2012). Pelo depoimento apresentado, é possível perceber com clareza o enfoque da vigilância à saúde da criança.

Para um melhor entendimento Ricco, Almeida e Del Ciampo (2001) definem a puericultura como uma área voltada principalmente para a prevenção e a promoção da saúde, 
atuando no sentido de manter a criança saudável para garantir seu pleno desenvolvimento, sua atuação enfoca a saúde em vez da doença. Seus objetivos básicos contemplam a promoção da saúde infantil, prevenção de doenças e educação da criança e de seus familiares, por meio de orientações antecipatórias aos riscos de agravos à saúde, podendo oferecer medidas preventivas mais eficazes. Para ser desenvolvida em sua plenitude, deve a puericultura conhecer e compreender a criança em seu ambiente familiar e social, além de suas relações e interações com o contexto socioeconômico, histórico, político e cultural em que está inserida.

O fluxograma de atendimento à criança nas unidades básicas de saúde de Teresina-PI revela que por meio da demanda espontânea ou por encaminhamento do agente comunitário de saúde, a criança deverá ser acolhida pelo SAME (Serviço de Arquivo Médico e Estatística) e encaminhada para consulta médica ou de enfermagem, sendo estas independentes entre si. Conforme o profissional que realiza a consulta, ela segue para uma coleta de dados e demais atribuições específicas (ALMEIDA, Et al., 2012).

Esse papel bem definido da enfermagem e da medicina engrandecem as possibilidades de um fluxo mais ativo e dinâmico no atendimento às crianças. As atribuições da enfermagem e da medicina se complementam no eixo maior da proposta da Política Nacional da Atenção Básica.

Em 2010, foram incorporado à Consulta de Enfermagem à criança, atribuições específicas do Programa Federal Bolsa Família, que visam controle e atualização periódica dos dados da criança para que haja o repasse financeiro à família da mesma. E então o Bolsa Família passou a ser uma rotina no acompanhamento da criança na atenção básica, como mostram os depoimentos a seguir:

Acompanho crianças com e sem Bolsa Família até os sete anos, pois o programa exige isto de mim. Isto ocorre na terça-feira, principalmente em crianças menores de dois anos onde o acompanhamento é mais rigoroso. Após essa idade, semestralmente atualizamos os dados no SIAB (Enfermeira B3).

Realizamos além dessas atividades, o registro do Bolsa Família a cada seis meses e nesse momento eu estendo o atendimento a crianças de até sete anos, alimentando os dados nos sistemas de informação como o SIAB e o SISVAN (Enfermeira A1). 
Por conta do Bolsa Família atualizamos nosso cadastro a cada seis meses e para isso destinamos quatro semanas de nosso atendimento para as crianças de dois a sete anos (Enfermeira B2).

Hoje possuo cinquenta e duas famílias com crianças cadastradas no Bolsa Família que devem passar por mim pelo menos duas vezes ao ano, porém elas vêm com frequência (Enfermeira A2).

Meu atendimento depois da inserção do Bolsa Família passou a ser a cada seis meses para crianças de dois anos até sete anos, após essa idade quem faz o acompanhamento é a escola (Enfermeira B3).

Os cinco depoimentos anteriormente transcritos, revelam pontos importantes para discussão. A exigência do Programa Bolsa Família como atribuição do enfermeiro, o dispêndio de tempo em ter que realizar controles e atualizações semestralmente, tornando uma rotina no cotidiano do enfermeiro que trabalha na estratégia Saúde da Família.

O Bolsa Família é um programa federal instituído pela Lei no 10.836 , de 09 de janeiro de 2004 e regulamentada pelo decreto $n^{\circ} 5.209$, de 17 de setembro de 2004, que repassa uma renda diretamente a estas famílias em situação de vulnerabilidade social e pobreza, mas este recebimento está condicionado ao cumprimento dos compromissos das famílias com as agendas da educação e da saúde, objetivando promover o acesso aos direitos sociais básicos voltados à criança. As famílias assistidas possuem crianças menores de sete anos, que são acompanhadas pelas equipes da ESF. As atividades pertinentes à saúde da criança incluem: a orientação alimentar, monitoramento do crescimento e desenvolvimento infantil e acompanhamento do esquema vacinal, devendo ocorrer a cada seis meses. Estas atividades corroboram o alcance dos principais objetivos de desenvolvimento do milênio que são: reduzir a mortalidade infantil e acabar com a fome e a miséria (BRASIL, 2011b).

De acordo com o informe da atenção básica no 56 do Ministério da Saúde (BRASIL, 2010b) os beneficiados com o Programa Bolsa Família deverão ser assistidos por uma equipe da estratégia Saúde da Família ou unidade básica de saúde para o atendimento às crianças menores de sete anos. As ações de saúde voltadas para a criança incluem: o cumprimento do calendário de vacinação preconizado pelo Ministério da Saúde (registrado no Mapa de Acompanhamento do Bolsa Família); realizar o acompanhamento do crescimento e desenvolvimento infantil; e realizar atividades educativas sobre temáticas específicas (aleitamento materno, cuidados gerais). O não cumprimento dessas ações implica em sansões para a família, que podem variar do bloqueio temporário até o cancelamento do benefício. 
Em Teresina, na primeira vigência de 2014, os dados consolidados em 30 de maio de 2014, revelam que existem 34.922 crianças para acompanhamento, sendo que 11.564 crianças são beneficiadas com o Programa Bolsa Família, o que representa 33,11\%, das quais 11.441 estão com a vacinação atualizada e 10.817 com os dados nutricionais (BRASIL, 2014b; BRASIL, 2014c).

Ressalta-se que embora seja um quantitativo considerável de crianças a serem assistidas pela atenção básica, o protocolo de enfermagem da Fundação Municipal de Saúde de Teresina não menciona nenhum direcionamento ou informação acerca do Programa Bolsa Família, evidenciando uma falha existente entre as normativas institucionais e a prática do enfermeiro.

Dentro da PNAB, as pertinências do Programa Bolsa Família estão descritas somente na oitava atribuição dos agentes comunitários de saúde, que visa o contato permanente e integral com as famílias no desenvolvimento de ações educativas e acompanhamento das condicionalidades deste Programa (BRASIL, 2012a).

Percebe-se que existe uma lacuna entre teoria e prática envolvendo as atribuições dos enfermeiros no Programa Saúde da Família, pois parte-se do pressuposto de que o enfermeiro integra uma equipe Saúde da Família e que tem como atribuição atender às demandas deste programa. Por outro lado, não existem informações que designem especificamente este profissional para onerar horas de serviço a fim de atualizar periodicamente este programa. $\mathrm{E}$ diante desse fato, questiona-se a participação dos demais membros na equipe no Programa Bolsa Família.

Por fim, a rotina de acompanhamento da Consulta de Enfermagem à criança finda com o início da adolescência, dando continuidade ao cuidado em outra dimensão.

Então até doze anos eles vem para o acompanhamento depois distribuímos a caderneta do adolescente e explicamos o cálculo do IMC, os deixo fazerem perguntas e damos seguimento, então de uma obrigação passa a ser um hábito de ir para o posto de saúde de seis em seis meses (Enfermeira A2).

Nós acompanhamos a criança de até dois anos de idade, mas fazemos este seguimento até os sete anos devido ao Programa Bolsa família, depois disso ela passa para o controle dos adolescentes e em seguida do adulto e idoso (Enfermeira A1). 
Os depoimentos revelam a continuidade da Consulta de Enfermagem independentemente do ciclo de vida humana, compreendendo as transformações de cada fase. É importante destacar os dois enfoques das representações sociais dos enfermeiros evidenciados nos depoimentos: a continuidade da assistência e a percepção da evolutiva diante do ciclo de vida humana.

Embora haja essa transformação evolutiva, o ser adolescente carece de atenções tanto quanto a criança, pois representa uma fase da vida na qual ocorrem importantes mudanças no crescimento e desenvolvimento biopsicossocial (BRASIL, 2005c).

A continuidade da assistência prestada à criança envolve a enfermagem em dimensões mais complexas e específicas dispostas em protocolos. Contudo, entende-se a importância das Consultas de Enfermagem realizadas neste ciclo de vida e que irão repercutir nas outras fases do desenvolvimento humano. Insere-se neste indivíduo, desde cedo, um significado particular das ações que promovam a saúde e previnam doenças e da acessibilidade aos serviços de saúde.

As representações sociais dos enfermeiros revelam uma prática fundamentada em aspectos legais que normatizam e padronizam as Consultas de Enfermagem à criança na rede de atenção básica em aspectos como quantidade e abordagem básica. A continuidade dessas consultas contemplando essa importante fase da vida transmite um significado particular das ações que promovem a saúde e previnem doenças e da acessibilidade aos serviços de saúde.

\subsubsection{CLASSE 4: Dimensão técnica da consulta - tecnologia do cuidado}

A classe 4 é constituída também de 16 seguimentos de textos (UCEs), sendo 29 palavras analisáveis. Estes seguimentos correspondem a 23,2\% (figura 16), trata-se de classe bastante significativa e está diretamente relacionada com a classe 03 , no envolvimento da dimensão sócio afetiva, por meio do uso de tecnologias leves. Os enfermeiros A1, A3, A4 e B1 foram os que mais contribuíram com três UCEs cada. Os vocábulos mais significativos são: exame físico, avaliar, além, meio, analisar, infância e anamnese, com o $\mathrm{X}^{2}$ respectivamente de: 17, 17, 14, 14, 10, 10 e 10 (figura 17).

Este conjunto de vocábulos que formam os seguimentos de textos constrói as representações sociais dos enfermeiros sobre as dimensões técnicas constituindo bases teóricas para a prática da Consulta de Enfermagem à criança na atenção básica. Por meio de Veronese e Guareschi (2007), percebe-se que as representações sociais constituem um campo 
de conhecimento conjugado, compartilhado, construído socialmente, através de interatividade social, que é capaz de explicar fenômenos sociais os quais se apresentam no cotidiano.

Ao descrever as dimensões técnicas da Consulta de Enfermagem à criança na atenção básica, emergem as principais etapas: anamnese e exame físico, das quais compartilham temáticas essenciais para o cuidado do enfermeiro à criança: alimentação e estado nutricional; crescimento e desenvolvimento; estado vacinal e cuidados de higiene com a criança.

No primeiro momento, a anamnese e exame físico da criança são relatados pelas enfermeiras com uma característica bem especifica: "detalhado". Isto implica em uma avaliação minuciosa das particularidades típicas dessa fase do desenvolvimento humano.

Isso é muito importante porque repercute em um maior controle com a população de nossa área, a Consulta de Enfermagem vê a criança como um todo, por meio da anamnese e exame físico bem detalhado com ênfase para cada faixa etária (Enfermeira A2).

Quando a criança chega para a Consulta de Enfermagem no posto de saúde, ela é pesada e medida pela técnica de enfermagem, seguida por mim com a anamnese e o exame físico detalhado procurando examinar e verificar seu estado de saúde frente às patologias típicas da infância (Enfermeira B1).

Avaliamos a criança por meio do exame físico seguindo o sentido cefalo caudal observando se ocorrem sinais e sintomas de anemia icterícia dermatites irritações alergias entre outros (Enfermeira A1).

Além de avaliar a criança como um todo tendo atenção para achados importantes como sinais e sintomas específicos das doenças principalmente as típicas da infância (Enfermeira A4).

A representação social da dimensão técnica descreve a anamnese e exame físico da criança, envolvendo uma realidade construída na formação do enfermeiro e expressa em seu cotidiano de cuidado à criança. Os depoimentos revelam dois aspectos peculiares deste detalhamento que norteiam a anamnese e o exame físico: a faixa etária e a investigação de evidências patológicas na criança.

A anamnese e exame físico do recém-nascido são diferenciadas em relação às outras faixas etárias, essa diferenciação é justificada pelas peculiaridades fisiológicas e anatômicas do recém-nascido, conforme o MS (BRASIL, 2012e). Na anamnese do recém-nascido 
investiga-se a história do mesmo, além da identificação, antecedentes obstétricos (dados do parto e condições do nascimento). No exame físico, devem-se seguir as regras do externo para o interno e no sentido crânio caudal com os métodos propedêuticos: inspeção, palpação, percussão e ausculta. No exame físico geral, avalia-se pele (textura, umidade, cor), tecido subcutâneo, gânglios, mucosas, musculaturas, esqueleto e articulações. $O$ exame físico especial (específico) envolve: crânio, olhos, ouvidos, nariz, boca, pescoço, tórax, aparelho respiratório, aparelho cardiocirculatório, abdômen, aparelho geniturinário, ânus, sistema nervoso.

No exame físico da criança na atenção básica, Ohara et al. (2009) confirmam as informações supracitadas, entretanto, adota outra sequência para operacionalização do exame físico: cabeça, pescoço, caixa torácica, abdome, coluna vertebral, quadril, membros superiores e inferiores, genitais externos, pele e anexos, reflexos e sinais vitais, utilizando os métodos propedêuticos cabíveis em cada seguimento. Esta discordância, segundo os autores, considera que a abordagem recomendada não é a crânio caudal, mas a que respeita a idade da criança e o nível de desenvolvimento desta. O exame físico compreende um importante instrumento de levantamentos de dados que enriquece e fundamenta a assistência de enfermagem.

$\mathrm{Na}$ anamnese, Almeida et al. (2003) colaboram apresentando-a como imprescindível para a realização do exame físico. Esta requer qualidades profissionais como tato, habilidade, paciência, observação, sensibilidade, tirocínio e, principalmente, conhecimento para interpretação dos dados. Deve-se considerar as impressões gerais do informante ou acompanhante; impressão geral sobre a criança; antecedentes familiares; antecedentes pessoais; antecedentes patológicos pessoais; hábitos da criança; queixa principal e história da doença atual. O exame físico relatado pelos autores é referenciado da seguinte forma: inspeção geral; verificação das condições neuropsicomotoras; inspeção de pele e anexos e por último, exame físico dos vários sistemas e regiões do corpo.

Anamnese e exame físico são temáticas divergentes entre autores da área. A vasta literatura proporciona muitas reflexões sobre como deve ser operacionalizada, a falta de uma padronização entre os autores causa enfraquecimento da prática. As discussões apresentadas trazem aspectos distintos que ora se aproximam ora se distanciam entre si dentro desta temática. As citações discutidas trazem divergências em relação à prática vivenciada na rede de atenção básica Teresinense. O protocolo local sobre a Consulta de Enfermagem à criança na atenção básica não menciona a operacionalização, nem referencia obras a cerca desta temática. 
No segundo momento desta classe, apresenta-se as temáticas relatadas pelos enfermeiros da atenção básica que retratam o conteúdo da Consulta de Enfermagem à criança.

Na minha equipe, a consulta de enfermagem ocorre por meio da anamnese e exame físico infantil, onde se avalia o estado de saúde da criança para isto se pesa mede a criança e analisa o cartão de vacina, além de ouvir as queixas (Enfermeira B4).

Avaliando como ela (criança) está em relação à alimentação adequada para idade, higiene básica e seus cuidados essenciais além de enfocar a vacinação em dia no exame físico. Avalio a simetria perímetro cefálico presença de anemia, icterícia, entre outros (Enfermeira B1).

Pergunto sobre suas preferências, o que a mãe tem oferecido à criança e o que ela tem comido, além de avaliar o crescimento e desenvolvimento da mesma por meio do cartão da criança (Enfermeira A1).

De extrema relevância, eu acompanho as crianças desde o nascimento com a visita domiciliar no puerpério materno e damos seguimento na puericultura onde avaliamos o crescimento e desenvolvimento, alimentação saudável e adequada, além do cartão de vacinação aqui na unidade básica de saúde (Enfermeira B3).

Aqui, a criança é vista como um todo, durante a consulta de enfermagem avaliamos o crescimento e desenvolvimento por meio da pesagem e medição, constituindo assim a avaliação nutricional, analisamos o cartão de vacina e aproveitamos para atualizar e aprazar (Enfermeira A3).

Esclarecemos sobre a higiene básica da criança com ênfase nas partes mais especiais como boca umbigo e genitais além das outras ações protocoladas para cada idade da infância é muito trabalho, mas vale a pena vejo crianças crescendo como realmente deve ser cheias de saúde (Enfermeira A4).

Além de explicar sobre a higiene da criança, analisar o peso e altura conforme a idade, administro sulfato ferroso e vitamina A. Fazemos exames de sangue para pesquisar anemia e também o parasitológico de fezes, para então prescrevermos vermífugos conforme nosso protocolo normativo (Enfermeira A1).

Quantificadas em dez temáticas diferentes, a Consulta de Enfermagem à criança na atenção básica de Teresina, entrelaça essas temáticas junto com anamnese e exame físico em um contexto amplo e indissociável, contemplando assim a integralidade da criança. 
Todas as temáticas relatadas nos depoimentos supracitados estão descritas no protocolo da Consulta de Enfermagem à criança na atenção básica Teresinense (ALMEIDA Et al., 2012), entretanto, houveram temáticas protocoladas que não foram mencionadas nos depoimentos: verificação da acuidade visual e auditiva, além de desenvolvimento psicomotor, social e psíquico.

Sobre alimentação saudável e adequada para a faixa etária, os depoimentos das enfermeiras 01, 05 e 07 revelam a presença do cuidado com alimentação infantil na Consulta de Enfermagem, contudo não detalham como deve ocorrer, de forma padronizada e explícita.

Visando orientações concisas e diretas, o Ministério da Saúde dispõe de uma vasta quantidade de manuais e guias que orientam os profissionais da saúde, neste caso, os enfermeiros, a conduzirem informações corretas sobre a alimentação infantil saudável e adequada. São alguns exemplos destes: Saúde da criança: nutrição infantil - aleitamento materno e alimentação complementar; Guia Alimentar - Como ter uma alimentação saudável; Dez passos para uma Alimentação Saudável; e o Guia alimentar para Crianças Menores de dois anos.

O caderno de atenção básica $N^{o} 23$ "Saúde da criança: nutrição infantill" descreve o aleitamento materno, seus tipos, importância, duração e informações pertinentes sobre este tema, além de descrever o manejo em diversas situações atípicas. Neste mesmo caderno, é possível encontrar informações sobre alimentação complementar para crianças menores de dois anos, com a importância, problemas nutricionais, formação de hábitos alimentares, e orientações sobre alimentação complementar saudável (BRASIL, 2009).

O guia alimentar "Como ter uma alimentação saudável” apresenta uma abordagem mais ampla, com o objetivo de orientar uma alimentação saudável, contribuindo para uma melhor qualidade de vida e na prevenção de doenças. No primeiro momento, o guia permite uma avaliação e reflexão da alimentação com base em um questionário autoaplicável. Em seguida, apresenta os dez passos para uma alimentação saudável e a avaliação com base no Índice de Massa Corpórea - IMC. E conclui orientando sobre as medidas caseiras para cada tipo de alimento (BRASIL, 2006d).

Na publicação, "Dez Passos para uma Alimentação Saudável”, o Ministério da Saúde apresenta objetivamente condutas que servem de base para os profissionais da saúde exercerem orientações e demais cuidados. São estas: 1- Aleitamento materno exclusivo até os seis meses, sem inserir nenhum outro alimento ou bebida; 2- Após os seis meses, introduzir outros alimentos gradualmente; 3- Após os seis meses, oferecer alimentos complementares três vezes ao dia, caso a criança mame ou cinco vezes, caso ela não mame; 4- Os horários da 
alimentação devem ser flexíveis, respeitando a vontade da criança; 5- A alimentação deve ser pastosa e gradativamente aumenta a consistência até chegar à alimentação infantil; 6Oferecer uma dieta variada e colorida; 7- Estimular o consumo de frutas, verduras e legumes; 8- Evitar açúcar, café, enlatados, frituras, refrigerantes, balas e outras guloseimas no primeiro ano de vida, evitando também o sal; 9- Cuidar da higiene no manuseio e preparo dos alimentos; e 10- Estimular a criança doente a se alimentar, respeitando suas preferências (BRASIL, 2002a).

No "Guia Alimentar para Crianças Menores de dois anos", existem orientações sobre práticas adequadas de alimentação infantil, relatando a importância e duração do aleitamento materno exclusivo e não exclusivo. Norteia a alimentação complementar, enfatizando o tempo de começar, frequência das refeições, fatores que afetam a indigestão e a prática de higiene para este tipo de alimentação. Ainda, fornece informações sobre o diagnóstico da situação nutricional brasileira em menores de dois anos e avaliação do estado nutricional. Relata as representações sociais, tabus e crenças acerca da alimentação infantil e sintetiza as principais recomendações alimentares (BRASIL, 2002b).

Autores como Vale e Carmona (2012), Fugimore e Rezende (2009a), Fugimore e Rezende (2009b), Nobrega (2009) tecem discussões aprofundadas sobre aleitamento materno e alimentação infantil, norteada pelas informações veiculadas pelo Ministério da Saúde.

Desta forma, entende-se que os depoimentos foram genéricos quanto à alimentação da criança, tendo em vista a grande quantidade de informações essenciais das quais as enfermeiras deveriam passar para as mães ou responsáveis pelo cuidado à criança seguindo as orientações preconizadas pelo Ministério da Saúde.

$\mathrm{Na}$ esfera municipal, uma das metas da Consulta de Enfermagem à criança é a estimulação do aleitamento materno exclusivo até o sexto mês de vida, atendendo assim, a estratégia da Rede Amamenta Brasil. É necessário que o enfermeiro no momento da consulta observe e avalie as condições alimentares, a fim de garantir o compromisso das unidades básicas de saúde que são incentivar o aleitamento materno e orientar sobre alimentação saudável. O protocolo menciona os pontos básicos a serem considerados sobre alimentação saudável (acessibilidade física e financeira; sabor; variedade; cor; harmonia), além de orientações nutricionais sobre o aleitamento materno exclusivo, aleitamento artificial, e alternativas alimentares (ALMEIDA et al., 2012).

Dada a ampla variedade de guias, manuais e protocolos sobre a alimentação infantil, percebe-se que a teoria está concisamente fundamentada e amplamente divulgada, cabendo ao enfermeiro muitas possibilidades de práticas durante a Consulta de Enfermagem. 
Sobre medidas antropométricas, os depoentes 03, 04, 05 e 08 avaliam pesar e medir como um dos componentes que integram a Consulta de Enfermagem à criança, que embora se trate apenas de uma simples técnica, a mesma exige muitos cuidados em sua realização e serve de base para a análise de outros componentes, como: estado nutricional, crescimento e desenvolvimento. $\mathrm{O}$ registro dessas informações na caderneta da criança garante uma apreciação mais complexa desta, tendo caráter longitudinal.

A técnica para a aferição de peso e altura exige profissionais habilitados e manutenção e calibração constantes dos equipamentos, a fim de assegurar medidas precisas e seguras na avaliação da criança. Esta prática possui somente uma variação em sua realização: a idade da criança. Crianças menores de dois anos devem ser pesadas em balanças de cuba metálica ou cesto com precisão mínima de dez gramas e verificada a altura ou estatura por meio de uma régua antropométrica. Em crianças maiores de dois anos usa-se balança antropométrica adulta com antropômetro de parede (FUJIMORE; BORGES, 2009).

Corroborando estas informações, o MS (BRASIL, 2002c) apresenta em seu caderno de atenção básica $\mathrm{n}^{\circ} 11$ "Saúde da criança: acompanhamento do crescimento e desenvolvimento infantil”, os instrumentos e descreve como deve ocorrer a avalição do peso e do comprimento/altura da criança com exatidão, padronização e qualidade.

Verificar as medidas antropométricas traz consigo uma grande responsabilidade por meio de uma simples técnica, desenvolvida durante a Consulta de Enfermagem. Garante dados importantes para uma avaliação real das condições da criança. Os enfermeiros que desenvolvem esta prática, não conseguem dissociar a mesma de outras avaliações a serem realizadas com a criança, em virtude da integralidade representada em suas ações.

Fugimore e Borges (2009) destacam a importância da integralidade entre nutrição, crescimento e saúde, por entenderem que a criança alimentando-se corretamente, cresce e desenvolve-se adequadamente.

Intimamente relacionada com a verificação das medidas antropométricas, a avaliação do estado nutricional e do crescimento e desenvolvimento da criança compõem a Consulta de Enfermagem com grande ênfase, pois o peso e o comprimento/altura da criança são apenas dados sujeitos a uma interpretação, e na avaliação do estado nutricional e do crescimento e desenvolvimento é possível mensurar e analisar esses dados com base em padrões. As enfermeiras 01, 03, 07 e 09 revelam o exercício deste cuidado em seus depoimentos.

Existem diversas formas de avaliar o estado nutricional das crianças. Melo (2005) destaca que para os profissionais de enfermagem, os critérios que mais interessam são exame clínico e a antropometria. No exame clínico é possível observar diversas alterações no cabelo, 
face, olhos, língua, lábios, dentes, gengivas, glândulas, pele, unhas, tecido subcutâneo, sistema musculoesquelético, cardiovascular, intestinal e nervoso, que são sugestivas de alterações nutricionais. A antropometria engloba peso, altura, pregas cutâneas e circunferência dos membros em um sistema estático que avalia a dimensão física global do corpo humano. No recém-nascido considera-se o peso ao nascer e a relação perímetro torácico e perímetro cefálico, enquanto que na criança com até dez anos utiliza-se a relação peso para idade disponibilizado no Cartão da Criança do MS, circunferência braquial e relação perímetro torácico e perímetro cefálico.

Utilizando a antropometria, Caram e Franciosi (2012) acrescentam que se pode realizar esta avaliação por meio do peso para a idade, altura para idade, índice de massa corpórea para idade, utilizando as curvas de crescimento estabelecidas pela Organização Mundial de Saúde (2007).

Em relação ao crescimento da criança que representa o tamanho corporal associado à idade, é importante ressaltar que o peso e a altura mudam conforme a faixa etária. $\mathrm{O}$ peso aumenta, entretanto o ganho de peso diminui a cada trimestre no primeiro ano de vida enquanto que a altura varia conforme a idade, sendo que no primeiro ano de vida, estima-se um aumento de $25 \mathrm{~cm}$; no segundo ano, 10 a $12 \mathrm{~cm}$; no terceiro e quarto anos, $7 \mathrm{~cm}$; e até a puberdade, de 4 a $6 \mathrm{~cm}$ (FUGIMORE; BORGES, 2009).

De acordo com o MS (BRASIL, 2012f), o crescimento da criança deve ser registrado e acompanhado na caderneta de saúde da criança, que dispõe de gráficos de: perímetro cefálico para crianças de zero a dois anos; peso para idade divididos de zero a dois anos, de dois a cinco anos e de cinco a dez anos; comprimento/estatura para idade divididos de zero a dois anos, de dois a cinco anos e de cinco a dez anos; e índice de massa corporal (IMC) divididos de zero a dois anos; de dois a cinco anos e de cinco a dez anos. As cadernetas da criança são individualizadas para cada gênero (masculino e feminino) proporcionando, assim, maior exatidão e direcionamento.

As curvas de crescimento dispostas na caderneta da criança são caracterizadas pela sua ascendência. Quando houver horizontalidade ou descendência, o enfermeiro deve realizar medidas eficazes para reverter essa situação preocupante, através de orientações claras e bem fundamentadas direcionadas aos cuidadores da criança, solicitando dos mesmos que retornem em quinze dias para novas avaliações antropométricas (CARVALHO, 2012).

Em um estudo desenvolvido por Moreira e Gaíva (2013) sobre o registro do crescimento e desenvolvimento infantil, foi constatado que nem todos os registros estavam adequados para uma avaliação do crescimento e desenvolvimento, o que influencia 
diretamente a qualidade da assistência prestada na rede de atenção básica. Todos tinham peso e altura, porém não se observaram registros da curva de crescimento e desenvolvimento no prontuário.

Embora os termos crescimento e desenvolvimento estejam sempre associados, remetem a fenômenos distintos (ALVES, 2003). Crescimento representa o aumento físico do corpo, enquanto que desenvolvimento corresponde ao processo de aquisição de habilidades e funções complexas.

O desenvolvimento consiste no surgimento e aperfeiçoamento de habilidades típicas de cada faixa etária, sendo estas: motoras, psíquicas, cognitivas e sociais. Cabe ao enfermeiro identificar esses atrasos ou alterações e orientar os familiares sobre as respostas da criança. No recém-nascido e lactante, o desenvolvimento é intenso, caracterizado pelo amadurecimento dos sistemas orgânicos e pela aquisição de competências básicas. No infante, existe uma intensa exploração do ambiente e da identificação do "eu". No pré-escolar, as habilidades são aperfeiçoadas e ampliadas, em especial a linguagem. E no escolar, desenvolve-se com mais ênfase o aspecto social (RIBEIRO, et al., 2009).

É importante que o enfermeiro oriente os cuidadores das crianças sobre atividades que estimulem o desenvolvimento global das mesmas, explicando a importância que existe na interação com o ambiente (CARVALHO, 2012).

Como representação da Consulta de Enfermagem à criança para o enfermeiro, percebe-se o entendimento claro da avaliação nutricional e do crescimento e desenvolvimento como atribuição do enfermeiro na atenção básica, contudo, destaca-se a carência de informações relativas à descrição destas atividades que compõem as ações básicas direcionadas à criança.

A vacinação também compõe essa representação dos enfermeiros sobre a Consulta de Enfermagem, refletida nos depoimentos dos enfermeiros 03, 07 e 09.

Araújo et al. (2009) afirmam que na atenção básica a vacinação é uma atividade regular e gratuita, oferecida diariamente. Além dessa vacinação de rotina, o Programa Nacional de Imunizações do Ministério da Saúde utiliza campanhas e outros instrumentos para intensificar a vacinação.

Carniel, Araújo e Carvalho (2012) destacam a participação do enfermeiro no Programa Nacional de Imunizações, por meio de ações em diversas instâncias, desde o nível local até a coordenação nacional, envolvendo ações de planejamento, organização, funcionamento das salas de vacina, manutenção do estoque, conservação e manipulação, além de capacitação dos outros profissionais, monitoramento e avaliação das atividades. 
O protocolo da Consulta de Enfermagem à criança de Teresina estabelece como meta a atualização vacinal de todas as crianças da área de abrangência, além de ter o compromisso com aplicação e orientação do esquema básico para a criança (ALMEIDA et al., 2012).

A vacinação possui uma considerável representatividade por parte dos enfermeiros em sua atuação na atenção básica, isto ocorre em virtude do caráter preventivo, que é bem característico na unidade básica de saúde e pelo direcionamento de quase todas as ações que envolvem a vacinação.

Por fim, menos mencionadas, mas compondo essa representação social dos enfermeiros sobre a Consulta de Enfermagem na atenção básica, os depoentes 03, 04, 05, 07, 08, 09 apresentam os cuidados: relacionados às orientações básicas; à higiene; ao uso de sulfato ferroso e vitamina $\mathrm{A}$; e à solicitação de exames como o parasitológico de fezes.

Mello, Tonete e Silva (2009) descrevem tais cuidados de enfermagem na atenção básica à saúde da criança, destacando a importância de assegurar essas condições mínimas, explícitas nas linhas de cuidado de atenção integral à criança. Assim, como o protocolo de Consulta de Enfermagem municipal, que descreve esses cuidados além de relacionar exames laboratoriais de rotina, tratamento medicamentoso e não medicamentoso (ALMEIDA, et al., 2012).

As peculiaridades do cuidado de enfermagem complementam a dimensão da integralidade à criança na atenção básica. $\mathrm{O}$ universo infantil desafia o profissional enfermeiro nesses inúmeros cuidados que compõem seu campo de atuação, na perspectiva da promoção da saúde e prevenção de doenças. Todas estas representações sociais compõem o conteúdo da Consulta de Enfermagem à criança.

Contudo, existem dificuldades em realizar a Consulta de Enfermagem à criança, representada pela falta de entendimento do caráter preventivo do cuidado e da promoção da saúde. As enfermeiras 03 e 05 revelam isto dos depoimentos a seguir:

No geral resolvemos tudo aqui, tudo que for saúde básica, eu estou aqui todos os dias e não entendo por que elas (pessoas) pesam que seja difícil. Vejo às vezes, urgências aqui, mas quando vamos falar eles acham ruim não ter atendimento de urgência e emergência (Enfermeira A3).

As pessoas deveriam saber que podem encontrar no posto de saúde um local de promoção da saúde e prevenir as doenças, por isso não me recuso a atender ninguém. Todos os que chegam independentemente do dia ou hora eu atendo (Enfermeira B1). 
A falta de compreensão da concepção e do conceito da atenção básica, assim como, o reconhecimento de suas atribuições perdura ao longo dos anos, fundamentada em um histórico de modelos hospitalocêntricos e sanitaristas, que somente a privilegia nos últimos anos, em virtude das atuais Políticas de Saúde Brasileira. A superação da fragmentação imposta por este modelo também constitui um considerável desafio e dilema (CASTRO; FAUSTO, 2012).

A PNAB do Ministério da Saúde (2012a) apresenta um importante referencial teórico para o entendimento da atenção básica como porta de entrada no sistema de saúde, configurando-se como centro da comunicação no mencionado sistema. A rede de atenção básica é estruturada e ordenada para ser a base, ter resolutividade, coordenar o cuidado e organizar a rede. Destaca-se, nesse ponto, o acolhimento qualificado para os indivíduos e a inclusão do primeiro atendimento às urgências como uma de suas atribuições.

A PNAB gera conflito com o exposto pelos relatos das participantes, que em seus depoimentos revelam contradições com o estabelecido pelo MS, emergindo a necessidade de um melhor entendimento da equipe e da população sobre tal Política. A teoria e a prática se divergem, revelando importantes campos a serem trabalhados e capacitados.

Os depoimentos revelam a carência de fundamentações teóricas por parte dos enfermeiros sobre o atendimento de urgência e emergência e demostra a ausência de estratégias que capacitem a população sobre o entendimento da atenção básica e os serviços que a mesma oferece.

O depoimento abaixo citado revela a importância do enfermeiro no âmbito da criança saudável e doente.

O próprio enfermeiro promove a saúde por meio da consulta de enfermagem, quando a criança está desnutrida, por exemplo, ele dispõe de suplementação, o multimistura, que possa passar para a criança, mas caso seja mais grave com a ocorrência de doenças devemos referenciar para o profissional habilitado (Enfermeiro A3).

O enfermeiro cuida da criança saudável e doente no âmbito da atenção básica por meio da Consulta de Enfermagem, mas quando se trata de casos mais graves de doenças, é necessário fazer uso de encaminhamentos especializados.

Os encaminhamentos especializados estão descritos no protocolo de Consulta de Enfermagem do Município, que atribui ao enfermeiro o qual realiza a Consulta, uma 
avaliação clínica da criança que possibilita identificar a necessidade de encaminhamentos de acordo com os problemas identificados. Existem os encaminhamentos dentro da própria unidade básica de saúde: cirurgião dentista e médico e os encaminhamentos especialistas: pediatra, oftalmologista, otorrinolaringologista, psicólogo e nutricionista (ALMEIDA, et al., 2012).

No caso apresentado pela enfermeira 03, observa-se o uso do suplemento alimentar chamado multimistura. Contudo, vários autores já pesquisaram sobre o uso deste suplemento no caso de crianças desnutridas e constataram a ineficácia do mesmo no sentido de promover um estado nutricional satisfatório para a criança, não justificando, assim, a sua aplicabilidade (FERREIRA; CAVALCANTE; ASSUNÇÃO, 2009).

Com isso, relacionam-se achados pertinentes, que estão de acordo com normativas municipais, mas que em outros aspectos se contradizem em relação à literatura científica, tecendo um importante arcabouço sobre a dimensão prática da Consulta de Enfermagem à criança na atenção básica.

\subsubsection{CLASSE 03: Dimensão socioafetiva da consulta - o vínculo}

A terceira classe constitui-se de 11 segmentos de textos (UCEs) com 12 palavras analisáveis, correspondente a $15,94 \%$ (figura 16). Trata-se da classe com menor quantidade de segmentos analisáveis, contudo, apresenta dados importantes que complementam com a classe 04 descritos anteriormente. Os depoentes A1 e B3 participam desta classe com maior frequência, cada um com três segmentos de textos. Os vocábulos mais significativos são: atividade, representar, cuidado, consulta de enfermagem, atenção, considerar, achar e momento com o qui-quadrado $\left(\mathrm{X}^{2}\right)$ respectivamente: 16, 16, 12, 12, 06, 06 e 04 (figura 17).

Os vocábulos supracitados tecem a classe sobre as dimensões afetivas que reflete os significados da Consulta de Enfermagem à criança elaborado pelas enfermeiras, que atuam na rede de atenção básica. Nesta classe, os depoimentos revelam suas representações sociais apresentados como atividade, cuidado, Consulta de Enfermagem, atenção e momento.

Os depoimentos a seguir referenciam a caracterização e a importância da Consulta de Enfermagem na construção do cotidiano de trabalho das enfermeiras e como é a percepção delas diante do trabalho e das crianças. 
Eu tenho dezesseis anos de PSF e considero a consulta de enfermagem à criança na atenção básica como muito importante, pois é nesse momento que se consegue ver o ser humano, a criança, como um todo por meio de vários aspectos e seus cuidados. (Enfermeira A1).

A consulta de enfermagem à criança é uma atividade privatista do enfermeiro que trabalha na atenção básica, junto com toda a equipe no cuidado a criança (Enfermeira B3).

A consulta de enfermagem à criança é essencial para o controle do enfermeiro, hoje tenho em mente quantas crianças eu tenho, quais as doentes, que são as que precisam de mais atenção e isso representa muito pra mim (Enfermeira A4).

Os depoimentos revelam que por traz da Consulta de Enfermagem à criança na atenção básica, existem atividades focadas no cuidado ao ser humano, considerando as peculiaridades da infância envolvendo a atenção específica para este momento.

O cuidar é definido como um ato ou atitude, o qual envolve mais que um momento de atenção, de zelo, e de desvelo. Concebendo uma atitude de ocupação, preocupação, responsabilização e de envolvimento afetivo para com o outro. Este cuidado encontra-se na primeira raiz do ser humano, antes de tudo, e se fizer, ele sempre virá acompanhado pelo cuidado. Em outras palavras, isto implica em reconhecer o cuidado como modo-de-ser essencial do ser humano, sempre presente e irredutível a outra realidade, impossível de ser desvirtualizada (BOFF, 1999).

Waldow (2001) descreve o cuidar como uma ação verdadeiramente interativa, o qual está associado com o comportamento, calcado em valores e no conhecimento de quem cuida, para e com o ser que é cuidado, que passa também a ser cuidador. Neste sentido, para que haja cuidado é necessário interação e relações interpessoais, pois implica em encontros de subjetividade socialmente conformados.

Segundo Boff (1999) o cuidado é o modo-ser-no-mundo que pode ocorrer de duas formas: trabalho e o cuidado. O modo-de-ser-no-mundo pelo trabalho pode ser por interação ou intervenção. O ser humano não vive à toa, ele interage com a natureza, procurando conhecer suas leis e ritmos, intervindo com ela a fim de torná-la mais cômoda. Por meio do trabalho ele a viabiliza, construindo seu habitat, adapta o meio ao seu desejo e conforma seu desejo ao meio. No ser humano, o trabalho se configura como modo-de-ser consciente, 
assumindo um caráter peculiar de estratégia e projeto. Anteriormente, o trabalho era mais uma inter-ação do que uma intervenção, por conta da veneração do ser humano pela natureza, somente utilizando aquilo que ele precisava para garantir a sua sobrevivência, tornando mais segura e prazerosa a sua existência.

O outro modo-de-ser-no-mundo operaliza-se pelo cuidado, e este não se opõe ao trabalho, mas lhe oferece um diferencial. Pelo cuidado, a natureza e tudo que nela existe, perde a condição de objetos. A relação não se trata de sujeito-objeto, mas sujeito-sujeito. Estes seres como sujeitos, possuem valores, símbolos que remetem a uma realidade frontal. $\mathrm{O}$ ser humano pode colocar-se junto a elas, não existindo uma relação de domínio sobre, mas de convivência. Não é uma intervenção, mas inter-ação e comunhão (BOFF, 2009; 1999).

Em uma perspectiva mais ampla, Boff (1999, p. 97) relaciona os modos-de-ser cuidado e trabalho:

O grande desafio para o ser humano é combinar trabalho com cuidado. Eles não se opõem, mas se compõem. Limitam-se mutuamente e ao mesmo tempo se complementam. Juntos constituem a integralidade da experiência humana, por um lado, ligada à materialidade e, por outro, à espiritualidade. O equívoco consiste em opor uma dimensão à outra e não vê-las como modos-de-ser do único e mesmo ser humano.

Ressalta-se ainda que, o ser profissional envolve mais do que a dimensão tecnicista, contemplando o resgate do cuidado mais humanizado, com a perspectiva de incorporação deste dentro do contexto sociocultural. Tendo a valorização de medos, dúvidas, angústias e crenças, revelando um respeito à autonomia do ser cuidado em relação às práticas adequadas, entendendo que a cultura do ser cuidado pode influenciar positivamente ou negativamente neste processo (MARQUES; COTTA; ARAÚJO, 2009; FROTA; BARROSO, 2005).

O entendimento dos enfermeiros que trabalham na atenção básica sobre suas atribuições descritas pela Política Nacional da Atenção Básica (BRASIL, 2012a), pelo Protocolo Municipal de Consulta de Enfermagem (ALMEIDA Et al., 2012) e demais legislações facilitam a sua compreensão, repercutindo em um cuidado direcionado, repleto de significados e singularidades.

As representações sociais dos enfermeiros acerca do controle social, referido pela enfermeira A4, de acordo com Geraldi Et al. (2012), demonstra a importância do controle 
social para a elaboração e implementação de Políticas Públicas mais condizentes com a realidade vivenciada. Porém Soratto e Witt (2013), alertam para uma percepção focada no monitoramento de doenças, o que significa certa fragilidade sobre a fundamentação teórica da temática apresentada.

Os depoimentos apresentam explicitamente uma assistência pautada em aspectos inseridos dentro das atuais políticas de saúde brasileira, o que evidencia representações sociais singulares que compartilham a mesma trama política e social.

Os depoimentos revelam ainda, as dimensões afetivas relacionadas às representações sociais, que carregam sentimentos e envolvimento afetivo entre as enfermeiras e os indivíduos ou comunidade assistida.

Nosso envolvimento é com a família, onde conversamos e praticamos a educação em saúde. (Enfermeira B3).

Sinceramente acho a consulta de enfermagem como ela é, um momento muito bom e proveitoso para todos e representa um momento afetivo para nós profissionais e a comunidade. (Enfermeira A1).

A consulta de enfermagem à criança é uma atividade muito boa e prazerosa, onde orientamos bastante sobre os cuidados e além disso, acrescento práticas alternativas do tipo shantalla, massagem terapêutica, florais de Bach, que ajudam não somente as crianças mas também as mães. (Enfermeira B3).

A Consulta de Enfermagem à criança se potencializa com o envolvimento afetivo e a formação de vínculos entre enfermeiro e comunidade, o que acarreta maior sensibilização e comprometimento profissional no cumprimento das ações propostas pela atenção básica.

Segundo um estudo apresentado por Campos Et al. (2011), os enfermeiros não realizam a Consulta de Enfermagem às crianças somente por uma normativa do programa, mas sim por entenderem a Consulta de Enfermagem como importante instrumento de cuidar, revelando inúmeros sentimentos vivenciados como: gratidão, frustação, esperança, empatia, além do estreitamento de vínculos com a família.

Haddad Et al. (2011) destacam a importância da expressão de sentimentos, valores, crenças, medos, ansiedade e vivência na construção de espaços que garantam uma assistência de qualidade, compatível com princípios como a integralidade. Desta forma, a rede de atenção 
básica incorpora em sua proposta atitudes, configurações e técnicas de trabalho que necessitam de tais expressões para que haja o atendimento das necessidades essenciais.

Os depoimentos supra referidos são corroborados pelos pressupostos da literatura pesquisada e das atuais Políticas Públicas de Saúde brasileiras (BRASIL, 2012).

Um depoimento destaca-se por apresentar uma função prática que envolve a pouca demanda em virtude de aspectos econômicos (plano de saúde). A pouca demanda é entendida como um agente potencializador das funções das práticas de educação em saúde desenvolvidas durante a Consulta de Enfermagem à criança.

Boa parte de nossas crianças tem plano de saúde o que representa pouca demanda e mais tempo para as conversas e atividades de educação em saúde (Enfermeira B3).

O depoimento revela significados e funções bem particulares referentes aos benefícios de haver pouca demanda de atividades para a jornada de trabalho, que gera maior liberdade de tempo para realizar suas atribuições. Conversas e atividades de educação em saúde requerem do profissional enfermeiro tempo para elaboração e realização. Outro aspecto importante é a condição limitadora que os planos de saúde adotam para restringir o acesso da população à rede de atenção básica.

Situação oposta foi encontrada por Trindade e Pires (2013), segundo os quais o estudo sobre as implicações dos modelos assistenciais da atenção básica no trabalho dos profissionais, em busca por assistência à saúde é incompatível com o número desses profissionais, com a estrutura e equipamentos, causando excesso de carga de trabalho.

As conversas terapêuticas na relação enfermeiro e usuário na rede de atenção básica segundo Haddad Et al. (2011), devem servir como instrumento de cuidar que estabeleça uma relação de ajuda, participação e de acordo com os princípios do Sistema Único de Saúde. Para os referidos autores, a comunicação é uma tecnologia leve para o cuidado e acolhimento na atenção básica, tendo em vista políticas públicas de promoção de usuários mais ativos na saúde.

Inerente a todos os profissionais que trabalham na rede de atenção básica, os enfermeiros devem realizar atividades de educação em saúde com a população adscrita, segundo a Política Nacional da Atenção Básica (BRASIL, 2012a). 
Percebe-se a peculiaridade existente nesta situação: a pouca demanda ocasionada pelo bom padrão financeiro das famílias assistidas, que repercute em uma assistência com maior tempo para elaboração e realização das atividades como conversas e educação em saúde.

Esse papel educativo que permeia as funções dos enfermeiros sobre a Consulta de Enfermagem à criança constitui um importante momento de promoção e valorização da mesma, como demonstra o depoimento a seguir.

Então fazemos atividades educativas com o intuito de instruir sobre o papel da Consulta de Enfermagem e isso é como se fosse uma das condicionalidades para ser consultado, explicamos isso antes (Enfermeira A2).

A promoção do entendimento da Consulta de Enfermagem pela comunidade é uma representação social importante e denota consideráveis progressos para o campo da enfermagem. Nesse sentido, Gautério, Irala e Cezar-Vaz (2012) apresentam em seu estudo, a necessidade de sensibilizar a população sobre as atividades e ações atribuídas à atenção básica, na perspectiva de internalizar conceitos como a promoção da saúde e prevenção de doenças.

É importante essas atividades que conscientizam a população dos serviços dispostos na atenção básica, fazendo com que os usuários se tornem agentes ativos e esclarecidos dos serviços que podem procurar e onde encontrar.

Mas a depoente B1 apresenta em seu relato, outro significado bem diferenciado dos demais anteriormente apresentados.

Considero a Consulta de Enfermagem à criança um momento comum na rotina do enfermeiro que trabalha na atenção básica, é algo básico em nosso cotidiano que deve seguir o protocolo da Fundação Municipal de Saúde. Gostaria muito de mudar essa concepção, mas acho difícil porque vai muito da questão cultural representando pra mim um desafio (Enfermeira B1).

Os protocolos normativos são instrumentos que norteiam a Consulta de Enfermagem à criança, mas também engessam esse momento, transformando o enfermeiro em um coadjuvante neste processo. Esses protocolos priorizam a rotina em detrimento das ações 
criativas e oportunistas para cada situação em que o enfermeiro se encontra, significando algo distante.

Discutindo o trabalho de enfermagem e a criatividade, Souza, Et al. (2009) resgata o conceito de improvisar, e acrescenta que para que haja um improviso em situações nas quais não se tem o material adequado (fato que ocorre com frequência nos locais de trabalho do enfermeiro), é necessário que a criatividade reconheça o raciocínio, entretanto percebe que pode construir novas equações e resolução de problemas, potencializando novas maneiras de pensar.

Percebe-se, portanto, o engessamento da enfermeira e a intencionalidade do uso de recursos como uma forma de otimizar o serviço de enfermagem, considerando, ainda, a criatividade como papel relevante e indispensável para a elaboração do cuidado na prática assistencial.

\subsubsection{CLASSE 2: Espaço social da consulta - acolhimento}

A classe 02 é composta de 13 segmentos de textos (UCEs) com 26 palavras analisáveis, correspondente a 18,8\% (figura 17). Esta classe se relaciona diretamente com a classe 05 descrita a seguir. Destaca-se a participação do enfermeiro A2 como o sujeito com maior quantidade de segmentos, tendo como vocábulos mais significativos: sempre, mãe, trazer, procurar, vir, posto, peso, conservar e dia, com o qui-quadrado $\mathrm{X}^{2}$ respectivamente de: 24, 23, 18, 14, 13, 05, 04, 04 e 04 (figura 17).

O arcabouço destes vocábulos tecem as representações sociais das enfermeiras sobre o espaço de cuidado formado por meio da Consulta de Enfermagem à criança na rede de atenção básica. Nestas, os depoimentos descrevem como as famílias com crianças se relacionam com a enfermeira da atenção básica, tanto na busca da Consulta de Enfermagem, bem como no momento em que ela ocorre.

Estes significados compõem as representações sociais, que segundo Jodelet (2011) permitem estudos no intuito de apreender e esposar, no seu devir as consideráveis tendências que norteiam a vida social dos indivíduos. A pesquisadora acrescenta, ainda, o "Zeitgeist" entendido como espírito do tempo, tal como essa repercute na experiência subjetiva das pessoas. 
As representações sociais das enfermeiras evidenciam como ocorre a busca e o atendimento da Consulta de Enfermagem com as crianças presentes e ausentes. Apontam o fator financeiro que também impacta nessa procura. Estas representações evidenciam, ainda, a busca pela Consulta de Enfermagem em virtude das dúvidas das mães em relação ao cuidar da criança e melhores práticas de promoção desse relacionamento, formando vínculo com a criança e a família e apontando caminhos e portas de entrada no Sistema de Saúde.

Segundo o Ministério da Saúde (BRASIL, 2012) a Política Nacional da Atenção Básica é a porta de entrada nos Sistemas de Saúde públicos brasileiros, e possui também um caráter centralizador de informações, composto por uma dinâmica específica e peculiar.

Os depoimentos das enfermeiras a seguir apresentam as representações sociais de como ocorre essa prática, desde a procura de atendimento até como ocorre o vínculo.

Nós fazemos a Consulta de Enfermagem à criança nesta unidade básica de saúde da seguinte forma: a criança chega acompanhada por seu responsável que geralmente é a mãe que conversa com as atendentes ou a técnica de enfermagem na recepção, e retira o prontuário no SAME, digo crianças por que quase sempre a mãe traz mais de uma traz as delas, as das irmãs, as das vizinhas (Enfermeira A1).

Temos remédios para verme, ou seja, o básico nós temos aqui, meu atendimento é agendado, mas caso a criança precise, não nego atendimento e se ela não vem nós vamos procurar saber junto com o agente comunitário de saúde o motivo da ausência e remarcar a consulta para outro dia (Enfermeira A3).

Oriento a mãe a sempre procurar o posto de saúde quando for à data aprazada na caderneta da criança ou no cartão de vacinação, como também procurar sempre um profissional que possa avaliar a situação vacinal da criança (Enfermeira B3).

Sempre registro na caderneta da criança que fica com a mãe ou o responsável, que vem com a criança para a consulta e no prontuário aqui do posto que ficasse no SAME (Enfermeira B2).

Em um estudo desenvolvido por Souza Et al. (2013) sobre a representações sociais dos usuários acerca da Consulta de Enfermagem, comprovou-se, por meio dos relatos dos usuários, que a disponibilidade dos enfermeiros em ouvir e valorizar a comunicação durante a Consulta oportuniza espaços de expressão de dúvidas e necessidades, propiciando vínculos e confiança, o que garante melhores práticas no âmbito da atenção básica. 
Outros autores como Viegas e Penna (2012) apontam em seu estudo, o vinculo, o compromisso e a corresponsabilização como essencial na construção de um cuidado com integralidade, garantindo qualidade na atenção à saúde.

A formação de vínculos entre os profissionais e as crianças na rede de atenção básica é registrado por Lima Et al. (2013) na visão das mães sobre a humanização do atendimento. Nesta, o profissional que mais cuida das crianças na atenção básica é o enfermeiro, por isso justifica-se uma maior atenção para o acolhimento, formação de vínculos e corresponsabilização.

Percebe-se que esta relação interpessoal disposta na Consulta de Enfermagem à criança gera a necessidade de um envolvimento afetivo, que valorize a formação de vínculos entre os enfermeiros e as crianças atendidas, garantindo práticas que contemplem confiança, respeito e interatividade para que haja o atendimento dos pressupostos da política Nacional de Saúde.

Destacam-se ainda nos depoimentos, que os vínculos da Consulta de Enfermagem à criança na atenção básica estão pautados com: 1)Relacionamento dos responsáveis com a Equipe Saúde da Família; 2)Busca por medicações; 3)Vigilância com a caderneta da criança. Considera-se, também, a dinâmica dentro e fora das unidades básicas de saúde com as crianças presentes e os ausentes na Consulta de Enfermagem, bem como o controle de busca e registro dessas informações para os profissionais e para os responsáveis pela criança.

$\mathrm{Na}$ atenção básica, a estratégia Saúde da Família é considerada um potente instrumento, que reorganiza o modelo de atendimento, e esta reorganização do modo de trabalho deve considerar o perfil epidemiológico das famílias e dos grupos sociais que habitam as áreas de abrangência da estratégia saúde da família, sendo esta uma forma de viabilizar a identificação mais genuína dos problemas vivenciados por eles, por meio de uma abordagem integral do processo saúde-doença e seus determinantes (TRAPÉ; FUJIMORE; BERTOLOZZI, 2009).

Rocha (2005) acrescenta que as tarefas realizadas por enfermeiros na atenção básica, expressam o seu modo de agir profissional. Neste contexto assistencial, a enfermagem está envolvida no cuidado com a criança sadia, buscando atuar na promoção da saúde, prevenindo doenças, embora, muitas vezes, ocorra a necessidade de cuidar de crianças doentes. A presente autora retrata a existência de estratégias de buscas aos faltosos como um cuidar da enfermagem na atenção básica.

Sobre o relacionamento com a equipe, Ghisi et al., (2013) revelam em uma pesquisa realizada na Estratégia Saúde da Família em um município do extremo sul de Santa Catarina 
que a satisfação da comunidade em relação à assistência prestada pela equipe da estratégia da saúde da família é considerada boa ou excelente em 86,6\% das famílias pesquisadas, o que representa que a capacidade de diálogo da comunidade com os membros da equipe é efetiva.

O relacionamento entre os profissionais da saúde e a família é destaque no artigo discutido por Cruz e Angelo (2011), pois estes autores entendem que o cuidado centrado na família em pediatria necessita redefinir estes relacionamentos para que possa ser incorporado a prática profissional.

Um estudo desenvolvido na atenção básica de Maracanaú-CE evidenciou que os profissionais que trabalham na Equipe Saúde da Família realizam suas atividades focadas na comunidade, com o envolvimento dos grupos familiares na unidade básica de saúde e que a comunicação pode potencializar estas relações (VIEIRA, et al., 2004).

Pautada na busca por medicações, Ribeiro, Siqueira e Pinto (2010), acrescentam que na atenção à saúde das crianças menores de cinco anos na atenção básica de Teresopólis-RJ, o acesso aos medicamentos prescritos no posto é possível para $44,3 \%$, enquanto que $35,4 \%$ dos entrevistados revelam a problemática da ausência dos medicamentos. Para os autores supracitados, estes resultados são considerados como satisfatórios, no entendimento que este é um problema estrutural do sistema público de saúde brasileiro.

Numa reflexão sobre as representações sociais das enfermeiras, entendendo a busca de medicações como um caminho e porta de entrada na Consulta de Enfermagem à criança na atenção básica, infere-se que esse estudo anteriormente descrito repercute na procura pela assistência, pois uma vez que o sistema de saúde garante medicações para menos da metade das crianças que necessitam, compromete toda a dinâmica de assistência à criança.

Realidade semelhante é encontrada por Sousa, Erdmann e Mochel (2011) em São LuisMa, onde a ausência de medicamentos também é um importante problema estrutural que compromete a assistência de enfermagem à criança na atenção básica. Essa escassez de medicamentos motiva e aumenta o número de encaminhamentos de crianças para os serviços de urgência repercutindo em baixa resolutividade, descontentamento entre profissionais e mãe além da sensação de insegurança.

Corroborando a presente pesquisa, Modes e Gaiva (2013) revelam que a maior frequência de mães que qualificam o atendimento como excelente ou bom está relacionado com o recebimento gratuito dos medicamentos prescritos no posto, reafirmando, portanto, esta relação.

No tocante à vigilância com a caderneta de saúde da criança, Abreu, Viana e Cunha (2012) divergem apresentando as disparidades existentes entre o ideal e o real. A revisão 
realizada pelos autores permitiu evidenciar os cinco principais fatores que dificultam esta vigilância: Ausência de capacitação para o uso correto da caderneta; Tempo insuficiente; Indisponibilidade da caderneta no serviço de saúde; A não utilização da caderneta por todos os membros da equipe de saúde e também a desvalorização e desconhecimento das mães/família sobre a caderneta.

Longe de ser um caminho ou uma porta de entrada na Consulta de Enfermagem à criança, a revisão construída por Gaiva e Silva (2014) destaca que a caderneta não tem sido utilizada pelos profissionais e famílias para a vigilância da saúde infantil, tendo em vista a qualidade insatisfatória dos registros realizados e o pouco envolvimento e participação da família neste processo.

O registro destas informações é fundamental para o controle do enfermeiro no cuidado à criança. O estudo de Barboza, Barreto e Marcon (2012) apresenta a escassez dessas informações e a desqualificação das mesmas, o que pode repercutir na qualidade da assistência prestada.

As informações registradas duplamente (na caderneta da criança e no prontuário) garantem uma dupla segurança. Tanto para a mãe ou responsável de acompanhar as informações e ficar atenta aos aprazamentos, quanto ao profissional enfermeiro, que detém esse banco de dados, o qual possibilita recuperar informações anteriores, bem como avaliar a assiduidade e ausência das crianças.

Outra faceta vivenciada no cotidiano da atenção básica pelo enfermeiro é a situação econômica dos usuários, que demonstra sua importância não somente pela busca dos serviços de saúde, mas também pela garantia de ser assistido por políticas assistenciais, como, por exemplo, o Programa Bolsa Família. O enfermeiro A2 retrata esta situação no depoimento a seguir.

Tem uma parte da microárea, em que elas (crianças) são melhores financeiramente, tendo plano de saúde particular e por isso não procuram tanto nosso posto, mas aí peço para que os agentes comunitários de saúde passem e sensibilizem essas mães para que elas venham por meio de um agendamento com o próprio agente. Existem também, as mães que recebem o bolsa família, que trazem as crianças e é por conta disso que elas procuram o sistema de saúde, isso mesmo, sem doença, somente para saber do peso, crescimento e acompanhamento da curva no cartão de vacinação da criança e elas sempre perguntam muito (Enfermeiro A2). 
Sobre a situação econômica dos usuários dos serviços da atenção básica, Soares, Chaves e Cangussu (2013) revelam em um estudo desenvolvido na Bahia, que o perfil destes usuários em relação à renda salarial é de 43,6\% recebem até um salário mínimo. Em Belo Horizonte, Pires et al. (2013) constataram que 53,8\% recebiam de um a três salários mínimos e 69,6\% não possuíam plano de saúde. Em Ceres-GO, Souza Neto et al. (2012) observaram que 54,8\% dos usuários possuem renda salarial de até um salário mínimo.

$\mathrm{Na}$ análise destes estudos, percebe-se que os usuários do serviço de atenção básica são os que possuem situação econômica restrita, ou seja, a procura é maior por aqueles que têm baixa renda. A existência de planos de saúde particular dita à dispensa por parte dos usuários dos serviços de saúde. Enquanto que o Programa Bolsa Família gera a obrigatoriedade de procurar os serviços da atenção básica, em virtude do atendimento dos critérios básicos para o recebimento do auxílio financeiro.

A Lei № 10.836 de 09, de janeiro de 2004, que dispõe sobre a criação do Programa Bolsa Família e dá outras providências, rege em seu artigo terceiro que a concessão dos benefícios será com base no cumprimento das condicionalidades relativas ao exame pré-natal, ao acompanhamento nutricional, ao acompanhamento de saúde, à frequência escolar de oitenta e cinco por cento em estabelecimento de ensino regular (BRASIL, 2004).

Com base no exposto, percebe-se que das quatro condicionalidades exigidas pela Lei que rege o Programa três são realizadas pela rede de atenção básica, o que representa grande vinculo entre as mesmas.

A busca pela Consulta de Enfermagem à criança em virtude das dúvidas das mães sobre o cuidado com a alimentação infantil também é uma realidade vivenciada, que constitui um caminho.

As mães e crianças perguntam muito principalmente sobre alimentação: papas salgadas, papas doces e outros alimentos que podem consumir (Enfermeira A2).

Para Marques, Cotta e Araújo (2009), as orientações para as mães devem ser contextualizadas, entendendo os significados socioculturais, dúvidas, angústias, mitos e crenças.

Ressalta-se ainda que, o ser profissional envolve mais do que a dimensão tecnicista, contemplando o resgate do cuidado mais humanizado, com a perspectiva de incorporação 
deste dentro do contexto sociocultural. Tendo a valorização de medos, dúvidas, angústias e crenças, revelando um respeito à autonomia do ser cuidado em relação às práticas adequadas de alimentação infantil, entendendo que a cultura do ser cuidado pode influenciar positivamente ou negativamente neste processo (MARQUES; COTTA; ARAÚJO, 2009; FROTA; BARROSO, 2005).

As dúvidas são habituais e pelo componente educativo atribuído à Consulta de Enfermagem à criança estruturam um meio de aproximar as famílias com a Enfermagem na atenção básica, por meio da busca de informações ou orientações.

Finaliza-se a discussão sobre os caminhos e portas da Consulta de Enfermagem à criança na atenção básica destacando a promoção do vínculo com a equipe, às famílias e as crianças.

Sempre vejo as crianças aqui no posto, que mesmo não sendo dia da consulta delas, elas acompanham as mães e quando me veem pergunta se elas vão conversar comigo. A minha interação com elas é muito boa (Enfermeira A2).

Como também procuro modificar aquela percepção ruim da criança em relação ao profissional, de injeção, dor, sofrimento, que elas têm. Eu sei que se não houver isso haverá ainda mais dificuldades para a mãe trazer essa criança no posto eu sei que é difícil, mas estou tendo grandes progressos (Enfermeira A2).

Quase sempre saio depois que acaba meu turno, pois é grande a quantidade de atendimento e prefiro esticar mais um pouco em meu horário do que esperar que essa mãe venha em outro dia, pois acaba não vindo não ganho nada a mais por isso mais faço minha parte (Enfermeira B1).

Sempre procuro conversar um pouco sobre a relação mãe e filho, pois nossa área possui muitas mães separadas que moram com outros parceiros que não são os pais das crianças e estes não possuem boa relação com a criança (Enfermeira B3).

Na promoção de vínculos existente nos caminhos para a Consulta de Enfermagem à criança, os depoimentos revelam quatro situações distintas e específicas: 1) A existência do laço afetivo entre o profissional enfermeiro e a criança; 2) A construção de uma nova percepção da criança em relação ao enfermeiro e ao posto; 3) Esforço para garantir que este vínculo continue; e 4) Contextualizar a assistência de acordo com a realidade vivenciada pela criança. 
O significado da Consulta de Enfermagem em puericultura segundo a percepção de enfermeiras que trabalham na estratégia saúde da família em um município do sul do Brasil confirmam a criação e formação do vínculo dos enfermeiros com as crianças e as famílias por meio do elo de confiança. Estas práticas convergem em um momento que traduz condições satisfatórias para que o enfermeiro possa introduzir-se no cotidiano da família e participar de maneira ativa, bem como propor cuidados que contribuam para a identificação de determinantes do processo saúde-doença e para a promoção e proteção à saúde da criança (COSTA et al., 2012).

Resultados semelhantes também foram encontrados por Terra, Dias e Reis (2011) que descrevem as ações da equipe de enfermagem, as quais contribuem para a formação do laço afetivo entre pais e filhos, por meio de orientações e investidas. Constatou-se que os profissionais de enfermagem procuram atuar de forma a promover a formação e o fortalecimento do vínculo materno-filial.

Caminhos e portas visíveis ou invisíveis para a Consulta de Enfermagem à criança na atenção básica garantem melhores práticas e atuações mais contextualizadas, o que resulta em uma maior possibilidade de sucesso para a promoção da saúde e prevenção de doenças das crianças.

Os vínculos promovidos pela Consulta de Enfermagem à criança na atenção básica garantem melhores práticas e atuações mais contextualizadas, o que resulta em uma maior possibilidade de sucesso para a promoção da saúde e prevenção de doenças das crianças.

\subsubsection{CLASSE 5: A consulta como espaço de poder - a autonomia profissional.}

Relacionada diretamente com a classe anterior (classe 02), a classe 05 possui 16 seguimentos de textos (UCEs) com 24 palavras analisáveis, correspondente a 23,2\% (figura 16). Os depoentes $\mathrm{C} 1$ e $\mathrm{C} 2$ destacam-se por possuírem três segmentos de textos individualmente. Os vocábulos mais significativos são: problema, importância, tratar, colocar, informação, minha, orientar, explicar, momento, grande, atender e prontuário, com o quiquadrado $\mathrm{X}^{2}$ respectivamente de: 17, 14, 14, 10, 09, 07, 07, 07, 07, 06, 06 e 04 (figura 17).

A convergência desse conjunto de vocábulos culmina com as representações sociais das enfermeiras sobre a rotina do cotidiano da Consulta de Enfermagem à criança na atenção básica, focada na educação em saúde contextualizada e problematizadora, que atende às reais necessidades colocadas pela população assistida. 
Moscovici (2011) discorre inferindo que pessoas e grupos pensam por si mesmo, construindo uma identidade própria, capaz de produzir e comunicar incessantemente suas próprias e legítimas representações. Estas pessoas e grupos apresentam também soluções cabíveis às questões colocadas e isto constitui uma realidade social.

As enfermeiras conduzem seu cotidiano de trabalho na atenção básica por meios de ações não explícitas nos depoimentos, que convergem em atividades de educação em saúde retratadas sobre três aspectos: 1) A rotina de cuidados; 2) Registros de produção; e 3) Dificuldades enfrentadas pelas enfermeiras nas atividades de educação em saúde.

A educação em saúde na Consulta de Enfermagem à criança na atenção básica é descrita e apresentada nos depoimentos como atividades habituais, que demonstram a sua proximidade e naturalidade em relação às atividades realizadas pelos enfermeiros, mas que possuem como pano de fundo um sentido educativo, o qual engloba a intencionalidade de promoção da saúde e prevenção de doenças. O cuidado à criança é tema central, abordado sobre diversas representações sociais das enfermeiras.

Para o Ministério da Saúde (2007) a educação em saúde é uma prática a ser exercida em todos os âmbitos do Sistema Único de Saúde, colaborando com a firmação de tal política pública. Estas práticas devem ser valorizadas e qualificadas para que possam promover a cidadania através da apropriação do significado de saúde, numa perspectiva dialógica, emancipadora, participativa, criativa e que contribua para a autonomia do usuário, considerando o mesmo como detentor de direitos e autor da sua trajetória, de aspectos que envolvem a saúde e a doença.

Nessa mesma linha de pensamento destaca-se Acioli e David (2008), para os quais no âmbito da enfermagem, a educação é tida como ação que constitui o processo de trabalho. $\mathrm{O}$ enfermeiro educador promove atividades de promoção da saúde e prevenção de doenças junto das famílias e comunidades. Na concepção dos autores supracitados, a educação em saúde é vista como um processo amplo e profundo, na perspectiva de uma construção compartilhada, orientada pela busca de interdisciplinaridade, cidadania e autonomia dos sujeitos.

É por meio da educação em saúde que se explica ao cliente, os conceitos e fatos sobre a saúde e doença, deve englobar o desenvolvimento de práticas de autocuidado, que considera sempre o processo de aprendizado do cliente. Este momento de ensino da prática do enfermeiro pode ser: informal e não planejado ou planejado e formal (POTTER; PERRY, 2009).

Em outras palavras, mas ainda contemplando o sentido educativo, o protocolo da Fundação Municipal de Teresina estabelece como meta trabalhar em orientações para as 
famílias sobre a prevenção de doenças infectocontagiosas e carenciais, além de focar na prevenção de acidentes na infância e orientações sobre alimentação e vacinação (Almeida, $E t$ al.,2012).

Os depoimentos a seguir revelam a autonomia implícita na educação em saúde durante a Consulta de Enfermagem à criança na atenção básica, considerando o aspecto: a rotina de cuidados.

Explicamos o quanto é importante o teste do pezinho e teste da orelhinha não só de fazer, mas também de ir buscar o resultado e mostrar para que possamos ter um controle disso porque muitas vezes eles não sabem e não vão buscar (Enfermeira A1).

Perguntam também, como preparar, se pode passar no liquidificador, na panela e tudo isso eu explico com muita calma e carinho, pois sinto que é nesse momento de dúvida que a mãe se sente bem se sente acolhida e com seu problema resolvido (Enfermeira A2).

Nesse momento, tenho que estar bem atenta para ouvir os problemas no intuito de tentar resolver [...] orientamos a importância do cartão de vacina atualizado e a necessidade da mãe em preservar e se atentar para os aprazamentos que coloco no mesmo, pois quando chegar à época ela não precisa passa na consulta para ir à sala de vacina, pode ir direto que certamente haverá um profissional habilitado para atualizar (Enfermeira A4).

Na minha concepção, a consulta de enfermagem à criança é bem ampla e nela fazemos a puericultura atendendo crianças de seis a vinte e quatro meses, nós orientamos quanto à alimentação adequada tendo como base a faixa etária e as indicações alimentares. Na higiene falamos sobre a higiene oral com a criança e seus cuidados, alertamos que o descuidado com a criança implica em grandes problemas. Orientamos quanto à situação vacinal e a importância do cartão de vacina atualizado e preservado (Enfermeira A1).

Atendemos todas as idades, mas enfocamos principalmente os menores de dois anos por se tratar de um momento com grandes mudanças que carecem de um acompanhamento rigoroso do crescimento e desenvolvimento sempre explicando para a mãe o que isso significa para ela e para a criança (Enfermeira B3).

Pode-se apreender por meio dos depoimentos, o envolvimento do profissional enfermeiro nas ações de educação em saúde que englobam a Consulta de Enfermagem à criança. Como se sabe, a Consulta é ampla e envolve diversas temáticas do cuidado à criança, os relatos dos enfermeiros apresentam a educação em saúde em seu intrínseco, de maneira não 
explícita, o que ocorre por meio de orientações, retirada de dúvidas, ensinamentos, conversas e explicações.

Em outras palavras, a educação em saúde é tão natural no cotidiano do enfermeiro, que se torna difícil e até impossível de dissociar o cuidado do enfermeiro e da construção de sua autonomia.

Para Cervera, Parreira e Goulart (2011) a educação em saúde é uma ferramenta importante que valoriza os contextos sociais, econômicos e culturais da comunidade, aliados ao processo de promoção da saúde. Em seus estudos, os autores mencionados identificaram no cotidiano dos enfermeiros, uma perspectiva de educação em saúde ampla, com uma associação singular entre os profissionais e a prática. Entretanto, ainda é uma prática percebida como estratégia de uma forma verticalizada, institucionalizada, com um sentido único profissional-usuário, o que limita muito seus efeitos e a construção de um novo olhar sobre a educação em saúde, fundamentada em relações dialógicas e na valorização do saber popular.

Silva et al., (2012) discutem em seu estudo as diferentes atuações no enfermeiro na atenção básica, que engloba concepções, ações dialogadas, reflexivas e problematizadoras e, por vezes, dispõe da educação em saúde como uma prática de repasse de informações, que reproduz o modelo pedagógico depositário, desconsiderando a efetivação da prática de educação em saúde emancipatória.

Em um aprofundamento sobre a temática Souza et al., (2012) resgatam a evolução das práticas de enfermagem em educação em saúde, considerando desde a imposição de práticas na política do sanitarismo campanhista à compreensão do indivíduo como sujeito autônomo. Os autores referenciam, ainda, a necessidade do enfermeiro em entender a importância do verdadeiro significado da educação em saúde, considerando a educação crítica e transformadora na perspectiva de melhor compreender as necessidades psicossociais.

Diferentemente do disposto nos depoimentos, Alves e Aerts (2011) criticam as metodologias tradicionais desprovidas de formação de vínculo entre profissional e comunidade, que pregam o modelo autoritário, em que os profissionais orientam sobre o comportamento mais coerente com as práticas de saúde, enquanto a comunidade permanece sem questionamentos ou sem relacionar este conteúdo à realidade vivenciada pelos mesmos.

A literatura converge no entendimento da relevância das atividades relacionadas à educação em saúde no exercício profissional dos enfermeiros na atenção básica, que carece de muitas reflexões para importantes avanços, em busca de uma fidedigna promoção da saúde. 
Realizada de forma não padronizada e indissociável das outras atividades do enfermeiro que atua no cuidado à criança na atenção básica, a educação em saúde relatada nos depoimentos, possui muita contextualização social do paciente, contudo desconsidera as possibilidades de verificação do aprendizado ou compreensão das orientações, o que pressupõe a necessidade de novos estudos com esse enfoque.

Além das atividades diretamente relacionadas com o cotidiano do enfermeiro em relação à educação em saúde, os quatro depoimentos a seguir revelam o registro desta produção.

Caso a vacinação esteja atrasada, encaminhamos a criança para sala de vacina e com o seu retorno registramos as informações no prontuário, exijo que ela retorne justamente para que não haja perdas nesse momento ou porque a sala de vacina está cheia ou a mãe está apressada (Enfermeira A1).

Ao final, registro tudo na caderneta da criança, oriento quanto à necessidade de conservar justamente por se tratar de um documento e também registro na ficha nossa, o prontuário, coloco todas as informações que obtive naquela consulta e outras na caderneta (Enfermeira A4).

Explico que se elas perderem, podem ir ao posto, pois guardo todas as informações da criança porém é necessário responsabilidade pois se trata de um documento do filho dela (Enfermeira B1).

Oriento a conservar e sempre levar nas consultas a caderneta da criança, mas também anoto todas as informações importantes da caderneta no prontuário da criança para que caso ocorra algum problema como esquecimento chuva ou perda eu possa resgatar essas informações para a mãe (Enfermeira B2).

As enfermeiras apresentam situações distintas, nas quais a importância do registro e da informação, seja ela no prontuário ou na caderneta da criança. É válido enfatizar que nas representações sociais das enfermeiras, este registro adquire valor singular e imensurável, a tal ponto de se colocar o resgate destas informações como algo oportuno e possível. Valorizando, assim, não somente o registro, mas também o cuidado descrito pelo mesmo.

Em divergência, Santos et al., (2012b) apontam em seu estudo, que os registros do Sistema de Informação da Atenção Básica e as atividades de educação em saúde estão incluídas na categoria de atendimentos em grupos e representam somente 1,3\% das atividades produzidas na atenção básica. Os autores descrevem a importância da educação em saúde 
dentro da Política Nacional da Atenção Básica, destacando a participação de todos os profissionais.

Nos depoimentos é possível perceber as potencialidades da educação em saúde inseridas no momento da Consulta de Enfermagem à criança na atenção básica e é fundamental para o enfermeiro o registro dessa produção, garantindo a documentação desse cuidado.

Em outras circunstâncias, a enfermeira B2 descreve as dificuldades existentes no exercício da autonomia durante a Consulta de Enfermagem à criança na atenção básica.

\begin{abstract}
A consulta de enfermagem à criança é importante e eu pessoalmente gostaria que fosse até melhor e me esforço pra isso, porém como minha área é periferia muitos dependem do posto por não possuir plano de saúde e isso acaba demandando de mim uma grande produção de consultas. Porém como a demanda é muito grande isso limita muito minhas ações em relação ao tempo e quantidade de pessoas que tenho que atender, me sinto mal por isso porque sei a importância de minha ação para a garantia de saúde para a criança (Enfermeira B2).
\end{abstract}

A sobrecarga de serviços relatados pela enfermeira revela as peculiaridades existentes no cuidado à criança. $\mathrm{O}$ depoimento não dispõe de atividades relacionadas à educação em saúde, tampouco menciona seu registro, mas apresenta, de forma clara, uma conjuntura problemática que confere uma justificativa à ausência da educação em saúde, representada pelas dificuldades vivenciadas pela enfermeira no cotidiano da atenção básica.

Pedrosa, Castro e Pereira (2012) revelam as expectativas dos indivíduos que procuram os serviços de saúde ofertados na rede de atenção básica, o que compreende encontrar um profissional que realize acolhimento, orientações e que seja compreensível às necessidades apresentadas, além de demonstrar confiança e segurança em suas ações. Os autores supracitados descrevem uma ocorrência distante da realidade disposta pela enfermeira B2.

Os desafios levantados por Souza et al. (2010) elucidam a dificuldade existente entre teoria e prática, ou seja, o desafio consiste em concretizar o conceito de educação em saúde como prática no campo de atuação do enfermeiro da rede de atenção básica.

A autonomia desenvolvida com atividades de educação em saúde durante a Consulta de Enfermagem à criança na rede de atenção básica evidencia a promoção da saúde, contudo, ainda se fazem necessárias reflexões e mudanças nesta realidade, principalmente por entender que estes entraves são meramente operacionais, passíveis de consideráveis intervenções. 


\subsection{ANÁLISE DE SIMILITUDE E NUVEM DE PALAVRAS}

O software IRAMUTEQ (Interface de R pour les Analyses Multidimensionnelles de Textes et de Questionnaires) permite também as análise de similitude e nuvem de palavras (CAMARGO; JUSTO, 2013). Tais analises estatísticas fomentam o objetivo principal desta pesquisa, contribuindo com o conteúdo simbólico proveniente do corpus sobre as representações sociais elaboradas pelas enfermeiras sobre a Consulta de Enfermagem à criança na rede de atenção básica.

A análise de similitude é fundamentada pela teoria dos grafos, e atualmente é adotada comumente por pesquisadores do campo das representações sociais. Este tipo de análise permite identificar as palavras e suas correlações, como resultado indica-se a conexidade entre as palavras, servindo como instrumento de estruturação das representações sociais pesquisadas (CAMARGO; JUSTO, 2013). O grande destaque em vocábulo nas representações sociais elaboradas pelas enfermeiras sobre a Consulta de Enfermagem à criança na atenção básica é: criança. A análise de similitude descreve também o universo de vocábulos em torno da centralidade da criança. 


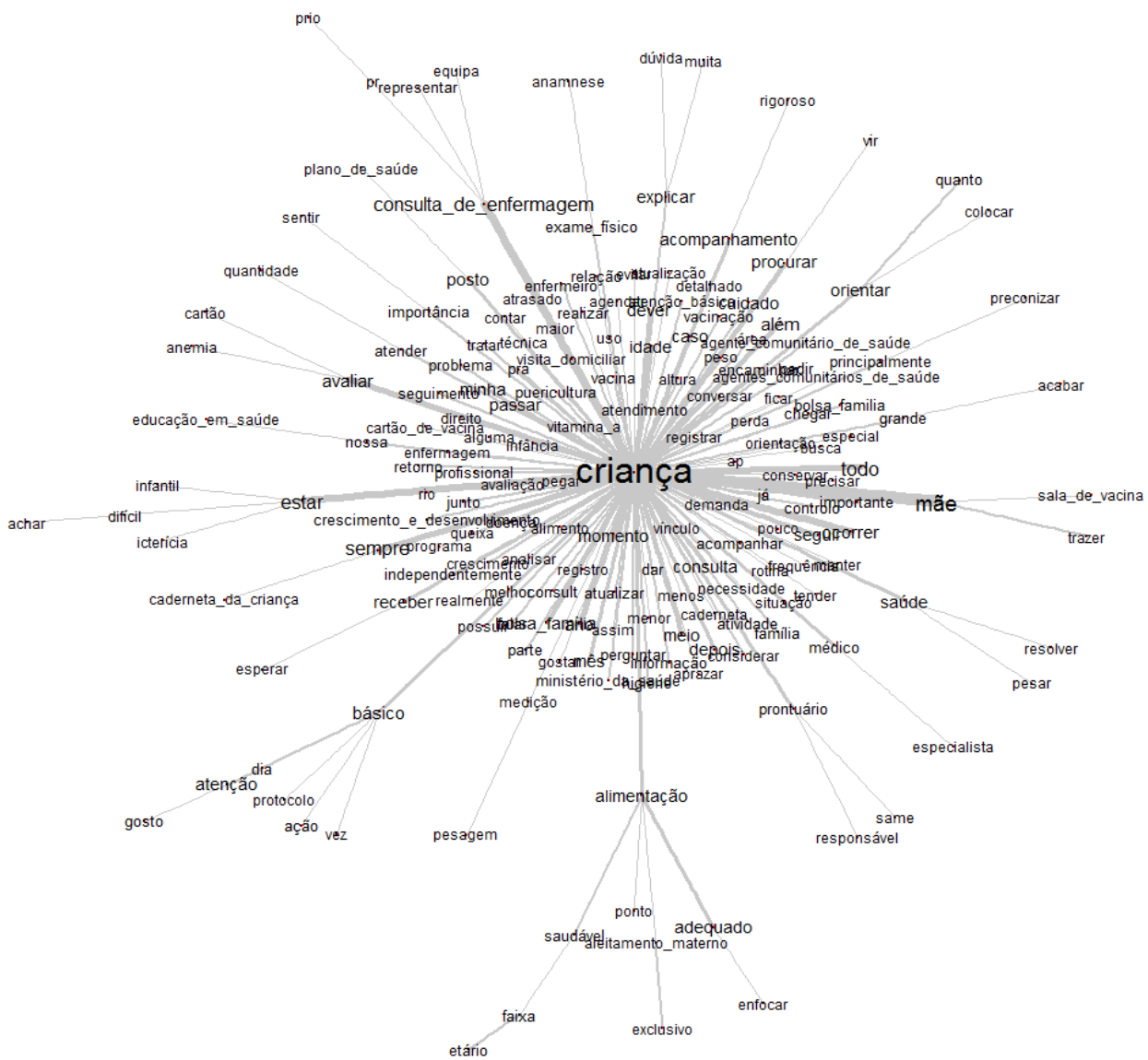

Figura 18. Análise de similitude das palavras da Consulta de Enfermagem à criança na atenção básica de Teresina-PI, 2016.

Fonte: Iramuteq.

$\mathrm{Na}$ análise de similitude é possível perceber que tudo ocorre em todo da criança, e as demais palavras estão estruturadas diretas e indiretamente com o vocábulo criança. Na figura 19 percebe-se a enorme diversidade de palavras organizadas dentro no contexto da criança. Em outras palavras, figura-se desta forma as representações sociais das enfermeiras sobre a Consulta de Enfermagem à criança na rede de atenção básica.

A nuvem de palavras organiza as palavras em agrupamentos gráficos com base em sua frequência. Trata-se de uma análise lexical simples e interessante do ponto de vista gráfico (CAMARGO; JUSTO, 2013). Na nuvem de palavras, criança aparece também com destaque, seguida por consulta de enfermagem, mãe e sempre. 


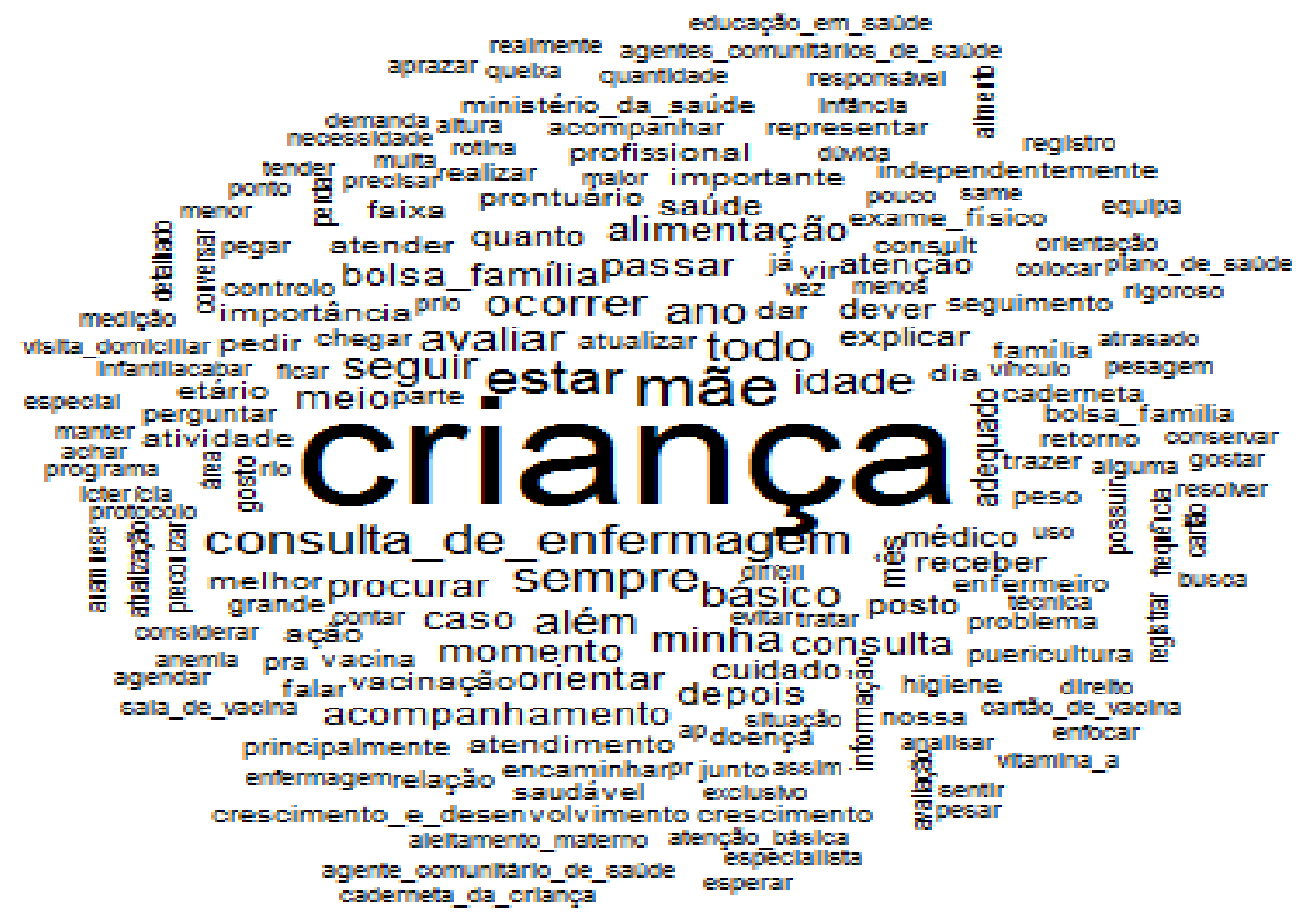

Figura 19. Nuvem de palavras sobre a Consulta de Enfermagem à criança na atenção básica de Teresina-PI, 2016.

Fonte: Iramuteq.

$\mathrm{Na}$ interpretação desta última análise das representações sociais das enfermeiras sobre a Consulta de Enfermagem à criança na atenção básica obtido pelo IRAMUTEQ, observa-se a centralidade do vocábulo criança, que representa sua estruturação no universo pesquisado e seu diferencial em tamanho, que representa uma maior ocorrência em relação aos demais vocábulos.

Mello, Tonete e Silva (2009) confirmam esta centralidade na criança, entendendo a importância de assegurar fundamentalmente os seguintes cuidados: Promoção de boas condições de saúde para a infância; Cuidados efetivos de promoção, prevenção e terapêutica à criança e a participação da família neste cuidado.

Araújo et al. (2014) declaram que a integração familiar, dos serviços de saúde e dos profissionais no cuidado à saúde da criança, amplia a relação entre os sujeitos transformando à assistência à criança. Os resultados de seu estudo, também apresentam o cuidado centrado no individuo ao longo do acompanhamento do ciclo de vida das crianças de zero a doze anos. 
A essência das representações sociais elaboradas pelas enfermeiras sobre a Consulta de Enfermagem à criança na atenção básica é a criança, dentro de uma perspectiva de contextualização problematizada e focada no universo da saúde da criança. 


\subsection{INTEGRAÇÃO DOS RESULTADOS}

A análise da Consulta de Enfermagem às crianças menores de cinco anos na rede de atenção básica de Teresina-PI se dividiu em duas fases (quantitativa e qualitativa), viabilizada por meio do método misto com o uso da estratégia explanatória sequencial. Para explanação e integração dos resultados busca-se articular as fases do estudo como forma de buscar aproximações e distanciamentos entre os dados obtidos a partir das diferentes fontes.

Na fase um, caracterizou na rede e nas unidades de saúde da atenção básica de Teresina-PI no ano de 2012, as crianças menores de cinco anos cadastradas pelas equipes Saúde da Família, segundo regional, zona, gênero e faixa etária. Com isso, foi possível identificar que as crianças menores de cinco anos cadastradas na atenção básica de TeresinaPI estão mais concentradas em zonas urbanas em relação às zonas rurais, não apresentam diferenças significativas entre os gêneros, porém a faixa etária de um a quatro anos foi a mais representativa. As discussões acerca deste ponto, elucidaram também a discrepância existente entre os quantitativos das crianças cadastradas pela Fundação Municipal de Saúde de Teresina-PI com os dados fornecidos por outros órgãos estatísticos, como no caso, Instituto Brasileiro de Geografia e Estatística (IBGE).

Os dados quantitativos apresentam objetivamente a caracterização das 19.019 crianças atendidas ou cadastradas na rede de atenção básica de Teresina-PI, que não possuem diferenças significativas de gênero, e em sua maioria com idade entre 1 e 4 anos, estão mais concentradas na regional leste/sudeste zona urbana e em menor concentração, na regional centro/norte rural. Essa quantidade de crianças representa somente $32 \%$ da população estimada pelo Instituto Brasileiro de Geografia e Estatística (IBGE).

A quantificação das Consultas de Enfermagem realizadas na rede de atenção básica apresentou considerável diferença existente entre os meses do ano de 2012, destacando meses de altíssima produção: setembro e novembro, intercalados por meses abaixo da média: agosto, outubro e dezembro. De forma mais detalhada e específica, apresentou-se a produção de Consultas de Enfermagem às crianças menores de cinco anos por mês em cada unidade básica pertencente às regionais: centro norte, leste sudeste e sul, zonas urbanas e rurais. Com isso, foi possível identificar a unidade com destaques máximos (unidade básica de saúde pertencente a regional leste sudeste, zona urbana - UBS A) e mínimos (unidade básica de saúde vinculada a regional sul zona urbana - UBS B) a serem utilizadas como cenário da fase dois desta pesquisa. 
Constatou-se que não existe um padrão no quantitativo de Consulta de Enfermagem à criança, puericultura, atendimento individual do enfermeiro e visita domiciliar na rede de atenção básica de Teresina-PI, havendo portanto uma enorme diversidade entre as unidades básicas que compõem a rede durante o ano de 2012. Esse levantamento quantitativo que culmina com a seleção das unidades básicas de saúde com maior e menor produção de Consulta de Enfermagem à criança evidencia a existência de fatores importantes no cotidiano do enfermeiro, que carecem de investigação por representarem impactos significativos.

$\mathrm{Na}$ última etapa da fase um, relatou-se a Consulta de Enfermagem, quanto às características: estrutura física e equipamentos observados, sendo desta forma descritos por meio da observação direta na Consulta de Enfermagem em duas unidades distintas (UBS A e UBS B), e constatou-se que a estrutura física atendia parcialmente o preconizado pelo Ministério da Saúde, possuindo limitações especificas em cada unidade: UBS A (adequação de paredes, instrumentos e desenhos, brinquedos e decoração infantil) e UBS B (identificação na porta, desenhos, brinquedos e decoração infantil).

Na fase dois, descreveu-se a Consulta de Enfermagem à criança quanto ao processo de trabalho, duração da consulta, participantes, objetivos da consulta, procedimentos e temas abordados, por meio do relatado expresso pela entrevista com as enfermeiras da UBS A e UBS B encontrando assim aproximações e distanciamento entre as duas, com particularidades próprias e coerentes com as características de produção de cada unidade básica de saúde pesquisada.

Por vez, foi identificado o perfil sócio demográfico das sete enfermeiras que participaram do estudo que trabalhavam nas UBS A e B. Todas trabalhavam no turno manhã e tarde, sendo a maioria no primeiro turno, boa parte das entrevistas tinha idade superior a cinquenta e cinco anos, com estado civil casada. O tempo de formação profissional variou entre dois e trinta e cinco anos, sendo que a maioria tinha mais que dez anos de experiência na estratégia Saúde da Família. Todas eram especialistas, e em sua maioria, possuíam curso de quarenta horas nos últimos cinco anos.

As contribuições dos perfis das enfermeiras entrevistadas nos conduzem a perceber um cuidado feminino envolto de muitas experiências pessoais e profissionais, que é desvelado na apreensão das representações sociais das enfermeiras sobre a Consulta de Enfermagem à criança.

As representações sociais das enfermeiras sobre a Consulta de Enfermagem à criança na atenção básica de Teresina descrevem um conhecimento socialmente elaborado e compartilhado, pautado em cinco classes: Base legal da consulta - protocolo; Dimensão 
técnica da consulta - tecnologia do cuidado; Dimensão sócio-afetivas da consulta - o vinculo; Espaço social da consulta - acolhimento e A consulta como espaço de poder - a autonomia profissional. Nas representações sociais denominadas protocolo, observa-se a sustentação ou apoio para as ações de vigilância à saúde, nela é possível entender o referencial deontológico adotado pelas enfermeiras e desta forma se constitui forte e independente das demais classes. A dimensão técnica da consulta descreve o conhecimento que orienta a prática e que também sustentam as ações de vigilância à saúde, tendo como base a anamnese e exame físico além das temáticas: alimentação e estado nutricional; crescimento e desenvolvimento; estado vacinal; e cuidados de higiene com a criança. Dimensão sócioafetivas da consulta descreve as atividades que envolvem os significados e sentimentos na prática da consulta. O espaço social da consulta relaciona as estratégias de acesso para a consulta, estreitando os laços entre comunidade e unidade básica. E por último, a consulta como espaço de poder apresenta a prática do enfermeiro com habilidades, familiaridade e a capacidade de resolutividade. A análise de similitude e nuvem de palavras ilustram estas representações sociais das enfermeiras por meio de palavras, onde o maior destaque em ambas é: a criança.

Com isso, percebe-se que existe uma dicotomia entre as representações sociais das enfermeiras sobre a Consulta de Enfermagem à criança na rede de atenção básica de TeresinaPI e o quantitativo levantado de produção de Consultas de Enfermagem à criança na atenção básica, puericultura, atendimento individual do enfermeiro e visita domiciliar. Tal fato se justifica, pois os resultados qualitativos apresentam representações sociais que culminam com dois pontos importantes: ações de vigilância, que englobam a promoção da saúde e prevenção de doenças potencializando assim a Consulta de Enfermagem; e a Criança, onde todas as classes norteiam para o atendimento à criança. Em outras palavras, as representações sociais das enfermeiras sobre a Consulta de Enfermagem à criança na atenção básica se referenciam principalmente na PNAB e nas ações de cuidado à saúde da criança. Enquanto que os resultados quantitativos limitam o alcance desse cuidado à criança, por atender menos de $32 \%$ da população.

Em síntese, é possível na integração dos dados, afirmar que os discursos das enfermeiras apresentam uma realidade bem fomentada e focalizada nas Políticas Públicas de saúde brasileiras, contudo seu alcance ainda é questionável, diante da grande potencialidade da alta cobertura populacional das equipes da Estratégia Saúde da Família, existentes em Teresina-PI. 


\section{CONSIDERAÇÕES FINAIS}

A compreensão de como se dá a Consulta de Enfermagem à criança na rede de atenção básica de Teresina-PI e as representações sociais das enfermeiras sobre esta prática, conduzem ao entendimento de uma dicotomia entre prática e discurso. Em 2012, a Consulta de Enfermagem à criança menor de cinco anos teve um alcance de somente um terço da população; em contrapartida, nos discursos é possível observar falas que contemplam aspectos amplos e distintos que tornam, segundo os relatos das enfermeiras, práticas bem qualificadas, contemplando aspectos abrangentes, norteados pelas ações de vigilância com foco na criança.

O método misto com o uso da estratégia explanatória sequencial foi extremamente oportuno no estudo da Consulta de Enfermagem à criança na atenção básica, pois permite diferentes análises de um mesmo objeto de estudo, evidenciando achados de importância científica.

Contudo, a presente tese possui limitações, a saber: coleta de dados por meio de relatos das enfermeiras; pequeno número de participantes; utilização de fontes secundárias e limitações cronológicas da data de coleta dos dados, todos remetendo à problemática de que esta temática carece de maior atenção por parte dos pesquisadores, pois é carregada de importância diante do melhoramento e aperfeiçoamento da prática. Além disso, é relevante como instrumento de análises comparativas com outras realidades brasileiras.

Espera-se contribuir, com este estudo, para a evolução da Consulta de Enfermagem à criança na atenção básica enquanto prática, por entender-se que há necessidade de ampliar a produção de consulta de Enfermagem, mantendo a sua qualidade. Além disso, observou-se a importância do valor desse momento na qualidade de vida das crianças, através das ações de vigilância à saúde e também em termos de pesquisa, tendo em vista suprir uma carência na literatura científica. 


\section{REFERÊNCIAS}

ABREU, T.G.T.; VIANA, L.S.; CUNHA, C.L.F. Desafios na utilização da caderneta de saúde da criança: entre o real e o ideal. J Manag Prim Health Care, Olinda, v.3, n.2, p. 80-83, abr.-jun., 2012.

ACIOLI, S.; DAVID, H.M.S.L. A educação em saúde e a enfermagem em saúde Coletiva. In..: SANTOS, I. Et al. Enfermagem e campos de prática em saúde coletiva. Realidade, questões e soluções. São Paulo: editora Atheneu, 2008. P. 3-8.

AGUIAR, Z.N. SUS: SISTEMA ÚNICO DE SAÚDE - antecedentes, percurso, perspectivas e desafios. $1^{\text {a }}$ ed. São Paulo: Editora Martinari, 2011.

ALBERTI, V. Manual de história oral. $3^{\text {a }}$ edição. Rio de Janeiro: Editora FGV, 2005.

ALMEIDA, M.J.L. Et al. Protocolo de enfermagem na atenção à saúde da criança. In.: Protocolo de enfermagem na atenção básica de saúde e ambulatórios. Prefeitura Municipal de Teresina-PI, 2012.

ALMEIDA, M.F.P.V. Et al. Cuidados para crianças e adolescentes hospitalizados. In.: FIGUEIREDO, N.M.A. Ensinando a cuidar da criança. São Caetano do Sul: Difusão Enfermagem, 2003.

ALMEIDA, F.A.; PINTO, M.C.M.; SANTOS, S.A.G.E. Sistematização da Assistência de Enfermagem em Pediatria. In.: ALMEIDA, F.A.; SABATÉS, A.L. Enfermagem pediátrica: a criança, o adolescente e sua família no hospital. Barueri: Manole, 2008.

ALVES, A.M.A. A criança sadia. In.: FIGUEIREDO, N.M.A. Ensinando a cuidar da criança. $1^{a}$ ed. São Caetano do Sul: Difusão Enfermagem, 2003, p. 1-30.

ALVES, G.G.; AERTS, D. As práticas educativas em saúde e a Estratégia Saúde da Família. Ciência \& Saúde Coletiva, Rio de Janeiro, v.16, n.1, p. 319-25, 2011.

ANDRADE, G.N.; REZENDE, T.M.R.L.; MADEIRA, A.M.F. Caderneta de saúde da criança: experiências dos profissionais da atenção primária à saúde. Rev. Esc. Enferm. USP., São Paulo, 48, 5, p. 857-64, 2014.

APPOLINÁRIO, F. Dicionário de Metodologia Científica: um guia para a produção do conhecimento científico. São Paulo: Atlas, 2004. 
ARAUJO, J.P. et al. Avaliação dos atributos de orientação familiar e comunitária na saúde da criança. Acta paul. enferm., São Paulo , 27, 5, p. 440-6, Out., 2014.

ARAUJO, P.N.; Et al. A visão dos trabalhadores da atenção básica acerca da presença de estudantes de enfermagem. Rev. Esc. Enferm. USP, São Paulo, 47, 3, p. 694-701, jul.-set., 2013.

ARAUJO, N.V.D.L. Aspectos práticos da imunização. In: FUJIMORE, E.; OHARA,C.V.C. Enfermagem e a saúde da criança na atenção básica. Barueri: Manole, 2009. P.266-86.

ARRUDA, A. Teoria das representações sociais e teoria de gênero. Cadernos de pesquisa, 117, p.127-47, nov., 2002.

ASSIS, W.D. Et al. Processo de trabalho da enfermeira que atua em puericultura nas unidades de saúde da família. Rev. Bras. Enferm., Brasília, 64, 1, p. 38-46, fev., 2011.

BARRETO, J.M.O.; NERY, I.S.; COSTA, M.S.C. Estratégia Saúde da Família e internações hospitalares em menores de 5 anos no Piauí, Brasil. Cad. Saúde Pública, Rio de Janeiro, 28, 3, p.515-526, mar, 2012.

BARBOZA, C.L.; BARRETO, M.S.; MARCON, S.S. Registros de puericultura na atenção básica: estudo descritivo. Online Brazilian Jounaul of Nursing, Rio de Janeiro, v. 11, n. 2, ago., 2012.

BAUER, M.W.; GASKELL, G. Pesquisa qualitativa com texto, imagem e som. Petrópolis: Vozes, 2002.

BENGUIGUI, Y; CUNHA, A.J.L.A.; SILVA, M.A.S.F. Atenção integrada às doenças prevalentes na infância: implantação e avaliação no Brasil. Rio de Janeiro: editora Fiocruz, 2006.

BICUDO, D.M. Et al. Organization of primary care child health professional's seconds: qualitative research. Online Brazilian Jounaul of Nursing, Rio de Janeiro, v. 9, n. 1, p. 1-14, abr., 2010 .

BOEHS, A.E.; Et al. A percepção dos profissionais de saúde sobre os cuidados das mães de crianças entre 0 e 6 anos usuárias da Estratégia Saúde da Família. Physis: rev. De saúde coletiva, Rio de Janeiro, 21, 3, p. 1005-1022, 2011. 
BORGES, M.S.; QUEIROZ, L.S.; SILVA, H.C.P. Representações sociais sobre cuidar e tratar: o olhar de pacientes e profissionais. Rev. esc. enferm. USP, São Paulo, 45, 6, p. 1427-1433, Dec., 2011.

BRASIL. Ministério da Saúde. Rede APS. 2016. Brasília: Ministério da Saúde, 2016. Disponível em: < http://dab.saude.gov.br/portaldab/rede_aps.php> Acessado em 17/03/16.

Ministério da Saúde. Histórico de Cobertura da Saúde da Família. 2014. Brasília: Ministério da Saúde, 2014a. Disponível em: <http://dab.saude.gov.br/portaldab/historico_cobertura_sf.php> Acessado em: 27/05/14.

Ministério da Saúde. Relatório Consolidado do Bolsa Família. Percentual de cobertura com base nas crianças acompanhadas. Ministério da Saúde. Secretaria Estadual do Piauí. DATASUS, 2014b.

Ministério da Saúde. Relatório Consolidado do Bolsa Família. Informações gerais sobre crianças. Ministério da Saúde. Secretaria Estadual do Piauí. DATASUS, 2014c.

BRASIL. Ministério da Saúde. Política Nacional de atenção básica. Departamento de atenção à saúde. Brasília: Ministério da Saúde, 2012a.

Ministério da Saúde. Programa Nacional de melhoria do acesso e da qualidade da atenção básica (PMAQ): Manual instrutivo. Brasília: Ministério da Saúde, 2012b.

Ministério da Saúde. Resolução no 466 de 12 de dezembro de 2012. Diário Oficial da República Federativa do Brasil. Brasília, p. 59, 12 dez. 2012c. Seção 1. 2012c

- Ministério da Saúde. Cadernos de atenção básica. Acolhimento à demanda espontânea: queixas mais comuns na atenção básica. Brasília: Ministério da Saúde, 2012d.

Ministério da Saúde. Atenção à saúde do recém-nascido: guia para os profissionais de saúde. $2^{\mathrm{a}}$ ed. - Brasília: Ministério da Saúde, 2012e.

Ministério da Saúde. Saúde da criança: crescimento e desenvolvimento. Brasília: Ministério da Saúde, 2012f.

Ministério da Saúde. Portaria no 2.488 de 21 de outubro de 2011. Dispõe sobre a Política Nacional de Atenção Básica, estabelecendo a revisão de diretrizes e normas para a organização da Atenção Básica, para a Estratégia Saúde da Família (ESF) e o Programa de Agentes Comunitários de Saúde (PACS). Brasília: Ministério da Saúde, 2011a. 
Ministério da Saúde. Departamento de Atenção Básica. Política Nacional de nutrição e alimentação: atribuições das equipes de saúde no programa Bolsa Família na Saúde Brasil. 2011b.

BRASIL. Ministério da Saúde. Secretaria de Vigilância em Saúde. Departamento de Vigilância Epidemiológica. Doenças infecciosas e parasitárias: guia de bolso. $8^{\mathrm{a}}$ ed., Brasília, 2010a.

Ministério da Saúde. Informe da atenção básica n56: a participação da saúde no programa Bolsa Família. Ano X, jan.-fev., 2010b.

Ministério da Saúde. Evolução da Estratégia Saúde da família. Brasília: Ministério da Saúde, 2012c. Disponível em: <http://dab.saude.gov.br/abnumeros.php\#historico> acessado em 17/05/2013.

BRASIL. Ministério da Saúde. Sistema de Informação de Mortalidade. Brasília: Ministério da Saúde, 2012d. Disponível em: http://www2.datasus.gov.br/DATASUS/index.php?area=0201> acessado em 17/05/2013.

Ministério da Saúde. Portaria no 2.488 de 21 de outubro de 2011. Dispõe sobre a Política Nacional de Atenção Básica, estabelecendo a revisão de diretrizes e normas para a organização da Atenção Básica, para a Estratégia Saúde da Família (ESF) e o Programa de Agentes Comunitários de Saúde (PACS). Brasília: Ministério da Saúde, 2011.

Ministério da Saúde. Saúde da criança: nutrição infantil: aleitamento materno e alimentação complementar. Departamento de Atenção Básica. Brasília: Ministério da Saúde, 2009.

Ministério da Saúde. Caderno de educação popular e saúde. Departamento de Atenção Básica. Brasília: Ministério da Saúde, 2007.

Ministério da Saúde. Política Nacional de atenção básica. Departamento de atenção à saúde. Brasília: Ministério da Saúde, 2006a.

Ministério da Saúde. Manual prático para elaboração de projetos para unidades de saúde. Espírito Santo. Governo do Estado do Espírito Santo; 2006b.

Ministério da Saúde. Sistemas de Informações Ambulatoriais do SUS (SIA/SUS): manual de orientações técnicas. Secretaria de assistência à saúde. Brasília: Ministério da Saúde, 2006c. 
Ministério da Saúde. Guia Alimentar: Como ter uma alimentação saudável. Departamento de atenção à saúde. Brasília: Ministério da Saúde, 2006d.

Ministério da Saúde. Agenda de compromissos para a saúde integral das crianças e redução da mortalidade infantil. Departamento de atenção à saúde. Brasília: Ministério da Saúde, 2005a.

BRASIL. Ministério da Saúde Manual para a utilização da Caderneta de Saúde da Criança. Departamento de atenção à saúde. Brasília: Ministério da Saúde, 2005b.

. Ministério da Saúde. Marco legal: saúde, um direito de adolescentes. Departamento de atenção à saúde. Brasília: Ministério da Saúde, 2005c.

Ministério da Saúde. LEI $\mathbf{N}^{\mathbf{0}}$ 10.836, DE 9 DE JANEIRO DE 2004. Cria o Programa Bolsa Família e dá outras providências. Departamento de atenção à saúde. Brasília: Ministério da Saúde, 2004.

.MINISTÉRIO DA SAÚDE. AIDPI. Brasília: Ministério da Saúde, 2003a.

Ministério da Saúde. Dez Passos para uma Alimentação Saudável. Departamento de atenção à saúde. Brasília: Ministério da Saúde, 2002a.

. Ministério da Saúde. Guia Alimentar para Crianças Menores de dois anos. Departamento de atenção à saúde. Brasília: Ministério da Saúde, 2002 b.

Ministério da Saúde. Saúde da criança: acompanhamento do crescimento e desenvolvimento infantil. Departamento de atenção à saúde. Brasília: Ministério da Saúde, 2002c.

BRASIL. Ministério da Saúde. SIAB: manual do sistema de informação de atenção básica. Secretaria de assistência à saúde. Brasília: Ministério da Saúde, 2003b.

.MINISTÉRIO DA SAÚDE. A implantação da Unidade Saúde da Família. Brasília: Ministério da Saúde, Secretaria de Políticas de Saúde; Departamento de Atenção Básica, 2000.

.MINISTÉRIO DA SAÚDE. Lei no 8.080 de 19 de setembro de 1990. Dispõe sobre as condições para a promoção, proteção e recuperação da saúde, a organização e o funcionamento dos serviços correspondentes e dá outras providências. Brasília: Ministério da Saúde, 1990a. 
Ministério da Saúde. Lei no 8.142 de 28 de dezembro de 1990. Dispõe sobre a participação da comunidade na gestão do Sistema Único de Saúde (SUS \} e sobre as transferências intergovernamentais de recursos financeiros na área da saúde e dá outras providências. Brasília: Ministério da Saúde, 1990b.

MINISTÉRIO DA SAÚDE. Lei no 8.069 de 13 de julho de 1990. Dispõe sobre o Estatuto da Criança e do Adolescente e dá outras providências. Brasília: Ministério da Saúde, 1990c.

BRASIL. Ministério da Saúde. Departamento de Atenção Básica. Atenção básica e saúde da família. Brasília - DF, 2011. Disponível em <http://dab.saude.gov.br/atencaobasica.php> Acessado em 20.03.11.

Ministério da Saúde. Constituição da República Federativa do Brasil. Brasília,DF: Senado, 1988.

Ministério da Saúde. Decreto $\mathbf{N}^{\mathbf{0}} 94.406$ de 08 de junho de 1987. Regulamenta a Lei $\mathrm{n}^{\circ} 7.498$, de 25 de junho de 1986, que dispõe sobre o exercício da Enfermagem, e dá outras providências. Brasília-DF, 1987.

Ministério da Saúde. Lei $n^{0} 7.498$ de 25 de junho de 1986. Dispõe sobre a regulamentação do exercício da enfermagem, e dá outras providências. Brasília-DF, 1986.

Ministério da Saúde. Assistência integral à saúde da criança: ações básicas. Brasília: Ministério da Saúde, 1984.

CAMARGO, B.V. O que o caminho interdisciplinar brasileiro da teoria das representações sociais não favorece? In.: MOREIRA, A.S.P.; CAMARGO, B.V. Contribuições para Teoria e o método de estudo das representações sociais. João Pessoa: Editora Universitária da UFPB, 2007, p. 93-112.

CAMARGO, B.V.; JUSTO, A.M. Iramuteq: um software gratuito para análise de dados textuais. Temas psicol., Ribeirão Preto, v. 21, n.2, p. 513-8, dez., 2013.

CAMPOS, R.M.C.; Et al. Consulta de enfermagem em puericultura: a vivência do enfermeiro na estratégia Saúde da Família. Rev. Esc. Enferm. USP, São Paulo, 45, 3, p.566-74, jul-ago., 2011. 
CANELLA, D.S.; SILVA, A.C.F.; JAIME, P.C. Produção científica sobre nutrição no âmbito da Atenção Primária à Saúde no Brasil: um revisão de literature. Ciênci. Saúde coletiva, Rio de Janeiro, v.18, n. 2, p. 297-308, fev., 2013.

CARAM, A.L.A.; FRANCIOSI, K.T.B. A importância da nutrição no desenvolvimento da criança e do adolescente. In.: CARVALHO, S.D. O enfermeiro e o cuidar multidisciplinar na saúde da criança e do adolescente. São Paulo: editora Atheneu, 2012. P. 89-98.

CARDOSO, T.Z. Et al. Processo de trabalho de auxiliaries e técnicos de enfermagem na atenção básica à saúde. Rev. bras. Enferm., Brasília, v. 64, n.6, p. 1087-93, nov.-dez., 2011.

CARNIEL, E.F.; ARAÚJO, E.P.; CARVALHO, S. D. Enfermeiro na assistência ao programa nacional de imunizações. In.: CARVALHO, S.D. O enfermeiro e o cuidar multidisciplinar na saúde da criança e do adolescente. São Paulo: editora Atheneu, 2012. P. 35-50.

CARVALHO, S.D. O dia a dia da Consulta de Enfermagem em puericultura. In.: $O$ enfermeiro e o cuidar multidisciplinar na saúde da criança e do adolescente. São Paulo: editora Atheneu, 2012. P. 13-20.

CASTRO, S.G. Os caçadores da serra da capivara e a face cruel da educação ambiental. Dissertação (Mestrado em Educação). Teresina, 2004.

CASTRO, A.L.B.; FAUSTO, M.C.R. A política brasileira de atenção primária à saúde. In.: MACHADO, C.V.; BAPTISTA, T.W.F.; LIMA, L.D. Políticas de saúde no Brasil: continuidades e mudanças. Rio de Janeiro: Editora FIOCRUZ, 2012, p. 173-96.

CERVERA, D.P.P.; PARREIRA, B.D.M.; GOULART, B.F. Educação em saúde: percepção dos enfermeiros da atenção básica de Uberaba (MG). Ciência \& Saúde Coletiva, São Paulo, v.16, s.1, p.1547-1554, s.m, 2011

CERVO, A.M.; BERVIAN, P.A.; SILVA, R. Metodologia Científica. $6^{\text {a }}$ ed. São Paulo: Pearson Prentice Hall, 2007.

COFEN, Conselho Federal de Enfermagem. Resolução No 358 de 15 de outubro de 2009. Dispõem sobre a Sistematização da Assistência de Enfermagem e a implementação do Processo de Enfermagem em ambientes, públicos ou privados, em que ocorre o cuidado profissional de Enfermagem, e dá outras providências. Brasília-DF: Cofen, 2009. 
COFEN, Conselho Federal de Enfermagem. Resolução $\mathbf{N}^{\circ} 272$ de 27 de agosto de 2002. Dispõe sobre a Sistematização da Assistência de Enfermagem - SAE - nas Instituições de Saúde Brasileiras. Brasília-DF: Cofen, 2002.

COFEN, Conselho Federal de Enfermagem. Resolução no 159 de 19 de abril de 1993. Dispõe sobre a Consulta de Enfermagem. Rio de Janeiro: COFEN, 1993.

CORRÊA, A.C.P.; Et al. Perfil sociodemografico e profissional dos enfermeiros da atenção básica de Cuiabá - Mato Grosso. Rev. Eletr. Enf., internet, 14, 1, p. 171-180, jan.-mar., 2012.

CORRÊA, E.N. Et al. Alimentação complementar e características maternas de crianças menores de dois anos de idade em Florianópolis (SC). Revista Paulista Pediátrica, São Paulo, v.27, n.3, p. 258-264, set., 2009.

COSTA, L. Et al. Significado da consulta de enfermagem em puericultura: percepção de enfermeiras de estratégia saúde da família. Cienc Cuid Saude, Maringá, v.11, n.4, p. 792-8, out.-Dez., 2012.

COSTA, G.D.; Et al. Avaliação da atenção à saúde da criança no contexto da Saúde da Família no município de Teixeiras, Minas Gerais. Ciênc. e Saúde coletiva, Rio de Janeiro, 16,7, p. 3229-3240, jun., 2011.

CHIZZOTTI, A. Pesquisa em Ciências Humanas e Sociais. 2 ed. São Paulo: Cortez, 1999.

CRESWELL, J.W.; CLARK, V.L.P. Pesquisa de métodos mistos. Porto Alegre: Artmed, 2013.

CRESWELL, J.W. Projeto de pesquisa. Métodos qualitativos, quantitativos e mistos. Porto Alegre: Artmed, 2007.

CRUZ, A.C.; ANGELO, M. Cuidado centrado na família em pediatria: redefinindo os relacionamentos. Cienc Cuid Saude, Maringá, v.10, n.4, p.861-5, out.-dez, 2011.

DEPINE JUNIOR, G. O cuidado no processo de trabalho do enfermeiro na atenção primária no município de Rodeio-SC. Blumenau-SC, 2012. Trabalho de Conclusão de Curso - Universidade Federal de Blumenau-SC.

DURKHEIM, E. As regras do método sociológico. São Paulo, SP, Abril, 1978. 
ESCOREL, S. Et al. O programa de saúde da família e a construção de um novo modelo para a atenção básica no Brasil. Rev. Panam Salud. Publica/Pan Am J Public Health, Washington 21, 2, mar., 2007.

ESPINDÔLA, P.S.; LEMOS, C.L.S.; REIS, L.B.M. Perfil do profissional de nível superior na estratégia saúde da família. Rev. Bras. Promoç. Saúde, Fortaleza, 24, 4, p. 367-375, out.dez., 2011.

FARR, R.M. Representações sociais: a teoria e sua história. In.: GUARESCHI, P; JOVCHELOVITCH, S. Textos em representações sociais. $2^{\mathrm{a}}$ ed. Petropolis, RJ: Vozes , 1995, p. 31-65.

FARIA, M.G.A.; DAVID, H.M.S.L.; ACIOLI, S.O. O perfil de enfermeiros fluminenses da ESF segundo um programa de educação permanente à distância. Rev. Enferm. UERJ, Rio de Janeiro, 20, 1, p. 591-5, dez., 2012.

FARIA, R.C.; CAMPOS, E.M.S. Demanda espontânea na estratégia saúde da família: uma análise dos fatores que a influenciam e os desafios na reorientação do modelo assistencial do SUS. Rev. APS, Juiz de Fora, 15, 2, p. 148-157, abri.-mai., 2012.

FELICIANO, K.V.O. Et al. Avaliação continuada da educação permanente na atenção à criança na Estratégia Saúde da Família. Revista Brasileira de Saúde Materno Infantil, Recife, v.8, n.1, p.45-53, jan.-mar., 2008.

FERREIRA H.S.; CAVALCANTE A.S.; ASSUNÇÃO, M.L. Composição química e eficácia da multimistura como suplemento dietético: revisão de literatura. Ciência \&Saúde Coletiva. 2009; 15(2): 3207-3220.

FIGUEREDO, G.L.A.; MELO, D.F. Atenção à saúde da criança no Brasil: aspectos da vulnerabilidade programática e dos direitos humanos. Rev. Latino-am. Enfermagem. São Paulo, v.15, n.6, p. 1-7, nov./dez., 2007.

FIGUIREDO, G.L.A.; MELLO, D.F. A prática de enfermagem na atenção à saúde da criança em unidade básica de saúde. Rev. Latino-am enfermagem, São Paulo, v.11, n.4, p. 544-551, jul./ago., 2003.

FLICK, U. Desenho da pesquisa qualitativa. 4ª ed. Porto Alegre: Artmed, 2009.

FREITAS, M.C.M.C.; NUNES, B.M.V.T. Processo de trabalho do enfermeiro na atenção básica. Rev. Interdisciplinar NOVAFAPI, Teresina, v. 3, n. 3, p. 39-43, jul.-set., 2010. 
FROTA, M.A., BARROSO, M.G.T. Repercussão da desnutrição infantil na família. Revista Latino-Americana Enfermagem, Ribeirão Preto, v. 13, n.6, p.996-1000, dez., 2005.

FUJIMORE, E.; BORGES, A.L.V. Avaliação do crescimento. In: FUJIMORE, E.; OHARA,C.V.C. Enfermagem e a saúde da criança na atenção básica. Barueri: Manole, 2009a. P.121-51.

FUJIMORE, E.; RESENDE, M.A. Alimentação complementar e nos primeiros anos de vida. In: FUJIMORE, E.; OHARA,C.V.C. Enfermagem e a saúde da criança na atenção básica. Barueri: Manole, 2009a. P.174-199.

FUJIMORE, E.; RESENDE, M.A. Alimentação complementar e nos primeiros anos de vida. In: FUJIMORE, E.; OHARA,C.V.C. Enfermagem e a saúde da criança na atenção básica. Barueri: Manole, 2009a. P.174-199.

FUJIMORE, E.; RESENDE, M.A. Aleitamento Materno. In: FUJIMORE, E.; OHARA,C.V.C. Enfermagem e a saúde da criança na atenção básica. Barueri: Manole, 2009b. P.152-173.

GAIVA, M.A.M.; SILVA, F.B. Caderneta de saúde da criança: revisão integrativa.

Rev enferm UFPE on line., Recife, v.8, n.3, p.742-9, mar., 2014.

GALVÃO, C. M.; SAWADA, N. O.; TREVIZAN, M. A. Revisão sistemática: recurso que proporciona a incorporação das evidências na prática da enfermagem. Rev Latino-Am Enfermagem, v.12, n. 3, maio/jun. 2004, p.1-9.

GAUTERIO, D.P.; IRALA, D.A.; CEZAR-VAZ, M.R. Puericultura em enfermagem: perfil e principais problemas encontrados em crianças menores de um ano. Rev. Bras. Enferm., Brasília, v. 65, n. 3, p. 508-513, mai./jun., 2012.

GERALDI, A.P. Et al. Percepção dos profissionais enfermeiros acerca do exercício do controle social. Revista de Enfermagem, Frederico Westphalen, v. 8, n. 8, p. 55-66, s.m., 2012.

GIOVANELLA, L. Et al. Saúde da família: limites e possibilidades para uma abordagem integral de atenção primária à saúde no Brasil. Ciênci. Saúde coletiva, Rio de Janeiro, 14, 3, p. 783-794, mai./jun., 2009. 
GHISI, F. Et al. Satisfação da comunidade em relação à assistência prestada pela equipe da estratégia da saúde da família. Revista Inova Saúde, Criciúma, v. 2, n. 1, jul. 2013.

GOMES, A.M.T.; OLIVEIRA, D.C. A representação social da Consulta de Enfermagem: importância, ambiguidades e desafios. REME - Rev. Min. Enf., Belo Horizonte, 9, 2, p. 10915, abr.-jun., 2005.

HADDAD, J.G.V. Et al. A comunicação terapêutica na relação enfermeiro-usuário da atenção básica: um instrumento para a promoção da saúde e cidadania. O Mundo da Saúde, São Paulo, v.35, n.2, p.145-155, 2011.

HORTA, W.A. Processo de Enfermagem. São Paulo: EPU, 1979.

INSTITUTO BRASILEIRO DE GEOGRAFIA E ESTATISTICA - IBGE. Indicadores sociais municipais: uma análise dos resultados do universo do censo demográfico 2010. Rio de Janeiro: Ministério do Planejamento, orçamento e gestão, 2011.

JODELET, D. Imbricações entre Representações sociais e intervenção. In.: MOREIRA, A.S.P.; CAMARGO, B.V. Contribuições para Teoria e o método de estudo das representações sociais. João Pessoa: Editora Universitária da UFPB, 2007, P. 45-74.

JODELET, D. Representações sociais: um domínio em expansão. In.: JODELET, D. As representações sociais. Rio de Janeiro, editora UERJ, 2001.

JOHNSON, R. B.; ONWUEGBUZIE, A. J.; TURNER, L. A. Toward a definition of mixed method research. Journal of Mixed Methods Research, v.1, n. 2, p. 112$133,2007$.

JOVCHELOVITCH, S. Vivendo a vida com os outros: intersubjetividade, espaço público e representações socias. In.: GUARESCHI, P; JOVCHELOVITCH, S. Textos em representações sociais. $2^{\mathrm{a}}$ ed. Petropolis, RJ: Vozes , 1995, p. 66-88.

LEÃO, C.D.A.; CALDEIRA, A.P. Avaliação da associação entre qualificação de médicos e enfermeiros em atenção primária em saúde e qualidade da atenção. Ciênc. Saúde coletiva, Rio de Janeiro, v. 16, n.11, p. 4415-22, nov., 2011.

LEMOS, R.C.A. Et al. Visão dos enfermeiros sobre a assistência holística ao cliente hospitalizado. Rev. Eletr. Enf. [Internet], v.12, n.2, p. 354-9, 2010. Disponivel em: <http://www.fen.ufg.br/revista/v12/n2/v12n2a20.htm> acessado em 15/04/2014. 
LENTSCK, M.H.; KLUTHCOVSKY, A.C.G.C.; KLUTHCOVSKY, F.A. Avaliação do Programa Saúde da Família: uma revisão. Ciênc. Saúde coletiva, Rio de Janeiro, v.15, n.3, p. 3455-3466, 2010.

LIMA, A.S. O trabalho da enfermeira na atenção básica: uma revisão sistemática. Salvador, 2011. Dissertação - Universidade Federal da Bahia.

LIMA, K.Y.M. Et al. Visão de mães sobre a humanização no atendimento da criança na atenção primária à saúde. Cogitare Enferm., Curitiba, v.18, n.3, p. 546-51, jul.-set., 2013.

LIMA, V.M.; MELLO, D.F. Assistência de enfermagem a crianças menores de um ano de idade em unidade básica de saúde. Rev. Bras. Enferm., Brasíllia, 57,5, p. 1-7, set./out., 2004.

LOBO, F.S.; LIMA, I.F.S.; ACIOLI, K.L.B.O. Pacto pela saúde. In.: AGUIAR, Z.N. SUS: SISTEMA ÚNICO DE SAÚDE- antecedentes, percurso, perspectivas e desafios. $1^{\mathrm{a}}$ ed. São Paulo: Editora Martinari, 2011.

MAHLER, H. Saúde para todos - as enfermeiras indicam o caminho. Boletim ABEN, 28, 3, 1986.

MARQUES, E.S.; COTTA, R.M.M.; ARAÚJO, R.M.A. Representações sociais de mulheres que amamentam sobre amamentação e o uso de chupeta. Revista Brasileira de Enfermagem, Brasília, v.62, n.4, p.562-9, jul.-ago. 2009.

MARTINEZ, E.A., SOUZA, S.R., TOCANTINS, F.R. As contribuições das representações sociais para a pesquisa em saúde e na Enfermagem. Invest Educ Enferm., 30,1, p. 101-7, 2012.

MARTINS, T.S.A.; Et al. A viabilidade da Sistematização da Assistência de Enfermagem em serviço pediátrico: uma abordagem reflexiva. Rev. Eletr. Gestão \& Saúde, Brasília, 4, 1, p.1820-34, jan., 2013a.

MARTINS, T.S.A.; Et al. Implementação da avaliação do crescimento e desenvolvimento neuropsicomotor em crianças menores de cinco anos na USF Grajaú na cidade de Brumadinho-MG, pelo internato rural da UFMG. Rev. Med. Minas Gerais, Belo Horizonte, v.23, n.1, p. 27-32, jan.-fev., 2013 b. 
MATUMOTO, S. Et al. Produção de atendimentos de enfermeiros em unidades da rede básica de saúde. Rev. Latino-Am. Enfermagem, São Paulo, v. 20, n.4, p. 1-9, jul.-ago., 2012.

MEIRELES, G.O.A.B.; LOPES, M.M.; SILVA, J.C.F. O conhecimento dos enfermeiros sobre a Sistematização da Assistência de Enfermagem. Ensaios e ciência: ciências biológicas, agrárias e da saúde, São Paulo, 16, 1, p. 69-82, out., 2012.

MELO, F. Nutrição aplicada à enfermagem. Goiânia: AB editora, 2005.

MENDES, K.D.; SILVEIRA, R.C.C.P.; GALVÃO, M.C. Revisão Integrativa: método de pesquisa para a incorporação de evidências na saúde e na enfermagem. Texto Contexto Enferm., Florianópolis, v. 17, n. 4, p. 758-64, out-dez., 2008.

MENEZES, R.S.T.; PRIEL, M.R.; PEREIRA, L.L. Autonomia e vulnerabilidade do enfermeiro na prática da Sistematização da Assistência de Enfermagem. Rev. Esc. Enferm. USP, São Paulo, v.45, n.2, p. 953-8, ago., 2011.

MELO, D.F.; LIMA, R.A.G.; SCOCHI, C.G.S. A saúde de crianças em situação de pobreza: entre a rotina e a eventualidade de cuidados cotidianos. Rev. Latino-am enfermagem, São Paulo, 15, n.e., p., 1-8, set./out., 2007.

MELO, D.F.; TONETE, V.L.P.; SILVA, M.A.. Atenção básica à saúde da criança. In: FUJIMORE, E.; OHARA,C.V.C. Enfermagem e a saúde da criança na atenção básica. Barueri: Manole, 2009, p.44-60.

MINAYO, M.C.S.; GOMES, S.F.D.R. Pesquisa social: teoria, método e criatividade. $28^{\mathrm{a}}$ ed. Petropólis: Vozes, 2009.

MINAYO, et al. Avaliação por triangulação de métodos: abordagem de programas sociais. Rio de Janeiro: FIOCRUZ, 2005.

MINAYO, M.C.S. O conceito de representações sociais dentro da sociologia clássica. In.: GUARESCHI, P; JOVCHELOVITCH, S. Textos em representações sociais. $2^{\mathrm{a}}$ ed. Petropolis, RJ: Vozes , 1995, p. 89-112.

MITRE, S.M.; ANDRADE, E.I.G.; COTTA, R.M.M. Avanços e desafios do acolhimento na operacionalização e qualificação do Sistema Único de Saúde na atenção primária: um resgate da produção bibliográfica do Brasil. Ciênc. \& Saúde Coletiva, Rio de Janeiro, 17, 8, p. 2071-85, ago., 2012. 
MODES, P.S.S.A.; GAIVA, M.A.M. Satisfação das usuárias quanto à atenção prestada à criança pela rede básica de saúde. Esc Anna Nery (impr.), Rio de Janeiro, v.17, n.3, p. 45565, jul.-set., 2013.

MONTEIRO, A.I.; Et al., A enfermagem e o fazer coletivo: acompanhando o crescimento e desenvolvimento da criança. Rev. RENE, Fortaleza, 12, 1, p. 73-80, jan./mar., 2011a.

MONTEIRO, A.I.; Et al. A expressão da autonomia do enfermeiro no acompanhamento do crescimento e desenvolvimento da criança. Rev. Enferm. UERJ, Rio de Janeiro, v.19, n.3, p. 426-31, jul./set. 2011b.

MOREIRA, M.D.S.; GAIVA, M.V.M. Acompanhamento do crescimento e desenvolvimento infantil: análise dos registros das consultas de enfermagem. R. pesq.: cuid. fundam. Online, Rio de Janeiro, 5, 2, p. 3757-66, abr./jun., 2013.

MOSCOVICI, S. Prefácio. In.: GUARESCHI, P; JOVCHELOVITCH, S. Textos em representações sociais. $2^{\text {a }}$ ed. Petropolis, RJ: Vozes, 1995, p. 7-16.

MOSCOVICI, S. A relatividade tem 100 anos. In.: MOREIRA, A.S.P.; CAMARGO, B.V. Contribuições para Teoria e o método de estudo das representações sociais. João Pessoa: Editora Universitária da UFPB, 2007, p. 21-44.

MOSCOVICI, S. Representações socias: investigação e psicologia social. Petropólis, RJ: Editora Vozes, 2003.

MOSCOVICI, S. Representações socias: investigação e psicologia social. Petropólis, RJ: Editora Vozes, 2001.

MOSCOVICI, S. A representação social da psicanálise. Rio de Janeiro: Zahar, 1978.

MOURA, M.A.P.; ROCHA, S.S. Dinâmica da Assistência de Enfermagem no cuidado à criança na atenção básica. Nursing, Barueri, v.167, n. 14, p. 221-6, abr., 2012.

NEVES, R.S. Análise do processo de implantação da Sistematização da Assistência de Enfermagem - SAE: um estudo de caso. Brasília-DF, 2010, 295p. Tese - Ciências da Saúde, Universidade Nacional de Brasília - UNB.

NOBREGA, V.M.; Et al. Atenção à criança com doença crônica na estratégia saúde da Família. Cogitare enfermagem, Curitiba, 18, 1, p. 57-63, jan.-mar, 2013. 
NOBREGA, S.M. Sobre a teoria das representações sociais. In.: MOREIRA, A.S.P.; JESUÍNO, J.C. Representações sociais: teoria e pratica. $2^{\mathrm{a}}$ ed. João Pessoa: universitária, 2003, p. 51-80.

NOBREGA, S.M.; FONTES, E.P.G.; PAULA, F.M.S.M. Do amor e da dor: representações sociais sobre o amor e o sofrimento psíquico . Estudos de psicologia, Campinas, 22, 1, p. 77-87, jan.-mar., 2005.

NOBREGA, F.J. Nutrição e vínculo mãe-filho. In.: PALMA, D; ESCRIVÃO, M.A.M.S.; OLIVEIRA, F.L.C. Nutrição clínica na infância e na adolescência. Barueri: Manole, 2009. P. 89-96.

NOBREGA, M.M.L.; SILVA, K.L. Fundamentos do cuidar em enfermagem. $2^{\mathrm{a}}$ ed. Belo Horizonte: ABEN, 2008/2009.

OHARA, C.V.S. Et al. In: FUJIMORE, E.; OHARA,C.V.C. Enfermagem e a saúde da criança na atenção básica. Barueri: Manole, 2009, p. 200-221.

OLIVEIRA, A.; LOPES, S.; LUZ, S. O paradigma biomédico e holístico face aos cuidados de enfermagem. Mindelo, 2013, 70p. Trabalho de Conclusão de Curso - Universidade de Mindelo.

OLIVEIRA, F.F.S.; et al. Consulta de puericultura realizada pelo enfermeiro na estratégia saúde da família. Rev. RENE, Fortaleza, 14, 4, p. 694-703, 2013 b.

OLIVEIRA, S.K.P.; Et al. Temas abordados na consulta de enfermagem: revisão integrativa de literatura. Rev. Bras. Enferm., Brasília, v.65, n.1, p. 155-66, jan.-fev., 2012.

PAIM, J.S. O que é o SUS. Rio de Janeiro: editora Fiocruz, 2009.

PAIM, J.S. Epidemiologia e planejamento: a recomposição das práticas epidemiológicas na gestão do SUS. Ciênci. Saúde coletiva, Rio de Janeiro, v. 8, n. 2, p.57-567, 2003.

PEDROSA, K.A.A.; CASTRO, L.O.; PEREIRA, W. Nursing and health education in primary care: an experiment in the neighborhood of mother luiza, NATAL-RN. R. pesq.: cuid. fundam. Online, Rio de Janeiro, v.4, n.4, p. 2806-15, out.-dez., 2012.

PEDROSO, M.L.R.; ROSA, N.G. Consulta de enfermagem em um programa de vigilância à saúde: vivências do Prá-Nenê. Rev.Gaúch enferm., Porto Alegre, v.30,n.2, p.221-7, jun., 2009. 
PEREIRA, R.T.A.; FERREIRA, V. A consulta de enfermagem na estratégia saúde da família. Revista UNIARA, v.17, n.1, p.99-111, jul., 2014.

PEREIRA, J.S.; Et al. Nurses knowlegde about the nursing process in the light of the framework of Wanda de Aguiar Horta. R. pesq.: cuid. fundam. Online, Rio de Janeiro, v.4, n.2, p. 2437-47, abr.jun., 2012.

PINA, J.C.; MELLO, D.F. LUNARDELO, S.R. Utilização de instrumentos de registro de dados da saúde e família e a prática do enfermeiro em atenção básica à saúde. Rev. Bras. Enferm., Brasília, v. 59, n.3, p. 270-3, mai./jun., 2006.

PIRES, M.R.G.M. Et al. A Utilização dos Serviços de Atenção Básica e de Urgência no SUS de Belo Horizonte: problema de saúde, procedimentos e escolha dos serviços.

Saúde Soc. São Paulo, v.22, n.1, p.211-222, jan., 2013.

PIAUÍ, Fundação Municipal de Saúde. PSF- PROGRAMA SAÚDE DA FAMília. Teresina-PI, 2011. Disponível em: < http://saude.teresina.pi.gov.br/psf.asp>, acessado em 20.01.2011.

POPE, C.; MAYS, N. Pesquisa qualitativa na atenção à saúde. $3^{\text {a }}$ ed. Porto Alegre: Artmed, 2009.

POTTER, P.A.; PERRY, A.G. Fundamentos de Enfermagem. Rio de Janeiro: Elsevier, 2009.

PRADO, S.R.L.A.; FUJIMORE, E. Registro em prontuário de crianças e a prática da integralidade. Rev. Bras. Enferm., Brasília, 59, 1, p. 67-71, jan./fev., 2006.

REBELLO, C.M.; KOOPMANS, F.F.; ROMANO, V.F. O acolhimento no processo de trabalho na estratégia saúde da família: reflexão sobre conceitos. Corpus et scientia, Rio de Janeiro, 8, 3, p. 127-138, dez., 2012.

REICHERT, A.P.S.; Et al. Vigilância do crescimento infantil: conhecimentos e práticas de enfermeiros da atenção primária à saúde. Rev. RENE, Fortaleza, v.13, n.1, p.114-26, jan./fev. 2012.

RIBEIRO, M.O.. Et al. Desenvolvimento infantil: a criança nas diferentes etapas de sua vida. In: FUJIMORE, E.; OHARA,C.V.C. Enfermagem e a saúde da criança na atenção básica. Barueri: Manole, 2009. P.61-120. 
RIBEIRO, C.A.; OHARA, C.V.S.; SAPAROLLI, E.C.L. Consulta de enfermagem em puericultura. In: FUJIMORE, E.; OHARA,C.V.C. Enfermagem e a saúde da criança na atenção básica. Barueri: Manole, 2009, p.223-248.

RIBEIRO, C.A.; SILVA, C.V.; SAPAROLLI, E.C.L. Consulta de enfermagem à criança num projeto de integração docente- assistencial: experiência de implantação. Acta Paul. Enf., São Paulo, 15, 2, p. 79-88, 2002.

RIBEIRO, J.M.; SIQUEIRA, S.A.V.; PINTO, L.F.S. Avaliação da atenção a saúde da criança (0 a 5 anos) no PSF de Teresopolis (RJ) segundo a percepção dos usuários. Ciênc. e Saúde coletiva, Rio de Janeiro, 15,2, p. 517-527, mar., 2010.

RICCO, R.G.; DEL CIAMPO, L.A., ALMEIDA, C.A.N. Puericultura: princípios e práticas. Atenção Integral à Saúde da Criança. $1^{a}$ ed. São Paulo: Editora Atheneu; 2001.

ROCHA, S.S. Enfermeiras da estratégia saúde da família no cuidado à saúde das crianças de Teresina. Rio de Janeiro, 2005. Tese - Escola de Enfermagem Anna Nery, Universidade Federal do Rio de Janeiro.

ROSSI, L.A. O processo de Enfermagem em uma unidade de queimados: da ideologia da rotina à utopia do cuidado individualizado. Ribeirão Preto, 1997.

Tese - Escola de Enfermagem de Ribeirão Preto, Universidade de São Paulo.

RODRIGUES, C.R.F. Do programa de saúde da família à estratégia saúde da família. In.: AGUIAR, Z.N. SUS: SISTEMA ÚNICO DE SAÚDE- antecedentes, percurso, perspectivas e desafios. $1^{a}$ ed. São Paulo: Editora Martinari, 2011.

RODRIGUES, T.M.M. A visita domiciliar como instrumento do cuidado na estratégia Saúde da Família. Dissertação de Mestrado (Mestrado em Enfermagem) - Universidade Federal do Piauí, Teresina, 2009.

SÁ, C.P. Representações sociais: o conceito e o estado atual da teoria. In.: SPINK, M.J.P. O conhecimento no cotidiano: as representações sociais na perspectiva da psicologia social. São Paulo: Brasiliense, 1995.

SAPAROLLI, E.C.L.; ADAMI, N.P. Avaliação da estrutura destinada à consulta de enfermagem à criança na atenção básica. Rev. Esc. Enferm. USP, São Paulo, v.44, n.1, p. 9298, mar., 2010.

SANTANA, P.P.; MARTINS, S.C.; GUIMARÃES, Z.S. Consulta de enfermagem: da teoria à prática. Goiânia: Editora $\mathrm{AB}, 2008$. 
SANTOS, A.M. Et al. Práticas assistenciais das Equipes de Saúde da Família em quatro grandes centros urbanos. Ciênc. saúde coletiva, Rio de Janeiro, 17, 10, Out., 2012a .

SANTOS, I. Et al. Cuidar da integralidade do ser: perspectiva estética/ sociopoética de avanço no domínio da enfermagem. Rev. enferm. UERJ, Rio de Janeiro, v.20, n.1, p.9-14, $2012 b$.

SANTOS, S.M.R. Et al. A consulta de enfermagem no contexto da atenção básica de saúde de Juiz de Fora, Minas Gerais. Revista texto e contexto, Florianópolis, 17, 1, p. 124-30, jan.marc., 2008.

SEVERINO, A.J. Metodologia do trabalho científico. $23^{\text {a }}$ ed. São Paulo: Cortez, 2007.

SILVA, S.É.D.; CAMARGO, B.V.; PADILHA, M.I.. The social representations theory in brazilian nursing research. Rev. bras. enferm., Brasília , 64, 5, p. 947-951, out. 2011.

SILVA, D.; GOMES, A.M.T.; CARVALHO, E.C. Informação e saúde. In.: SANTOS, I.; Et. al. Enfermagem e campos de prática em Saúde Coletiva: realidade, questões e soluções. São Paulo: Atheneu, 2008.

SILVA, A.M.F.; MARTINI, J.G.; BECKER, S.G.. A teoria das representações sociais nas dissertações e teses em enfermagem: um perfil bibliométrico. Texto contexto enferm., Florianópolis , 20, 2, p. 294-300, Jun., 2011.

SILVA, M.H.N.; Et al. Perfil epidemiológico e social da população atendida em uma unidade básica de saúde em Cuiabá. Rev. Eletr. Gestão \& Saúde, Brasília, 4, 2, p. 257-266, mai.ago., 2013.

SILVA, L.D. Et al. O enfermeiro e a educação em saúde: um estudo bibliográfico.

Rev Enferm UFSM, Santa Maria, v.2, n.2, p. 412-9, mai.-ago., 2012.

SILVA, L.W.S.; et al.. Sistematização da Assistência de Enfermagem - a práxis no ser-saberfazer o cuidado. Cogitare enferm., Curitiba, v.16, n.3, p. 560-4, jul-set., 2011.

SPINK, M.J. Desvendando as teorias implícitas: uma metodologia de análise das representações sociais. In.: GUARESCHI, P; JOVCHELOVITCH, S. Textos em representações sociais. $2^{a}$ ed. Petropolis, RJ: Vozes , 1995. 
SOARES, F.F.; CHAVES, S.C.L.; CANGUSSU, M.C.T. Desigualdade na utilização de serviços de saúde bucal na atenção básica e fatores associados em dois municípios brasileiros. Rev Panam Salud Publica, Washington, v.34, n.6, p.401-6, nov.-dez., 2013.

SOARES, M.D.; COELHO, T.C.B. O cotidiano do cuidado infantil em comunidades rurais do estado da Bahia: uma abordagem qualitativa. Revista Brasileira de Saúde Materno Infantil, Recife, v.8, n.4, dez., 2008.

SORATTO, J; WITT, R.R. Participação e controle social: percepção dos trabalhadores da saúde da família. Texto Contexto Enferm, Florianópolis, v.22, n.1, p.89-96, jan.-mar., 2013.

SOUZA, E.A.S. Análise de representações sociais. In.: SPINK, M.J.P. O conhecimento no cotidiano: as representações sociais na perspectiva da psicologia social. São Paulo: Brasiliense, 1995.

SOUSA, F.G.M.; ERDMANN, A.L.; MOCHEL, E.G. Condições limitadoras para a integralidade do cuidado à criança na atenção básica de saúde. Texto contexto - enferm., Florianópolis, 20, n.e., p. 263-271, 2011.

SOUSA, F.G.M.; ERDMANN, A.L.; MOCHEL, E.G. Modelando a integralidade do cuidado à criança na atenção básica de saúde. Rev. Gaúcha Enferm. (Online), Porto Alegre, 31, 4, p. 701-7, dez., 2010.

SOUSA, L.B. Et al. Práticas de educação em saúde no Brasil: a atuação de enfermagem. Rev. enferm. UERJ, Rio de Janeiro, v.18, n.1, p. 55-60, jan.-mar., 2010.

SOUSA, M.F. Et al. Gestão da atenção básica: redefinindo contexto e possibilidades. Saúde para Debate, Rio de Janeiro, n. 21, p. 7-14, dez. 2000.

SOUSA NETO, M.A. Et al. Perfil dos usuários de medicamentos das unidades básicas de saúde de Ceres-GO. Rev. Eletron. Da Faculdade Ceres, v.1, n.1, jan., 2012.

SOUZA, A.P. Et al. Percepção dos usuários da atenção básica acerca da consulta de enfermagem. Rev Min Enferm., Belo Horizonte, v.17, n.1, p.11-7, jan.-mar., 2013.

SPLENDOR, V.L.; ROMAN, A.R. A mulher, a enfermagem e o cuidado na perspectiva de gênero. Rev. Contexto \& saúde, Ijuí, 2, 4, p. 31-44, jan.-jun., 2003. 
TANNNURE, M.C.; PINHEIRO, A.M. SAE - Sistematização da Assistência de Enfermagem: guia prático. $2^{\mathrm{a}}$ ed. Rio de Janeiro: Guanabara Koogan, 2010.

TEIXEIRA, C.; PAIM, J.S.; VILASBOAS, A.L. Promoção e vigilância da saúde. Salvador: Instituto de Saúde Coletiva, 2002, p. 23-52.

TERRA, A.A.A.; DIAS, I.V.; REIS, V.N. A enfermagem atuando como facilitadora do apego materno-filial. R. Enferm. Cent. O. Min., Belo Horizonte, v.1, n.3, p. 332-41, jul./set., 2011.

TOMASI, E. Et al. Características da utilização de serviços de atenção básica à saúde nas regiões sul e nordeste do Brasil: diferenças por modelo de atenção. Ciênc. Saúde coletiva, Rio de Janeiro, 16, 11, p. 4397-4404, nov., 2011.

TRAPÉ, C.A.; FUJIMORE, E.; BERTOLOZZI, M.R. O Sistema Único de Saúde e as políticas de atenção à saúde da criança. In.: FUJIMORE, E.; OHARA,C.V.C. Enfermagem e a saúde da criança na atenção básica. Barueri: Manole, 2009, p.25-43.

TRINDADE, L.L.; PIRES, D.P.E. Implicações dos modelos assistenciais da atenção básica nas cargas de trabalho dos profissionais de saúde. Texto Contexto Enferm, Florianópolis, v.22, n.1, p. 36-42, jan.-mar., 2013.

UNICEF, United Nations Children's Fund. Committing to Child Survival: A Promise Renewed. Progress Report, 2013.

VALE, I.N.; CARMONA, E.V. Aleitamento materno e alimentação complementar. In.: CARVALHO, S.D. O enfermeiro e o cuidar multidisciplinar na saúde da criança e do adolescente. São Paulo: editora Atheneu, 2012. P. 77-88.

VARELA, G.C. Et al. Sistematização da Assistência de Enfermagem na estratégia saúde da família: limites e possibilidades. Rev. RENE, Fortaleza, 13, 4, p. 816-24, out.-dez., 2012.

VASCONCELOS, E.N. Et al. Puericultura em enfermagem e educação em saúde: percepção de mães na estratégia saúde da família. Esc. Anna Nery, Rio de Janeiro, 16, 2, p. 326-331, abr.-jun., 2012.

VASCONCELOS, E.N. Et al. A normatização do cuidar da criança menor de um ano: estudo dos significados atribuídos pelos profissionais do Programa Saúde da Família (PSF). Ciênc. Saúde coletiva, Rio de Janeiro, 14, 4, p. 1225-1234, jul./ago., 2009. 
VIEGAS, S.M.F.; PENNA, C.M.M. O vínculo como diretriz para a construção da integralidade na estratégia saúde da família. Rev. Rene, Fortaleza, v.13, n.2, p. 375-85, abr.jun., 2012.

VIEIRA, E.T. Et al. O programa saúde da família sob o enfoque dos profissionais de saúde. RBPS, Fortaleza, v.17, n.3, p. 119-26, 2004. 


\section{Universidade de Brasília \\ FACULDADE DE CIENCIAS DA SAÜDE \\ PROGRAMA DE POS-GRADUAÇÄO EM ENFERMAGEM}

APÊNDICE A: INSTRUMENTO DE COLETA I (IC1)

\section{INSTRUMENTO DE OBSERVAÇÃO DA \\ CONSULTA DE ENFERMAGEM À CRIANÇA NA ATENÇÃo BÁSICA}

\section{-ESTRUTURA, INSTRUMENTOS E RECURSOS UTILIZADOS}

A Unidade Básica de Saúde possui estrutura mínima composta por: recepção, consultório médico; consultório de enfermagem; ambiente para armazenamento e dispensação de medicamentos; laboratório; sala de vacina; banheiro público; banheiro exclusivo para os funcionários; expurgo; cabines com leitos em número suficiente para toda a equipe; cozinha; sala de procedimentos; e, se forem compostas por profissionais de saúde bucal, será necessário consultório odontológico com equipo odontológico completo:

$\square$ Sim $\square$ Não $\square$ Parcialmente

A UBS dispõem de balança e antropometro infantil:

$\square \operatorname{Sim} \quad \square$ Não $\quad \square$ Parcialmente

Possui Consultório de enfermagem para cada equipe da UBS:

$\square$ Sim $\square$ Não $\square$ Divide com outros profissionais

O consultório possui identificação com logomarcas do SUS e da ESF:

$\square \mathrm{Sim} \quad \square$ Não $\quad \square$ Divide com outros profissionais

Consultório de Enfermagem possui luz branca (ou natural) e ventilação adequada:

$\square \operatorname{Sim} \quad \square$ Não $\square$ Parcialmente

Consultório de Enfermagem possui piso e paredes laváveis:

$\square$ Sim $\quad \square$ Não $\quad \square$ Parcialmente

Consultório de Enfermagem pia com água e dispensador de sabão:

$\square \operatorname{Sim} \quad \square$ Não $\square$ Parcialmente

Consultório de Enfermagem possui mesa e cadeiras adequadas para a consulta:

$\square$ Sim $\quad \square$ Não $\quad \square$ Parcialmente

Consultório de Enfermagem possui maca e instrumentos para o exame físico adaptado para atendimento infantil (estetoscópio, esfigmomanômetro, otoscópio, lanterna, fita métrica, termômetro):

$\square \operatorname{Sim} \quad \square$ Não $\quad \square$ Parcialmente

Consultório de Enfermagem dispõem de desenhos, brinquedos ou decoração para crianças: $\square$ Sim $\square$ Não $\quad \square$ Parcialmente 


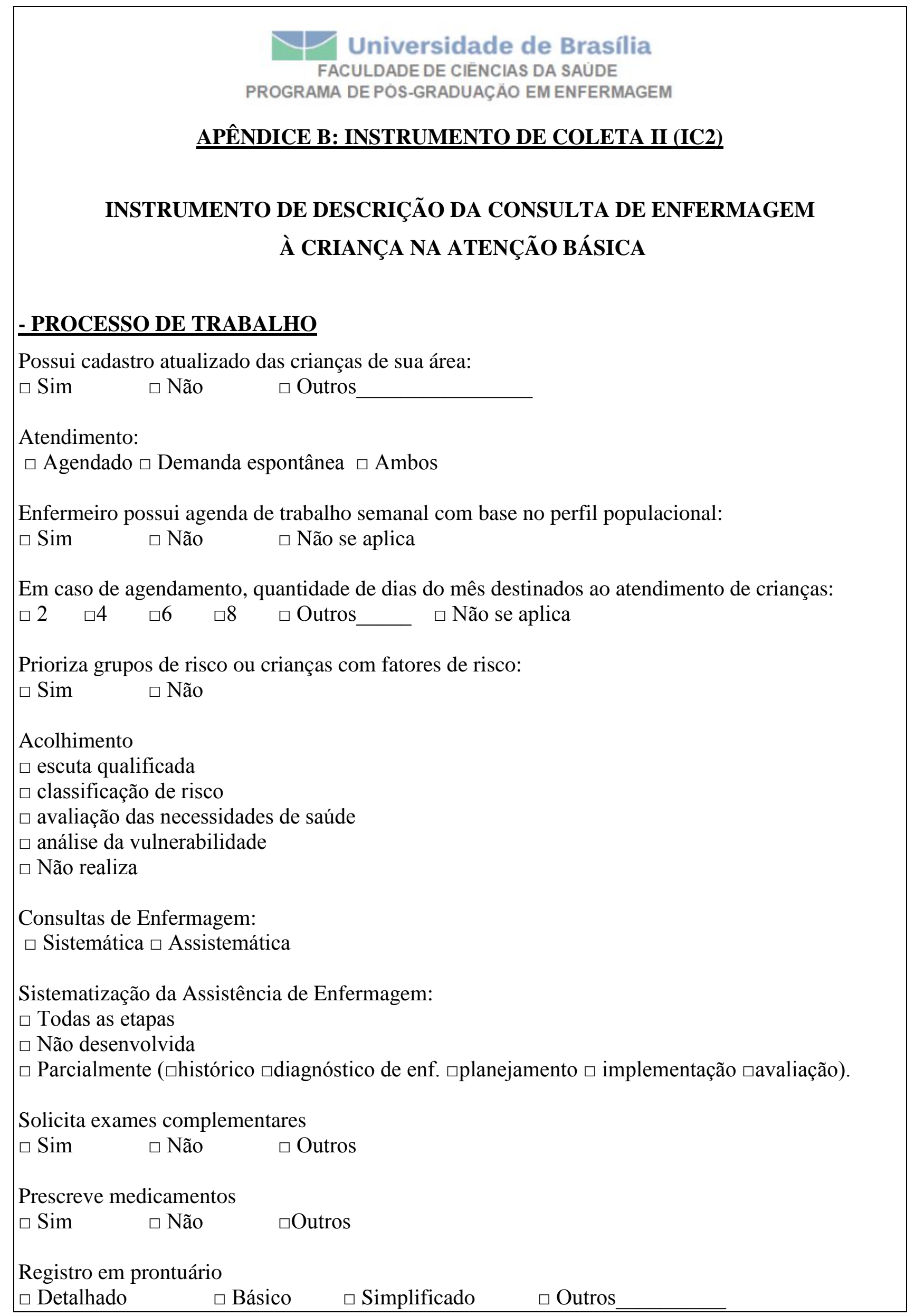




\section{-TEMPO DE REALIZACÃO DA CONSULTA DE ENFERMAGEM}

Tempo que ocorre dentro no consultório

$\square$ até $10 \mathrm{~min} . \quad \square 11-20 \mathrm{~min} . \square$ 21-30 min. $\square 31 \mathrm{~min}$. à 1 hora $\square$ Maior que $1 \mathrm{~h}$.

Criança pesada e medida anteriormente

$\square$ Sim $\square$ Não

Profissional responsável:

\section{-PARTICIPANTES ENVOLVIDOS NO MOMENTO DA CONSULTA}

Quem mais acompanha a criança na consulta:

$\square$ Pai $\square$ Mãe $\square$ Parentes $\square$ Vizinhos $\square$ Amigo $\square$ Outros

Acompanhantes do enfermeiro:

$\square$ Médico

$\square$ Técnico ou auxiliar de enfermagem

$\square$ Agente comunitário de saúde

$\square$ Estagiário

\section{-OBJETIVOS DA CONSULTA}

$\square$ Promoção da saúde e prevenção de doenças

$\square$ Doença ou agravo em curso

$\square$ Educação em saúde

$\square$ Retorno

$\square$ Bolsa Família

$\square$ Cadastro /primeira consulta

$\square$ Resolutividade

\section{-PROCEDIMENTOS REALIZADOS PELO ENFERMEIRO NA CONSULTA}

$\square$ Lavagem das mãos

$\square$ Administração de medicamentos

Medidas antropométricas

$\square$ Toque terapêutico

$\square$ Uso de brinquedos

$\square$ Orientações alimentares

$\square$ Curativos

$\square$ Outros:

- TEMÁTICAS ABORDADAS DURANTE A CONSULTA

Alimentação infantil

Crescimento e Desenvolvimento

$\square$ Vacinações

Bolsa Famílias

- Mudanças biopsicossociais da infância

$\square$ Desenvolvimento neuropsicomotor

$\square$ 


\section{APÊNDICE C: INSTRUMENTO DE COLETA 3 (IC3)}

\section{REPRESENTAÇÕES SOCIAIS DA CONSULTA DE ENFERMAGEM À CRIANÇA NA ATENÇÃO BÁSICA}

\section{ROTEIRO PARA ENTREVISTA}

Número de ordem: Data:

\section{I- Perfil sociodemográfico e profissional dos enfermeiros}

1. Gênero:
) Masculino
) Feminino

2. Idade:
) 20 a 30 anos (
) 31 a 40 anos (
) 41 a $50 \operatorname{anos}($
) Maior que 51 anos

3. Tempo de serviço na estratégia Saúde da Família:

( ) Menor que 5 anos ( ) 6 a 10 anos ( ) Maior que 10 anos

4. Estado civil:

( ) Solteiro ( ) Casado ( ) União estável( ) Viúvo ( ) Divorciado

5. Naturalidade:

6. Tempo de formado em enfermagem:

7. Possui pós-graduação: ( ) especialização ( ) mestrado Área:

8. Capacitação/atualização com C.H. de no mínimo 40 horas nos últimos 5 anos: ( ) Sim ( ) Não

9. Vínculo empregatício:

( ) efetivo ( ) contrato temporário ( ) Outros:

10. Turno de trabalho:

( ) manhã ( ) tarde

I- Questão sobre as representações sociais dos enfermeiros sobre a Consulta de Enfermagem na atenção básica:

a) Para você, como é a Consulta de Enfermagem à criança na atenção básica. 
ANEXOS 


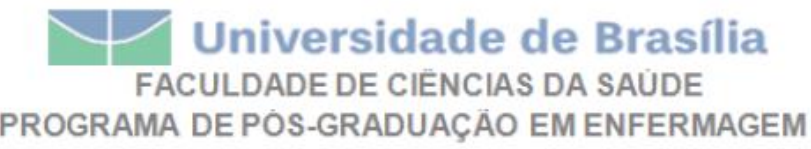

\section{ANEXO A - TERMO DE CONSENTIMENTO LIVRE E ESCLARECIDO}

Você está sendo solicitado para autorizar uma pesquisa. Você precisa decidir se quer autorizar ou não. Por favor, não se apresse em tomar a decisão. Leia cuidadosamente o que se segue e pergunte ao responsável pelo estudo sobre qualquer dúvida que tiver. Este estudo está sendo conduzido pela Dra. Diana Lúcia Moura Pinho e Ma. Mayara Águida Porfírio Moura. Após ser esclarecido (a) sobre as informações a seguir, no caso de autorizar este estudo, assine este documento, que está em duas vias. Uma delas é sua e a outra é do pesquisador responsável. Em caso de recusa você não será penalizado (a) de forma alguma. Em caso de dúvida você pode procurar o Comitê de Ética em Pesquisa da Universidade Federal do Piauí pelo telefone (086) 32155564.

\section{ESCLARECIMENTO SOBRE A PESQUISA:}

\section{Título do Projeto: CONSULTA DE ENFERMAGEM À CRIANÇA NA ATENÇÃO BÁSICA}

Pesquisadores Responsáveis: Diana Lúcia Moura Pinho e Mayara Águida Porfírio Moura.

Telefones para contato: (86) 9925 -1540.

- O presente estudo se configura como um estudo de abordagem mista, do tipo descritivo e exploratório, a ser realizado na Estratégia Saúde da Família, Teresina-PI. A coleta dos dados realizar-se-á no segundo semestre de 2013, após a aprovação por este pelo comitê de ética e autorização da instituição. Objetiva-se nesta pesquisa, Identificar na rede de atenção básica no ano de 2012 a quantidade de: crianças menores de cinco anos cadastradas pelas equipes Saúde da Família; a produção de Consultas de enfermagem a população e às crianças menores de cinco anos; puericulturas, o atendimento individual realizado pelo enfermeiro e visitas domiciliares exclusiva dos enfermeiros; Construção de um instrumento de descrição da Consulta de Enfermagem às crianças na atenção básica pautando-se nos seguintes aspectos qualitativos: processo de trabalho; tempo de duração da realização da consulta; estrutura, instrumentos e recursos utilizados, participantes, objetivos da consulta, procedimentos realizados, perfil das crianças atendidas e temas abordados; Descrever a Consulta de Enfermagem à criança na atenção básica de Teresina-PI, utilizando instrumento específico para devido fim; Relatar o perfil sócio demográfico e profissional dos enfermeiros da atenção básica e Apreender as representações sociais dos enfermeiros em relação à temática da Consulta de Enfermagem no contexto da saúde da criança na atenção básica de Teresina- PI.

O instrumento de coleta de dados será um roteiro de entrevista semiestruturado e um instrumento de descrição das consultas de enfermagem à criança na atenção básica. 
- Ressalta-se que a presente pesquisa trará riscos mínimos, sem que haja prejuízos, desconforto, lesões, formas de indenização, nem ressarcimento de despesas.

- Garantia de acesso: em qualquer etapa do estudo, você terá acesso aos profissionais responsáveis pela pesquisa para esclarecimento de eventuais dúvidas. Os investigadores podem ser encontrados pelo seguinte telefone (86) 9925 -1540. Se você tiver alguma consideração ou dúvida sobre a ética da pesquisa, entre em contato com o Comitê de Ética em Pesquisa (CEP) da Universidade Federal do Piauí, no mesmo endereço Rua Marcos Parente, 1204. Bairro Fátima, Teresina-PI, Pró-Reitoria de Extensão e Pós-Graduação, CEP: 64.048-070.

- O participante terá o direito de retirar o consentimento a qualquer momento.

\section{Diana Lúcia Moura Pinho}

\section{Mayara Águida Porfírio Moura}

\section{CONSENTIMENTO}

$\mathrm{Eu}$,

RG:

$\mathrm{CPF}$ : , abaixo assinado, concordo em autorizar a coleta de dados neste centro de saúde. Tive pleno conhecimento das informações que li ou que foram lidas para mim, descrevendo o estudo "CONSULTA DE ENFERMAGEM À CRIANÇA NA ATENÇÃO BÁSICA”. Discuti com Mayara Águida Porfírio Moura, sobre a minha decisão em participar nesse estudo. Ficaram claros para mim quais são os propósitos do estudo, os procedimentos a serem realizados, os riscos mínimos, as garantias de confidencialidade e de esclarecimentos permanentes. Ficou claro também que minha participação é isenta de despesas e que tenho garantia do acesso à pesquisa. Concordo, voluntariamente, em participar deste estudo e poderei retirar o meu consentimento a qualquer momento, antes ou durante do mesmo. A retirada do consentimento da participação no estudo não acarretará penalidades ou prejuízos nessa Instituição ou Serviço.

Teresina, de de 2013.

Nome e Assinatura do sujeito ou responsável:

Presenciamos a solicitação de consentimento, esclarecimento sobre a pesquisa e aceite do diretor em autorizar a coleta de dados.

Testemunhas (não ligadas à equipe de pesquisadores):

Nome:

Assinatura:

Nome:

Assinatura: 


\section{Universidade de Brasília FACULDADE DE CIENCIAS DA SAUUDE PROGRAMA DE POS-GRADUAÇÄO EM ENFERMAGEM}

ANEXO B - APROVACÃO EM COMITÊ DE ÉTICA NA PESQUISA

\section{UNIVERSIDADE FEDERAL DO PIAUÍ - UFPI}

\section{PARECER CONSUBSTANCIADO DO CEP}

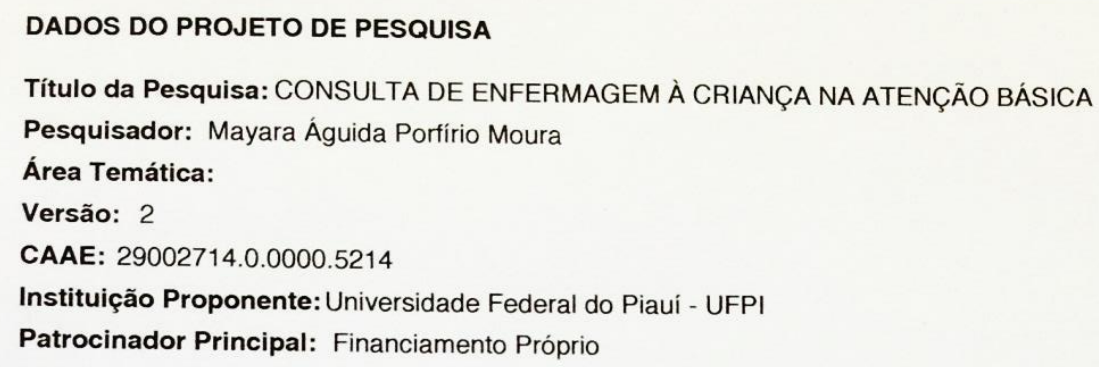

\section{Apresentação do Projeto:}

Ao longo dos anos, ocorreram severas mudanças na Consulta de Enfermagem à criança no contexto das Políticas Públicas de Saúde Brasileira. Em convergência com as tendências que emergiram, busca-se uma investigação científica sobre o cuidado com a saúde da criança no contexto da Consulta de Enfermagem na rede de atenção básica de Teresina-PI, na perspectiva de uma compreensão abrangente sobre a assistência à saúde da criança, por considerar a importância deste momento na prevenção de doenças e promoção da saúde.a Consulta de Enfermagem cresce e repercute em uma maior incorporação pelas instituições de saúde brasileiras. Exercida privativamente pelo enfermeiro, representa um modo de trabalho que incorpora técnicas científicas na identificação de situações de saúde e doença, no intuito de buscar a promoção da saúde, prevenção de doença, tratamento e recuperação do paciente.Neste escopo,justifica-se o presente estudo pela necessidade de empreender aspectos qualitativos inexplorados no universo da Consulta de Enfermagem dentro do contexto da saúde da criança que ocorre na rede de atenção básica de Teresina-PI. Em convergência, os questionamentos que norteiam este trabalho são: Qual a quantidade de crianças menores de cinco anos, Consultas de Enfermagem à criança, puericulturas, atendimentos individualizados e visitas domiciliares realizadas no ano de 2012 na atenção básica de Teresina-PI? Como se dá a Consulta de Enfermagem à criança na atenção básica, pautando-se nos aspectos qualitativos: processo de

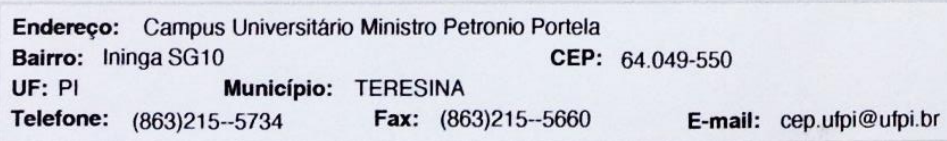




\section{UNIVERSIDADE FEDERAL DO PIAUÍ - UFPI}

Continuação do Parecer: 667.489

trabalho; tempo de realização; estrutura, instrumentos e recursos utilizados, participantes, objetivos da consulta, procedimentos realizados e perfil das crianças atendidas? Qual o perfil sócio demográfico e profissional dos enfermeiros da atenção básica? Quais as Representações Sociais dos enfermeiros em relação à temática da Consulta de Enfermagem à criança na atenção básica?

\section{Objetivo da Pesquisa:}

Objetivo Primário:

- Analisar a Consulta de Enfermagem às crianças menores de cinco anos na rede de Atenção Básica, Teresina-PI no ano de 2012.

Objetivo Secundário:

- Identificar na rede de atenção básica de Teresina-PI no ano de 2012 a quantidade de: crianças menores de cinco anos cadastradas pelas equipes Saúde da Família; a produção de Consultas de enfermagem a população e às crianças menores de cinco anos; puericulturas, o atendimento individual realizado pelo enfermeiro e visitas domiciliares exclusiva dos

enfermeiros. - Construção de um instrumento de descrição da Consulta de Enfermagem às crianças na atenção básica pautando-se nos aspectos qualitativos: processo de trabalho; tempo de duração da realização da consulta; estrutura, instrumentos e recursos utilizados, participantes, objetivos da consulta, procedimentos realizados, perfil das crianças atendidas e temas abordados/discutidos. - Descrever a Consulta de Enfermagem à criança na atenção básica de Teresina-PI, utilizando instrumento específico construído. - Relatar o perfil sócio demográfico e profissional dos enfermeiros da atenção básica.- Apreender as Representações Sociais dos enfermeiros em relação à temática da Consulta de Enfermagem no contexto da saúde da criança na atenção básica de Teresina- PI.

\section{Avaliação dos Riscos e Benefícios:}

\section{Riscos:}

Existe a possibilidade de danos aos sujeitos, tais como: desconforto ao falar da temática, dispêndio de tempo.

Benefícios:

Acrescentar muito para o melhoramento da consulta de enfermagem à criança na atenção básica.

Comentários e Considerações sobre a Pesquisa:

Estudo relevante, pertinente com intuito de analisar a consulta de Enfermagem à criança na atenção básica optou-se por uma abordagem qualitativa e quantitativa, pautado em um estudo

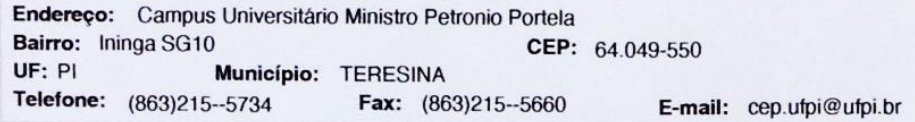




\section{UNIVERSIDADE FEDERAL DO \\ PIAUI - UFPI \\ Platoformo \\ Brasi}

Continuaçăo do Parecer: 667.489

descritivo utilizando o Método História Oral Temática e a Teoria das Representações Sociais.Os participantes desta pesquisa serão os enfermeiros efetivos das unidades de atenção básica de Teresina. A Fundação Municipal de Saúde conta atualmente com duzentos e seis enfermeiros na atenção básica, sendo oitenta na zona norte,

cinquenta e oito na zona leste/sudeste e sessenta e oito na zona sul (PIAUÍ, 2011). Serão excluídos sujeitos que apresentarem-se afastados do trabalho por férias, licença médica durante a coleta de dados, ou que não aceitaram participar do estudo. Para a produção dos dados será utilizada o instrumento de descrição das consultas de enfermagem à criança na atenção básica e a técnica de entrevista previamente agendada com o participante da pesquisa, seguindo um instrumento do tipo roteiro semiestruturado com gravação de áudio, equipamento tecnologicamente adequado. Nesta ocasião, o participante da pesquisa será informado sobre este estudo, e concordando com a participação, ocorrerá a assinatura do Termo de Consentimento Livre e Esclarecido antes da realização da pesquisa. No intuito de descrever como ocorre a Sistematização da Assistência de Enfermagem à Saúde da Criança na Atenção Básica de Teresina- PI e delinear o processo de implantação da Sistematização da Assistência de Enfermagem no atendimento à criança na atenção básica, será realizada pesquisa com o método história oral temática híbrida, utilizando entrevistas e documentos relacionados a este processo. Além das entrevistas com os enfermeiros, será apresentado documentos, impressos e demais fontes escritas que registrem a Sistematização da Assistência de Enfermagem no âmbito da atenção básica pela Fundação Municipal de Teresina-PI, realizando assim uma triangulação dos dados

\section{Considerações sobre os Termos de apresentação obrigatória:}

Foram apresentados os seguintes termos: TCLE,Carta de encaminhamento, termo de confidencialidade, declaração de compromisso, projeto, curriculo da pesquisadora, folha de rosto

\section{Recomendações:}

Sem recomendações.

Conclusões ou Pendências e Lista de Inadequações:

O projeto atendeu todas as exigências relacionadas anteriormente pelo parecer do colegiado CEP/UFPI.

\section{Situação do Parecer:}

Aprovado

Endereço: Campus Universitário Ministro Petronio Portela

Bairro: Ininga SG10

CEP: $64.049-550$

UF: PI Município: TERESINA

Telefone: (863)215--5734

Fax: (863)215--5660

E-mail: cep.utpi@utpi.br 


\section{UNIVERSIDADE FEDERAL DO \\ PIAUI - UFPI}

Continuaçăo do Parecer: 667.489

Necessita Apreciação da CONEP:

Não

Considerações Finais a critério do CEP:

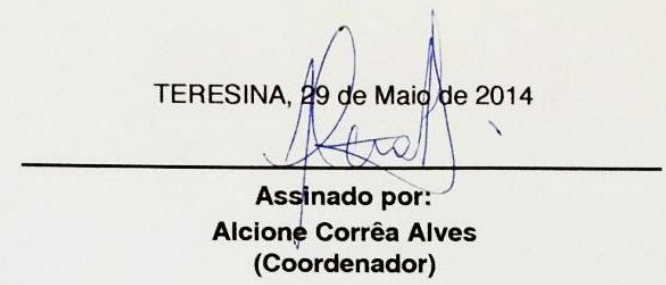

Endereco: Campus Universitário Ministro Petronio Portela

Bairro: Ininga SG10

UF: PI Município: TERESINA

CEP: $64.049-550$

Telefone: (863)215--5734

Fax: (863)215--5660

E-mail: cep.utpi@ufpi.br 